\title{
Management Challenges in the Era of Globalization
}

Edited by Anna Kuźmińska

\section{Imy}

University of Warsaw Faculty of Management Press

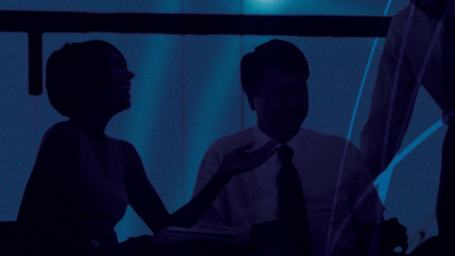

$\longrightarrow$ 


\section{Management ChaLlenges IN THE ERA OF GLOBALIZATION}




\section{Management ChALLENGES \\ IN THE ERA OF GLOBALIZATION}

EDITED BY

ANNA KUŹMIŃSKA

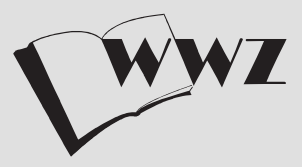

Wydawnictwo Naukowe Wydziału Zarządzania Uniwersytetu Warszawskiego

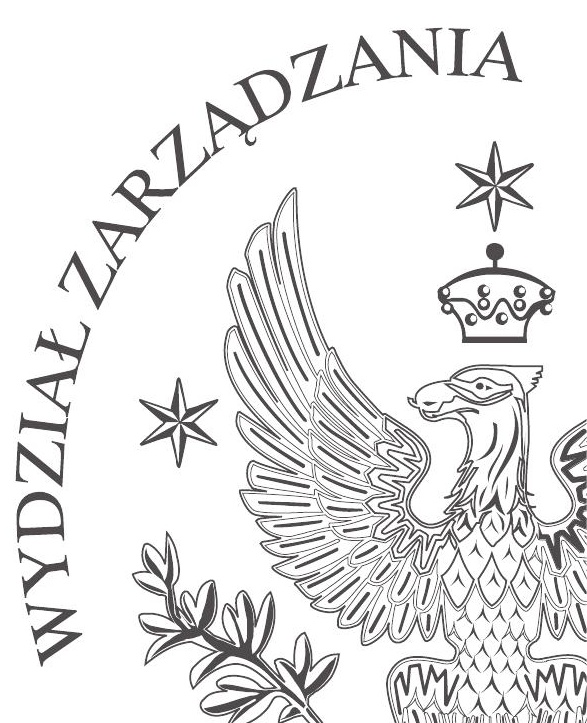




\author{
Reviewers: \\ Prof. Eugene Burnstein - University of Michigan, USA \\ Dr Adam Stivers - Gonzaga University, USA \\ Prof. Alireza Khorakian - Ferdowsi University of Mashhad, Iran \\ Prof. zw. dr hab. Jerzy Kisielnicki - Uniwersytet Warszawski, Poland \\ Prof. zw. dr hab. Grażyna Wieczorkowska-Wierzbińska - Uniwersytet Warszawski, Poland \\ Prof. dr hab. Jerzy Wierzbiński - Uniwersytet Warszawski, Poland \\ Prof. dr. hab. Przemysław Hensel - Uniwersytet Warszawski, Poland \\ Dr hab. Renata Karkowska - Uniwersytet Warszawski, Poland \\ Dr hab. Marta Postuła - Uniwersytet Warszawski, Poland \\ Dr hab. Igor Postuła - Uniwersytet Warszawski, Poland \\ Dr hab. Anna Pawłowska - Uniwersytet Warszawski, Poland \\ Dr hab. Maciej Bernatt - Uniwersytet Warszawski, Poland \\ Dr Marzena Starnawska - Uniwersytet Warszawski, Poland
}

Editorial Supervision: Jerzy Jagodziński

Cover design: Agnieszka Miłaszewicz

The project "Multicultural Management in the Era of Globalization" is realised by the Faculty of Management at University of Warsaw on the basis of the legal agreement no POWR.03.02.00-00-I053/16-00 within the Operational Programme Knowledge Education Development 2014-2020 financed through the EU Structural Funds.

Copyright by Wydawnictwo Naukowe Wydziału Zarządzania, Uniwersytetu Warszawskiego, Warsaw 2019

ISBN (on-line): 978-83-65402-94-3

DOI: 10.7172/978-83-65402-94-3.2019.wwz.3

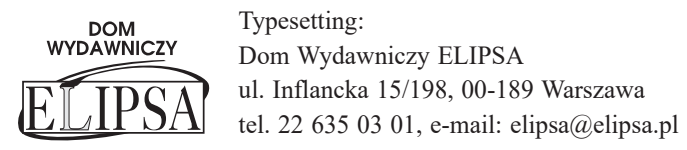




\section{Contents}

Preface

\section{PART 1 EMPIRICAL PAPERS}

Who Doesn't Want to Share Leadership? The Role of Personality, Control Preferences, and Political Orientation in Preferences for Shared vs. Focused Leadership in Teams

A. Kuźmińska, D. Schulze, \& A. Koval. . .

The Correlates of Two Types of Leadership Motivation

K. Nowak \& R. Mahari

Identifying Differences in Values: Comparison between Iran and Poland

A. Yousefpour

Gender Gap on the Job Market: Poland vs. Iran

M. Simkowska-Gawron \& Z. Momenfar.

Two Approaches to Analyzing Data of Project Teams

K. Nowak \& K. Pietrzak.

Employees' Predispositions to Routinised Work: Measurement Issues

G. Wieczorkowska \& W. Karczewski ...

The Investigation of a Weak Form of the Efficient Market Hypothesis:

Evidence From Stock Markets in the European Union

J. Karasiński. .

\section{PART 2 LITERATURE REVIEWS}

The Challenges of Knowledge Workers Management

t. Pietrzak.

Quality Systems at Universities in Academics' Perception: A Systematic Literature Review

A. Lęgocka . ... 
Perspectives for More Inclusive and Impactful Fair Trade. Analysis of the Handloom Industry in Nepal

K. Osterczuk.

Refugees or Immigrants - How Does it Matter for Entrepreneurship? Systematic Review of Refugee Entrepreneurship Literature Inspired by the Immigrant Entrepreneurship Research

N. Lazarczyk-Bilal.

Developing Employee Adaptive Behaviors by Organizational Employability Culture in the Flexible Human Resource Management. Scholars' Perspective

L. Shoraka ...

The Dark Side of Extra Role Behaviors: Investigating the Link between Extra-role and Counterproductive Behaviors in Organizations using Moral Licensing Theory

A. Sodeiri. .

The Future of Corporate Bonds - Collateral, Risks, New Legal Regulations

E. Ciborowska...

Main Barriers of the Implementation of the Blockchain Technology 


\section{Preface}

We live in the times of an overflow of scientific publications (Siebert, Machesky, \& Insall, 2015; Wieczorkowska, Król, Wierzbiński, 2016). The number of abstracts indexed by the leading U.S. secondary publishers increased from 555,000 in 1957 to 3.7 million in 1997 (Kaser, 1998) and this tendency continued to grow, with more and more journals appearing every year (Thompson, 2005). As an overflow of knowledge may result in shallow processing of information, it is important to always ask oneself a question - why to publish yet another volume?

The authors that contributed to this volume are mostly PhD students (in two cases with their supervisors) participating in the "Multicultural Management in the Era of Globalization" $\mathrm{PhD}$ program $^{1}$ realized by the Faculty of Management, University of Warsaw and financed through the EU structural funds. Many of them are publishing for the first time in their lives! The chapter of our youngest contributor - Raphael Mahari - is based on the analyses performed during his scientific internship at the University of Warsaw, completed after graduating from high school in Switzerland and before starting his further academic career in the US.

All these young scientists faced a challenge of presenting a linear line of argumentation and starting a public debate on their ideas. For this reason, this volume might not be offering many answers, but is full of interesting questions and new, potentially fruitful research paths.

The strong point of the volume is its multicultural perspective. The authors come from Poland, Iran, Germany, Ukraine, and Switzerland. In the context of globalization, it is important to look at the variety of managerial issues, from a variety of viewpoints. Hence, the subjects of the chapters touch on a number of problems: leadership, entrepreneurship, knowledge management, stock markets, blockchain technology, and many more.

To organize the chapters we loosely grouped them into two main parts. The first consists of empirical papers, the second - literature reviews aimed at discovering and pointing to relevant research gaps worth of further, empirical exploration.

In the empirical part:

- Anna Kuźmińska, Dominic Schulze, \& Anna Koval reported the results of a study performed on 184 U.S. respondents, investigating whether one can predict people's preference for shared vs. focused leadership in teams based on their personality, control preferences, and political orientation;

- Krzysztof Nowak \& Raphael Mahari analyzed the responses of 580 future or current employees who completed the Survey of Activity Styles in search of personality correlates of the two types of potential leaders - both characterized by high power motivation, but differing in affiliation motivation;

- Afsaneh Yousefpour used the World Value Survey data (2005-2007) to investigate the differences in basic human values between Iran and Poland, with the moderating role of age and education level;

- Magdalena Simkowska \& Zahra Momenfar compared the gender gap on the job market in Iran and Poland and illustrated it with the analysis of gender discrimination beliefs among the respondents of the fifth wave of World Value Survey (2667 Iranians and 1000 Poles);

1 Legal agreement no POWR.03.02.00-00-I053/16-00 within the Operational Programme Knowledge Education Development 2014-2020 
- Krzysztof Nowak \& Kamila Pietrzak tested the impact of team size and team gender composition on team climate and compared the obtained results with three different statistical methods. The analyses were performed on 87 work teams from eight Polish companies (636 employees in total);

- Grażyna Wieczorkowska \& Wojciech Karczewski, reported the analyses of the data obtained from 1132 employees of different corporations and their 4748 colleagues, while discussing methodological issues of measurement in management science,;

- Jacek Karasiński analyzed the main indexes of eight selected stock exchanges in the European Union in the years 2000-2017 to investigate the Weak Form of the Efficient Market Hypothesis;

In the literature review part:

- Lukasz Pietrzak described the challenges of managing teams composed of knowledge workers;

- Agnieszka Łęgocka presented a systematic literature review of the scholars' perception of newly introduced quality system and the corporatization of universities;

- Karolina Osterczuk performed an analysis of handloom industry in Nepal and discussed the possibilities for fair international collaboration between craftsmen and designers;

- Nina Łazarczyk-Bilal reviewed the literature on entrepreneurial experiences of refugees and immigrants;

- Leila Schoraka focused on the role of employability culture in shaping employees' employability in modern organizations characterized by flexible human resource management;

- Atefeh Sodeiri employed moral licensing theory to discuss how employees who engage in Organizational Citizenship Behaviours may subsequently participate in counterproductive work behaviors;

- Ewa Ciborowska focused on corporate bonds as one of the sources of financing for entrepreneurs, while also explaining the new legal regulations and the potential risks of using such a form of financing;

- Jan Zadrożny reviewed the basic concepts related to blockchain technology, focusing on the technical, socio-organizational, and legal barriers of its implementation.

All authors greatly benefited from the invaluable input and comments obtained from the international group of reviewers, which included Eugene Burnstein (University of Michigan, USA), Adam Stivers (Gonzaga University, USA), and Alireza Khorakian (Ferdowsi University of Mashhad, Iran), as well as eight reviewers from the University of Warsaw, Poland: Jerzy Kisielnicki, Przemysław Hensel, Renata Karkowska, Marta Postuła, Igor Postuła, Maciej Bernatt, Anna Pawłowska, Marzena Starnawska. We would also like to thank Maria Schulders and Marta Kabut for diligent proofreading of the chapters.

Anna Kuźmińska Grażyna Wieczorkowska - Head of the PhD Program

\section{Literature}

Kaser, R. T. (1998). Secondary information services - Mirrors of scholarly communication: Forces and trends. In A. Henderson (Ed.), Electronic databases and publishing (pp. 9-23). New Brunswick, NJ: Transaction.

Siebert, S., Machesky, L. M., \& Insall, R. (2015). Overflow in science and its implication for trust. Elife, 14(4). doi: $10.7554 /$ eLife.10825.

Thompson, J. B. (2005). Books in the Digital Age The Transformation of Academic and Higher Education Publishing in Britain and the United States. New York, NY: John Wiley \& Sons.

Wieczorkowska-Wierzbińska, G., Król, G.,\& Wierzbiński, J. (2016). Przeszłość, Teraźniejszość i Przyszłość Edukacji Akademickiej. Nauka, 3, 87-106. 
PART I: EMPIRICAL PAPERS 



\title{
Who Doesn't Want to Share Leadership? The Role of Personality, Control Preferences, and Political Orientation in Preferences for Shared vs. Focused Leadership in Teams
}

\author{
Anna Olga Kuzminska*, Dominic Schulze ${ }^{* *}$, \& Anna Koval ${ }^{* * *}$
}

\begin{abstract}
Summary
An increasing number of institutions decide to adopt the premises of shared or distributed leadership models and reduce the level of organizational hierarchy. Such models were shown to positively affect employee well-being, creativity, and - indirectly - effectiveness. However, while shared leadership assumes a relatively equal division of control in interdependent situations, some people display preferences to dominate or submit. What is more, unequal/equal division of power may be preferable to people with a more conservative/liberal political orientation. In the current research we examine whether the shared leadership model is likely to be equally attractive to all employees. We focus on the effect of personality traits, control preferences, and political orientation on preferences for shared vs. focused leadership. One-hundred-and-eighty-four participants declared their team preferences (focused vs. shared leadership), as well as answered questions regarding their personality (HEXACO), control preferences, and political orientation through the Amazon Mechanical Turk platform. Control preferences, as well as political orientation were related to preferences for shared vs. focused leadership. Specifically, while dominance and conservative political orientation was associated with higher preference for focused leadership, collaboration predicted higher preference for shared leadership. Personality traits did not predict the preferences for focused vs. shared leadership.
\end{abstract}

Keywords: shared leadership, distributed leadership, teal organizations, HEXACO, control preferences, political orientation

JEL: M12, O15, J24, J28

\section{INTRODUCTION}

The first action of Ricardo Semler, when he first took over SEMCO (Semler and Co., a manufacturing company founded by his father), was to fire all senior managers. Semler challenged the status quo and asked questions such as: Why should a few managers decide on the allocation of parking slots or office desks, or what the new shop floor or social area should look like, instead of letting the employees decide on their own? Why is the management board a closed group - can we keep 1-2 seats free in each session for the first employee who asks to join and be the voice of the other workers? Why shouldn't all members of the organization take a share of the leadership (including decision making and responsibility) within the group, team, or organization (Semler, 2001)?

Semler was not the only one to question the organizational status quo. Frederic Laloux (2014) identified similar examples, listing so-called teal organizations that emphasize - among others - self-management in their activities. In consequence, they choose a leadership style that is more distributed or shared. While having little or no formal hierarchy, these organizations seem to be highly effective and outstanding in customer and employee satisfaction (Laloux, 2014; Semler, 2001).

Faculty of Management, University of Warsaw, Poland, https://orcid.org/0000-0002-6060-4549, e-mail: akuzminska@ wz.uw.edu.pl

** Faculty of Management, University of Warsaw, Poland, https://orcid.org/0000-0001-7314-2737, e-mail: Dominic.Schulze@ gmx.de

*** Faculty of Management, University of Warsaw, Poland, https://orcid.org/0000-0002-8192-762X, e-mail: Koval.anna.v@, gmail.com 
Scientific interest in these new forms of management comes at a time when more and more studies point at the interpersonal risks of having power over others. Those in power are more likely to treat others as means to their ends, take risks, categorize others, and break social norms (e.g. Anderson, \& Galinsky 2006; Bendahan, Zehnder, Pralong, Antonakis, 2015; Fiske, 1993). They are less trustful, cooperative, and empathetic - which is even evident in their brain responses (e.g. Gonzaga, Keltner, \& Ward 2008; Guinote, Judd, \& Brauer, 2002; Hogeveen, Inzlicht, \& Obhi, 2014; Keltner, Gruenfeld, \& Anderson, 2003; Kipnis, 1972; van Kleef, Oveis, van der Löwe, LuoKogan, Goetz, \& Keltner, 2008). Maybe sharing leadership within a team or an organization is one way of counteracting these negative effects by balancing the source of power?

In the scientific literature, the phenomenon of shared leadership is still relatively new and understudied. Although incoming research results suggest its positive consequences on performance, innovation, and employee satisfaction (e.g. Ensley, Hmieleski, \& Pearce, 2006; Hoch, 2013; Wang et al., 2013), it is not certain what is the role of situational or individual difference factors (such as employees' personalities or preferences). Not everyone likes to take on additional responsibilities. Some people like clear hierarchical structures (e.g. Grzelak, 2001). Would such people feel comfortable participating in shared leadership?

\section{AIM OF THE STUDY}

The aim of the current paper is twofold. First, in order to reduce the definitional chaos observable in the literature, we try to untangle the concept of shared leadership, as well as review its antecedents and consequences towards organizational outcomes and employee wellbeing. Second, we investigate whether shared leadership is equally preferred by everyone. In other words, are there individual differences that could predict preference for such an organizational model? Since this subject has not yet - to our knowledge - been undertaken in empirical research, we start by focusing on three factors - personality, control preferences, and political orientation as predictors of preference for shared vs. focused leadership in teams.

\section{THEORETICAL BACKGROUND}

\section{Shared Leadership as a Form of Collective Leadership}

The broadest definition of shared leadership is that of the plurality of leadership: the combined influence of multiple leaders in specific organizational situations. Collective forms of leadership started to gain more research attention some 2-3 decades ago and are becoming a more and more prominent subject of research in the leadership domain (e.g. Denis, Langley, \& Sergi 2012; Gibb, 1954; Gronn, 2002; Lord, Day, Zaccaro, Avolio, \& Eagly, 2017; Pearce, 2007; Thorpe, Gold, \& Lawler, 2011). The focus was shifted from an individual, trait based approach to leadership to that of a continuum between focused and shared/distributed leadership (Gibb, 1954). On this continuum:

- concentrated and focused leadership refers to a dominant influence by one person, while

- distributed or shared leadership refers to mutual \& reciprocal influence of different participants.

Over the last decades a number of concepts and terminologies were used to describe collective forms of leadership within a team or an organization (see Table 1 and the review of Ulhøi \& Müller, 2014). However, the most commonly used terminologies are: distributed leadership and shared leadership. Although the meaning of those two concepts is to a large extent the same and they are sometimes used interchangeably (Goksoy, 2016), for our purposes we decided to use the concept of shared leadership, because it is most recognized in management literature. In the current work we will understand shared leadership as: 
"A dynamic, interactive influence process among individuals in groups for which the objective is to lead one another to the achievement of group or organizational goals or both. This influence process often involves peer, or lateral influence and at other times involves upward or downward hierarchical influence" (Pearce \& Conger, 2003, p. 1).

Importantly, the existence of shared leadership does not mean the absence of vertical leadership (Pearce \& Sims, 2002). These two concepts exist in parallel, which means that "group members actively and intentionally shift the role of a leader to one another as necessitated by the environment or circumstances in which the group operates" (Pearce, Hoch, Jeppesen, \& Wegge, 2010, p. 151) no matter of the level of verticality of the leadership structure. Also, it might involve a certain degree of supervision from a vertical or an external leader, balanced with a certain degree of team's selfdirection (Gibb, 1954).

Table 1. Diffrent concepts of collective forms of leadership in the literature (Ulhøi et al., 2014)

\begin{tabular}{|c|c|}
\hline Concept & Author(s) \\
\hline Shared cognition & Ensley \& Pearce, 2001 \\
\hline Distributed leadership & Barry, 1991; Brown et al., 2002 \\
\hline Participative leadership & Bass, 1990, in Carte et al., 2006; Collins, 1995 \\
\hline Relational leadership & Uhl-Bien, 2006 \\
\hline Participatory management & Wu, Lee, 2001 \\
\hline Concertive action & Gronn, 2002 \\
\hline Collectiveleadership & Denis et al., 2001; Hiller et al., 2006 \\
\hline Collaborative leadership & Finch, 1977; Vangen et al., 2003 \\
\hline Collaborativegovernance & Huxham et al., 2000 \\
\hline Informal leadership & McCrimmon, 2005 \\
\hline Emergent leadership & Pearce \& Sims, 2002 \\
\hline Co-leadership & Sally, 2002 \\
\hline Dual leadership & Etzioni, 1965; Etzioni et al., 1968 \\
\hline Split management & Choi \& Beamish, 2004 \\
\hline Connective leadership & Klakovich, 1994, 1996 \\
\hline
\end{tabular}

Shared/distributed leadership follows three premises (Bennett, Wise, Woods, \& Harvey, 2003).

- It is not just a result of structural relationships, but emerges through a network of interacting individuals, contributing their initiative and expertise in a variety of ways over time.

- The boundaries of leadership are open, which allows to constantly raise the question of "Who" will be the leader. A leader can be found within, but also outside of the respective group.

- Expertise is distributed across many members of the team. Leadership capabilities and perspectives are distinct, numerous, and spread within the group of individuals. The result is more than the sum of the individual contributions. 


\section{Consequences of Shared Leadership}

In order to be competitive in terms of effectiveness and innovativeness, organizations need to leverage their human and social capital. Although yet understudied, research already indicates shared leadership as a strong candidate to address these challenges. "As organizations have steadily progressed into the knowledge economy we can no longer rely on simple notions of top-down, command-and-control leadership, based on the idea that workers are merely interchangeable drones" (Pearce, 2007, p. 1).

Creativity and innovation. Shared leadership environments enable employees to enact their collective psychological capital and support knowledge sharing, which leads to a more participative and innovative organizational culture (Nonaka, Hirose, \& Takeda, 2016). For example, shared leadership was found to be a predictor of a teams' level of innovative behavior (Hoch, 2013). Shared leadership was also found to positively impact creativity on a team and individual level a relationship partially mediated by knowledge sharing (Gu, Chen, Huang, Liu, \& Huang 2018; Lee, Lee, $\&$ Seo, 2015). On a team level, these effects were even more pronounced when tasks required greater interdependence (Gu et al., 2018).

A study of engineering design teams found that creativity within the team was higher when the team leadership network was high in density and low in centrality - indicators of the distribution of leadership activities (Wu \& Cormican, 2016). The more leadership ties between team members in the network, the higher is the density of the leadership network. A higher density is predictive of more knowledge sharing and higher creativity. The more the network is dominated by one or a few members of the team, the more centralized it is. Lower centralization predicts higher cooperation among team members. Shared leadership may contribute towards increasing the level of creativity, also by weakening the negative effects of team conflicts (relational conflicts and task conflicts) (Hu, Chen, Gu, Huang, \& Liu, 2017).

Effectiveness and performance. Compared to focused leadership approaches, shared leadership was shown to be a better predictor of higher performance, although the relationship seems to be indirect (Han, Lee, Beyerlein, \& Kolb, 2018; Mathieu, Kukenberger, D'innocenzo, \& Reilly, 2015; Robert \& You, 2018). Research indicated that the relationship is mediated by team cohesion (Mathieu et al., 2015), team-satisfaction (Robert et al., 2018), coordination activities, goal commitment, and knowledge sharing (Han et al., 2018). A meta-analysis on team-cohesion and performance in teams varying in their level of shared leadership suggested that higher levels of team-cohesion predict higher performance (Mathieu et al, 2015). While shared leadership had no direct impact on performance, it played an important role in enhancing team-cohesion.

Similarly, surveys conducted among graduate and undergraduate students in project teams indicated that shared leadership indirectly affected teams' performance through coordination activities, goal commitment, and knowledge sharing (Han et al., 2018). Other studies supported the positive effect of shared leadership on performance. Shared leadership was shown to work better than vertical leadership in change management teams (Pearce \& Sims, 2002), new venture top management teams (Ensley et al., 2006), and virtual teams (Hoch \& Kozlowski, 2014).

Employee well-being. Compared to focused leadership, shared leadership predicted lower levels of conflict and greater consensus, as well as higher intragroup trust and cohesion in teams (Bergman, Rentsch, Small, Davenport, \& Bergman, 2012). It was also shown to facilitate team satisfaction in virtual teams and moderate the impact of trust and autonomy on satisfaction (Robert et al., 2018). In creative contexts, shared leadership mediated the relationship task and team characteristics (such as task cohesion) and task satisfaction (Serban \& Roberts, 2016). In a study of top management team members in Christian church organizations shared leadership negatively related to team member role overload, role conflict, role ambiguity, and job stress (Wood \& Fields, 2007). It was also positively related to job satisfaction. 


\section{The antecedents of Shared Leadership}

Since shared leadership was shown to give rise to many of the above-mentioned positive organizational consequences, research investigated factors facilitating its emergence. So far, the antecedents of shared leadership emergence uncovered by scholars include supporting team and organizational factors and behaviors of vertical leaders.

Team and organizational factors. Internal team environment, interdependence and team integrity, as well as task cohesion and ambiguity were identified in the literature as the antecedents of shared leadership on a team and organizational level.

Internal team environment. The overall team environment comprised of shared purpose, social support, and voice was shown to enable shared leadership emergence in teams (e.g. Carson, Tesluk, \& Marrone, 2007; Daspit, Tillman, Boyd, \& Mckee, 2013). These three dimensions collectively create a context, in which team members are more open to offer their own leadership and to rely on other members' leadership. Shared purpose is a sense of similar understanding of the primary objectives among team members. Social support is a mutual emotional and psychological support of each other. Voice is a degree of participation and input into the team's purpose. Voice is also associated with participative behaviors, such as being part of the decision-making process and debating around alternative approaches to the team's procedures and tasks. Several studies confirmed the positive relationship between internal team environment and the level of shared leadership in a team (e.g. Carson et al., 2007; Daspit et al., 2013).

Interdependence and team integrity. Interdependence is defined as a degree to which team members rely and depend on the skills of others and interact to complete the team's tasks. Interdependence was found to be positively related to shared leadership emergence by enhancing solidarity among team members (Fausing, Joensson, Lewandowski, \& Bligh, 2015). Team integrity, also referred to as social responsibility, consists of reliability and trustworthiness which enable transparent communication among team members. If team members show a higher level of reliability and trust, as well as a tendency to behave fairly, ethically and transparently, the emergence of shared leadership is more likely (Hoch, 2013).

Task cohesion and ambiguity. Task cohesion is defined as a team's shared interest in a task, based on the collective perception of skillfulness and ability to perform the task. Task ambiguity appears when team members carry out their roles in the absence of necessary task-related information. It was found that task cohesion facilitates the emergence of shared leadership, while task ambiguity impedes it (Serban \& Roberts, 2016). Shared leadership affected team and task satisfaction only when task ambiguity was low.

Vertical leadership behaviors. As mentioned above, shared leadership does not necessitate a context devoid of any form of vertical leadership, as it exists on a continuum (Gibb, 1954). The sharing of leadership and verticality of leadership are independent constructs (a team could be very high or very low on both of these dimensions). Such a vertical leadership can, however, either facilitate or impede the emergence of shared leadership in an organization or a team, as presented below.

External leadership. External leadership is a guidance provided by a leader within an organization, who is not a part of the team. For instance, in the study of Carson et al. (2007), an external leader acted as a partner in a consulting organization, helping to supervise multiple projects. It was shown that coaching by an external leader may enable shared leadership by providing encouragement and reinforcement (Carson et al., 2007). External leaders may use these strategies when team members demonstrate leadership behaviors.

Additionally, fair rewards strategy was shown to directly influence shared leadership by stimulating and initiating team members' participation (Grille, Schulte, \& Kauffeld, 2015). External leaders can provide general encouragement, help when internal conflicts arise, and - if needed suggest or contribute to the team's strategies and processes (see also: Carson et al., 2007). 
Vertical empowering leadership. Vertical empowering leadership can be carried out by an external or internal leader and can be performed on a regular basis or when needed. Such a leader provides motivational support and empowerment to the team members. Studies on the relationship between vertical empowering leadership and the emergence of shared leadership show mixed results. Some document a positive effect of empowering leadership on shared leadership (Fausing et al., 2015; Hoch, 2013), while others find no effect whatsoever (Grille et al., 2015).

Leader humility. Leader humility signifies a leader's willingness to admit to their own mistakes, be open to advice, ideas, and feedback from other employees, as well as highlight team members' unique skills. Leader humility was shown to stimulate the interaction between leaders and followers and - as a result - contribute to the development of shared leadership (Chiu, Owens, \& Tesluk, 2016). Consequently, to facilitate the development of shared leadership in teams, a leader should: (1) admit the lack of knowledge or expertise, (2) acknowledge that someone else has more knowledge or skills, and (3) be open to new ideas.

Transformational leadership and gatekeeping leadership. Transformational leadership is focused on strengthening the motivation and morale of team members, whereas gatekeeping leadership is based on a leader's ability to perform internal and external communication effectively. This ability is exemplified by using external communication skills to acquire technical information and transmit it to the team members (Ishikawa, 2012).

Gatekeeping leadership (but not transformational leadership) was shown to positively affect the emergence of shared leadership (Ishikawa, 2012). Also, results suggest that gatekeeping leadership is promoting the internal and external communication of team members, which encourages them to display leadership behaviors, and consequently, enhances a shared leadership environment.

\section{Who Does Not Want to Share Leadership?}

Prior literature has advanced our knowledge on consequences and antecedents of shared leadership. However, one question remains unattended: Is everyone equally willing to work in shared leadership environments? Prior literature largely ignores potential individual differences in whether people desire share leadership in an organizational context. Given our knowledge on a variety of social orientations, control preferences, habits, and situational factors people's willingness to get involved in leadership activities might be dramatically affected. To function properly, shared leadership teams need - to a much greater extent than hierarchically governed teams - highly involved individuals. Individuals who are willing to balance between taking control (when the team needs direction) and letting go of control (when other team members oppose one's idea). People who do not believe in a given management method (especially if it involves change) are likely to engage in counterproductive behaviors. In the current study we would like to look at three sets of factors that might predict people's preference for shared vs. focused leadership - personality, control preferences, and political orientation. The rationales for this selection are provided below.

Control preferences. Control over our environment enables us to reach desired outcomes avoid events we consider unpleasant and obtain things we desire. However, previous research shows that being in control is not equally attractive to everyone (Grzelak, 2002). Some people prefer to submit to control of others, especially in the context of uncertainty, as predicted by the theory of Defensive Orientation (Dolinski, 1993). Getting rid of personal control protects one's self-esteem by transferring the responsibility for the potentially negative outcomes of the situation to a different agent (Dolinski, 1993; Zinserling \& Winiewski, 2011).

In the current study we adopt the framework of control preferences developed by Grzelak (2001) and based on Kelley and Thibaut's (1978) theory of interdependence. Control preferences signify 
a relatively stable (but situationally dependent) inclination towards a certain division of control in an interdependent situation. Each interdependent actor, in an interaction with others might try to intensify:

1) “one's control over one's own outcomes: self-control preference (proactive autonomy)

2) one's control over others' outcomes: power preference (dominance)

3) others' control over one's own outcomes: dependence preference (submissiveness)

4) others' control over others' own outcomes: respect preference (respect for autonomy)

5) joint, one's and others' control over one's own and others' outcomes: collaboration preferencel" (Grzelak, 2001).

Studies of Grzelak (2001) indicated one additional preference - that of reactive autonomy, characterized by strong reactance or a lack of acceptance for others' control over one's own outcomes.

Control preferences determine the interest of individuals to stay in, or to exit from, the particular relationship or situation (Grzelak, Kuhlman, Yeagley, \& Joireman, 2010). For instance, some will look for jobs which allow them to control both own and other people's outcomes, while others will prefer to give up control to a competent boss. Indeed, dominance predicts placing greater value at success and job promotion (Modrzejewska, 2004), while collaboration is related to a higher pro-ecological orientation (Grzelak, 2002), which is characterized by a joint social effort.

Based on the above, we predict collaboration to be positively related to shared leadership preference, with dominance and submissiveness positively related to focused leadership preference. With respect to the autonomy scales, it is not easy to predict a clear direction. On one hand, those with high preference for autonomy might want to share leadership in teams because of the willingness to influence their own outcomes (proactive autonomy) and to respect others' independence (respect for autonomy). On the other hand, being in a shared leadership team requires giving up at least some degree of control as one needs to allow other members of the team to influence one's outcomes as well. This might reduce the perceived control over the situation to a similar or greater extent than in focused leadership teams. In a focused leadership team one needs to win over one boss, in a shared leadership team there is a need to convince a greater number of team members to one's point of view. Finally, individuals high in reactive autonomy might want to reduce the possibility for any sort of interdependence.

\section{H1: Control preferences predict preference for shared leadership in teams.}

H1a: Higher preferences for collaboration predicts higher preference for shared leadership in teams.

H1b \& H1c: Higher preferences for (b) submissiveness and (c) dominance predict higher preference for focused leadership in teams.

Political orientation. In the current study we treat political orientation as a proxy for a variety of opinions on social and economic issues it was shown to predict (Jost, 2006). For instance, conservatives are more likely to believe that individuals need to be constrained by authorities and rules to guarantee social order (Sowell, 2002). They prefer familiarity, stability, and predictability (McCrae, 1996), are more resistant to change and likely to accept inequality (Jost, Glaser, Sulloway, \& Kruglanski, 2003; Pratto, Sidanius, Stallworth, \& Malle, 1994). Such believes might predict a higher preference for more traditionally adopted focused leadership, in which order is guaranteed by a hierarchical structure.

1 Grzelak (2001) distinguishes between two collaboration preferences: (1) joint, one's and others' control over one's own outcomes: collaboration preference A and (2) joint, one's and others' control over others' outcomes: collaboration preference B". 
Liberals, on the other hand, are more likely to believe that individuals should have as much influence over own lives as possible without hurting others (Sowell, 2002). They were also shown to be more open to experience, and endorse change and novelty (McCrae, 1996). It is, therefore, reasonable to expect that liberals would endorse the novelty of the shared leadership approach as a means to greater self-expression of individual team members.

\section{H2: Conservative political orientation predicts higher preferences for focused leadership in teams.}

Personality. In the current study we also explore the relationship between personality traits and preference for shared vs. focused leadership. Shared leadership teams need to function in a climate of constant collaboration, engagement, and a need to balance the needs and visions of all team members. Because of that, we believe that such an environment might be easier to deal with by extraverts rather than introverts because of their participative and communicative nature and lower emotional reactivity (McCrae \& John, 1992). What is more, openness to experience, which involves curiosity, openness to new ideas, and adaptability to changing situations might predict higher willingness to try a different style of management (McCrae \& John, 1992). Finally, emotional stability, associated with higher leadership performance expectations and higher stress-resistance (McCrae \& John, 1992), might predict better compatibility with complex team environments, such as teams with shared leadership.

However, it is not clear whether personality traits are associated with preferences for different environments, since people are often unaware of their internal states (Lambie \& Marcel, 2002). It is possible that people of certain personality traits feel and fare worse in shared/focused leadership environments, but are unaware of their psychophysiological costs beforehand. For this reason, our inclusion of personality traits in this study is merely exploratory.

\section{METHOD}

\section{Participants}

We recruited one-hundred and eighty four participants $(63 \%$ men, ages $20-71, \mathrm{M}=33.48$, $\mathrm{SD}=10.41$, median $=30$ years $)$ via the Amazon Mechanical Turk platform. None were excluded. Most participants were currently employed (80.4\% full-time, $10.9 \%$ part-time). Mturk participants were all US nationals. Data was collected between August, 24, 2018 and August, 30, 2018. Due to recent reports of automated responses to Mturk questionnaires (Kennedy, Clifford, Burleigh, Jewell, \& Waggoner, 2018) we used an option offered by Mturk to (1) verify worker country location and (2) block duplicate IP addresses. What is more, we used two red herring items to check for the randomness of the answers: (1) what is the current year and 2) "Please mark a strongly agree to answer for this questions". In all studies, participants each received $\$ 0.50$ as a reward for their participation.

\section{Materials and Procedure}

After reading and accepting an informed consent, participants filled in their sociodemographic information (age, gender, and occupational status). On the following pages participants filled in the following measures, the order of which was assigned randomly.

Team preferences. The measure investigated preferences for working in a team characterized by focused vs. a shared leadership. The scale was adapted from Wood and Fields (2007) who measured the perception of actual shared leadership in a team on a four-point Likert-type scale. The scale was 
transformed for the purpose of this study and measured preference between two types of teams, e.g. 'Team A: Each member of the team participates in establishing the goals for the organization. Team B: A leader of the team establishes the goals for the organization.' Items were answered on a 5-point scale ( 1 = I would definitely like to work for Team A, 5 = I would definitely like to work for Team B.). Cronbach's alpha for the scale equaled $\alpha=.84$. On the scale level, the higher the score, the higher the preference for focused leadership in teams. The entire scale can be found in the appendix.

Control preferences were measured with scale developed by Grzelak, 2001. The shortened, 28 -item scale consists of five sub-scales measuring: Collaboration ( 5 items, e.g. "I like being in a group in which everyone has something to say"), Dominance (5 items, e.g. "I like to have influence on what others do"), Proactive Autonomy (4 items, "I like choosing goals for myself"), Reactive Autonomy (5 items, "I don't like it when someone makes decisions about my business"), Respect for Autonomy ( 5 items, "It would be good if everyone were responsible for their own decisions"), and Submissiveness (4 items, "I like it when someone makes decisions for me"). Items were answered on a 5 -point scale $(1=$ Strongly disagree, $5=$ Strongly agree). The entire scale can be found in the appendix. Cronbach's alpha for the scale ranged from $\alpha=.80$ to $=.86$. The three autonomy scales were correlated at a very high level $(\mathrm{r}=.60$ for proactive autonomy and reactive autonomy, $r=.60$ for reactive autonomy and autonomy respect, and $r=0.77$ for autonomy respect and proactive autonomy). They also formed one factor in a factor analysis explaining $77.32 \%$ of total variance. For this reasons we decided to compute one Autonomy indicator out of the above three scales - a decision deemed appropriate in certain situations (Zinserling \& Winiewski, 2001).

Political orientation was measured with two items: "How would you describe your political outlook with regard to economic/social issues?" (Talhelm, Haidt, Oishi, Zhang, Miao, \& Chen, 2015). Response scale ranged from 1: very liberal to 7: very conservative). An indicator was computed by averaging these two items $(r=0.74)$. A higher score meant a more conservative orientation.

Personality. A 24-item Brief HEXACO Inventory (BHI) was used to measure personality (De Vries, 2013). Recent research suggests that the Big Five model fails to encompass an additional dimension that was shown to form a separate factor - Honesty-Humility (e.g. Ashton et al., 2004). The HEXACO model consists of the following personality scales: Honesty-Humility, Emotionality, eXtraversion, Agreeableness, Conscientiousness, and Openness to experience. Each of these domain scales is measured by 4 facets that capture behaviors associated with a given personality domain. The HEXACO model was shown to be a good predictor of workplace delinquency, status-driven risk-taking, egoism, narcissism, Machiavellianism, or psychopathy - all related to ModestyHumility domain, not included in the Big Five model (Ashton, Lee, Pozzebon, Visser, \& Worth, 2010; De Vries, De Vries, De Hoogh, \& Feij, 2009; De Vries \& Van Kampen, 2010; Lee, Ashton, Wiltshire, Bourdage, Visser, Gallucci, 2013). The BHI scale measures six personality domains with 1 item per facet. The alpha reliability coefficients are rather low, however the scales perform well in terms of test-retest stability and self-other agreement. It was also shown to have relatively high convergent correlations with full-length scales. Items were answered on a 5-point scale $(1=$ Strongly disagree, 5 = Strongly agree).

\section{RESULTS}

To test our hypotheses we used a hierarchical multiple regression. We used multiple regression analysis in order to determine which of the individual difference variables are best at predicting participants' preference for shared leadership, while controlling for other variables. We regressed team preference (high values equal higher preference for focused leadership) on 1) gender $(1=$ male, 2 = female $)$ and age in the first step in order to rule them out as alternative explanations, 
2) personality variables in the second step, 3) control preferences in the third step, and 4) political orientation in the fourth step. The results can be seen in Table 2.

For the analyzed sample, age and gender had no relationship to the team preference and neither did any of the personality variables. Among control preferences, the strongest effect could be observed for collaboration - the higher the preferences for joint outcome control, the higher the preference for shared leadership in teams, $\beta=-0.40, p<.001$. Additionally, focused leadership was preferred by those higher in preference for dominance, $\beta=0.30, p=.002$. Autonomy was not related to team preference. Finally, political orientation also predicted team preference - a more conservative (social and economic) outlook was related to higher preference for focused leadership in teams, $\beta=0.21, p=.007$.

Table 2. Results of hierarchical linear regression predicting shared leadership preferences

\begin{tabular}{|c|c|c|c|c|c|c|c|c|c|c|c|c|}
\hline & \multicolumn{3}{|c|}{ Model 1} & \multicolumn{3}{|c|}{ Model 2} & \multicolumn{3}{|c|}{ Model 3} & \multicolumn{3}{|c|}{ Model 4} \\
\hline & $\beta$ & SE & $p$ & $\beta$ & $\mathrm{SE}$ & $p$ & $\beta$ & $\mathrm{SE}$ & $p$ & $\beta$ & SE & $p$ \\
\hline Age & .01 & .01 & .558 & .01 & .01 & .201 & .01 & .01 & .221 & .01 & .01 & .449 \\
\hline Gender & -.13 & .12 & .283 & -.10 & .13 & .435 & -.07 & .12 & .582 & -.09 & .12 & .439 \\
\hline Honesty & & & & -.06 & .08 & .449 & .12 & .08 & .148 & .15 & .08 & .069 \\
\hline Emotionality & & & & .04 & .09 & .660 & .05 & .08 & .488 & .04 & .08 & .577 \\
\hline Extraversion & & & & -.09 & .08 & .270 & -.07 & .08 & .387 & -.07 & .08 & .408 \\
\hline Agreeableness & & & & .04 & .07 & .547 & .03 & .07 & .727 & -.01 & .07 & .900 \\
\hline $\begin{array}{l}\text { Openness to } \\
\text { Experience }\end{array}$ & & & & -.10 & .08 & .230 & .01 & .08 & .863 & .07 & .08 & .384 \\
\hline Conscientiousness & & & & -.19 & .10 & .066 & -.10 & .10 & .299 & -.11 & .10 & .268 \\
\hline Autonomy & & & & & & & -.10 & .11 & .359 & -.08 & .10 & .435 \\
\hline Submissiveness & & & & & & & .13 & .08 & .114 & .10 & .08 & .226 \\
\hline Dominance & & & & & & & $.28^{* *}$ & .08 & .001 & $.26^{* *}$ & .08 & .002 \\
\hline Collaboration & & & & & & & $-.38^{* * *}$ & .08 & .000 & $-.40^{* * *}$ & .08 & .000 \\
\hline Political Orientation & & & & & & & & & & $.10^{* *}$ & .04 & .007 \\
\hline $\mathrm{R}^{2}$ & & 0.01 & & & 0.11 & & & 0.29 & & & 0.32 & \\
\hline $\mathrm{F}(\mathrm{dt})$ & & $\begin{array}{c}0.8 \\
(2.173)\end{array}$ & & & $\begin{array}{c}2.46^{*} \\
(8.167)\end{array}$ & & & $\begin{array}{c}5.49^{* * *} \\
(12.163)\end{array}$ & & & $\begin{array}{c}5.86^{* * *} \\
(13.162)\end{array}$ & \\
\hline
\end{tabular}

\section{DISCUSSION}

The primary objective of the present study was to investigate if shared leadership is a form of organizational order that would fit everybody. If people want to work in teams that share leadership, the probability of the emergence of shared leadership will be higher and the application of shared leadership would lead to better organizational effects. We were interested in checking whether individual differences predict preference for shared vs. focused leadership. Specifically, we analyzed the relationship between personality traits, control preferences, and political orientations and preferences for shared vs. focused leadership. 


\section{Control Preferences}

Consistent with our expectations, preference for collaboration predicted higher preference for shared leadership (H1a). Grzelak (2001) argued that collaboration preference promotes democracy by accepting joint effort and coordination among individuals and social groups in attaining their interests. Collaboration requires one to give up at least some element of control over one's outcomes and accept the influence of others. Hence, those high in collaboration preference need to believe in other people's competence and good will - strong prerequisites for shared leadership.

Preference for dominance predicted higher preference for focused leadership in teams (H1c). Dominant individuals were previously shown to value success and promotion (Modrzejewska, 2004), the potential for which is arguably higher in focused leadership teams. What is more, such individuals - even if not yet in leadership positions - might envision themselves occupying one in the future - a prospect diminished in shared leadership teams. Contrary to our expectations, submissiveness was not related to preference for focused leadership in teams.

We did not form any predictions with regards to the autonomy scales. In our study the three autonomy scales (proactive autonomy, reactive autonomy, and respect for autonomy) were highly correlated, which justified collapsing them into one autonomy measure. The results of our study did not show any relationship between joint autonomy scale and preference for shared leadership. Individuals high in preference for autonomy prefer situations in which personal freedom is not limited. We can imagine both shared and focused leadership teams to promote or limit individual freedom of team members. Hence, the relationship between preference for autonomy and preference for shared leadership might be more complex and dependent on personal construal.

\section{Political Orientation}

As predicted, a conservative political orientation - in contrast to a liberal political orientation was related to higher preferences for focused leadership in teams (H2). Conservatives may be less open to shared leadership in teams as such teams violate the hierarchy of authority and social order conservatives tend to endorse (Sowell, 2002). Such teams might also be perceived as less stable and predictable (Friesen, Kay, Eibach, \& Galinsky, 2014) - attributes considered more valuable by conservatives (McCrae, 1996). In contrast, liberals were more likely to prefer shared leadership in teams. Such teams guarantee greater equality and freedom of expression - values endorsed by liberals (Sowell, 2002).

\section{Personality}

Finally, we decided to explore whether personality traits of individuals predict their preferences for shared leadership in teams. None of the personality variables proved to significantly predict preference for shared vs. focused leadership in teams. However, it is possible that people of certain personality traits might feel and fare worse in shared/focused leadership environments, without being able to predict their psychophysiological costs beforehand. Therefore, as a follow up it may be interesting to consider whether personality variable predict behavior or emotions experienced in a shared leadership context.

\section{Limitations and Future Research Directions}

Our results implicate several directions for future research. First, although in the current study control preferences were measured as relatively stable dispositions, it is important to note that they are situationally dependent (Grzelak, 2001). It is possible that individuals want to give up control in the work environment, but assume it with close others, or vice versa. Even at work, one's control preferences might depend on the level of personal significance of issues decided on by the 
team or the extent to which one's job relates to personal interests. Further research could explore these caveats.

What is more, previous research showed that a feeling of the lack of personal control might influence people's preferences for more hierarchical structures at work (Friesen et al., 2014). Further research could investigate whether perceived job or economic instability affects preferences for hierarchy via affecting people's control preferences.

In the current study, attitudes towards shared leadership were measured only on a declarative, hypothetical level. Such a situation - devoid of context, such as the number of people in the team, area of functioning, interpersonal relationships between team members, etc. - is too abstract. For instance, research showed that although self-management increased organizational citizenship behavior, if the employees did not believe that the organization trusts them, the only consequence of self-management was an increase in counterproductive work behaviors (Jensen \& Raver, 2012).

As mentioned above, due to limitations in people's ability to introspect and predict one's emotional reactions, we cannot be sure how our participants would feel in the actual shared or focused leadership teams. A study measuring employees' satisfaction and experienced emotions in shared vs. focused leadership teams would be valuable to understand the real impact of employees' individual differences (including that of personality and temperamental differences). What is more, it would be of interest to investigate the work performance of employees who either fit or do not fit into given organizational structures.

Finally, we need to address a relatively small size and homogeneity of our sample. Our participants were predominantly in full-time employment $(80.4 \%)$ and US based. A replication on different populations would be of value for generalizability of the obtained results.

\section{CONCLUSIONS}

Recent publications on shared leadership praise its ability to make employees more satisfied and organizations more effective. However, we believe that it is dangerous to assume the homogeneity of preferences. While one person finds meaning and joy in taking on responsibility at work, another one might find it a burden that pulls them away from their family or hobby. In order to prevent counterproductive behaviors from the employees forced to take on control they do not want, it is essential to identify the potential obstacles to introducing a more collaborative and egalitarian organizational structure.

Our study was aimed at investigating three individual difference variables that we assumed might predict preferences for the leadership structure. We found that both control preferences, as well as political orientations, predict preferences for shared leadership in teams. However, personality variables were not related to preferences for shared leadership. Control preferences explain individuals' willingness to enter situations of different interdependence structures. When those preferences are not met, people might experience discomfort and engage in counterproductive work behaviors. Further research should investigate to what extend control preferences can be situationally affected, as well as their impact on employee outcomes and wellbeing in shared vs. focused leadership environments.

\section{Literature}

Anderson, C., \& Galinsky, A. D. (2006). Power, optimism, and risk-taking. European Journal of Social Psycho$\log y, 36,511-536$.

Ashton, M. C., Lee, K., Perugini, M., Szarota, P., de Vries, R. E., Di Blas, L., et al. (2004). A six-factor structure of personality-descriptive adjectives: Solutions from psycholexical studies in seven languages. Journal of Personality and Social Psychology, 86, 356-366.

Ashton, M. C., Lee, K., Pozzebon, J. A., Visser, B. A., \& Worth, N. C. (2010). Status-driven risk taking and the major dimensions of personality. Journal of Research in Personality, 44, 734-737. 
Barry, D. (1991). Managing the bossless team: Lessons in distributed leadership. Organizational dynamics, 20, 31-47.

Bendahan, S., Zehnder, C., Pralong, F., P, \& Antonakis, J. (2015). Leader corruption depends on power and testosterone. The Leadership Quarterly, 26, 101-122.

Bennett, N., Wise, C., Woods, P. A., \& Harvey, J. A. (2003). Distributed leadership: A review of literature. National College for School Leadership.

Bergman, J. Z., Rentsch, J. R., Small, E. E., Davenport, S. W., \& Bergman, S. M. (2012). The shared leadership process in decision-making teams. Journal of Social Psychology, 152, 17-42.

Brown, M. E., \& Gioia, D. A. (2002). Making things click: Distributive leadership in an online division of an offline organization. The Leadership Quarterly, 13, 397-419.

Carson, J. B., Tesluk, P. E., \& Marrone, J. A. (2007). Shared leadership in teams: An investigation of antecedent conditions and performance. Academy of Management Journal, 50, 1217-1234.

Carte, T. A., Chidambaram, L., \& Becker, A. (2006). Emergent leadership in self-managed virtual teams. Group Decision and Negotiation, 15, 323-343.

Chiu, C. C., Owens, B. P., \& Tesluk, P. E. (2016). Initiating and utilizing shared leadership in teams: The role of leader humility, team proactive personality, and team performance capability. Journal of Applied Psychology, 101, 1705-1720.

Choi, C. B., \& Beamish, P. W. (2004). Split management control and international joint venture performance. Journal of International Business Studies, 35, 201-215.

Collins, D. (1995). Death of a gainsharing plan: Power politics and participatory management. Organizational Dynamics, 24, 23-38.

Daspit, J., Tillman, C. J., Boyd, N. G., \& Mckee, V. (2013). Cross-functional team effectiveness: An examination of internal team environment, shared leadership, and cohesion influences. Team Performance Management, 19, 34-56.

De Vries, R. E. (2013). The 24-item Brief HEXACO Inventory (BHI). Journal of Research in Psychology, 47, 871-880.

De Vries, R. E., \& Van Kampen, D. (2010). The HEXACO and 5DPT models of personality: A comparison and their relationships with psychopathy, egoism, pretentiousness, immorality, and machiavellianism. Journal of Personality Disorders, 24, 244-225.

De Vries, R. E., De Vries, A., De Hoogh, A., \& Feij, J. (2009). More than the Big Five: Egoism and the HEXACO model of personality. European Journal of Personality, 23, 635-654.

Denis, J. L., Lamothe, L., \& Langley, A. (2001). The dynamics of collective leadership and strategic change in pluralistic organizations. Academy of Management Journal, 44, 809-837.

Denis, J. L., Langley, A., \& Sergi, V. (2012). Leadership in the plural. The Academy of Management Annals, 6, 211-283.

Doliński, D. (1993). Orientacja defensywna. Warsaw: Wydawnictwo Instytutu Psychologii PAN.

Ensley, M. D., Hmieleski, K. M., \& Pearce, C. L. (2006). The importance of vertical and shared leadership within new venture top management teams: Implications for the performance of startups. The Leadership Quarterly, 17, 217-231.

Ensley, M. D., \& Pearce, C. L. (2001). Shared cognition in top management teams: Implications for new venture performance. Journal of Organizational Behavior: The International Journal of Industrial, Occupational and Organizational Psychology and Behavior, 22, 145-160.

Etzioni, A. (1965). Dual leadership in complex organizations. American Sociological Review, 30, 688-698.

Etzioni, A., \& Lehman, E. (1968). Dual leadership in a therapeutic organization. Revue Internationale De Psychologie Appliquée, 17, 51-67.

Fausing, M. S., Joensson, T. S., Lewandowski, J., \& Bligh, M. (2015). Antecedents of shared leadership: Empowering leadership and interdependence. Leadership and Organization Development Journal, 36, 271-291.

Finch, F. E. (1977). Collaborative leadership in work settings. Journal of Applied Behavioral Science, 13, 292-302.

Fiske, S. T. (1993). Controlling other people. The impact of power on stereotyping. 48, 621-628.

Friesen, J. P., Kay, A. C., Eibach, R. P., Galinsky, A. D. (2014). Seeking structure in social organization: Compensatory control and the psychological advantages of hierarchy, Journal of Personality and Social Psychology, 106, 590-609.

Gibb, C. A. (1954). Leadership. In G. Lindzey (Ed.), Handbook of Social Psychology vol. 2, (pp. 877-920). Reading, MA: Addison-Wesley.

Goksoy, S. (2016). Analysis of the relationship between shared leadership and distributed leadership. Eurasian Journal of Educational Research, 65, 295-312.

Gonzaga, G. C., Keltner, D., \& Ward, D. (2008). Power in mixed-sex stranger interactions. Cognition and Emotion, 22, $1555-1568$. 
Grille, A., Schulte, E.-M., \& Kauffeld, S. (2015). Promoting shared leadership: A multilevel analysis investigating the role of prototypical team leader behavior, psychological empowerment, and fair rewards. Journal of Leadership and Organizational Studies, 22, 324-339.

Gronn, P. (2002). Distributed leadership as a unit of analysis. The Leadership Quarterly, 13, 423-451.

Grzelak, J. (2002). O orientacji kontroli. In J. Brzeziński \& H. Sęk (Eds.), Psychologia w obliczu nadchodzących przemian społeczno-kulturowych. Kolokwia Psychologiczne vol. 10, (pp. 239-253). Warsaw, Poland: Instytut Psychologii PAN.

Grzelak, J. (2001). Control preferences. In J. A. Bargh \& D. K. Apsley (Eds.), Unraveling the Complexities of Social Life (pp. 141-154). Washington, DC: American Psychological Association.

Grzelak, J., Kuhlman, D. M., Yeagley, E. and Joireman, J. (2010). Attraction to Prospective Dyadic Relationships: Effects of Fate Control, Reflexive Control and Partner's Trustworthiness. In Kramer, R., Tenbrunsel, A., and Bazerman, M. (Eds) Social Decision Making: Social Dilemmas, Social Values and Ethical Judgments. Routledge.

Gu, J., Chen, Z., Huang, Q., Liu, H., \& Huang, S. (2018). A multilevel analysis of the relationship between shared leadership and creativity in inter-organizational teams. The Journal of Creative Behavior, 52, 109-126.

Guinote, A., Judd, C. M., \& Brauer, M. (2002). Effects of power on perceived and objective group variability: Evidence that more powerful groups are more variable. Journal of Personality and Social Psychology, 82, 708-721.

Han, S. J., Lee, Y., Beyerlein, M., \& Kolb, J. (2018). Shared leadership in teams: The role of coordination, goal commitment, and knowledge sharing on perceived team performance. Team Performance Management, 24, 150-168.

Hiller, N. J., Day, D. V., \& Vance, R. J. (2006). Collective enactment of leadership roles and team effectiveness: A field study. Leadership Quarterly, 17, 387-397.

Hoch, J. E. (2014). Shared leadership, diversity, and information sharing in teams. Journal of Managerial Psychology, 29, 541-564.

Hoch, J. E. (2013). Shared leadership and innovation: The role of vertical leadership and employee integrity. Journal of Business and Psychology, 28, 159-174.

Hoch, J. E., \& Dulebohn, J. H. (2017). Team personality composition, emergent leadership and shared leadership in virtual teams: A theoretical framework. Human Resource Management Review, 27, 678-693.

Hoch, J. E., \& Kozlowski, S. W. J. (2014). Leading virtual teams: Hierarchical leadership, structural supports, and shared team leadership. Journal of Applied Psychology, 99, 390-403.

Hoch, J. E., Pearce, C. L., \& Welzel, L. (2010). Is the most effective team leadership shared? the impact of shared leadership, age diversity, and coordination on team performance. Journal of Personnel Psychology, 9, 105-116.

Hogeveen, J., Inzlicht, M., \& Obhi, S. S. (2014). Power changes how the brain responds to others. Journal of Experimental Psychology: General, 143, 755-762.

Hu, N., Chen, Z., Gu, J., Huang, S., \& Liu, H. (2017). Conflict and creativity in inter-organizational teams: The moderating role of shared leadership. International Journal of Conflict Management, 28, 74-102.

Huxham, C., \& Vangen, S. (2000). Leadership in the shaping and implementation of collaboration agendas: How things happen in a (not quite) joined-up world. Academy of Management Journal, 43, 1159-1175.

Ishikawa, J. (2012). Transformational leadership and gatekeeping leadership: The roles of norm for maintaining consensus and shared leadership in team performance. Asia Pacific Journal of Management, 29, 265-283.

Jensen, J. M., \& Raver, J. L. (2012). When self-management and surveillance collide. Consequences for employees' organizational citizenship and counterproductive work behaviors. Group and Organization Management, 37, 308-346.

Jost, J. T. (2006). The end of the end of ideology. American Psychologist, 61, 651-670.

Jost, J. T., Glaser, J., Sulloway, F., \& Kruglanski, A. W. (2003). Political conservatism as motivated social cognition. Psychological Bulletin, 129, 339-375.

Kelley, H. H., Thibaut, W. (1978). Interpersonal relations. A theory of interdependence, New York: Wiley.

Keltner, D., Gruenfeld, D.H. \& Anderson, C. (2003) Power, approach, and inhibition. Psychological Review, $110,265-284$.

Kennedy, R., Clifford, S., Burleigh, T., Jewell, R., \& Waggoner, P. (2018). The Shape of and Solutions to the MTurk Quality Crisis. Available at SSRN: https://ssrn.com/abstract=3272468 or http://dx.doi.org/10.2139/ ssrn.3272468

Kipnis, D. (1972). Does power corrupt? Journal of Personality and Social Psychology, 24, 33-41.

Klakovich, M. D. (1994). Connective leadership for the 21st-century - A historical-perspective and future-directions. Advances in Nursing Science, 16, 42-54. 
Klakovich, M. D. (1996). Registered nurse empowerment - Model testing and implications for nurse administrators. Journal of Nursing Administration, 26, 29-35.

Laloux, F. (2014). Reinventing organizations: A guide to creating organizations inspired by the next stage in human consciousness. Brussels: Nelson Parker.

Lambie, J. A., \& Marcel, A. J. (2002). Consciousness and the varieties of emotion experience: a theoretical framework. Psychological Review, 109, 219-259.

Lee, K., Ashton, M. C., Wiltshire, J., Bourdage, J. S., Visser, B. A., \& Gallucci, A. (2013). Sex, Power, and Money: Prediction from the Dark Triad and Honesty-Humility. European Journal of Personality, 27, 169-184.

Lee, D. S., Lee, K. C., \& Seo, Y. W. (2015). An analysis of shared leadership, diversity, and team creativity in an e-learning environment. Computers in Human Behavior, 42, 47-56.

Lord, R. G., Day, D. V., Zaccaro, S. J., Avolio, B. J., \& Eagly, A. H. (2017). Leadership in applied psychology: Three waves of theory and research. Journal of Applied Psychology, 102, 434-451.

Mathieu, J. E., Kukenberger, M. R., D'innocenzo, L., \& Reilly, G. (2015). Modeling reciprocal team cohesion-performance relationships, as impacted by shared leadership and members' competence. Journal of Applied Psychology, 100, 713-734.

McCrae, R. R. (1996). Social consequences of experiential openness. Psychological Bulletin, 120, 323-337.

McCrae, R. R., \& John, O. P. (1992). An introduction to the five-factor model and its applications. Journal of Personality, 60, 175-215.

McCrimmon, M. (2005). Thought leadership: A radical departure from traditional, positional leadership. Management Decision, 43, 1064-1070.

Modrzejewska, I. (2004). Satysfakcja zawodowa, wartości zawodowe a preferencje kontroli u pracowników zatrudnionych $w$ organizacji prywatnej $i$ państwowej (unpublished master's thesis). Warsaw: Faculty of Psychology, University of Warsaw, Warsaw, Poland.

Nonaka, I., Hirose, A., \& Takeda, Y. (2016). 'Meso'-foundations of dynamic capabilities: team-level synthesis and distributed leadership as the source of dynamic creativity. Global Strategy Journal, 6, 168-182.

Pearce, C. L. (2007). The future of leadership development: The importance of identity, multi-level approaches, self-leadership, physical fitness, shared leadership, networking, creativity, emotions, spirituality and on-boarding processes. Human Resource Management Review, 17, 355-359.

Pearce, C. L., \& Conger, J. A. (2003). Shared Leadership: Reframing the Hows and Whys of Leadership. Thousand Oaks, Calif: SAGE Publications, Inc.

Pearce, C. L., Hoch, J., Jeppesen, H., \& Wegge, J. (2010). New forms of management: shared and distributed leadership in organizations. Personnel Psychology, 9, 151-153.

Pearce, C. L., \& Sims, H. P. (2002). Vertical versus shared leadership as predictors of the effectiveness of change management teams: An examination of aversive, directive, transactional, transformational, and empowering leader behaviors. Group Dynamics-Theory Research and Practice, 6, 172-197.

Pearce, C. L., \& Sims, H. P. J. (2000). Shared leadership: Toward a multi-level theory of leadership. In M. Beyerlein, D. A. Johnson, \& S. T. Beyerlein (Eds.), Advances in interdisciplinary studies of work teams: Team development (Vol. 7, pp. 115-139). New York: Elsevier.

Pratto, F., Sidanius, J., Stallworth, L. M., \& Malle, B. F. (1994). Social dominance orientation: A personality variable predicting social and political attitudes. Journal of personality and social psychology, 67, 741.

Robert, L. P., \& You, S. (2018). Are you satisfied yet? Shared leadership, individual trust, autonomy, and satisfaction in virtual teams. Journal of the Association for Information Science and Technology, 69, 503-513.

Sally, D. (2002). Co-leadership: Lessons from republican Rome. California Management Review, 44, 84-99.

Semler, R. (2001). Maverick!: the success story behind the world's most unusual workplace. London: Arrow.

Serban, A., \& Roberts, A. J. B. (2016). Exploring antecedents and outcomes of shared leadership in a creative context: A mixed-methods approach. Leadership Quarterly, 27, 181-199.

Sowell, T. (2002). A conflict of visions: The ideological origins of political struggles. New York: Basic Books.

Talhelm, T., Haidt, J., Oishi, S., Zhang, X., Miao, F. F., \& Chen, S. (2015). Liberals think more analytically (more "WEIRD") than conservatives. Personality and Social Psychology Bulletin, 41, 250-267.

Thorpe, R., Gold, J., \& Lawler, J. (2011). Locating distributed leadership. International Journal of Management Reviews, 13, 239-250.

Uhl-Bien, M. (2006). Relational leadership theory: Exploring the social processes of leadership and organizing. Leadership Quarterly, 17, 654-676.

Ulhøi, J. P., \& Müller, S. (2014). Mapping the landscape of shared leadership: A review and synthesis. International Journal of Leadership Studies, 8, 66-87.

van Kleef, G. A., Oveis, C., van der Löwe, I., LuoKogan, A., Goetz, J., \& Keltner, D. (2008). Power, distress, and compassion: Turning a blind eye to the suffering of others. Psychological Science, 19, 1315-1322. 
Vangen, S., \& Huxham, C. (2003). Enacting leadership for collaborative advantage: Dilemmas of ideology and pragmatism in the activities of partnership managers. British Journal of Management, 14, 61-76.

Wang, D., Waldman, D. A., \& Zhang, Z. (2014). A meta-analysis of shared leadership and team effectiveness. Journal of Applied Psychology, 99, 181-198.

Wood, M. S., \& Fields, D. (2007). Exploring the impact of shared leadership on management team member job outcomes. Baltic Journal of Management, 2, 251-272.

Wu, Q., \& Cormican, K. (2016). Shared Leadership and Team Creativity: a Social Network Analysis in Engineering Design Teams. Journal of technology management \& innovation, 11, 2-12.

Wu, W. P., \& Lee, Y. D. (2001). Participatory management and industrial relations climate: A study of Chinese, Japanese and US firms in Taiwan. International Journal of Human Resource Management, 12, 827-844.

Zhou, W., Zhang, Y., \& Shen, Y. (2017). How shared leadership and team personality composition interact to improve entrepreneurial team performance: Evidence from china. Journal of Small Business and Enterprise Development, 24, 426-445.

Zinserling, I., \& Winiewski, M. (2011). Uwarunkowania orientacji kontroli. 15 lat badań Inwentarzem Upodobań i Opinii (IUiO). In J. Czarnota-Bojarska \& I. Zinserling (Eds.), W kręgu psychologii spotecznej (pp. 37-58), Warsaw, Poland: Wydawnictwa Uniwersytetu Warszawskiego. 


\section{APPENDIX}

\section{Shared vs. Focus Leadership Scale}

- Team A: Each member of the team participates in establishing the goals for the organization. Team B: A leader of the team establishes the goals for the organization.

- Team A: The team has one leader who takes on the responsibility for the team outcomes and guides the team members. Team B: Each team member shares the responsibility for the team outcomes and helps in guiding others. (Reversed)

- Team A: Each team member helps to frame the vision for the organization. Team B: A leader of the team frames the vision for the organization.

- Team A: The team has one person in charge who ensures that the work is well organized. Team B: The team members collaborate to organize the workflow. (Reversed)

- Team A: Each member shares in deciding on the best course of action when a problem faces the team. Team B: A leader decides on the best course of action when a problem faces the team.

- Team A: A leader insures the team fulfills its obligations. Team B: Each member chip in (even if it is outside an area of personal responsibility) to insure the team fulfills its obligations. (Reversed)

- Team A: Each member is evaluated by and is accountable to all other members of the team. Team B: Each member is evaluated by and is accountable to a leader of the team.

- Team A: A leader decides how resources are allocated in regard to the team's priorities. Team B: Each member has a say in deciding how resources are allocated in regard to the team's priorities. (Reversed)

- Team A: Team members collaborate with one another in making decisions that affect the organization. Team B: A leader makes decisions that affect the organization.

- Team A: A leader identifies, diagnoses, and resolves the problems that face the team. Team B: Each member helps to identify, diagnose, and resolve the problems that face the team. (Reversed)

Control Preferences Scale (Grzelak, 2001)

\begin{tabular}{|c|c|}
\hline Collaboration & $\begin{array}{l}\text { I like being in a group in which everyone has an influence on what happens } \\
\text { I like being in a group in which everyone has something to say } \\
\text { It is best to solve a problem together with others } \\
\text { I like being in a group in which everyone makes decisions together } \\
\text { I like working in a team }\end{array}$ \\
\hline Dominance & $\begin{array}{l}\text { I like making decisions for others } \\
\text { I like leading other people } \\
\text { I think I have leadership tendencies } \\
\text { I like to have influence on what others do } \\
\text { I like to wield power }\end{array}$ \\
\hline Proactive Autonomy & $\begin{array}{l}\text { I like taking care of my own business myself } \\
\text { I like controlling my own fate } \\
\text { I like choosing goals for myself } \\
\text { I like taking care of myself }\end{array}$ \\
\hline Reactive Autonomy & $\begin{array}{l}\text { I don't like it when someone interferes in my life } \\
\text { I don't like it when someone rules over me } \\
\text { I don't like it when someone makes decisions about my business } \\
\text { I don't like it when someone forces their opinion on me } \\
\text { I don't like it when someone butts into what I'm doing }\end{array}$ \\
\hline Respect for Autonomy & $\begin{array}{l}\text { I like people who lead their own lives } \\
\text { I like people who are masters of their own fate } \\
\text { It would be good if everyone were responsible for their own decisions } \\
\text { I like people who are autonomous, independent from others } \\
\text { I like it when other people can think for themselves }\end{array}$ \\
\hline Submissiveness & $\begin{array}{l}\text { I like it when someone directs me in various things } \\
\text { I am readily subordinate to others on a day to day basis } \\
\text { I like it when someone makes decisions for me } \\
\text { I like it when someone is responsible for me }\end{array}$ \\
\hline
\end{tabular}




\title{
The Correlates of Two Types of Leadership Motivation
}

\author{
Krzysztof Nowak* \& Raphael Mahari**
}

\begin{abstract}
Summary
The paper deals with the sense of satisfaction in people with traits related to effective leadership, considering three domains: personal, achievement, and self-worth. A segmentation analysis performed on 580 current or future employees, who combine their work with studying management at the University of Warsaw, revealed two groups that had traits related to effective leadership. The subjective feeling of satisfaction across three domains: personal relationships, work-related satisfaction, and self-worth, was compared between both groups with leadership trait profiles and peers with non-leadership trait profiles. Both groups with leadership trait profiles had a higher feeling of satisfaction in work/school relative to their peers. The leadership trait profile group with a high need for power, medium need for achievements and low need for affiliation had higher self-acceptance than peers, while the leadership group with a high need for power, need for achievement and need for affiliation had higher satisfaction with relationships than their peers. Participants in both leadership trait profile groups were divided based on their temperament and preferred working style. Although highly reactive individuals in both groups felt less satisfaction with work/school, this effect was completely canceled out for individuals with a working style matched to a leadership position in the group with a high need for affiliation and achievement. Implications of these findings for organizational practice are discussed.
\end{abstract}

Keywords: leadership motive profile theory, temperament, activity-style, sense of satisfaction

JEL: M12, O15, J24

\section{INTRODUCTION}

Leadership is key to organizational success. Groups of people working together have achieved the most extraordinary human accomplishments. Through history, the members of these groups became more specialized for specific tasks and group roles became more defined. In modern companies, diversification and specialization improve quality and efficiency, but this also means that the company needs to hire more people. The problem with growing companies is that communication, organization, and decision-making became more difficult. Therefore, companies need leaders to ensure efficient operation irrespective of the size.

Who is a leader, and what is his or her impact on an organization? A leader is a single individual with enormous influence on a group of people (De Jong \& Den Hartog 2007). Evidence strongly suggests that leaders have major impact on job performance. One study examined the effect leaders have on vigor. The study found that a good leader can impact vigor which in turn affects job performance (Carmeli, Ben-Hador, Waldman, \& Rupp, 2009). It has also been shown that poor leadership can decrease both job satisfaction and the company's reputation among employees (Schyns \& Schilling, 2013). Many modern company types, such as tech companies, require highly trained and specialized personnel. Employees are essential for companies but, in some cases, finding them is also difficult. Therefore, if their job satisfaction in the company they work for is low, many talented employees will leave, which can result in loss of profits (Yukl, 2008). Studies found evidence that 23.8 billion U.S. dollars are lost by companies due to poor leadership each year in the U.S.A. alone (Schyns \& Schilling, 2013).

A leader affects job performance and innovative behavior. Many modern companies can only remain competitive and profitable by innovating regularly. A company's employees contribute much

\footnotetext{
* Faculty of Management, University of Warsaw, Poland, https://orcid.org/0000-0001-9615-1222

** Tulane University, New Orleans, Louisiana, USA
} 
to its innovation. The importance of R\&D teams and general innovative behavior from employees is already apparent from the massive amounts spent on innovative behavior. Still, recent studies suggest that an essential component of an innovative environment is the leader (De Jong \& Den Hartog, 2007).

Leaders affect the general effectiveness of companies. While it is not always a company's main priority to be efficient, leaders are both essential to identifying the company's priorities and implementing them. Therefore, if a company does not have appropriate leadership, then the goal and its implementation might have adverse effects on profit (Yukl, 2008).

These are just a few examples that show an ever-growing body of evidence suggesting that leaders are essential to establishing, maintaining and regulating companies. Leaders can mean the difference between a profitable company and a company going bankrupt. However, there are many types of leaders and leadership styles. Depending on various variables, some leaders are better suited to their task than are others. A company must not only find a good leader but a good leader suited to the company's (or department) specific environment.

\section{THEORETICAL BACKGROUND}

\section{Leadership motive profile theory}

Since the 1960's, McClelland's motivation theory (McClelland, 1961) has been used in assessing what drives people in the workplace. This theory is based on the premise that three basic needs are key:

- $\quad$ need for power

- need for affiliation

- need for achievement.

Need for power is realized when a person has control over the decisions and processes by other people or groups (MClelland, 1970). Need for affiliation refers to the subjective feeling of contact and getting along well with other people (Deci \& Ryan, 2000). Need for achievement is realized through feeling competent at the tasks one performs.

The structure of these needs plays off each of them and is thought to regulate a person's actions. For example, an underpaid middle manager with a high need for affiliation may prefer to not ask for a rise from his or her employer in order to avoid conflict, while a fellow manager with a high need for power and a low need for affiliation may use conflict to strengthen his or her position within the company. Thus, various profiles of these needs have been associated with successful career outcomes.

One such profile refers to leaders. Effective leadership has been associated with a particular structure of needs: high need for power, medium need for achievement and low need for affiliation. This combination of needs has been termed McClelland's leadership motive profile (McClelland \& Burnham, 1976).

Recently, it has been found that another leadership motive profile is associated with a favorable outcome in modern organizations: relationship-focused high achievers (Steinmann, et al. 2015). This profile has a high need for power, achievement and affiliation. Managers with this profile have been found to earn more than their peers and achieve team goals more frequently. Thus, they are more successful which is reflected in greater satisfaction.

\section{Leadership cognitive resource theory}

Different attributes make leaders more or less suitable for specific tasks and environments. Numerous research papers have examined specific leadership attributes and their effect on the company. A major theory dealing with this topic was Fiedler's contingency model of leadership (Fiedler, 
$1967)$ and the modified version: cognitive resource theory (Fiedler, 1986). The latter proposes to explain the link between cognitive resources and leadership performance. In stable and low-stress situations, higher cognitive resources (intelligence being among them) are proposed to increase leadership performance. In highly chaotic and stressful environments, highly intelligent leaders are predicted to perform worse than less intelligent leaders. This prediction is exceptionally accurate for leaders with considerable experience to guide them in decision-making.

Cognitive resource theory aims to explain why, while more intelligent leaders have many benefits, more effective planning, decision-making and employee training being among them, the relationship between leadership intelligence and leadership is weak at best (Neider \& Schriesheim, 1988). This is especially surprising since it has been empirically demonstrated that employees who are provided training enchancing the cognitive resources avalable to them can come up with solutions of considerably higher quality and originality (Mumford, Todd, Higgs \& McIntosh, 2017). For example, one study found that the correlation between leadership intelligence and leadership effectiveness in mid- and higher-level managers had a correlation of just 0.22 and decreased when job stress was high (Judge et al. 2004).

\section{Temperament and working style misfit in leaders}

A leader's individual characteristics and preferred working style may fit to various degrees the demands of his or her role in an organization. As a leadership position is often prestigious, and often pays well a leadership position may be sought after by individuals who's temperament (eg. a person reacting very strongly to stressful situations) or working style (a person not liking to change the way of approaching a problem), does not fit to a highly stressful and chaotic environment. A mismatch between temperamental characteristics, associated with a low level of resources and a working style and environment requiring a lot of cognitive resources has been described as a lasting "sore point" (Eliasz, 2006). Such a mismatch can be associated with psychological costs to the leader, and reduced leader effectiveness posing costs for the organization as a whole.

One study that has shown how personality characteristics can be associated with increased costs while performing tasks with different requirements of working styles comes from Szymura and Nęcka (1998). In the study, introverts and extraverts were given two tasks and had to perform then in one of two conditions. In the first condition the participants could focus on one task at a time, while in the second condition they had to complete the tasks simultaneously. While introverts performed better in the condition where they could focus on one task, extraverts performed better when multitasking. This was consistent with the hypothesis that extraverts have a higher need for stimulation and resources needed to complete tasks under stressful situations then do introverts.

Studies also show that people can modify their working styles based on work demands (Wieczorkowska, 1998; Wieczorkowska et al., 2009). In response to instructions requiring various levels of precision when performing a task, people are able to temporarily change their working style. Hover, temperamental characteristics are much more persistent, to changing work demands. In the case of a leadership position, that demands many decisions in a chaotic environment, this can lead to the aforementioned mismatch.

Studies on job requirements - employee personality misfit have found that (Jeśka, 2016, Wieczorkowska, Król, Wierzbiński, 2015):

- when performing tasks that require following a strict procedure, employees that have a more methodical working style incur smaller psychological costs then employees that have a less methodical working style; 
- in workplaces where there are more formalized procedures, less reactive employees earn more;

- less reactive employees deal with multitasking and chaotic work environments better then more reactive employees.

Since working environments in leadership positions rarely have clear procedures and are constantly changing and highly demanding, a preference for non-methodical work can fit such an environment better and thus protect some highly reactive leaders from too high levels of stress.

\section{Research question and hypotheses}

This paper deals with two research questions concerning leadership and satisfaction:

1. How are leadership traits related to sense of satisfaction?

2. Can a leader's working style that is well-suited to his or her temperament and environment influence his or her sense of satisfaction?

The hypotheses related to these were as follows:

H1 People with high leadership motivation feel a higher level of satisfaction than their peers.

$H 2$ Various profiles of leadership traits are related to sense of satisfaction across different domains.

H3 Leaders with a working style suited to their temperament and environment feel greater satisfaction than leaders with a working style unsuited to their temperament.

\section{METHOD}

\section{Participants}

Five hundred eighty (580) faculty students and participants of the MBA program at the faculty of Management at the University of Warsaw took part in the study. 394 (68\%) of them were women and $186(32 \%)$ men. Their mean age was $18-56$, with a mean age of 23.08 years (SD = 4.52). All were sent a link to an online questionnaire consisting of an updated version of the Survey of Activity styles as well as supplementary questions.

\section{Measures}

Survey of Activity styles. A revised version of the Survey of Activity Styles (SAS) has been used. This tool has been validated and used multiple times in research in Poland (e.g., WieczorkowskaNejtardt, 1998; Wieczorkowska \& Burnstein, 1999; Turska, 2014). It consists of a variety of statements about two hypothetical people. The participant is asked to indicate whether he is more like person A or B on a 5-point scale:

- typically, like person A,

- more often like person A,

- more often like person B,

- typically, like person B,

- it is hard to say.

"Typically, like person A" corresponds to a value of 1 and "typically, like person B" to value 5, and "it is hard to say" corresponds to the median value: 3 . Below are lists of questions comprising the scales used in the study. Measures of reliability as well as cross tables, with a frequency of each response, may be found in the Appendix. 
Preference for a methodical working style:

- Person A commences a task only once he or she has thought of a method to do it. Person B starts a task even before he or she knows exactly how to do it and hopes to figure it out on the fly.

- Person A starts writing an essay not knowing what he or she will write. Person B first thinks of the essay's structure and only then begins writing it.

- Person A often starts tasks thinking that things will work out. Person B feels worried if he or she does not know how to do something.

- When person A is preparing to start a new task, he or she always prepares the required materials and tools beforehand. Person B finds the required tools and materials while doing the task so as not to delay commencing the task.

- Person A always completes tasks in a set order while person B does the tasks in a different order because it is easier or more interesting for him or her.

Reactivity:

- When person A sleeps less than usual, he or she usually feels worn out and tired. Person B can work intensely after a sleepless night.

- When upset, person A has difficulty focusing on a book or a newspaper and often reads the same sentence several times. If necessary, person B is able to focus on this situation.

- Person A works very well at the last minute. Time pressure disorganizes the behavior of person B.

- Person A belongs to those resistant to stress. Person B always sleeps worse BEFORE an important event (an exam, a long journey).

- Person A does not like deciding under time pressure, for person B pressure makes it easier to make decisions

Need for power:

- When working in a team, it is easier for person A when somebody else is responsible for the task. Person B prefers to be the one responsible for the task.

- Person A prefers to let someone else be responsible for planning and decisions, Person B prefers to plan and decide for others.

- Person A likes when someone else decides for him or her. Person B feels irritated when someone else decides for him or her.

- Person A usually plays the role of group leader. Person B shuns the responsibility associated with being a leader.

- When taking part in group activities, person A feels good in a leadership role. Person B does not feel comfortable deciding how his or her team performs its tasks.

Need for affiliation:

- People say that person A is an individualist that always worries about his or her own interest. Person B tries to take other peoples' best interest into account when doing things.

- Person A does not like it when others come to him or her with their problems. Friends of person B always know they can count on him or her when they have issues.

- Person A likes tasks in which he or she can compete with others. Person B prefers situations that require cooperation.

- Before person A makes a decision, he or she tries to imagine what others think. Person B does not care about the point of view of other people.

- Person A does not understand why he or she has to think of other people's feelings. Person B thinks of other's point of view before he or she decides how to act. 
Need for achievement:

- Person A often works until collapse, or tries to do more than he or she can. Person B avoids overworking him or herself.

- Person A is more demanding of him or herself because he or she tries to live the most efficient life possible. B does not want to overwork himself or herself.

- Person A could probably achieve more but does not see a reason to work more than necessary. Person B works more than other people.

- Person B does not want to work more than he or she is being paid for. Person A has a tendency to fully engage in work that he or she is working on without regard to the amount of money he or she is being paid.

- Person A feels bad when he or she does not have a lot to do at work. Person B prefers work that does not require his or her full engagement.

Feeling of satisfaction:

The feeling of satisfaction was measured on a 7-point Likert-type scale indicating whether a person feels that he or she satisfied with a given domain (1 - very bad, 7 - very good). The feeling of satisfaction with work/school was measured using the question: "Overall, compared to my peers, I rate my achievements at work/school as:" The feeling of satisfaction with relationships was measured with the question: "Overall I rate my relationships with other people as:" The sense of satisfaction associated with one's self-worth was measured with the question: "Overall I rate myself as:".

\section{Analytic strategy}

A model-based cluster analysis was used to segment the participants based on the need for power, need for achievement and need for affiliation and to distinguish leadership trait profiles. This was done using the MCLUST package (Scrucca et al., 2016) that uses a Bayesian Information Criterion to determine the best clustering model and the number of clusters. This approach has the advantage of comparing many types of clustering methods in one framework, and removing the arbitrary choice of choosing the number of clusters. The variables were standardized before clustering to ensure the best solution. Next, the subjective sense of satisfaction (at work/school, self-work, and in relationships) was compared between the various groups using a linear model with age and gender as covariates. Lastly, participants were additionally split into groups of high and low reactivity and preference for methodical working style based on the median. In both leadership groups with a leadership profile, a linear model with interaction was used to determine the effect of reactivity and preference for methodical working style on the subjective feeling of satisfaction at work/school.

\section{RESULTS}

\section{Leadership trait profiles}

Participants were segmented into four groups (see Table 1). Two groups had a high need for power and were congruent with a) McClelland's classic leadership motive profile (LMP) characterized by a high need for power, medium need for achievement and low need for affiliation; and $b$ ) a leader motive profile with a high need for power, achievement, and motivation. We labeled them as McClelland's classic LMP and relationship-focused high achiever LMP, respectively. The two nonleadership motive profiles both had a low need for power, but one had medium need for achievement and high need for affiliation, while the other had a low need for both achievement and power. Both groups were combined for further analyses as the paper's focus is on the differences between leadership and non-leadership profiles. The descriptive statistics in both leadership profile groups 
and non-leadership profile group can be seen in Table 1. All groups had a very similar age profile. However, there were slightly more females ( $72 \%$ vs. $68 \%$ for the rest of the participants) in the relationship-focused high achievers' group than in either one of the other groups.

Table 1. Descriptive statistics within the clusters corresponding to McClelland's classic LMP, relationship-focused high achievers LMP and non LMP participants

\begin{tabular}{lccc}
\hline & McClelland's LMP & $\begin{array}{c}\text { Relationship-focused } \\
\text { high achiever LMP }\end{array}$ & Non-LMP \\
\hline Need for power & $4.42(0.40)$ & $4.91(0.33)$ & $3.13(0.88)$ \\
Need for achievement & $3.90(0.43)$ & $4.80(0.18)$ & $3.23(0.89)$ \\
Need for affiliation & $3.15(0.69)$ & $4.13(0.69)$ & $3.88(0.71)$ \\
Gender - female & $68 \%$ & $72 \%$ & $68 \%$ \\
Age & $23.14(4.84)$ & $23.26(3.71)$ & $23.03(4.52)$ \\
\hline
\end{tabular}

Notes: The tables show the mean (standard deviation) of the variables in the three groups found in the cluster analysis.

\section{Leadership motive profile and sense of satisfaction}

Sense of satisfaction at work/school was higher for both leadership motive profiles relative to their peers (Table 2). The McClelland's classic LMP was associated with a greater sense of satisfaction related to self-worth compared to peers, while the relationship-oriented high achievers LMP was related to greater sense of satisfaction related to personal relationships relative to peers. The results can be seen in Figure 2 and the results of the model comparing these groups appear in Table 2. Additionally, women had a lower sense of satisfaction related to achievements at work/school and a lower sense of satisfaction related to self-worth. Age was not significantly related to sense of satisfaction in any case.

Table 2. The effect of leadership motive profiles on the feeling of satisfaction across three domains: achievements at work/school, personal relationships, and self-worth

\begin{tabular}{|c|c|c|c|c|c|c|c|c|c|}
\hline & \multicolumn{3}{|c|}{ Achievements at work/school } & \multicolumn{3}{|c|}{ Personal relationships } & \multicolumn{3}{|c|}{ Self-worth } \\
\hline & beta & $t$ & $p$ & beta & $t$ & $p$ & beta & $t$ & $p$ \\
\hline McClelland's LMP & 0.24 & 5.92 & $<0.001$ & 0.02 & 0.44 & 0.66 & 0.15 & 3.71 & $<0.001$ \\
\hline $\begin{array}{l}\text { Relationship-oriented } \\
\text { high achiever LMP }\end{array}$ & 0.2 & 4.83 & $<0.001$ & 0.12 & 2.77 & 0.006 & 0.08 & 2 & $<0.05$ \\
\hline Age & 0.02 & 0.5 & $<0.62$ & 0.06 & 1.38 & 0.17 & 0.07 & 1.75 & $<0.08$ \\
\hline Gender & -0.09 & 2.26 & $<0.02$ & 0.008 & 0.2 & 0.84 & -0.12 & -2.77 & $<0.005$ \\
\hline$F$ & & 13.95 & & & 2.44 & & & 7.34 & \\
\hline$p$ & & $<0.001$ & & & 0.05 & & & $<0.001$ & \\
\hline$R^{\wedge} 2$ & & 0.09 & & & 0.02 & & & 0.05 & \\
\hline
\end{tabular}

Note: beta refers to the standardized regression coefficients.

\section{The consequences of temperament and working-style mismatch in leaders}

Among participants with McClelland's classic LMP, higher reactivity was associated with significantly lower sense of satisfaction related to work/school level achievements irrespective of the preferred working-style. See Figure 3 A for the graphical comparison of the low and high 
reactivity group and the low and high preference for methodical working-style groups. See Table 3 for the model coefficients.

Figure 1. The interaction of reactivity and a methodical working-style on the feeling of satisfaction through achievements at work/school for the relationship-focused high achievers LMP.

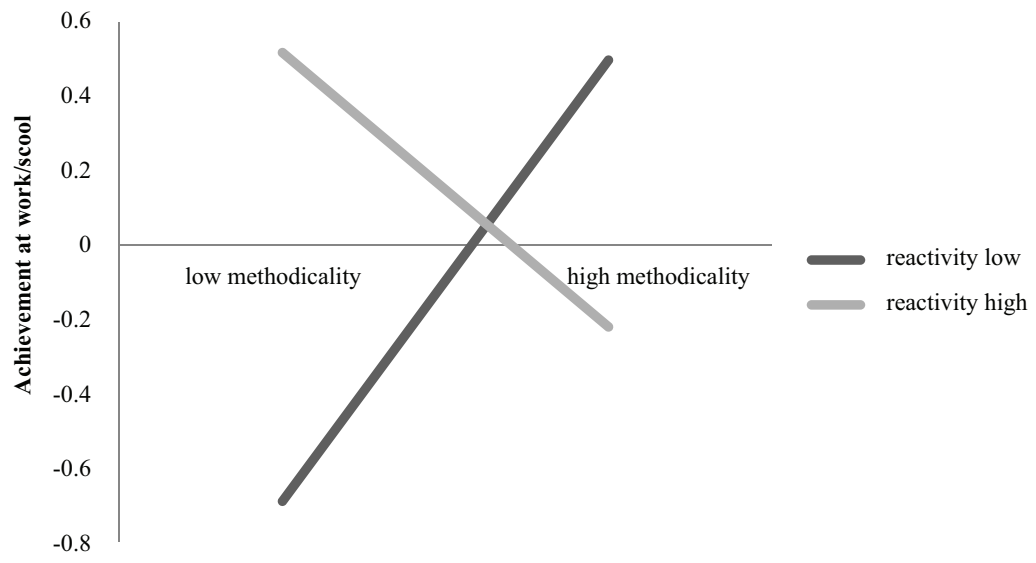

Among participants with a relationship-oriented high achiever LMP with a non-methodical working-style, reactivity was not significantly associated with the feeling of satisfaction with achievements in work/school. For participants with highly methodical working-style the pattern was the same as in the McClelland's classic LMP: high reactivity was associated with a lower feeling of satisfaction in work/school achievements. See Figure $3 \mathrm{~B}$ for graphical comparison of the low and high reactivity group and low and high preference for methodical working-style groups. See also Table 3 for the model coefficients. Neither age nor gender was significantly associated with the sense of satisfaction with achievements in work/school in either group.

Table 3. The effect of reactivity, methodical working-style and their interaction on sense of satisfaction in work/study related achievements

\begin{tabular}{|c|c|c|c|c|c|c|}
\hline & \multicolumn{3}{|c|}{ McClelland's LMP } & \multicolumn{3}{|c|}{ Relationship-oriented high achievers LMP } \\
\hline & beta & $t$ & $p$ & beta & $t$ & $p$ \\
\hline Reactivity & $-0.46^{*}$ & -3.36 & 0.001 & 0.15 & 0.72 & 0.47 \\
\hline Methodical working-style & 0.05 & 0.49 & 0.62 & 0.14 & 0.94 & 0.35 \\
\hline $\begin{array}{l}\text { Reactivity x methodical } \\
\text { working-style }\end{array}$ & 0.15 & 0.96 & 0.32 & $-0.51^{*}$ & -2.14 & 0.04 \\
\hline Age & -0.03 & -0.38 & 0.71 & 0.06 & 0.41 & 0.68 \\
\hline Gender & 0.03 & -2.26 & 0.02 & -0.02 & -0.17 & 0.86 \\
\hline F & & 4.00 & & & 1.6 & \\
\hline$p$ & & 0.002 & & & 0.18 & \\
\hline$R^{\wedge} 2$ & & 0.14 & & & 0.13 & \\
\hline
\end{tabular}

Note: beta refers to the standardized regression coefficients and * to significance below the $\mathrm{p}<0.05$ level. 


\section{CONCLUSIONS}

Based on the need for power, need for affiliation, and need for achievement we have found two leadership motive profiles. One of these was associated with McClelland's classic leader motive profile that has a high need for power, medium need for achievement, and low need for affiliation. This leadership motive profile was shown in various studies to be related to successful leadership. The other leadership motive profile found was a relationship-focused high achievers leadership motive profile, characterized by a simultaneous high need for power, affiliation, and need for achievement. This motive profile was recently found predictive of effective leadership in modern organizations.

Both leadership motive profiles were related to a higher sense of satisfaction in work or study-related achievements relative to peers as well as satisfaction related to self-worth. However, only the relationship-focused high achievers' group had a higher sense of satisfaction in personal relationships compared to peers. Additionally, we found that relationship-focused high achievers that had a temperament predisposing them to feel lower satisfaction related to achievements at work or school, could compensate by adopting a working style suited to a leadership-like role, which was not true for the McClelland's classic leadership motive profile group. In this group, adopting a working style better suited to leadership and work environment did not diminish the effect of temperament on the feeling of satisfaction.

These findings show that sense of satisfaction across personal, work, and relationship domains, is higher for leader motive profiles relative to peers. Additionally, relationship-focused high achievers seem to have more opportunities to enhance their sense of satisfaction compared to McClelland's classic leadership motive profile. First of all, by focusing on relationships, they can achieve a greater sense of satisfaction when successful in a domain not necessarily directly related to work outcome. Second of all, they can increase their sense of satisfaction in work achievements by modifying their working style to fit their temperament. Further work is needed to examine how the subjective sense of satisfaction across the dimensions studied here is related to leadership effectiveness in the context of leadership motive profile theory.

\section{Literature}

Carmeli, A., Ben-Hador, B., Waldman, D. A., \& Rupp, D. E. (2009). How leaders cultivate social capital and nurture employee vigor: Implications for job performance. Journal of Applied Psychology, 94(6), 1553.

Deci, E. L., \& Ryan, R. M. (2000). The" what" and" why" of goal pursuits: Human needs and the self-determination of behavior. Psychological Inquiry, 11(4), 227-268.

De Jong, J. P., \& Den Hartog, D. N. (2007). How leaders influence employees' innovative behaviour. European Journal of Innovation Management, 10(1), 41-64.

Eliasz, A. (2006). Internal incongruence among personality mechanisms as a constant 'sore point'. European Health Psychologist, 8(2), 5-7.

Fiedler, F. E. (1986). The Contribution of Cognitive Resources and Leader Behavior to Organizational Performance 1. Journal of Applied Social Psychology, 16(6), 532-548.

Jeśka, M. (2016). The consequences of the fit between employee characteristic and tasks differing in the degree of process standardization. (Doctoral dissertation, University of Warsaw.).

Judge, T. A., Colbert, A. E., \& Ilies, R. (2004). Intelligence and leadership: a quantitative review and test of theoretical propositions. Journal of Applied Psychology, 89(3), 542.

McClelland, D. (1961). The achieving society. New York: Van Nostrand Reinhold.

McClelland, D. (1970). The two faces of power. Journal of International Affairs, 24(1), 29-47.

McClelland, D. C., \& Burnham, D. H. (1976). Power is the Great Motivator. Harvard business review, 54(2), $100-110$

Mumford, M. D., Todd, E. M., Higgs, C., \& McIntosh, T. (2017). Cognitive skills and leadership performance: The nine critical skills. The Leadership Quarterly, 28(1), 24-39. 
Scrucca, L., Fop, M., Murphy, T. B., \& Raftery, A. E. (2016). Mclust 5: clustering, classification and density estimation using Gaussian finite mixture models. The R Journal, 8(1), 289.

Steinmann, B., Dörr, S. L., Schultheiss, O. C., \& Maier, G. W. (2015). Implicit motives and leadership performance revisited: What constitutes the leadership motive pattern? Motivation and Emotion, 39(2), 167-174.

Szymura, B., \& Nęcka, E. (1998). Visual selective attention and personality: An experimental verification of three models of extra version. Personality and Individual Differences, 24(5), 713-729.

Schyns, B., \& Schilling, J. (2013). How bad are the effects of bad leaders? A meta-analysis of destructive leadership and its outcomes. The Leadership Quarterly, 24(1), 138-158.

Turska, E., Uniwersytet Śląski (Katowice), \& Wydawnictwo. (2014). Kapitat kariery ludzi młodych: uwarunkowania $i$ konsekwencje. Katowice: Wydawnictwo Uniwersytetu Śląskiego.

Wieczorkowska-Nejtardt, G. (1998). Motivational intelligence: Smart goal setting and action strategies. Warsaw: WISS.

Wieczorkowska, G., \& Burnstein, E. (1999). The role of search costs and screening strategies in social change: Adapting to the transition from socialism to capitalism in Poland. Psychological Science, 10, 98e105.

Wieczorkowska, G., Krol, G., \& Wierzbinski, J. (2015). Who suffers from a big number of procedures at work? Paper presented at the conference Future Challenges in Management and Business. Istanbul.

Wieczorkowska, G. Burnstein, E. Wierzbiński, J. (2009). When Our Action Style Doesn't Fit the Situation: the Behavioral and Affective Consequences of Using Point or Interval Decision Strategies in Adapting to Environmental Constraints. W: R. Siemieńska P. Radkiewicz (eds.) Społeczeństwo polskie o sobie, gospodarce, polityce w świetle Polskiego Generalnego Sondażu Spotecznego. Warszawa: Wydawnictwo Naukowe Scholar 145-160.

Yuk1, G. (2008). How leaders influence organizational effectiveness. The Leadership Quarterly, 19(6), 708-722. 


\section{APPENDIX}

Table i. Questions relating to need for power.

\begin{tabular}{|c|c|c|c|c|c|}
\hline & ar3 & $\operatorname{ar13}$ & $\operatorname{ar} 16$ & ar19 & ar9 \\
\hline & $\begin{array}{l}\text { While working in } \\
\text { a team, Person A } \\
\text { finds it easier when } \\
\text { somebody else } \\
\text { feels responsible } \\
\text { for how things } \\
\text { evolve. Person B } \\
\text { takes complete } \\
\text { responsibility for } \\
\text { their actions. }\end{array}$ & $\begin{array}{l}\text { Person A would } \\
\text { rather delegate } \\
\text { planning and } \\
\text { decision-making } \\
\text { to another team } \\
\text { member. Person B } \\
\text { is keen on planning } \\
\text { and deciding } \\
\text { what other people } \\
\text { should do. }\end{array}$ & $\begin{array}{l}\text { Person A likes } \\
\text { to be replaced } \\
\text { in decision- } \\
\text { making. Person } \\
\text { B is rather upset } \\
\text { when somebody } \\
\text { else cuts in what } \\
\text { they do. }\end{array}$ & $\begin{array}{l}\text { Person A usually } \\
\text { plays the role of } \\
\text { a leader within } \\
\text { their group. } \\
\text { Person B avoids } \\
\text { responsibility } \\
\text { related with the } \\
\text { role of a group } \\
\text { leader. }\end{array}$ & $\begin{array}{l}\text { While carrying out } \\
\text { tasks in teamwork } \\
\text { projects, Person A } \\
\text { feels good in the } \\
\text { role of a leader. } \\
\text { Person B is } \\
\text { reluctant to decide } \\
\text { on the way the } \\
\text { team's tasks are } \\
\text { performed. }\end{array}$ \\
\hline $\begin{array}{l}\text { Usually } \\
\text { like A }\end{array}$ & 16.7 & 8.3 & 5 & 25.9 & 34.3 \\
\hline $\begin{array}{l}\text { More often } \\
\text { like A }\end{array}$ & 24.3 & 16.6 & 14 & 36.9 & 32.9 \\
\hline $\begin{array}{l}\text { Hard to } \\
\text { say... }\end{array}$ & 5.3 & 8.6 & 9.8 & 8.8 & 6.7 \\
\hline $\begin{array}{l}\text { More often } \\
\text { like B }\end{array}$ & 27.6 & 35 & 39.5 & 18.8 & 18.1 \\
\hline $\begin{array}{l}\text { Usually } \\
\text { like B }\end{array}$ & 26 & 31.6 & 31.7 & 9.7 & 7.9 \\
\hline
\end{tabular}

Note: Cronbach's alpha $=0.79$.

Table ii. Questions relating to need for achievement.

\begin{tabular}{|c|c|c|c|c|c|}
\hline & $\operatorname{ar} 10$ & $\operatorname{ar} 18$ & ar2 & ar8 & $\operatorname{ar} 15$ \\
\hline & $\begin{array}{l}\text { Person A often works } \\
\text { on the verge of what } \\
\text { his or her organism } \\
\text { will handle, or tries to } \\
\text { do more than what is } \\
\text { possible. Person B shies } \\
\text { away from overworking } \\
\text { him or herself, or tries } \\
\text { to do things that she or } \\
\text { he can handle. }\end{array}$ & $\begin{array}{l}\text { When it comes to } \\
\text { herself, person A } \\
\text { is more demanding } \\
\text { than other people, } \\
\text { because she wants } \\
\text { to live as effectively } \\
\text { as possible. Person } \\
\text { B does not want } \\
\text { to bust his or her } \\
\text { hump. }\end{array}$ & $\begin{array}{l}\text { Person A could } \\
\text { probably achieve } \\
\text { more, but he or } \\
\text { she doesn't see } \\
\text { the reason to } \\
\text { work more than } \\
\text { is absolutely } \\
\text { necessary. Person } \\
\text { B works more } \\
\text { than other people. }\end{array}$ & $\begin{array}{l}\text { Person A does not } \\
\text { want to work more } \\
\text { than they pay him } \\
\text { or her. Person B has } \\
\text { a tendency to fully } \\
\text { immerse herself } \\
\text { into the work that } \\
\text { he or she is doing } \\
\text { irrespective of the } \\
\text { pay. }\end{array}$ & $\begin{array}{l}\text { Person A feels } \\
\text { bad if she } \\
\text { feels that there } \\
\text { is little work } \\
\text { for her to do. } \\
\text { Person B likes } \\
\text { tasks that don't } \\
\text { require much } \\
\text { effort from } \\
\text { her part. }\end{array}$ \\
\hline $\begin{array}{l}\text { Usually } \\
\text { like A }\end{array}$ & 27.2 & 40.9 & 12.4 & 25.9 & 38.8 \\
\hline $\begin{array}{l}\text { More often } \\
\text { like A }\end{array}$ & 28.1 & 32.6 & 20.2 & 30.9 & 32.6 \\
\hline $\begin{array}{l}\text { Hard to } \\
\text { say... }\end{array}$ & 8.1 & 6 & 8.1 & 5.9 & 7.9 \\
\hline $\begin{array}{l}\text { More often } \\
\text { like B }\end{array}$ & 24.8 & 14.5 & 32.8 & 21 & 14.1 \\
\hline $\begin{array}{l}\text { Usually } \\
\text { like B }\end{array}$ & 11.7 & 6 & 26.6 & 16.4 & 6.6 \\
\hline
\end{tabular}


Table iii. Questions relating to need for affiliation.

\begin{tabular}{|c|c|c|c|c|c|}
\hline & $\operatorname{ar} 11$ & $\operatorname{ar} 20$ & $\operatorname{ar} 62$ & $\operatorname{ar} 57$ & $\operatorname{ar} 59$ \\
\hline & $\begin{array}{l}\text { Person A is } \\
\text { regarded an } \\
\text { individualist always } \\
\text { after their own } \\
\text { business. Person } \\
\text { B always tries } \\
\text { to consider other } \\
\text { people's business in } \\
\text { anything they do. }\end{array}$ & $\begin{array}{l}\text { Person A dislikes } \\
\text { to be bothered } \\
\text { by others with } \\
\text { their problems. } \\
\text { Friends of Person } \\
\text { B know they } \\
\text { can always rely } \\
\text { upon them in any } \\
\text { troubled situation. }\end{array}$ & $\begin{array}{l}\text { Person A likes } \\
\text { situations where } \\
\text { there is an } \\
\text { opportunity to } \\
\text { compete with others. } \\
\text { Person B prefers } \\
\text { situations requiring } \\
\text { collaboration rather } \\
\text { than rivalry. }\end{array}$ & $\begin{array}{l}\text { Before making } \\
\text { decision, Person } \\
\text { A attempts to } \\
\text { imagine what } \\
\text { other people feel } \\
\text { or think. Person B } \\
\text { is not interested } \\
\text { in others' point } \\
\text { of view. }\end{array}$ & $\begin{array}{l}\text { Person A doesn't } \\
\text { understand why should } \\
\text { they empathize with } \\
\text { other people's feelings. } \\
\text { Person B considers } \\
\text { several points of view } \\
\text { before deciding how } \\
\text { to behave in any } \\
\text { given situation. }\end{array}$ \\
\hline $\begin{array}{l}\text { Usually } \\
\text { like A }\end{array}$ & 14 & 5 & 15.9 & 37.6 & 4.3 \\
\hline $\begin{array}{l}\text { More often } \\
\text { like A }\end{array}$ & 18.6 & 9.1 & 18.1 & 42.9 & 10.3 \\
\hline $\begin{array}{l}\text { Hard to } \\
\text { say... }\end{array}$ & 7.6 & 3.1 & 5.2 & 4.3 & 6.4 \\
\hline $\begin{array}{l}\text { More often } \\
\text { like B }\end{array}$ & 39.1 & 36.7 & 36.4 & 10.7 & 47.2 \\
\hline $\begin{array}{l}\text { Usually } \\
\text { like B }\end{array}$ & 20.7 & 46 & 24.5 & 4.5 & 31.7 \\
\hline
\end{tabular}

Note: Cronbach's alpha $=0.61$.

Table iv. Questions relating to a methodical working style.

\begin{tabular}{|c|c|c|c|c|c|}
\hline & sr26 & $\operatorname{sr} 17$ & $\mathrm{sr} 29$ & $\mathrm{sr} 43$ & $\operatorname{sr} 13$ \\
\hline & $\begin{array}{l}\text { Person A } \\
\text { commences a task } \\
\text { only once he or } \\
\text { she has thought of } \\
\text { a method to do it, } \\
\text { Person B starts a } \\
\text { task even before } \\
\text { he or she knows } \\
\text { exactly how to do it } \\
\text { and hopes to figure } \\
\text { it out on the fly. }\end{array}$ & $\begin{array}{l}\text { Person A begins } \\
\text { to write an essay } \\
\text { without having } \\
\text { any precise idea } \\
\text { of what will } \\
\text { come up in the } \\
\text { end. Person B } \\
\text { starts with the } \\
\text { clear idea in their } \\
\text { mind and only } \\
\text { then begins to } \\
\text { write. }\end{array}$ & $\begin{array}{l}\text { Person A often } \\
\text { starts tasks } \\
\text { thinking that } \\
\text { things will work } \\
\text { out. Person B } \\
\text { feels worried if he } \\
\text { or she does not } \\
\text { know how to do } \\
\text { something }\end{array}$ & $\begin{array}{l}\text { When person } \mathrm{A} \text { is } \\
\text { preparing to start a } \\
\text { new task he or she } \\
\text { always prepares the } \\
\text { required materials } \\
\text { and tools beforehand, } \\
\text { person B finds the } \\
\text { required tools and } \\
\text { materials while doing } \\
\text { the task as not to stall } \\
\text { with commencing } \\
\text { the task }\end{array}$ & $\begin{array}{l}\text { Person A always } \\
\text { carries out } \\
\text { individual stages } \\
\text { of a task one after } \\
\text { another. Person } \\
\text { B performs them } \\
\text { without any specific } \\
\text { order, depending on } \\
\text { what seems easier } \\
\text { or more interesting } \\
\text { at any given } \\
\text { moment. }\end{array}$ \\
\hline $\begin{array}{l}\text { Usually } \\
\text { like A }\end{array}$ & 14.8 & 18.6 & 14.7 & 22.6 & 15.5 \\
\hline $\begin{array}{l}\text { More often } \\
\text { like A }\end{array}$ & 30.5 & 20.3 & 31 & 37.1 & 20 \\
\hline $\begin{array}{l}\text { Hard to } \\
\text { say... }\end{array}$ & 4.5 & 5.2 & 4.1 & 3.8 & 2.8 \\
\hline $\begin{array}{l}\text { More often } \\
\text { like B }\end{array}$ & 35.3 & 33.8 & 31.7 & 27.8 & 41.6 \\
\hline $\begin{array}{l}\text { Usually } \\
\text { like B }\end{array}$ & 14.8 & 22.1 & 18.4 & 8.8 & 20.2 \\
\hline
\end{tabular}


Table v. Questions relating to reactivity.

\begin{tabular}{|c|c|c|c|c|c|}
\hline & $\operatorname{sr} 10$ & sr49 & $\mathrm{sr} 47$ & $\mathrm{sr} 44$ & $\mathrm{sr} 27$ \\
\hline & $\begin{array}{l}\text { Person A does } \\
\text { not like to make } \\
\text { decisions when } \\
\text { feeling pressure. } \\
\text { Person B makes } \\
\text { decisions under } \\
\text { stress easier than } \\
\text { when there is } \\
\text { no pressure. }\end{array}$ & $\begin{array}{l}\text { Person A is } \\
\text { resilient to } \\
\text { stress. Person B } \\
\text { always sleeps } \\
\text { worse before } \\
\text { an important } \\
\text { event (exam, } \\
\text { travelling). }\end{array}$ & $\begin{array}{l}\text { Person A works } \\
\text { very effectively } \\
\text { when time is } \\
\text { running out. } \\
\text { For Person B, } \\
\text { too much time } \\
\text { pressure is } \\
\text { disrupting. }\end{array}$ & $\begin{array}{l}\text { When irritated, Person } \\
\text { A has difficulty in } \\
\text { concentrating upon reading } \\
\text { a book or a paper, for } \\
\text { example reading the same } \\
\text { sentence several times. } \\
\text { Person B knows how } \\
\text { to focus in a stressful } \\
\text { situation if necessary. }\end{array}$ & $\begin{array}{l}\text { For person A, } \\
\text { chaos and too } \\
\text { much incoming } \\
\text { information are } \\
\text { tiring. Person B } \\
\text { is more tired } \\
\text { when here } \\
\text { is too much } \\
\text { monotony. }\end{array}$ \\
\hline $\begin{array}{l}\text { Usually } \\
\text { like A }\end{array}$ & 26.9 & 15.9 & 24.1 & 35.2 & 13.4 \\
\hline $\begin{array}{l}\text { More often } \\
\text { like A }\end{array}$ & 26.2 & 24.5 & 29.8 & 35.9 & 23.3 \\
\hline $\begin{array}{l}\text { Hard to } \\
\text { say... }\end{array}$ & 4.5 & 4.8 & 4.8 & 2.2 & 8.1 \\
\hline $\begin{array}{l}\text { More often } \\
\text { like B }\end{array}$ & 25.7 & 31.2 & 27.1 & 18.4 & 31.9 \\
\hline $\begin{array}{l}\text { Usually } \\
\text { like B }\end{array}$ & 16.7 & 23.6 & 14.1 & 8.3 & 23.3 \\
\hline
\end{tabular}

Note: Cronbach's alpha $=0.58$. 


\title{
Identifying Differences in Values: Comparison between Iran and Poland
}

\begin{abstract}
Afsaneh Yousefpour*
Summary

Values are the central features of societies and they are one of the essential elements in culture. The main aim of this research was examining the differences in basic human values in Iran and Poland, taking into the account sociodemographic variables (gender, age, and education level). Analyses were performed on data coming from the fifth wave of the World Value Survey (2005-2009). The results indicated that Iranians were more likely to embrace power, security, conformity, and universalism values. Poles, on the other hand, reported higher importance of stimulation, hedonism, achievement, tradition, and benevolence values. Age moderated the relationship between country and self-direction, power, and benevolence values. Education moderated the relationship between country and tradition value.
\end{abstract}

Keywords: Schwartz's Basic Human Values, World Value Survey, Iran, Poland, culture

JEL: J28, Z13, M14

\section{INTRODUCTION}

For more than two decades, Schwartz's value model (1992, 1994, 2005a) has been used in various studies across the world (e.g., Blisky, Janik and Schwartz, 2011; Cieciuch and Davidov, 2012; Schwartz and Rubel_Lifschitz, 2009; Fontaine, Poortinga, Delbeke and Schwartz, 2008). Values are trans-situational goals, which act like directorial principles in people's lives (Schwartz, 1992; Rokeach, 1973). Each nation can be differentiated by a distinctive culture and values (Schwartz, 1992), so it is of importance - also from an organizational perspective - to study the values across different nations and cultures. These personal values are standing behind people's approaches (e.g., Dobewall and Rudnev, 2014; Vauclair, Fischer, et al., 2015), feelings (e.g., Roccas and McCauley, 2004; Sortheix and Lonnqvist, 2014), and conducts (e.g., Fischer and Boer, 2015; Verplanken and Holland, 2002).

Majority of earlier researches has concentrated on scrutinizing sociodemographic variables in order to envision people's priorities in values. However, research that examines the moderating role of education and age between country and human basic values is scarce. In addition, studies that attempt to study the primacy of human values on both individual and country level are truly limited.

In the current study I investigate three demographic variables: country, age, and education as predictors of human values. Specifically, I address the differences in basic human values between Iran and Poland - a comparison that has not been undertaken in previous studies. Additionally, I check how human values in these two countries vary as a result of age (socialization if different sociopolitical contexts) and the level of education. 


\section{LITERATURE REVIEW}

\section{Schwartz's individual values model}

Theory of basic human values, presents ten comprehensive values (Table 1), which were developed in a circular structure. This circle determines the conflicting and congruent relations of values (Figure 1) (Schwartz, 1994; Schwartz and Huismans, 1995). For instance, openness to change (selfdirection and stimulation), is in contrast with conservation (tradition, conformity and security), while self-enhancement (power and achievement) is in conflict with self-transcendence (universalism and benevolence).

Table1. Types of Motivational Values with representing definitions, single Values and their goals

\begin{tabular}{|c|c|}
\hline $\begin{array}{c}\text { Power } \\
\text { (Importance of being very rich) }\end{array}$ & $\begin{array}{l}\text { Social status and prestige, control or dominance over people and resources } \\
\text { (social power, authority, wealth, preserving my public image, social recognition) }\end{array}$ \\
\hline $\begin{array}{l}\text { Self-direction (Importance } \\
\text { of adventures and taking risks) }\end{array}$ & $\begin{array}{l}\text { Independent thought and action-choosing, creating, exploring (freedom, } \\
\text { independent, choosing own goals, creativity, curious, self-respect) }\end{array}$ \\
\hline $\begin{array}{l}\text { Achievement (Importance of } \\
\text { being very successful) }\end{array}$ & $\begin{array}{l}\text { Personal success through demonstrating competence according to social standards } \\
\text { (successful, capable, ambitious, influential, intelligent) }\end{array}$ \\
\hline $\begin{array}{l}\text { Stimulation (Importance of } \\
\text { thinking up to new ideas) }\end{array}$ & Excitement, novelty and challenge in life (daring, a varied life, an exciting life) \\
\hline $\begin{array}{l}\text { Hedonism (Importance of having } \\
\text { a good time) }\end{array}$ & $\begin{array}{l}\text { Pleasure and sensuous gratification for oneself (pleasure, enjoying life, self- } \\
\text { indulgence, sexuality) }\end{array}$ \\
\hline $\begin{array}{l}\text { Security (Importance of living } \\
\text { in a secure surroundings) }\end{array}$ & $\begin{array}{l}\text { Safety, harmony, and stability of society, of relationships and of self (national } \\
\text { security, social order, sense of belonging, family security, clean, reciprocation } \\
\text { of favors, healthy) }\end{array}$ \\
\hline Tradition (Importance of tradition) & $\begin{array}{l}\text { Respect, commitment and acceptance of the customs and ideas traditional culture } \\
\text { or religion provide (humble, devout, respect for tradition, moderate, detachment, } \\
\text { accepting my portion in life) }\end{array}$ \\
\hline $\begin{array}{l}\text { Conformity (Importance } \\
\text { of behaving properly) }\end{array}$ & $\begin{array}{l}\text { Restraint of actions, inclinations, and impulses likely to upset or harm others } \\
\text { and violate social expectations or norms (obedient, politeness, honoring parents } \\
\text { and elders, self-discipline) }\end{array}$ \\
\hline $\begin{array}{l}\text { Benevolence (Importance } \\
\text { of helping the people) }\end{array}$ & $\begin{array}{l}\text { Preservation and enhancement of the welfare of people with whom one is in } \\
\text { frequent personal contact (helpful, honest, forgiving, loyal, responsible, true } \\
\text { friendship, mature love) }\end{array}$ \\
\hline $\begin{array}{l}\text { Universalism (Importance } \\
\text { of looking after environment) }\end{array}$ & $\begin{array}{l}\text { Understanding, appreciation, tolerance \& protection for the welfare of all people } \\
\text { and for nature (broad-minded, social justice, equality, a world at peace, a world } \\
\text { of beauty, unity with nature, protecting the environment, wisdom) }\end{array}$ \\
\hline
\end{tabular}

Note: Adapted from Schwartz and Huismans, 1995 and Schwartz, 1994.

The general pattern of conflicting and congruent relationship between values has been drawn below (Figure 1). Those values that have conflicting relations are opposite to each other, and values that are congruent are placed next to each other. This model has been tested in 74 countries among 220 samples, which can confirm the universality of these ten motivational values and the circular structure of relations among them (Schwartz, 2006; Schwartz and Bardi, 2001; Schwartz and Sagiv, 1995; Schwartz, Caprara and Vecchione, 2010). 
Figure 1. Model of relations among ten motivational types of values

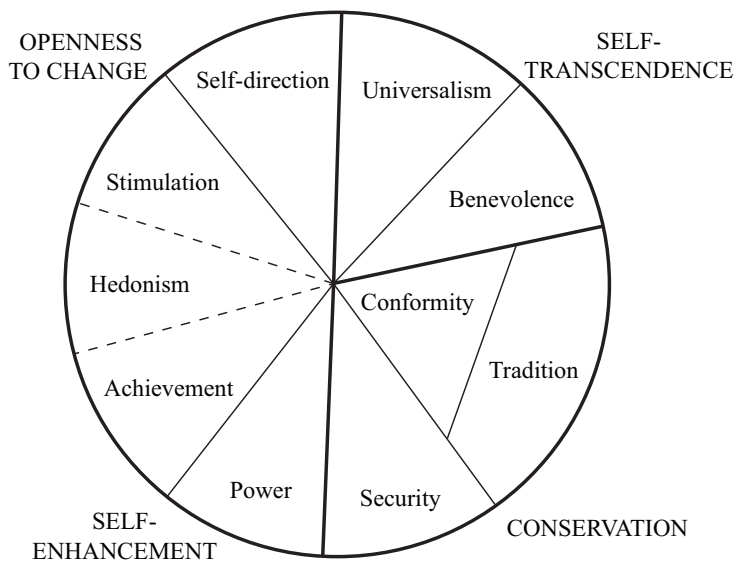

Source: Schwartz, 1994.

Human values differ among people of different ages, stemming from different conditions in which they were raised. Similarly, educational experiences can also boost the intellectual openness, flexibility, and attitudes towards the importance of adventures and taking risks. Additionally, educational experiences challenge the importance of behaving properly and the importance of tradition, questioning dominant norms and outlooks (Kohn and Schooler, 1983; Prince-Gibson and Schwartz, 1998). Consequently, study of values should take into account age and education.

\section{Cultural Differences in Human Values - Iran vs. Poland}

Prior research suggests that some differences in values can be traced back to differences in cultures (Schwartz, 1992, 1994; Schwartz and Sagiv, 1995). For instance, Eastern European countries show a significant deviance from the value model proposed by Schwartz (Schwartz and Bardi, 1997, Bardi and Schwartz, 1996). For instance, there is a relationship between the importance of looking after environment and the importance of living in secure surroundings values in Eastern Europe, even though these values are generally opposite to each other. These differences are possibly stemming from the impact of communism on citizen basic values, affecting citizens' ideology and political atmosphere.

A similar impact might have been observed in Iran. Latest socio-political transformations in Iran's governance structure might have affected people's values. In Islam materialism has been condemned, therefore, we can expect that the meaning of "the importance of being very successful" and "self-transcendence" might be getting closer to each other, instead of being against each other. This can also be observed in the speeches of Supreme Leader of Iran, in which he states that every country has a special meaning for the importance of being very successful. In Islamic Iran this is not only about material issues, but also about spiritual aspects. Furthermore, in Islam being ultraconservative is not accepted, as a result, it can be expected that the importance of living in a secure surroundings has deviated in the same manner as in Eastern European samples (Schwartz and Bardi, 1997, Bardi and Schwartz, 1996). 


\section{THE AIM OF THE STUDY}

In the current study I investigate three demographic variables: country, age, and education as predictors of human values. As people get older, they have more tendency to be away of social and public networks and less willing to take risks and face challenges, instead, they have more obligation to routines (Tyler and Shuller, 1991). Based on this, I hypothesize that age has a positive and significant relationship with conservation values (tradition, conformity, and security), negative relationship with openness to change values (self-direction, stimulation), and negative relationship with hedonism. As people grow old, they demand attaining a stable position. They tend to be less anxious and more focused on the prosperity of others (Veroff, Reuman, and Feld, 1984). Thus, I expect that age has a positive relationship with self-transcendence values (benevolence, universalism) and negative relationship with self-enhancement values (power, achievement). Finally, based on previous literature I expect that educational level is related to higher openness, flexibility, and self-direction values (Kohn \& Schooler 1983). Conversely, being educated is expected to weaken conformity and tradition values by questioning fundamental norms, beliefs and traditions.

Based on the above considerations, I propose the following questions to be addressed in the current study. What is the difference in terms of values between Iran and Poland? Does age have a significant positive relationship with the importance of helping the people, looking after environment, tradition, behaving properly and living in secure surroundings? Dose age have a negative relationship with the importance of adventures and taking risks, thinking up new ideas, having a good time being rich and being very successful? Dose age moderate the relationship between country and the importance of thinking up new ideas? Dose age moderate the relationship between country and the importance of helping the people? Does education has a significant positive relationship with the importance of thinking up new ideas and adventures and taking risks? Does education has negative link with the importance of tradition? And finally does education moderate the relationship between country and the importance of tradition?

\section{METHOD}

\section{Participants and Procedure}

Data in the current study involved respondents from national samples of Iran and Poland who took part in the fifth (2005-2009) wave of the World Value Survey (WVS). The World Values Survey (www.worldvaluessurvey.org) is a worldwide research studying various values and their influence on societal and political life (http://www.worldvaluessurvey.org). I chose to use the data of WVS because it is one of the few international social surveys that contains the data for Iran.

The following respondents from the current study were removed from the analyses: 1 . those younger than 20 years old and 2. Those older than 69 years old. The sample size in Iran equaled $\mathrm{N}=2577$ and in Poland it equaled $\mathrm{N}=880$. Therefore, $74.6 \%$ of respondents were Iranian and $25.4 \%$ of them were Polish. Besides, $49.6 \%$ were male and $50.4 \%$ of them were female. I summarized the features of samples in Table 2. I included $99.39 \%$ of respondents $(\mathrm{N}=3435.8)$ who responded to 10 human value questions. 
Table 2. Share of respondents by region/country by gender and be age (n, percentage).

\begin{tabular}{|c|c|c|c|c|c|c|c|}
\hline \multirow{2}{*}{ Country } & \multicolumn{2}{|c|}{ Gender } & \multicolumn{5}{|c|}{ Age } \\
\hline & Male & Female & $20-29$ & $30-39$ & $40-49$ & $50-59$ & $60-69$ \\
\hline Iran & $1282(50.1 \%)$ & $1295(49.9 \%)$ & $1013(44.1 \%)$ & $633(27.6 \%)$ & $392(17.1 \%)$ & $190(8.3 \%)$ & $67(2.9 \%)$ \\
\hline Poland & $433(47.6 \%)$ & $447(52.4 \%)$ & $198(23.9 \%)$ & $153(18.5 \%)$ & $210(25.3 \%)$ & $164(19.8 \%)$ & $104(12.5 \%)$ \\
\hline
\end{tabular}

\section{Measurement}

The dependent variables for my analyses were: 1) the importance of being rich (power value), 2) the importance of adventures and taking risks (stimulation value), 3) the importance of being very successful (achievement value), 4) the importance of thinking up new ideas (self-direction value), 5) the importance of having a good time (hedonism value), 6) the importance of living in a secure surroundings (security value), 7) the importance of tradition (tradition value), 8) the importance of behaving properly (conformity value), 9) the importance of helping the people (benevolence value), 10) the importance of looking after environment (universalism value). Each of these values was measured in the form of third person statement, for instance: "It is important to this person to always behave properly" or "It is important to this person looking after environment" (response scale from 1 - not at all like me to 6 - very much like me) ${ }^{1}$. Following recommendations of Schwartz (2003) values were ipsatized, which reduces the impact of response styles that might affect the preferences for the usage of response scales. It is especially important to control for response bias in cross-cultural research, as representatives of different cultures might show different response styles (Wieczorkowska-Wierzbinska, Wierzbinski, \& Kuzminska, 2014). Predictor variables were: age, country (1: Iran vs. 2: Poland), and education (in years). I excluded respondents with age above 70 years old and below 20 years old.

\section{RESULTS}

An independent samples t-test was conducted to determine the significance of difference between Iranians and Poles in their age, education, and basic human values. The results of these analyses can be seen in Table 3. Since Levene's test of homogeneity of variance was significant for all variables, a t statistic assuming unequal variances was analyzed.

Iranian sample had a similar level of education measured in years of schooling $(\mathrm{M}=11.15, \mathrm{SD}=3.01)$ to the Polish sample $(\mathrm{M}=11.09, \mathrm{SD}=2.12)$. Poles sample was older than Iranian sample (Poland: $\mathrm{M}=40.96, \mathrm{SD}=1.34$; Iran: $\mathrm{M}=32.09, \mathrm{SD}=11.60$ ).

Table 3. Results of Independent Samples t-test for Iran and Poland

\begin{tabular}{lcccccc}
\hline & $\begin{array}{c}\text { Iran } \\
\text { Mean }\end{array}$ & $\begin{array}{c}\text { Poland } \\
\text { Mean }\end{array}$ & $\begin{array}{c}\text { Iran } \\
\text { Standard deviation }\end{array}$ & $\begin{array}{c}\text { Poland } \\
\text { Standard deviation }\end{array}$ & $t$ & $p$ \\
\hline Age & 32.09 & 40.96 & 11.60 & 14.42 & -16.51 & 001 \\
Education & 11.15 & 11.09 & 3.01 & 2.12 & 0.68 & 0.50 \\
Gender & 1.50 & 1.52 & 0.500 & 0.500 & -1.352 & 0.18 \\
\hline
\end{tabular}

1 The above given response scales were recoded from the original version provided in WVS. 


\section{Values, Age, Country and Education: Relations across Cultural Groups}

In the next stage, I performed regression analyses to see if human values are different for Iran and Poland and if they are related to age and education. What is more, I checked if education and age moderates the relationship between country and these values. The results of regression analyses and the coefficients of the regression model are presented in Tables 4 to 13 .

Self-direction. There was no difference between Iran and Poland in valuing self-direction (important to think up new ideas). This value was predicted by education $(\beta=0.179, p<.001)-$ the higher the education the higher the self-direction value. This value was also slightly higher for men than for women $(\beta=-0.034, p=.044)$. This value was also significantly predicted by interaction between country and age, which is presented in Figure 2. In Iran, the older the respondents the more important this value was to them. In Poland, an opposite pattern was observed - importance of thinking up new ideas was reversely related to age. The regression model was significant and accounted for $4.4 \%$ of variability in self-direction value, $F(6,3399)=26.27, p<.001$ (see Table 4 ).

Table 4. Multiple regression coefficients predicting the importance of thinking up new ideas

\begin{tabular}{|c|c|c|c|c|}
\hline & \multicolumn{2}{|c|}{ Regression coefficients } & \multirow{2}{*}{$t$} & \multirow{2}{*}{$p$} \\
\hline & $\mathrm{B}$ & Beta & & \\
\hline Constant & 0.132 & & 7.115 & $<.001$ \\
\hline Country & 0.004 & 0.003 & 0.187 & .852 \\
\hline Age & -0.027 & -0.025 & -1.333 & .182 \\
\hline Education & 0.191 & 0.179 & 9.707 & $<.001$ \\
\hline Gender & -0.036 & -0.034 & -2.012 & .044 \\
\hline Country-Age & -0.063 & -0.066 & -3.541 & $<.001$ \\
\hline Country-education & -0.037 & -0.030 & -1.634 & .102 \\
\hline
\end{tabular}

Note: Country (1: Iran, 2: Poland), Gender (1: Male, 2: Female).

Figure 2. Interaction between age and country on the importance of thinking up new ideas

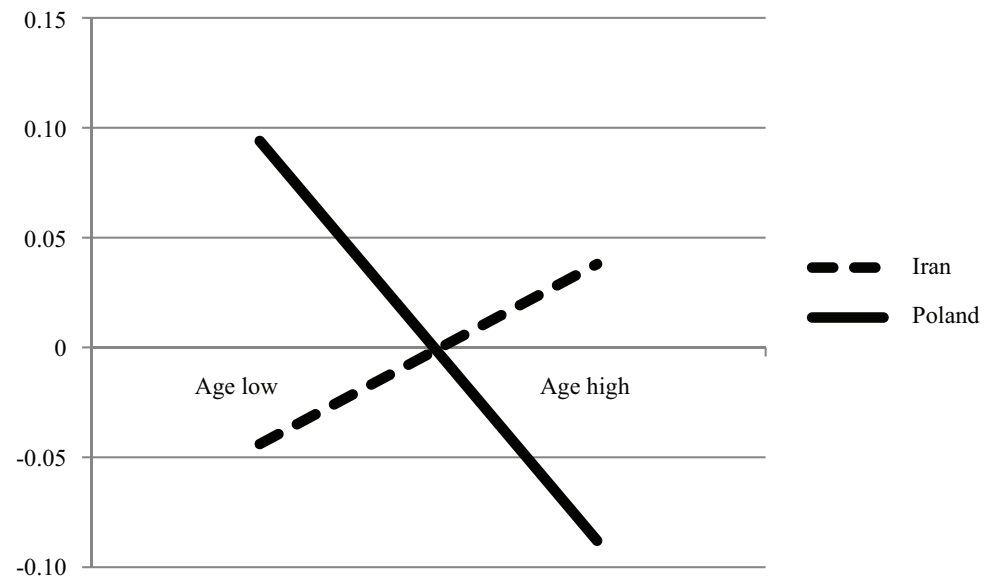


Stimulation. There was a difference between Iran and Poland in valuing adventure and taking risks, with Poles valuing stimulation more than Iranians $(\beta=0.130, p<.001)$. This value was predicted by education $(\beta=0.086, \mathrm{p}<.001)$ - the higher the education the higher the value of adventure and taking risks. This value was also higher for men than for women $(\beta=-0.098$, $p<.001)$. Moreover, the younger the respondents the more important this value was to them $(b=-0.215, p<.001)$. The regression model was significant and accounted for $7.4 \%$ of variability in stimulation value, $F(6,3403)=46.143, p<.001($ see Table 5$)$.

Table 5. Multiple regression coefficients predicting the importance of adventure and taking risks

\begin{tabular}{|c|c|c|c|c|}
\hline & \multicolumn{2}{|c|}{ Regression coefficients } & \multirow{2}{*}{$t$} & \multirow{2}{*}{$p$} \\
\hline & $\mathrm{B}$ & Beta & & \\
\hline (Constant) & -0.864 & & -38.608 & $<.001$ \\
\hline Country & 0.169 & 0.130 & 7.313 & $<.001$ \\
\hline Age & -0.279 & -0.215 & -11.439 & $<.001$ \\
\hline Education & 0.112 & 0.086 & 4.721 & $<.001$ \\
\hline Gender & -0.128 & -0.098 & -5.917 & $<.001$ \\
\hline Country-Age & 0.004 & 0.004 & 0.207 & 0.836 \\
\hline Country-education & -0.018 & -0.012 & -0.669 & 0.504 \\
\hline
\end{tabular}

Note: Country (1: Iran, 2: Poland), Gender (1: Male, 2: Female).

Hedonism. There was significant difference between Iran and Poland in the importance of having a good time, with Poles embracing this value more than Iranians $(\beta=0.074, p<.001)$. This value was predicted by age $(\beta=-0.183, p<.001)$ - younger respondents valued having a good time more than older respondents. Besides, this value was higher for men than for women $(\beta=-0.049$, $p=.004)$. The regression model was significant and accounted for $3.3 \%$ of variability in hedonism value, $F(6,3398)=19.552, p<.001($ see Table 6$)$.

Table 6. Multiple regression coefficients predicting the importance of having a good time

\begin{tabular}{|c|c|c|c|c|}
\hline & \multicolumn{2}{|c|}{ Regression coefficients } & \multirow{2}{*}{$t$} & \multirow{2}{*}{$p$} \\
\hline & B & Beta & & \\
\hline (Constant) & -0.988 & & -45.505 & $<.001$ \\
\hline Country & 0.091 & 0.074 & 4.047 & $<.001$ \\
\hline Age & -0.226 & -0.183 & -9.539 & $<.001$ \\
\hline Education & -0.013 & -0.011 & -0.586 & 0.558 \\
\hline Gender & -0.061 & -0.049 & -2.899 & 0.004 \\
\hline Country-Age & -0.013 & -0.012 & -0.631 & 0.528 \\
\hline Country-education & -0.022 & -0.015 & -0.817 & 0.414 \\
\hline
\end{tabular}

Note: Country (1: Iran, 2: Poland), Gender (1: Male, 2: Female). 
Power. There was a significant difference between Iran and Poland in the importance of being rich (power value), with Iranians embracing this value to a greater extent than Poles $(\beta=-0.165$, $p<.001)$. This value was also predicted by age $(\beta=-0.119, p<.001)$ - younger respondents attached more importance to being rich. Moreover, this value was higher for men than for women $(\beta=-0.058, p=.001)$. Furthermore, it has been predicted by an interaction between country and age $(\beta=0.046, p=0.014)$, which can be observed in Figure 3. Among Iranians, younger respondents attach much higher importance to this value than older respondents. Polish respondents also follow the same pattern, but difference between younger and older respondents was much less pronounced. The regression model was significant and accounted for $5 \%$ of variability in power value, $F(6,3408)=30.135, p<.001$ (see Table 7$)$.

Table 7. Multiple regression coefficients predicting the importance of being rich

\begin{tabular}{|c|c|c|c|c|}
\hline & \multicolumn{2}{|c|}{ Regression coefficients } & \multirow{2}{*}{$t$} & \multirow{2}{*}{$p$} \\
\hline & $\mathrm{B}$ & Beta & & \\
\hline (Constant) & -0.833 & & -39.044 & $<.001$ \\
\hline Country & -0.201 & -0.165 & -9.121 & $<.001$ \\
\hline Age & -0.146 & -0.119 & -6.279 & $<.001$ \\
\hline Education & -0.007 & -0.006 & -0.325 & 0.745 \\
\hline Gender & -0.071 & -0.058 & -3.415 & 0.001 \\
\hline Country-Age & 0.050 & 0.046 & 2.471 & 0.014 \\
\hline Country-education & -0.004 & -0.002 & -0.136 & 0.892 \\
\hline
\end{tabular}

Note: Country (1: Iran, 2: Poland), Gender (1: Male, 2: Female).

Figure 3. Interaction between age and country on the importance of being rich

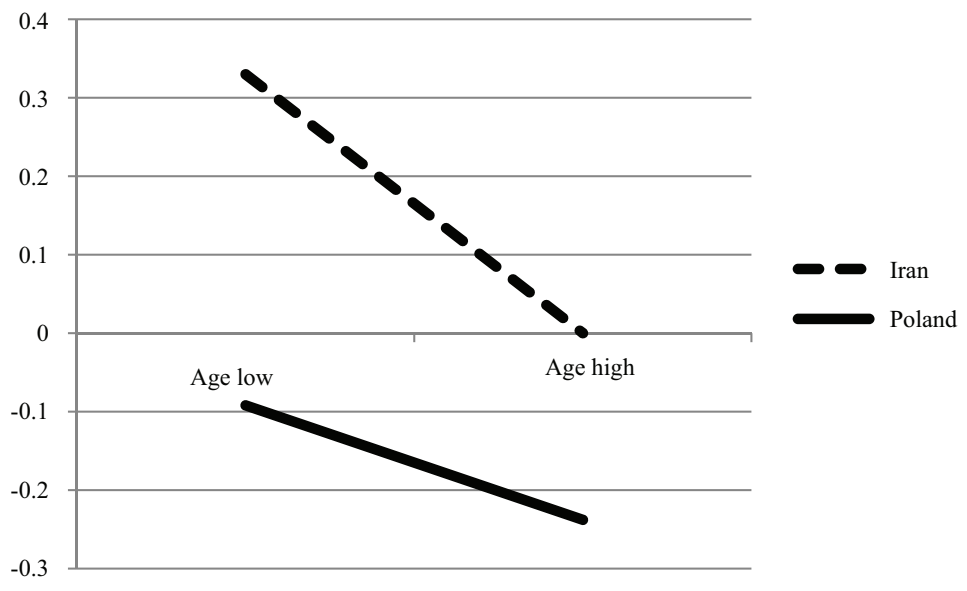

Achievement. There was a difference between Iran and Poland in attaching importance to being successful, with Poles valuing achievement more than Iranians $(\beta=0.128, p<.001)$. This value was also predicted by age $(\beta=-0.088, p<.001)$ - younger respondents valued achievement more 
than older respondents. The regression model was significant and accounted for $1.6 \%$ of variability in achievement value, $F(6,3399)=10.520, p<.001$ (see Table 8$)$.

Table 8. Multiple regression coefficients predicting the importance of being very successful

\begin{tabular}{|c|c|c|c|c|}
\hline & \multicolumn{2}{|c|}{ Regression coefficients } & \multirow{2}{*}{$t$} & \multirow{2}{*}{$p$} \\
\hline & $\mathrm{B}$ & Beta & & \\
\hline (Constant) & -0.158 & & -8.140 & $<.001$ \\
\hline Country & 0.139 & 0.128 & 6.941 & $<.001$ \\
\hline Age & -0.096 & -0.088 & -4.552 & $<.001$ \\
\hline Education & 0.003 & 0.003 & 0.139 & 0.889 \\
\hline Gender & 0.011 & 0.010 & 0.578 & 0.563 \\
\hline Country-Age & 0.017 & 0.017 & 0.902 & 0.367 \\
\hline Country-education & 0.012 & 0.009 & 0.494 & 0.621 \\
\hline
\end{tabular}

Note: Country (1: Iran, 2: Poland), Gender (1: Male, 2: Female).

Security. There was significant difference between Iran and Poland in the importance of security value, with Iranians embracing this value to a greater extent than Poles $(\beta=-0.106, p<.001)$. This value was also predicted by age $(\beta=0.149, p<.001)$ - living in a secure surroundings is more important to older respondents. It was also higher for women than for men $(\beta=0.044, p=.009)$. The regression model was significant and accounted for $2.4 \%$ of variability in living in security value, $F(6,3406)=14.110, p<.001$ (see Table 9).

Table 9. Multiple regression coefficients predicting the importance of living in secure surroundings

\begin{tabular}{|c|c|c|c|c|}
\hline & \multicolumn{2}{|c|}{ Regression coefficients } & \multirow{2}{*}{$t$} & \multirow{2}{*}{$p$} \\
\hline & $\mathrm{B}$ & Beta & & \\
\hline (Constant) & 0.669 & & 38.961 & $<.001$ \\
\hline Country & -0.107 & -0.106 & -5.780 & $<.001$ \\
\hline Age & 0.152 & 0.149 & 7.739 & $<.001$ \\
\hline Education & 0.026 & 0.026 & 1.384 & 0.166 \\
\hline Gender & 0.045 & 0.044 & 2.605 & 0.009 \\
\hline Country-Age & -0.004 & -0.005 & -0.262 & 0.794 \\
\hline Country-education & -0.042 & -0.035 & -1.924 & 0.054 \\
\hline
\end{tabular}

Note: Country (1: Iran, 2: Poland), Gender (1: Male, 2: Female).

Conformity. There was significant difference between Iran and Poland in the importance of always behaving properly, with Iranians embracing conformity value to a greater extent than Poles $(\beta=-0.201, p<.001)$. This value was predicted by age $(\beta=0.116, p<.001)-$ older respondents attach more importance to conformity than younger ones. Additionally, this value was higher for 
women than for men $(\beta=0.057, p=.001)$. Furthermore, this value was predicted by education $(\beta=-0.085, p<.001)$ the higher the education the lower the value of always behaving properly. The regression model was significant and accounted for $5.3 \%$ of variability in conformity value, $\mathrm{F}(6,3403)=32.664, p<.001($ see Table 10$)$.

Table 10. Multiple regression coefficients predicting the importance of always behaving properly

\begin{tabular}{lcccc}
\hline & \multicolumn{2}{c}{ Regression coefficients } & & \\
& B & Beta & & $p$ \\
\hline Constant $)$ & 0.447 & & 25.909 & $<.001$ \\
Country & -0.199 & -0.201 & -11.118 & $<.001$ \\
Age & 0.115 & 0.116 & 6.127 & $<.001$ \\
Education & -0.084 & -0.085 & -4.626 & 001 \\
Gender & 0.057 & 0.057 & 3.391 & 0.001 \\
Country-Age & 0.011 & 0.012 & 0.640 & 0.522 \\
Country-education & -0.013 & -0.011 & -0.598 & 0.550 \\
\hline
\end{tabular}

Note: Country (1: Iran, 2: Poland), Gender (1: Male, 2: Female).

Tradition. There was a difference between Iran and Poland in valuing tradition, with Poles embracing it to a greater extent than Iranians $(\beta=0.082, p<0.001)$. This value was predicted by education $(\beta=-0.142, p<0.001)$ - the lower the education the higher the value of tradition. This value was also higher for women than for men $(\beta=0.068, p<0.001)$. Furthermore, older respondents also attach more importance on tradition than younger respondents $(\beta=0.167, p<0.001)$. Tradition was also significantly predicted by an interaction between country and education, which is presented in Figure 4. In Iran, respondents with lower education value tradition slightly more than respondents with higher education. In Iran, the importance of tradition decreases as the level of education increases much more steeply than in Poland. The regression model was significant and accounted for $10.1 \%$ of variability in tradition value, $F(6,3406)=64.043, p<.001$ (see Table 11).

Table 11. Multiple regression coefficients predicting the importance of tradition

\begin{tabular}{lcccc}
\hline & \multicolumn{2}{c}{ Regression coefficients } & & \\
& B & Beta & & $p$ \\
\cline { 2 - 4 } (Constant) & 0.506 & & 26.668 & $<.001$ \\
Country & 0.092 & 0.082 & 4.678 & $<.001$ \\
Age & 0.187 & 0.167 & 9.046 & $<.001$ \\
Education & -0.160 & -0.142 & -7.943 & $<.001$ \\
Gender & 0.076 & 0.068 & 4.117 & 0.983 \\
Country-Age & 0.018 & 0.018 & 0.326 \\
Country-education & 0.107 & 0.081 & 4.602 & $<.001$ \\
\hline
\end{tabular}

Note: Country (1: Iran, 2: Poland), Gender (1: Male, 2: Female). 
Figure 4. Interaction between education and country on the importance of tradition

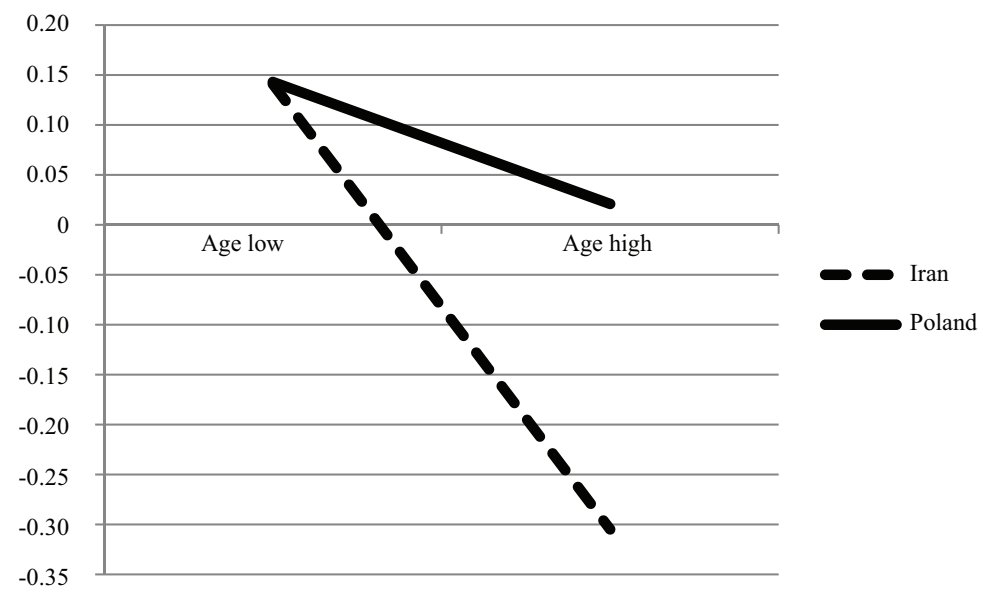

Benevolence. There was a significant difference between Iran and Poland in valuing to help people, with Poles embracing this value to a greater extent than Iranians $(\beta=0.064, p<.001)$. This value was also predicted by education $(\beta=-0.094, p<.001)$ - the higher the education the lower the value of helping people. This value was also higher for women than for men $(\beta=0.152$, $p<.001$ ). Benevolence was also significantly predicted by interaction between country and age, which is presented in Figure 5. In both countries the older the respondents the more important this value was to them. However, in Iran younger respondents expressed an even lower importance of benevolence compared to the older ones. The regression model was significant and accounted for $5.5 \%$ of variability benevolence value, $\mathrm{F}(6,3383)=33.788, p<.001$ (see Table 12$)$.

Table 12. Multiple regression coefficients predicting the importance of helping people

\begin{tabular}{|c|c|c|c|c|}
\hline & \multicolumn{2}{|c|}{ Regression coefficients } & \multirow{2}{*}{$t$} & \multirow{2}{*}{$p$} \\
\hline & B & Beta & & \\
\hline (Constant) & 0.503 & & 31.453 & $<.001$ \\
\hline Country & 0.059 & 0.064 & 3.563 & $<.001$ \\
\hline Age & 0.139 & 0.152 & 7.992 & $<.001$ \\
\hline Education & -0.087 & -0.094 & -5.126 & $<.001$ \\
\hline Gender & 0.058 & 0.064 & 3.771 & $<.001$ \\
\hline Country-Age & -0.039 & -0.047 & -2.521 & 0.012 \\
\hline Country-education & 0.035 & 0.032 & 1.760 & 0.078 \\
\hline
\end{tabular}

Note: Country (1: Iran, 2: Poland), Gender (1: Male, 2: Female). 
Figure 5. Interaction between age and country on the importance of helping people

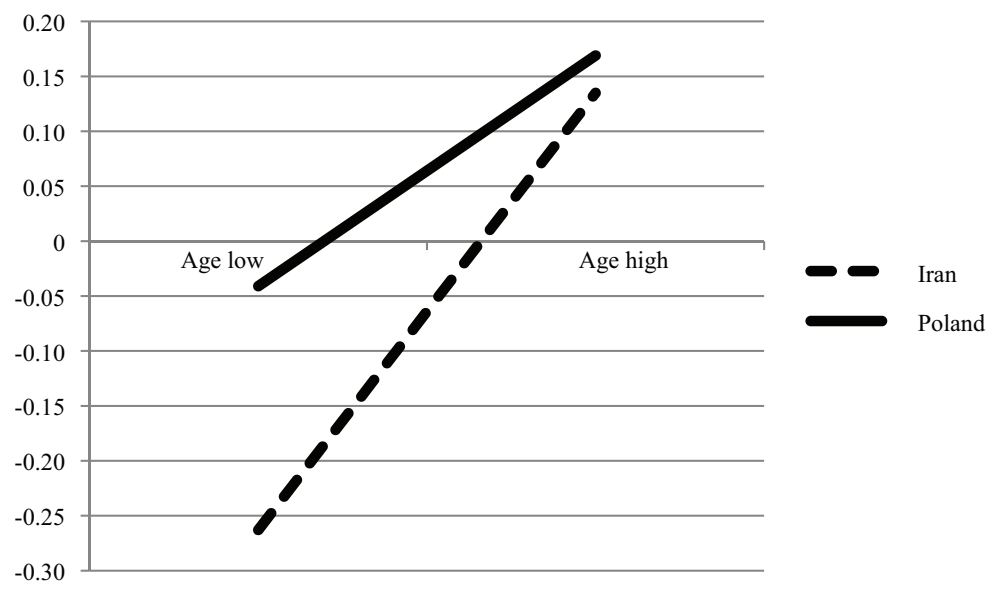

Universalism. There was significant difference between Iran and Poland in the importance of looking after environment, with Iranians valuing universalism to a greater extent than Poles $(\beta=-0.047, p=.010)$. This value was also predicted by age $(\beta=0.180, p<.001)-$ older respondents attach more importance on looking after environment than younger ones. Moreover, universalism value was higher for women than for men $(\beta=0.047, p=0.006)$. The regression model was significant and accounted for $3.1 \%$ of variability in universalism value, $F(6,3403)=19.312$, $p<.001$ (see Table 13).

Table 13. Multiple regression coefficients predicting the importance of looking after environment

\begin{tabular}{|c|c|c|c|c|}
\hline & \multicolumn{2}{|c|}{ Regression coefficients } & \multirow{2}{*}{$t$} & \multirow{2}{*}{$p$} \\
\hline & $\mathrm{B}$ & Beta & & \\
\hline (Constant) & 0.549 & & 33.413 & $<.001$ \\
\hline Country & -0.044 & -0.047 & -2.590 & 0.010 \\
\hline Age & 0.169 & 0.180 & 9.403 & $<.001$ \\
\hline Education & 0.016 & 0.017 & 0.928 & 0.354 \\
\hline Gender & 0.044 & 0.047 & 2.766 & .0 .006 \\
\hline Country-Age & 0.025 & 0.030 & 1.602 & 0.109 \\
\hline Country-education & -0.013 & -0.011 & -0.620 & 0.535 \\
\hline
\end{tabular}

Note: Country (1: Iran, 2: Poland), Gender (1: Male, 2: Female).

\section{DISCUSSION}

The main purpose of the present study was to investigate the differences in basic human values between Iran and Poland - a comparison that has not been undertaken in previous studies. Additionally, I check how human values in these two countries vary as a result of age (socialization if different sociopolitical contexts) and the level of education. 
The results values between showed that the differences in Poland and Iran were evident for all studied values, except for self-direction. The results indicated that Iranians were more likely to embrace power, security, conformity, and universalism values. Poles, on the other hand, reported higher importance of stimulation, hedonism, achievement, tradition, and benevolence values.

Iran culture over the Shah regime was closed to Western culture and regime was trying to develop the views that traditional and Islamic beliefs belong to the past. However, after Islamic revolution in 1978-79, Islamic values have been disseminated again. New government has tried to emphasize more on obtaining human dignity and values rather than on materialism. As a consequence, conformity and priority of behaving properly, avoiding harm others and violating social expectations or norms, being obedient and polite, honoring parents and elders, self-discipline, benefit of social cohesiveness, work in harmony, justice and equity, belonging, humility and simplicity have been reinforced. Theses principals are transmitted by schools, families and many different religious ceremonies all for the purpose of underlining collectivism and being liberated of external and foreign influences (Abbas \& Amirshahi, 2002). Therefore, safety, harmony, and stability of society and relationships, national security, social order, sense of belonging, family security, understanding, appreciation, tolerance and protection for the welfare of all people and for nature has become more imperative in Iran today. Although, the process of nationalization and reconstructing has changed distribution of power in Iran, it led to great deal of power distance in Iran society. According to Javadian and Dastmalchian (2003) extreme advantages and positions has been given to people in places of power and authority. As a result at the end it can be seen that institutional collectivism was not really a strong suit of Iranians.

In this study, age moderated the relationship between country and self-direction, power, and benevolence values. As it can be observed the importance of thinking up to new ideas, novelty and change in life is more important when you are young, but the results in Iran is a bit different. Young generation attach not so much important in self-direction while old generation pay more attention to this value. This also has been proven in Delkhamosh and Ahmadi Mobarake (2012) study. It could be somehow related to the different education that older generation had in a different era, they had been taught that traditional principals belong to our past. Consequently, they attach more importance to this value. Nevertheless, this results might be changed if we use data related to this decade. With developing technology, mass media, internet, etc. people especially younger generation has obtained more knowledge about the necessities of being open to new ideas. Moreover, based on what have been told, young generation value power and have dominance on other people way more that old generation and it origins from the perspective they have taken during the years of living in Iran by observing all the privileges that people in authority have possessed. Furthermore, preservation and enhancement of the welfare of people with whom one is in frequent personal contact and benevolence getting more importance as people growing old. It is mostly roots in nowadays hectic lifestyle. Younger people usually find less time and resources to devote to people who they do not know.

Education also moderated the relationship between country and tradition value, it is observable that there is a large gap between higher education and lower education people in terms of valuing into tradition in Iran. As people gain more knowledge, use more internet, media and get to know what is going on around the world they less tend to value tradition.

In addition to country differences, age differences are evident for all values except the importance of self-direction value. Unsurprisingly, higher importance of benevolence, universalism, tradition, conformity, and security was related to being older, while higher level of stimulation, hedonism, power and achievement was higher among the younger respondents. The fact that young people value success more than older people has been demonstrated in different studies that younger generations are exceedingly motivated and achievement-oriented (e.g., Conger, 1997; Tulgan, 1997). 
The importance of looking after environment was more highly appreciated among older people in both analyzed countries. However, previous research (e.g., DiDio, Saragovi, Koestner, and Aube, 1996; Rokeach, 1973; Feather, 1987) showed that the importance of looking after the environment has been mostly unchanged from one generation to the other.

My findings indicated that older people in Iran and Poland placed more importance on tradition than younger generation, which confirmed previous research results (Lyons, Duxbury, and Higgins, 2005; DiDio, Saragovi, Koestner, and Aube, 1996; Rokeach, 1973; Feather, 1987). In addition, in this study, age was significantly and positively related with the importance of conformity and security, which is a novel result, compared to previous studies which the importance of conformity and security is not positively related to age (e.g., Lyons, Duxbury, and Higgins, 2005; DiDio, Saragovi, Koestner, and Aube, 1996; Rokeach, 1973; Feather, 1987). What is more, power and stimulation values were negatively related to age, which is consistent with other studies, which showed that a younger generation (particularly men) place more importance on being rich, powerful, and autonomous because they feel consistently disempowered by the deficiency of occupation and disadvantageous economic situation (Lyons, Duxbury, and Higgins, 2005).

In this study, we found a significant and negative relationship between age and the importance of adventures and taking risks. This generational patterns is also authenticated in Lyons, Duxbury, and Higgins study in 2005. Younger generation is valuing happiness and enjoyment, they always seek out new challenges and changes in life, whilst older people are more interested to be in secure surroundings and to behave properly. I also found a positive significant relationship between the importance of helping the people and age. Younger people were raised to be more independent and self-reliant (Lyons, Duxbury, and Higgins, 2005).

Moreover, self-direction, stimulation, conformity, benevolence, hedonism, security and tradition values were significantly related with education. Higher education can increase openness to change values and decrease conservation values, and this can be observed in other studies (i.e., GonzalezRodriguez, Fernandez, Spers, and Leite, 2016).

\section{Limitation and Future Research}

The nature of sample may have had an influence on the results, because the analysis of sample characteristics clearly reveals that it was not representative of the population, especially the Iranian sample. For example, in Iran there were more respondents than in Poland (Iran $=72.7 \%$ and Poland $=$ $27.3 \%$ of the total sample) and it is not exactly obvious why. Besides, Iranian respondents have been shown to be 10 years younger than Polish respondents. Also, most of Iranian respondents (72.8\%) lived in urban areas, while 42.4 percent of Polish respondents lived in small cities, while 57.6 percent lives in big cities. The most striking difference is the level of education. Highest level of education was claimed by $20.2 \%$ of the respondents in Iran vs. $4.6 \%$ in Poland. All this demonstrates the unrepresentativeness of the sample, which can stem from the participation of mostly urban residents in Iran. All these issues can mislead our results, therefore, further research and investigations is needed.

\section{Literature}

Ali, A. J., \& Amirshahi, M. (2002). The Iranian manager: Work values and orientations. Journal of Business Ethics, 40(2), 133-143.

Bardi, A., \& Schwartz, S. H. (1996). Relations among Sociopolitical Values in Eastern Europe: Effects of the Communist Experience? Political Psychology, 17(3), 525-549. doi: 10.2307/3791967 
Bilsky, W., Janik, M., \& Schwartz, S. H. (2011). The Structural Organization of Human Values-Evidence from Three Rounds of the European Social Survey (ESS). Journal of Cross-Cultural Psychology, 42(5), $759-776$. doi: $10.1177 / 0022022110362757$

Cieciuch, J., \& Davidov, E. (2012). A comparison of the invariance properties of the PVQ-40 and the PVQ-21 to measure human values across German and Polish Samples. Journal of the European Survey Research Association, 6(1), 12. doi: 10.18148/srm/2012.v6i1.5091

Conger, J. (1997). The generation game. Management, 44(9), 72-73.

Di Dio, L., Saragovi, C., Koestner, R., \& Aubé, J. (1996). Linking personal values to gender. Sex Roles, 34(9), 621-636. doi: 10.1007/bf01551498

Dobewall, H., \& Rudnev, M. (2014). Common and Unique Features of Schwartz's and Inglehart's Value Theories at the Country and Individual Levels. Cross-Cultural Research, 48(1), 45-77. doi: 10.1177/10693971134 93584

Feather, N. T. (1987). Gender Differences in Values: Implications of the Expectancy-Value Model, Berlin, Heidelberg.

Fischer, R., \& Boer, D. (2015). Motivational Basis of Personality Traits: A Meta-Analysis of Value-Personality Correlations. Journal of Personality, 83(5), 491-510. doi: doi:10.1111/jopy.12125

Fontaine, J. R. J., Poortinga, Y. H., Delbeke, L., \& Schwartz, S. H. (2008). Structural Equivalence of the Values Domain Across Cultures:Distinguishing Sampling Fluctuations From Meaningful Variation. Journal of Cross-Cultural Psychology, 39(4), 345-365. doi: 10.1177/0022022108318112

Gonzalez-Rodriguez, M. D. R., Diaz-Fernandez, M. D. C., Spers, V. R. E., \& Leite, M. D. S. (2016). Relation between background variables, values and corporate social responsibility. Revista de Administração de Empresas, 56(1), 8-19.

Haslam, N. (2004). Relational Models Theory: A Contemporary Overview, New Jersey: Lawrence Erlbaum Associates.

Herskovits, M. J. (1955). Cultural anthropology, Oxford, England: Knopf.

Javidan, M., \& Dastmalchian, A. (2003). Culture and leadership in Iran: The land of individual achievers, strong family ties, and powerful elite. Academy of Management Perspectives, 17(4), 127-142.

Kohn, M. L., \& Schooler, C. (1983). Work and personality: An inquiry into the impact of social stratification: Ablex Pub.

Lyons, S., Duxbury, L., \& Higgins, C. (2005). Are Gender Differences in Basic Human Values a Generational Phenomenon? Sex Roles, 53(9), 763-778. doi: 10.1007/s11199-005-7740-4

Prince-Gibson, E., \& Schwartz, S. H. (1998). Value Priorities and Gender. Social Psychology Quarterly, 61(1), 49-67. doi: 10.2307/2787057

Rokeach, M. (1973). The nature of human values. New York, NY, US: Free Press.

Schwartz, S. H. (1992). Universals in the Content and Structure of Values: Theoretical Advances and Empirical Tests in 20 Countries. In M. P. Zanna (Ed.), Advances in Experimental Social Psychology (Vol. 25, pp. 1-65): Academic Press.

Schwartz, S. H. (1994). Are there universal aspects in the structure and contents of human values? Journal of Social Issues, 50(4), 19-45. doi: 10.1111/j.1540-4560.1994.tb01196.x

Schwartz, S. H., \& Bardi, A. (1997). Influences of Adaptation to Communist Rule on Value Priorities in Eastern Europe. Political Psychology, 18(2), 385-410.

Schwartz, S. H., \& Bardi, A. (2001). Value Hierarchies Across Cultures:Taking a Similarities Perspective. Journal of Cross-Cultural Psychology, 32(3), 268-290. doi: 10.1177/0022022101032003002

Schwartz, S. H., \& Huismans, S. (1995). Value Priorities and Religiosity in Four Western Religions. Social Psychology Quarterly, 58(2), 88-107. doi: 10.2307/2787148

Schwartz, S. H., \& Rubel-Lifschitz, T. (2009). Cross-national variation in the size of sex differences in values: effects of gender equality. Journal of personality and social psychology, 97(1), 171-185. doi: 10.1037/ a0015546

Schwartz, S. H., \& Sagiv, L. (1995). Identifying Culture-Specifics in the Content and Structure of Values. Journal of Cross-Cultural Psychology, 26(1), 92-116. doi: 10.1177/0022022195261007

Schwartz, S. H., Caprara, G. V., \& Vecchione, M. (2010). Basic Personal Values, Core Political Values, and Voting: A Longitudinal Analysis. Political Psychology, 31(3), 421-452.

Sortheix, F. M., \& Lönnqvist, J.-E. (2014). Personal Value Priorities and Life Satisfaction in Europe:The Moderating Role of Socioeconomic Development. Journal of Cross-Cultural Psychology, 45(2), $282-299$. doi: $10.1177 / 0022022113504621$

Tulgan, B. (1997). The manager's pocket guide to Generation X: Human Resource Development. Amherst: HRD Press. 
Vauclair, C.-M., Fischer, R., Ferreira, M. C., Guerra, V., Hößler, U., Karabati, S., . . . Spieß, E. (2015). What Kinds of Value Motives Guide People in Their Moral Attitudes? The Role of Personal and Prescriptive Values at the Culture Level and Individual Level. Journal of Cross-Cultural Psychology, 46(2), 211-228. doi: $10.1177 / 0022022114557487$

Veroff, J., Reuman, D., \& Feld, S. (1984). Motives in American men and women across the adult life span. Developmental psychology, 20(6), 1142.

Verplanken, B., \& Holland, R. W. (2002). Motivated decision making: effects of activation and self-centrality of values on choices and behavior. Journal of personality and social psychology, 82(3), 434-447.

Wieczorkowska-Wierzbińska, G., Wierzbiński, J., Kuzminska, A. (2014). Porównywalność danych zebranych w różnych krajach. Psychologia Społeczna, 2(29), 128-143. 


\title{
Gender Gap on the Job Market: Poland vs. Iran
}

\author{
Magdalena Simkowska-Gawron* \& Zahra Momenfar**
}

\begin{abstract}
Summary
Every year the number of Iranian students take the opportunity to complete their tertiary education in Poland increases - currently a third of them are women. Looking at the cross-cultural differences between Poland and Iran, it has become the aim of the authors to examine how they might affect educational attainment and employment opportunities of females in these respective countries. For that reason, they review relevant literature referring to a situation of women in terms of their educational and employment opportunities in Poland in Iran. They also look at gender-related stereotypes that might hinder professional opportunities of women in these two countries. As a complementing element, authors analyse the World Values Survey responses referring to stereotypical attitudes and their possible impact on gender discrimination at workplace in Poland and Iran.
\end{abstract}

Keywords: Women, Educational attainment, Female labour participation, Gender gap, Gender stereotypes.

JEL: M12, M14, J16

\section{INTRODUCTION}

Living in the era of globalisation marks intercultural and cross-national cooperation as essential for further growth - in a human and economic dimension. Seeking common denominators across cultures, and at the same time knowing the differences between them, may enhance exchange of knowledge, skills and talent. And through this - an increase of chances for successful collaborations in business, education, and other areas may be possible. Best example of such a cooperation is the collaboration between the authors of this paper - doctoral candidates at the cross-cultural management studies, one Polish and one Iranian. Even though they come from different cultural circles, in which they were brought up, gained education, and got their first employment experiences, they share their gender.

Being a woman in Poland and Iran may be associated with various social and economic factors and forces. However, gender-related behaviours and situations experienced by women on job markets in Poland and Iran, seem to be a natural way toward creating a starting point for future cross-cultural studies. It is worth remembering that the number of Iranian students at universities in Poland is constantly growing. With more Iranian students taking opportunity to complete their tertiary education in Poland every year (Polish Statistical Bureau, 2014, 2017a), and a third of them being females, it is essential to initiate a research on differences and similarities affecting such fields as education attainment and labour force participation in these two countries. Gender differences and inequalities stemming from these fields, are still alive and persistent. Even though they might be only of a stereotypical nature, they still determine such basic rights as access to education or employment opportunities of men and women, among others (Mandal, 2000). And these two elements directly translate into the level of economic and social participation, empowerment and overall success of representatives of the two genders (WEF, 2018).

The 21 st century is characterised by fast development of technology and innovation, which is associated with unprecedented pace of social changes. In such circumstances, unique skills and talents play a crucial role in sustainable growth and every effort should be made to make it as

\footnotetext{
Faculty of Management, University of Warsaw, Poland, https://orcid.org/0000-0002-3998-5068, e-mail: msgawron@ wz.uw.edu.pl

** Ferdowsi University of Mashhad, Iran \& Faculty of Management, University of Warsaw, Poland, https://orcid.org/00000001-5639-5265, e-mail: z.momenfar@yahoo.com
} 
inclusive an environment as possible. Otherwise, all of the spheres, either public or private, business or education - would not only continue to waste talent but would also fail to follow the changes and modernisation that already commenced. Economists argue that the three assets, namely: fixed capital, human capital, and labour force have crucial and utmost impact effect on economic growth (World Economic Forum, 2018). They emphasise the relation between economic growth and gender inequality in basic human domains: health, education, employment, or remuneration. Some theorists refer to positive impact of gender inequality on economic growth (Barro \& Lee, 1994). While others (Galor \& Weil, 1996; Lagerlöf, 2003) proving negative influence - suggest that development in Europe (at least in economic and social terms) over the recent centuries has been connected with long-term changes in gender equality and development of egalitarian society. Clearly, the connection between gender (in)equality and economic growth has been one of the most debated concepts in recent times, regardless of the geographic latitude or socio-economic circumstances.

Recent economic analyses provide (WEF, 2018; Ferrant, 2015) that only an equal participation and contribution of women and men in world-changing processes will let the economies and societies prosper. Losing out on the skills, competitiveness, and innovative approach of half of the world's talent, has been reported as one of the major obstacles for sustainable growth and developmental opportunities the future may hold (WEF, 2018; Jaumotte, 2004). At the same time the effect is seen as mutual. Since lack of gender equality is affecting economic growth, economic progress also alters gender inequalities. Economic development is believed to impact gender inequalities by reducing access barriers in a job market for women, thus decreasing the amount of time spent at homecare and non-paid labour, and by changing institutional standards (van der Lippe \& van Dijk, 2002; Ferrant, 2015). It creates a joint relationship between economic growth and gender equality.

Multiple studies on women's employment show that economic development is an important factor in support of gender equality (WEF, 2018). It is often emphasised, however, that access to high quality education - at secondary level and beyond - is of utmost importance in the decisionmaking process of females whether to participate in the labour market or not. When combining paid and unpaid work, women - especially in developing countries - work more than men (that includes twice as much time on housework and other unpaid activities), with significantly less time for education, leisure, political participation, and self-care (Bielby \& Bielby, 1989; Fortin, 2005; Nagore Garcia, 2017; Vella, 1994; Verick, 2014).

The aim of this article, therefore, is twofold. First, we would like to review relevant literature referring to situation of women in terms of their educational and employment opportunities in Poland in Iran. Second, we would like to make an outlook on gender-related stereotypes that may hinder such opportunities. We will also analyse the opinions of Polish and Iranian respondents to the World Values Survey questions referring to stereotypical attitudes showing level of discrimination toward gender roles in society and at workplace.

Hence, the differences on the job market in Poland and Iran will be described in four main sections referring to potential gender disparities:

- Educational attainment

- Employment participation

- Gender pay gap

- Gender stereotypes

\section{COUNTRY COMPARISON - POLAND AND IRAN}

Poland and Iran are diverse countries in many dimensions - starting from the geographical location and cultural circles, up to social, demographic, or economic situation. There are also significant disparities in terms of women's participation in the public and economic spheres. In order to bring those differences closer to the readers, basic data comparison between Poland and Iran has been compiled. 
Iran has more than five times larger area and over twice as many inhabitants than Poland. Age structure of the two nations reveals that while Iran has a relatively young population with nearly a quarter of Iranian population below the age of 14 and less than $10 \%$ over 60 years old, Poland will have to face many of the challenges of an aging society with age rates reversed as compared to Iran $-14,8 \%$ of population below 14 years old, and $24 \%$ of Poles above the age of 60 years.

Women's representation in the public sphere looks slightly different in the two countries. Even though women constitute a near half of the population in both Iran and Poland, and on average are much better educated than men, their underrepresentation in the job market and political structures is significant, though more severe in Iran. In Iran less than 2 out of 10 women are active workforce, as compared to half of the female population in Poland. Only $16 \%$ of legislators and senior staff in Iran are women, with twice as high rate for women in Poland. The most acute example of gender disparity is, however, visible at the political decision-making level - only 3\% of seats in Iranian parliament are occupied by women, while in Poland - a quarter of the available parliamentary posts are represented by women.

Table 1. Data comparison between Iran and Poland

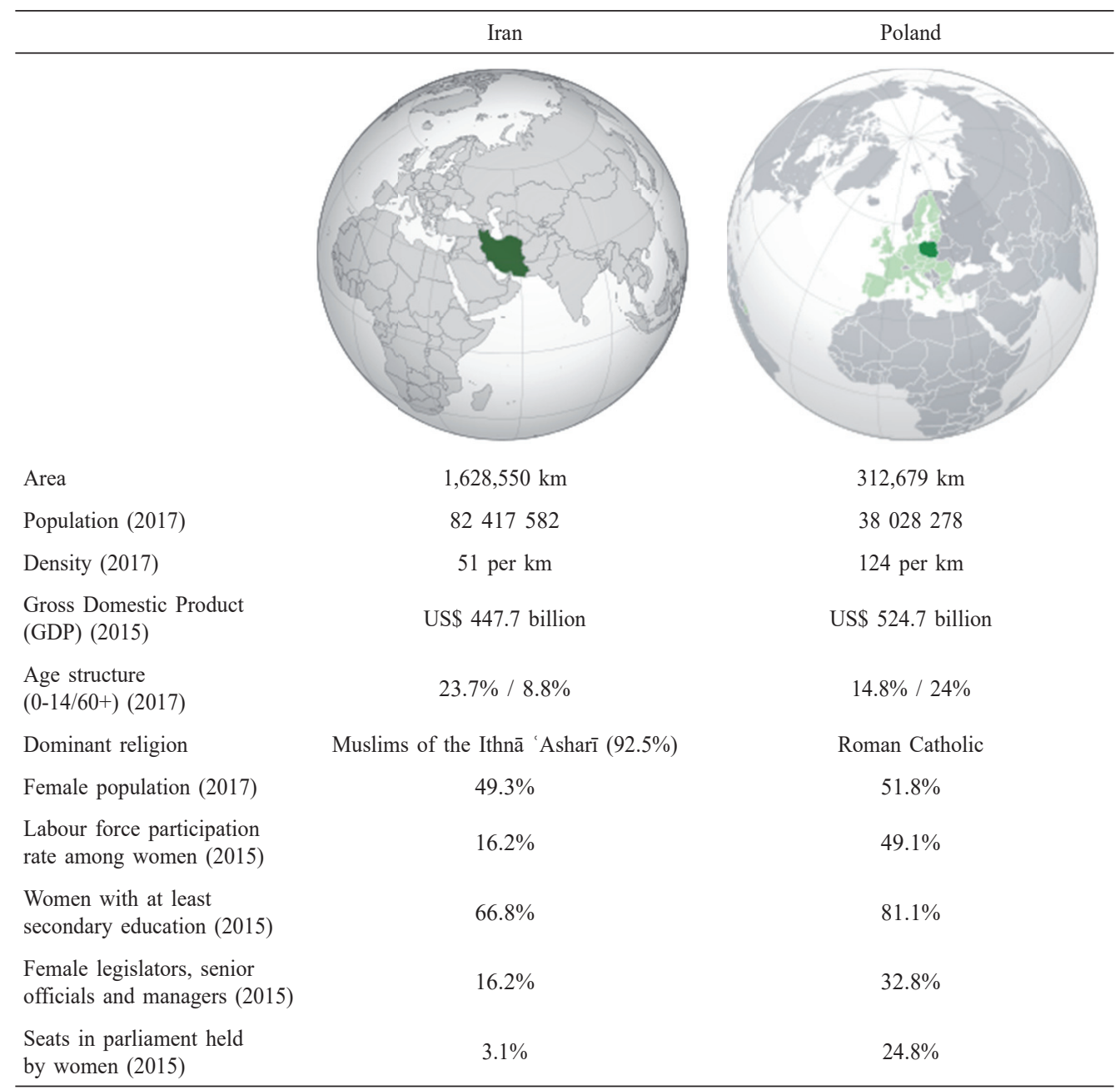




\section{EDUCATIONAL ATTAINMENT}

In the recent decades quick growth of educational investment and attainment among women has been observed. Women got to dominate men in secondary and tertiary education attainment in most of developed countries and among many of developing countries (UNESCO, 2018). There are more women among secondary education enrolled students and graduates, and that trend spreads toward the tertiary level rates of graduates. The widening gender gap in education in favour of women seems to be steady, with further potential growth in the future. Educational attainment datasets available at the Barro \& Lee's website ${ }^{1}$ confirm there were more women among university graduates in $54 \%$ of the advanced economies in 2010 . That number is even more remarkable taking into account that 60 years earlier men significantly outnumbered women in all of these economies (24 countries in total).

Multiple studies on women's employment show that professional career is an important factor in support of gender equality. In fact, in developing countries access to high quality education - at secondary level and beyond - is of crucial importance in the decision-making process of females whether to participate in the labour market or not (Bielby \& Bielby, 1989; Fortin, 2005; Nagore Garcia, 2017; Vella, 1994; Verick, 2014). It is not easy to relate directly labour market participation of women and socio-economic development of a particular territory. Yet, transformations of specific socio-economic issues such as access to quality education (understood as at least upper secondary), fertility rates, changes of social norms and others, might have had a key impact on the female labour participation rate (Verick, 2014). The more educated women are, the higher workforce participation rates. Therefore, as level of well-educated women increased worldwide, more women have undertaken paid occupations and the combination of the work and family roles in an adult life have become an ordinary situation. Despite a general character of the construct, these dimensions might take a different course for women and men - mainly due to normative expectations, social constraints, and biological conditions they face on a daily basis.

In Iran the number of women attending institutions of higher education has been steadily growing since 1989 (Kazemipour, 1999). Some argue (Shavarini, 2006) that women's college education is a waste of the nation's resources since the majority of college-educated women (approximately $75-80 \%$ ) do not get to participate in the labour market. To fully grab the complexity of that phenomenon it is necessary to get familiar with the Iranian higher education system. A high school diploma is earned after the completion of the third year. Out of the total eligible students, only $36 \%$ opt to continue to a fourth year on a college track by preparing for the national college entrance examination called "Konkur". That percentage of students continuing education is not equally distributed between the two genders - only $29 \%$ of men, compared to $42 \%$ of women, continue in the university stream. The final year of high school is an intense year of preparation to the National Entrance Examination. Konkur is an examination held annually in one of the summer months, and its participants attempt to get the results allowing them to attend the tuition-free public universities, seats at which are limited.

The results provide that merely $20 \%$ of the students taking the exam could count on seats at top public tertiary education institutions (others - if only can afford - may apply to courses at private universities in the country). In 2018 around $1 \mathrm{mln}$ individuals have registered for the exam, and female students constituted $59 \%$ of all the participants (Teheran News, 2018). Winning a seat at a public university is perceived in Iran as a privilege of a highly selected group, best of the best, who gain access to greater social and economic opportunities. Data from the beginning of the

$1 \quad$ The Barro \& Lee datasets provide educational attainment data for 146 countries in 5-year intervals from 1950 to 2010. It also provides information about the distribution of educational attainment of the adult population over age 15 and over age 25 by sex at seven levels of schooling, retrieved from: http://www.barrolee.com 
current millennium showed that out of 152000 students who passed Konkur in 2001, 60\% were women (Shavarini, 2005). The gender gap has continued to widen since then. In $2003,62 \%$ of those who passed the exam were women (Shavarini, 2006). Shortly after the results showing that women outnumber men in the national exam were released, not only these were the last results published officially afterwards, but also led to an implementation of gender quotas in public academia.

Over the following years Iranian parliament proceeded with laws limiting access to over 70 courses for female students. On one hand, among the banned courses there were such disciplines as engineering, technology, and mathematics-related. It was explained through the argument of waste of resources since majority of Iranian women with higher education would never join the workforce and pay back to the society (Winn, 2016). On the other hand, women were restricted from attending courses perceived as "Western" and "not in harmony with religious fundamentals" in Iran (Tait, 2012) - mainly in social sciences, psychology, law or management. Additional concerns were also expressed by national clerics who claimed that excessive educational attainment in these disciplines would have far-reaching social negative side effects to family life in Iran. These obstacles, nevertheless, have not discouraged Iranian women from pursuing university degree.

Iranian men, however, are not under pressure to gain higher education since college credentials do not enhance their abilities to improve their financial situation as it is in case of women. The Iranian labour market's need for skilled labour (i.e., a college-educated workforce) is limited, and what is more - men have priority over women in most areas of the employment market. For women, university education becomes one of a few viable means by which they can shape their future. Many Iranian women do not consider college a way through which they can acquire skills and knowledge (Shavarini, 2006). For Iranian women, university education is an experience of intangibles. It is giving them some sense of freedom beyond restrictive family control. It may also be seen as an asset, increasing woman's value in the marriage market (Rezai-Rashti \& Moghadam, 2011). Educational attainment is helping them to gain respect in the community, and of acquiring independence - also in financial terms, even though it does not necessarily mean entering a job market. All of these are rarely available to women in Iranian society (Shavarini, 2005). Nonetheless, as the research show (Salehi-Isfahani, 2001) in Iran educated mothers increase chances of better education of their children. One-year increase of mother's schooling increased her child's education - in rural areas by almost a year, and in urban areas - by nearly half a year. Thus, the role of development of human capital is another argument to take into account as an intangible advantage.

Slightly different situation appears in Poland. Education and skills are indispensable for finding a job. Primary education of men and women is at the same near $100 \%$ level, as it is obligatory at this stage. In terms of secondary education, 91\% of adults aged 25-64 have completed school at that level, which is a score higher by 17 percent points than the average for the OECD countries (OECD, 2017). Gender parity has been achieved here $-91 \%$ of eligible men and $92 \%$ of eligible women have successfully completed high-school education. Tertiary education enrolment and graduation rates are slightly shifted, though. In Poland, there is a visible trend among women striving to acquire knowledge and education, which is indicated by high rates of women among tertiary education graduates. There are almost twice as many female graduates than male among those completing tertiary education nowadays. Women dominate among most of the university disciplines, except IT and Engineering - perceived as typically male scientific domains (Polish Statistical Bureau, 2017).

The quality of education in Poland is perceived as high. And as more women graduate from tertiary education, that makes them more competitive on the job market - also at the European level (Dobosz, 2009). In Poland the recent testing of young students as a part of the Programme for International Student Assessment (PISA) conducted by OECD (2017) showed that the quality of the educational system in Poland on average is higher than for the OECD countries. The average Polish 
student got 504 points in reading literacy, mathematics and science. That gave a higher score than the OECD average which equalled 486 points. On average in Poland, girls outperformed boys by 4 points (average for OECD - girls scored 2 points more than boys).

Figure 1. Women among tertiary education graduates in Poland by discipline, academic year 2016/2017

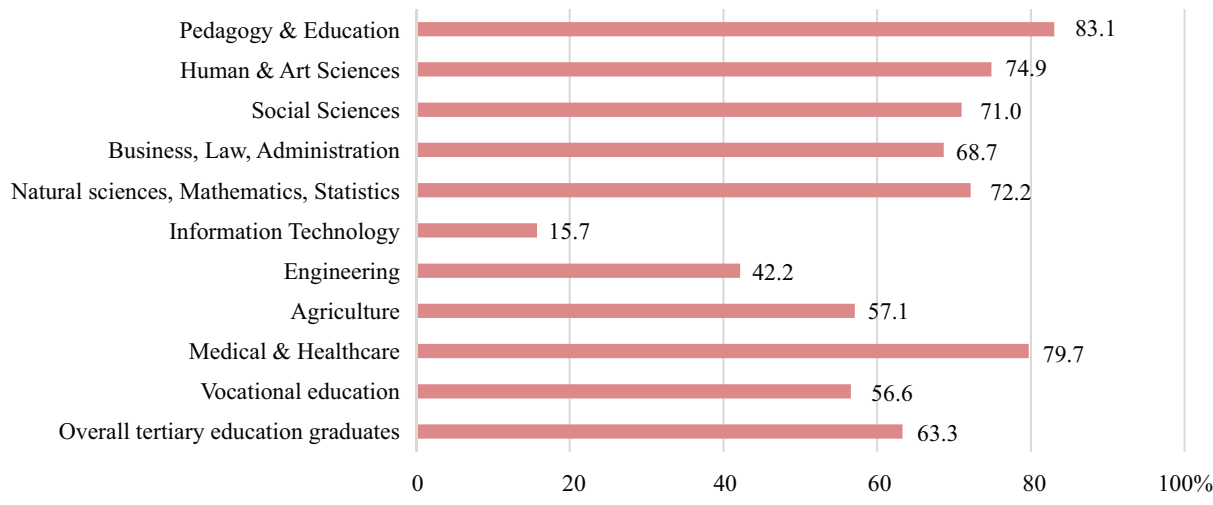

Source: Polish Statistical Bureau, 2017.

Education is one of the factors distinguishing level of unemployment in Poland. Higher levels of education significantly decrease the risk of unemployment among Polish women. What is significant, women with primary or basic vocational education are at largest risk of long-term unemployment or participation in shadow economy (Dobosz, 2009).

\section{EMPLOYMENT PARTICIPATION}

Gender differences are often discussed from the perspective of economic opportunities women and men might have or have taken advantage of. One of its elements is the labour market participation. Over the past decades ${ }^{1}$ number of women involved in a paid occupation has been increasing gradually around the world. The global labour participation rate in 1994 reached the ever-highest level of $51,5 \%$ of female population (age of 15 years and more), dropping later slightly to the level of 48,7\% in 2017. An analysis (Çagatay \& Ozler, 1995) looking for the connection between the work performed by women, their share in the labour market and long-term economic growth revealed that demographic and cultural issues determine significantly the degree of feminisation of the labour force. Female labour force participation is both an important driver and outcome of growth and development - not only in economic terms but also individual empowerment.

Women still work less hours in paid jobs than men over their whole lives, regardless of the level of education. Therefore, the return on the educational investment is much higher for men, who can fully benefit from the attainment of a university degree. Changes in that situation have been visible with female labour participation increasing substantially across the globe over the past decades. Women hold occupations adequate to their qualifications and education degree (Mulligan \& Rubinstein, 2008), and since 1980's there is a positive trend among highly educated women who are more likely to participate in the labour force. Since mid 1980's when enrolment and graduation

1 World Bank Data, International Labour Organization, ILOSTAT database. 
rates became a subject of socio-demographic and economic analyses, it has been observed there is a positive correlation between female labour force participation and the ratio of women to men in tertiary enrolment.

There are still some discussions on evidence regarding the causes of discrepancies in the labour market participation and return on investment in education, as well as what makes the shifts in these rates between women and men. Decreased gender discrimination in society might be seen as one of the reasons of the growing rates of female professional careers. Others claim (Ferrant, 2015; Fortin, 2005) that technology development has served as a time-saver in home chores performed by women, allowing them to devote more time to job outside of home. Other studies (Goldin \& Katz, 2002) provided evidence that common availability of oral contraceptives led to postponement of marriage plans and acts. There has been created a model (Galor \& Weil, 1996) considering link between fertility and growth. A lowered level of fertility rates is often an outcome of higher degree female education, which leads to reduced population growth. And looking further - has a positive effect on children's education and health. As a consequence, the quality of future human capital is enhanced. The human capital development resulted not only directly from women's educational attainment and their involvement in the labour market. It has been, though, an outcome of raising healthier and better educated offspring - an essential factor for further sustainable development (e.g.: Behrman, Foster, \& Rosenzweig, 1999).

The cause of workplace inequality comes from several sources. It may be manifested in such elements as appointment levels, amount of work, opportunity to get higher positions, access to role models and other actors that might contribute to job promotion (Haeri, 2013). It also results from having different level of human capital of men and women for instance in their choice between childbearing and work (Probert, 2005). Several studies in the gender diversity field conclude that there is a noticeable inequality between men and women in professional environments (Bedmar, Vaquero, \& Granados, 2017). In the workplace, men are more likely to be supported for jobs and advancement than women with the same conditions (Budworth \& Mann, 2010).

Figure 2. Changes in female labour force participation rate in Iran and in Poland (1990-2017)

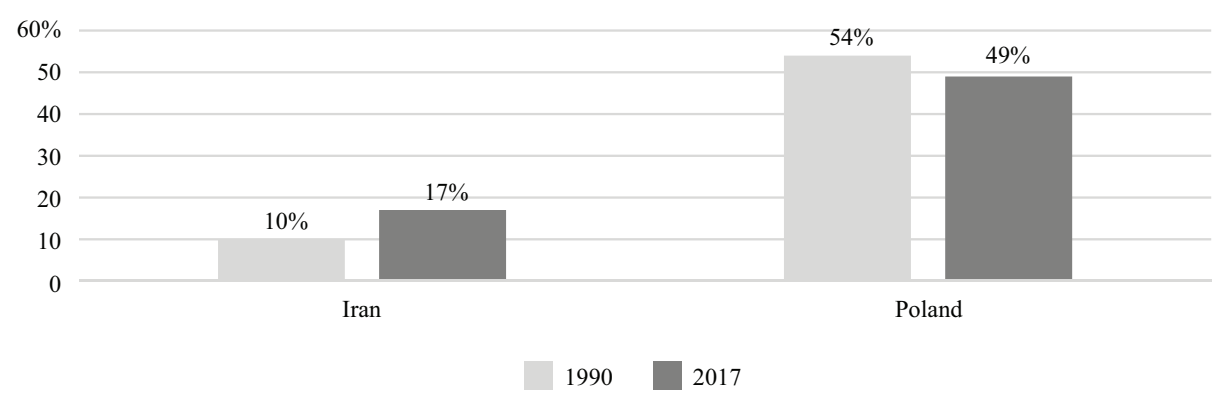

Source: World Bank, 2017.

According to World Bank data that factor in Iran showed 10\% rate of female employment in 1990 and $17 \%$ in 2017, whereas in Poland 54\% and 49\% accordingly.

The pool of well-educated women in Iran is perceived as an "untapped source of growth and productivity gains" (International Monetary Fund, 2018). The report (IMF, 2018) points out that more Iranian women actively participating in a job market could significantly increase country's GDP, productivity, tax compliance, among others. Reduction of the gender pay gap by half can 
potentially enhance GDP by up to $26 \%$ (IMF, 2018). This could be possible through alleviating some of the obstacles, women experience in their daily life in Iran - laws restricting from joining the labour force, gender wage gap as the most oppressive sign of workplace discrimination, and lack of subsidies to childcare for lower income working mothers.

In Iran religious beliefs and ethnic biases significantly affect attitudes toward women's employment. In the constitution, labour law and civil law there are some restrictions on the free admission of women to certain occupations (Shavarini, 2006). Such attitudes and observations might threaten opportunities for women to enter the labour market and eventually upgrade their quality of life. Although there is a significant number of educated women in the Iranian labour market, the employment rate of women in Iran is very low. Only one in four women holding university degree has got a paid occupation, and among women with no higher education diploma that likelihood is even smaller (Burkova, 2017). In 2017 female labour force participation (FLFP) was around 17\%, which was a lower level than in countries with similar income per capita, including within the Middle East, and North Africa region (IMF, 2018).

Iran is perceived as a country that already closed its gender gap in terms of educational attainment, even though women have no access to certain university courses, or their access is limited by genderbased parities. Currently there have been very few new jobs created in Iranian private sector, which normally offered more job posts for women than the public sector. What is more, economic reliance on oil extraction and trade makes it even harder to shift that trend in employment opportunities for women. As it has been reported (IMF, 2018), even though there were almost six hundred thousand jobs created in Iran in 2017, most of which required low-skilled workers or agriculture workers, not matching both the aspirations and the skillset obtained by university-educated Iranian women. In such a situation frustration of highly-skilled women may increase. Especially that laws being implemented in Iran refer to the value of a woman as a housekeeper and recommend women to engage in such sorts of careers as midwifery and medical or teaching disciplines - as jobs that are best suited to them.

Eventually, laboratory science, electronic engineering, pharmacy, counselling, translations were pointed as jobs that do not match physically with the characteristics of fragile and weak women (Sedghi, 2007). Apart from social constraints in the job market participation and gender discrimination, women are more often employed in humanities and social sciences fields, traditionally associated with lower wages and lower status - therefore not necessarily preferred by men. In 2006 Iranian men were three times more likely to take up engineering courses at universities $(40 \%$ among men, 13\% among women), while women more than twice more often chose subjects from such fields as arts, humanities, education, or health-related (12\% of men and $27 \%$ of women).

Entrepreneurship is seen as a great engine of the Iranian economy machine (Faghih, 2017). The average entrepreneur in Iran is male and young. Accordingly, $67 \%$ of Iranian emerging entrepreneurs are seen as risk-takers. Women and men entrepreneurs are networking in the same way in the private sphere, but men are networking more than women in the public domain. Men enter entrepreneurship to increase social status and family income, while women choose entrepreneurship to fulfil their aspirations, self-satisfaction and needs for power (Jaimie, Sullivan, Chan Halbrendt, \& Qingbin, 1998; Hisrich, Peters, \& Shepherd, 2005). Financial needs and security needs are further priorities of any Iranian entrepreneurial woman.

In the civil law, the economic responsibility of the household to provide family livelihoods is by the husband's side. That is to say, the provision of alimony (food, clothing, housing) is normally borne by the husband, as well as the provision of education and training expenses for children. Also, in spousal relationships, the head of the family is male (Burkova, 2017). According to the maternal sacrament and the upbringing of the future generation and the management of the house - a part of the Iranian constitution, it is stated that the spiritual and material value of the role of women in the 
family and their work at home should be taken into consideration. It also holds a recommendation regarding hiring women - mainly in cultural, social and administrative jobs, including "conditions and the means of realizing social justice and social excellence".

Another example of a law attempting to regulate the role of a woman in Iran is a draft of the bill titled "The Comprehensive Population and Family Excellence Plan" (Human Rights Watch, 2015). The draft bill outlines incentive packages encouraging marriage and childbearing. It also includes discriminatory provisions such as creating a hierarchy for hiring in the public and private sectors based on gender and marital status of candidates, according to which businesses should focus on hiring employees in the given order: first - married men with children, then - married men without children, followed by women with children. There is, however, no mention about the female occupations in law and political activities. The low participation rate of women in political and managerial positions demonstrates that they do not belong in the Iranian decision and policy making process. Also, the role of women in the development process has not been recognised in Iran yet (Rostami-Povey, 2016).

With systemic transformations experienced within the recent three decades in Poland, the economic situation must have affected employment structure as well. In general, the impact of these changes has been perceived as more severe with regards to women than to men. Women more often were losing their jobs, remained unemployed in a long term, and experienced impoverishment due to gender discrimination in the job market (Gąciarz, 2011). Response of women to that state of events (namely unemployment, lack of development perspectives, poor work conditions) was entrepreneurship and establishment of own companies. In 2002 Polish female entrepreneurs were the third largest group in Europe $-37 \%$ percent of all entrepreneurs (mainly on the self-proprietorship basis), after Ireland and Iceland with more established business rules and traditions (World Bank, 2004).

Since then, in Poland the labour market has been improving gradually, and in the past five years for the prime-aged individuals (age 20-49) there has been observed a sharp fall of unemployment rate to a record low level of around 6-7\% for both genders (Magda, Kiełczewska, \& Brandt, 2018). The employment rate of men remains at a high level of around $75-80 \%$ in the last decade, compared to $60-70 \%$ of women actively participating in the Polish workforce. Interestingly enough, labour force participation among women in Poland depends hugely on the number of children and their marital status (Magda et al., 2018). On average, almost $80 \%$ of mothers of one or two children (below 18 years of age) are active in the job market, whereas it true for around $70 \%$ of mothers of three. This rate falls significantly to around $50 \%$ in case of mothers of four children. What is more, being a single mother lowers the likelihood of employment by $3-5 \%$ percentage points. Being in a formal relationship without children increases the chance of employment by 10 percentage points when compared to single women without offspring, since many young women stay longer in education and as a consequence join the employment market relatively later than their married peers (Magda et al., 2018).

According to data on the employment structure in Poland (Kompa \& Witkowska, 2018), up to $30 \%$ of all job posts are in manufacturing, around $15 \%$ in retail and wholesale, up to $10 \%$ in education, and another $10 \%$ in healthcare and social services. The most feminised industries in Poland appear to be the following (Kompa \& Witkowska, 2018):

- Healthcare and social services - around $80 \%$ of women,

- Education - almost 80\% (in 2015),

- Financial intermediation - up to $70 \%$,

- $\mathrm{HoReCa}-$ up to $70 \%$.

The above are some of the least paid occupations in Polish economy. Taking into account that majority of women occupy lower and middle level in the professional ladder, that leads to even greater wage disparity between men and women. The biggest share of women (up to $70 \%$ ) is among 
the lower and medium level professionals, service workers, and clerks. Nonetheless, the biggest increase of women's participation in the recent years has been observed in the public sector (on the governmental level), as well as among senior officials and managers (by 10 percentage points) (Kompa \& Witkowska, 2018).

As compared to the EU average - Poland has one of the lowest female employment participation rates. The still strong stereotype of women responsible for child-bearing makes even more difficult for women to convince employers about their fitness and degree of flexibility required for employment. Another sign of discrimination is visible in the private sector dominated by male employees, who supposedly prefer to work with representatives of their own gender and consequently favour men in recruitment processes (Dobosz, 2009). The above is even more surprising that on average, Polish women have been perceived as more competitive in terms of their skills and educational preparedness - not only on a national level, but also on the European employment arena.

\section{THE PAY GAP}

Gender differences have been identified as induced by gaps in opportunities stemming from disparity in access to such assets as education, legal system, or financial services (Hakura, Hussain, Newial, Thakoor, \& Yang, 2016). Inequality resulting from gender differences may also emerge due to general lower representation of women in a job market, low wages (women are often thrown out of the official job market, supplying the shadow economy employment), and reduced political power with no impact on policy-making processes. Female workers' shift towards more specialised job, mainly due to the computerisation and reduction of middle-skill job for routine tasks, have either moved them up in the occupational ladder or pushed out of the labour market. And that have inevitably affected the income level of female workers.

A recent study (Ge, Isaac, \& Miller, 2018) of college degree graduates in USA showed that attending an elite school affects later-life outcomes - and that is true especially for women. Their advanced degree attainment was associated with increased earnings, and reduced likelihood of marriage. According to the researchers the declining marriage rate for those women was most likely due to them setting a higher bar for their potential life partners.

As female workplace segregation - either horizontal or vertical - continues to thrive, there might be no quick end to inequality in the area of paid work. Feminisation of particular industries or particular categories of work may therefore be perceived as a main reason for the widening gender pay gap (Kompa \& Witkowska, 2018). Simple comparisons of earnings, however, either within an industry between men and women or comparing productivity of men and women performing same or similar work, may not give measurable outcomes.

Gender discrimination may also take forms other than a pay gap between men and women. There might be discrimination in recruitment, occupational segregation, or human capital discrimination, when access to possible forms of training and development is not the same for both men and women, thus reducing human capital and its potential to grow (Kompa \& Witkowska, 2018). Among the key reasons of gender discrimination (Gąciarz, 2007), expressed also in a wage gap between men and women, there might be a perception of women as "high-risk" workers, who - as compared to "universal" men - would have to perform their maternal duties. This notion is very often strengthened by the stereotypical definition of a man as a family breadwinner. Another one is strong stereotype of typically feminine professions. That is seen as ability to work only in certain professional "feminised" branches offering low-paid occupations or observed through gender bias in a form of a "glass ceiling", or "sticky floor" to name just a few examples (Zuo \& Tang 2000).

In Islamic practice, women's work combines three areas - household, formal workforce, and shadow economy. According to the Islamic tradition strengthening family values and reproduction 
have priority over other occupations reserved for women. Recent governmental projects in Iran praise mothers and their effort put to childbearing and upbringing of children. Official communication promotes predominant female duties, highlighting "the importance of women as trainers of the Islamic community and [...] the role of motherhood and the image of pious and devout mothers. Biology became the prescribed destiny for all Iranian women" (Sedghi, 2007: 228).

Even though Iranian women hold such a high position in the society, they are primary victims of economic violence. No access to formal employment means substantial dependence on a partner or relatives, which translates to limited access to financial services, controlled access to basic health services, and exclusions from decision-making (Financial Tribune, 2017). Such an approach in Iran, forces women to search for paid employment outside the formal economic system, where no strict rules limiting women's access to work do not exist. Although the official reports talk about the formal employment of women at the level of $13-16 \%$, economists claim it is significantly underestimated (IMF, 2018). It simply does not include informal work and part-time employment, which might be even twice as high. According to Iranian statistics, women who are contributing to the home budget constitute $12 \%$ of the total number of households in Iran, there also women who in practice are sole breadwinners, for example, due to their husbands' addiction or absence, which are not reported in official statistics. Most of these families would not make their end meet and would slip under poverty line if not for that income from informal employment. These jobs are mainly in the services industry or private-own small enterprises, imposing on these women huge threat to health and safety, and offering remuneration below the standard pay and no benefits (IMF, 2018).

IMF (2018) reports the shadow economy in Iran constituted a third of the Iran's GDP in 2016. Access to employment is described by the vice president for women and family affairs, Shahindokht Molaverdi as a major demand of Iranian women reporting through the website of the department. And still, World Economic Forum's 2018 Global Gender Gap ranked Iran 142nd among 149 countries, providing that only seven other countries are doing worse on the gender equality agenda. Although Iran can boast about closing its gender gap in education, it may backslide on wage equality, labour force participation rates, professional workers market access (WEF, 2018).

In Poland, educational attainment of women has resulted in their increased participation in the job market in the recent years. And even though they earn gradually more in some occupations, earnings of men in general have been higher than those of women (Dobosz, 2009). Econometric analysis of data ${ }^{1}$ (Roszkowska \& Majchrowska, 2014) showed that although women on average earned around a dozen percent less than men, there is no reason to reject the hypothesis about equality of education return between men and women. Authors of the analysis argue that the lower average wages of women in Poland result from several issues:

- women more often than men work in lower-paid occupations, but which provide greater employment stability (differences in the employment structure);

- employment breaks related to motherhood and childbearing - after their maternal leaves, women return to their "old" salaries, while the rest of the company received increases in the meantime;

- more frequent need to combine professional life with home and family duties, which often reduces women's/ mothers' availability, possibility of foreign travels, or willingness to take managerial positions (giving higher earnings, though requiring greater time commitment, often unpredictable).

For Poland, wage discrimination of women is one of the lowest in Europe (7.2\% in 2018 compared to the average of $16.2 \%$ in the EU). The gender pay gap in Poland is often explained by differences

\footnotetext{
1 Analysis based on average monthly gross wages and salaries from reports submitted by employers employing at least 10 employees in 2004-2010 in Poland.
} 
in the amount of paid work performed by men and women and that through their lifetime women work less, with long-term breaks - mainly due to pregnancy and maternity leave. As a consequence of some lack of flexibility from in that respect, women less often request pay rise and express higher readiness to low-paid work in exchange for stability and predictability of working hours. It is also claimed (Kompa \& Witkowska, 2018) that women accept lower pay due to possible risk of losing the job or not getting the job offer. In such a situation self-valuation and self-esteem of women might be one of the factors as well, originating from the Christian-catholic tradition referring to shared values, specific cultural norms and traditional roles, dominant in Poland and accepted by majority of the Polish society Kopycińska \& Kryńska, 2016).

The conducted analyses (Kopycińska \& Kryńska, 2016) show that Polish female employees normally occupy industries that traditionally offer lower wages. Highest earnings are offered in such branches as mining, energy, water supply, finance and banking, governmental administration. In the two latter sectors, in 2014 women earned $36.7 \%$ and 16\% less than men, respectively. Disproportions are visible at particular levels of education. Nonetheless, the smallest income disparity is observed between men and women with tertiary education (and the gap here is steadily narrowing), while the largest among employees with lowest education degrees. In most of the traditionally feminised sectors, average salaries fell below the average earnings for the whole Polish economy. Consequently, wage discrimination originating from industry segregation is present in Poland. It is also visible that the gender pay gap is shrinking for most of professions except technology specialists and associate professionals.

\section{GENDER STEREOTYPES}

The word "stereotype" comes from the Greek phrase "stereos" (meaning: solid, hard) and "typos" (meaning: imprint, pattern). Stereotypes are therefore defined patterns that allow for easier information processing. Gender is one of simplifications - it is the basis of effortless, automatic categorisation. Thus, one cannot escape from activating the prototype of a woman or man. An intercultural research conducted in 28 countries (Williams \& Best, 1982) provided explanation to the existence of gender stereotypes in all of the cultures under study. The masculinity-femininity stereotypes have a complex structure (Deaux \& Lewis, 1984, which consists of information about physical and mental characteristics, as well as social and professional roles.

Together with the stereotype of a woman, there is activated a set of "feminine" associations:

- physical features containing the image of a delicate, graceful lady called the "weak sex" and "beautiful sex" (except apart from the prototype of "a sweet fragile woman" there is also a prototype of "a hoyden");

- mental traits related mainly to emotionality, warmth, sensitivity, caring, ability to sacrifice, submission;

- social roles such as caring for children and running a home;

- professional roles related to care and help (nurse, kindergarten teacher, assistant).

- Along with the stereotype of a man, there is activated a set of "male" associations:

- physical features containing the image of a well-built, "as hard as steel" man referred to as "strong sex" and "ugly sex";

- mental traits related to self-confidence, risk-taking, independence, aggressiveness, competence, or rationality (to be a winner, to win a competition, not to be like a woman/ girl) (Brannon, 2002);

- social roles such as keeping the family (being a breadwinner), taking care of finances, protecting the family from any threats;

- professional roles related to decision making in typically masculine areas: politics, military, inventiveness. 
The activation of these stereotypes is associated with diverse expectations regarding the behaviour of representatives of the two genderss. The prototypical woman cares for a fulfilling family life, beauty, sacrifices herself for children. Professional career is the second priority in a woman's life at its best. For a prototypical man, professional work is of the utmost importance. It is the family that is held in the background.

Gender stereotypes concern the features that differentiate one gender from another. For example, normally when referring to a gender stereotype, one would make no additional reference to the eye color or hair color, nonetheless there might be included information about the height. Still, the stereotypical information would suggest that men are taller than women. The symptoms of stereotypes can be overt (Thornton, Alwin, \& Camburn, 1983) - when one openly criticises the son-in-law who decided to quit his job to become a "homemaker" or a "work-at-home dad" - or covert when one supports his decision, considering it a rational choice, feeling at the same time uncomfortable for some reason. The stereotype of a woman consists of a prototype and information about the extent of its permissible transformations (Wieczorkowska-Wierzbińska, 2018).

Tests measuring school performance or ability to further education attainment show that gender differences are evident. Typically, on average, men score higher in mathematical tests while results in verbal skills testing are higher among women (Wieczorkowska-Nejtardt, 1997). What is worth emphasizing, however, the variance of scores among men is higher than among women - regardless of the discipline (Hedges \& Nowell, 1995; Machin \& Pekkarinen, 2008).

And it is true in terms of the central/mean value because on average men are taller than women. Nonetheless, it significantly distorts reality as it gives an impression that there is no intra-group diversity (variance) - suggesting that all women are shorter than all the men, causing short men and tall women feel somehow "inadequate", not fitting the standard/ stereotype. A similar distortion might be possible in terms of intellectual features. It is a fact that men prevail among people exceptionally talented mathematically. However, this does not mean that there are no women among that talented group. Yet, men also prevail among people who lack mathematical abilities, and that would untrue to claim that there are no women lacking that talent (Wieczorkowska \& Siarkiewicz, 2006). However, the variance in the group of women is much smaller than in the group of men. Achievement tests measuring school performance of student show there are gender differences. Typically, on average, men score higher in mathematical tests, while women's scores in verbal skills testing are greater (Wieczorkowska-Nejtardt, 1997; Król, 2002). Even though, regardless of subjects, the scores variance among men is higher than among women (Hedges Nowell, 1995; Machin \& Pekkarinen, 2008).

Likewise, gender stereotypes affect the attribution of success - the success of a woman is explained by her beauty, luck, high motivation, or other situational attributes. Man's success is associated with his fitness and personal abilities (Mandal, 2000; Deaux \& Emswiller, 1974). The discriminating influence of gender stereotypes was shown in classical studies (Goldberg, 1968) in which students rated significantly higher articles in various fields: law, linguistics, art history, architecture, dietetics, and teaching when they were signed by the author named "John" than when the name of the author "Jane" pointed a female author. This discriminatory gender stereotype could be distributed in different ways in different countries.

In Iran, like in other cultural circles, gender stereotypes and gender-specific socialisation practices impact individuals' viewpoints, thinking, judgments, self-concepts, and social behaviour (Poya, 1999). Such stereotypes represent men as active and independent, while women are portrayed as subordinate to and dependent on men. This gender inequality is reflected in less decision-making opportunities and agency for women compared with men (Sedghi, 2007). Women are socialised to care for others but are often considered too emotional and less capable to handle difficult and challenging situations. Men, by contrast, are portrayed to possess wisdom and sound judgment. 
To better understand the position of the women in Iran is worth to mention one of the Muslim feminist frameworks, which highlight the supposedly superior role of women in Iranian society (Shavarini, 2005). According to that framework it is capitalist and communist systems that exploit women as cheap labour. Western modernity has brought about sexual exploitation, alienation, and the depersonalisation of women, unlike the Muslim agenda. In the view of that framework, Islam is a socio-political and socio-economic system that does not take advantage of women. On the contrary - according to that framework - Islam honours, respects, and empowers women. For example, women are encouraged to work and are not obligated to share their income with either their family or their community. Women are in fact given the right to charge their husbands an entitlement (nafaqa) for nursing their own babies. It is the Western world that marks the veil as a symbol of women's bondage in a religiously legitimised patriarchal world (Bauer, 1985; Betteridge, 1983; Ramazani, 2001) and represents the seclusion, gender segregation, modesty, subordination. For Muslim feminists the veil liberates and protects women from the sexual harassment that permeates Western societies (Afshar, 1995). The major drawback of this framework is that it focuses on ideological issues rather than material and practical concerns of women's status in Iranian society, as that looks different in the real day-to-day life (Poya, 1999).

In Islamic tradition the attitude toward religion and spiritual issues among women is believed to be higher than among men. Therefore, men tend to be seen and more materialistic than women. There are many differences between the innate and the innocent men and women accordingly, it is natural that they should not be socially expected to behave in the same way that is why their gender differences in the preparation of duties and responsibilities from the beginning of childhood to young ages should be taken into consideration (Bauer, 1985). According to that belief - competitive works are recommended for boys, and due to the emotional and physical power of girls and women, they should learn home-based principles. Putting side by side the Iranian culture between two complex and interlocking traditions - that one has its roots in ancient Persia, the other in Islam - could be helpful to understanding Iranian culture. Cultural values dominate the structure, organisation and behaviours as they are deeply rooted in religious and philosophical beliefs.

International comparisons conducted at the European level indicate that even though Poles are not more conservative in terms of gender roles than other Eastern European countries, gender stereotypes in Poland seem to be still alive (Szelewa, 2011). In Poland, the stereotype of the "Polish Mother" has been in force for years. It consisted of such features as diligence, readiness for sacrifice, conviction about being irreplaceable in performing household duties, a certain level of multifunctionality in realizing these tasks and taking care of the family at the same time. The cultural characteristics of the "Polish Mother" syndrome - heroic and capable of bearing any burden, grew directly out of the Polish history. When the absent husbands died in the struggles for their homeland or they were imprisoned, women were engaged in running family farms or firms, they took care of ensuring the continuity of the Polish culture, language, and customs. The patriotic upbringing of children was a guarantee to maintain the national identity.

In the poem "To the Polish Mother", in which Adam Mickiewicz appeals that the mother's ultimate duty is to prepare her son for the role of a warrior for the Homeland. And the analogy to the fate of the Mary Mother of God is evident. The Marian Cult, which was typical to Catholicism in Poland, also had a positive influence on the position of Polish women. In the period of real socialism, related to the shortage economy, one can observe a "household matriarchy". For it was women who then had a sense of agency, as without their sacrifice (e.g. through gaining food in a kilometre-long-queues, or culinary ingenuity in a situation of total limitation of produce), the family would not have a chance to survive. It was women who made (and continue to make) most of the household purchasing decisions, but they pay for this "power" with exhaustion. Women manage their family households, giving men the power to decide on important issues which take place in the public sphere in return. 
Another element of gender relations in the era of socialism was the "gentry-knightly contract" (Walczewska, 1992), according to which a woman encourages a man to fight for his homeland, she sacrifices herself taking over his duties in the due time, and later also dresses his wounds incurred during the fight. But in the times of peace a knight is a gentleman who adores his lady, and is a gallant social activist who handles carnation flowers on the occasion of the Women's Day. The functioning of that contract created the illusion that women in Poland have always been surrounded with extraordinary reverence, respect, and admiration, so all movements fighting for equality have been unnecessary. The socialist gender equality - expressed in the common slogan "women on tractors" - in the long run has increased the number of women in typically men's professions in which they performed very well. Yet, the times have changed and among younger generations, brought up in a democratic system, more egalitarian attitudes are observable - both at home and in the professional environment (Baranowska, 2007). Modern women in Poland with their thrive to knowledge attainment associated with entrepreneurial approach are perceived as innovators "seeking a remedy for the social discrimination inflicted on them" (Gąciarz, 2009). This approach stands in opposition to the old stereotypical notion of women as passive, obedient and dependable, compared to men who are natural leaders, decisive, competitive, and successful.

It is still comfortable to use these stereotypes in the public sphere in order to control the environment, and setting traditional roles to men as managers and to women as those who execute orders. However, contemporary Polish women empowered by good quality education, commitment, ability for adaptation and their readiness to innovate, are creating potential for business development. This constitutes a promising foundation for further changes in social status of women not only in Poland but also anywhere in globalised economy where they would like to work and live.

\section{Gender stereotypes in the world values survey - Poland and Iran}

To illustrate the possible gender-related stereotypes in Poland and Iran, we have conducted an analysis of responses to selected statements from the World Values Survey, Wave 5 (Inglehart et al., 2007). We looked at the statements that refer to level of gender discrimination and other possible cross-cultural disparities in that respect.

\section{Participants}

Our analyses were conducted with regards to responses provided by 3667 people -2667 individuals from Iran and 1000 from Poland. Gender and age structure of the two cohorts reflected population composition of the two countries:

- in Iran: 49.9\% women $/ 50.1 \%$ men (ages 16-90; $\mathrm{M}=32.69 ; \mathrm{SD}=12,769 ;$ median $=30$ years);

- in Poland 52.4\% women $/ 47.6 \%$ men (ages 18-92; $\mathrm{M}=45.21 ; \mathrm{SD}=17.845 ;$ median $=44$ years).

\section{Materials and Procedure}

In the analyses we focused on the following statements from the World Values Surveys (Wave 5), which all combined allowed further to measure the DV: "level of discrimination":

- When jobs are at scarce men have more right to a job than women

- Men make better business executives than women

- Men make better political leaders than women

- University education is more important for boys

In case of the first statement ("When jobs are at scarce men have more right to a job than women") responses were given with a three-point Likert-like scale $(1=$ disagree, 2 = neither agree nor disagree, 3 = agree). In case of the three remaining statements - responses were recorded with a four-point Likert-like scale $(1=$ strongly disagree, $2=$ disagree, $3=$ agree, $4=$ strongly agree $)$. 
The items formed one factor in a factor analysis explaining $57.6 \%$ of total variance. Cronbach's alpha for the scale equaled $\alpha=.749$. Factor scores were computed and used in the further analyses. The higher the score, the higher level of discrimination observed.

\section{RESULTS}

We used a regression analysis in order to determine which of the individual variables are best at predicting respondents' level of gender discrimination. We regressed level of discrimination (high values equal higher level of gender discrimination) on gender ( 1 = male, 2 = female $)$ and country (364 $=$ Iran, $616=$ Poland) and interaction of the two variables, as well as educational attainment ( $1=$ below primary, $5=$ tertiary $)$, job status $(1=$ employed, $2=$ not employed $)$, and marital status $(1=$ in a relationship, $2=$ not in a relationship). The results can be seen in Table 2 and in Figure 3.

Table 2. Regression analysis of the level of gender discrimination.

\begin{tabular}{|c|c|c|c|c|}
\hline & $\mathrm{B}$ & Beta & $t$ & $p$ \\
\hline Constant & 4.458 & & 59.129 & .000 \\
\hline gender & -.299 & -.231 & -13.880 & .000 \\
\hline country & -.003 & -.463 & -29.479 & .000 \\
\hline interaction gender* country & .038 & .058 & 3.906 & .000 \\
\hline age & .002 & .039 & 2.044 & .041 \\
\hline education & -.037 & -.164 & -10.537 & .000 \\
\hline employment status & .075 & .054 & 2.804 & .005 \\
\hline relationship status & -.020 & -.015 & -.960 & .337 \\
\hline
\end{tabular}

For the analysed sample - gender, country and education level proved to be strongest predictors and showed negative relationship to the level of gender discrimination. Women $(\beta=-0.231$, $p<.000)$, respondents in Poland $(\beta=-0.463, p<.000)$, and well-educated respondents $(\beta=-0.164$, $p<.000)$ in general tend to display lower lever of gender discrimination. Age $(\beta=0.039, p<.041)$ and employment status $(\beta=0.054, p<.005)$ are related with level of gender discrimination. In their case higher age and lack of employment of respondents predicted higher level of gender discrimination. At the same time relationship status of respondents proved to be insignificant in predicting level of gender discrimination they presented $(p<.337)$.

Based on the conducted regression analysis, women display lower level of gender discrimination than men. Together, respondents in Poland present more egalitarian attitude than those in Iran. At the same time, differences between men and women in terms of the presented levels of gender discrimination are larger in Iran than in Poland (for illustration, please see Figure 3).

The primacy of men and their right to rule the job market is more visible in Iran, both among men and women. In Poland, respondents were more reluctant to prefer men in the race for scarce jobs, nonetheless there were still (almost a third of all responses) many accepting male dominance in that respect (Figure 5). 
Figure 3. Interaction of gender and country on the level of gender discrimination

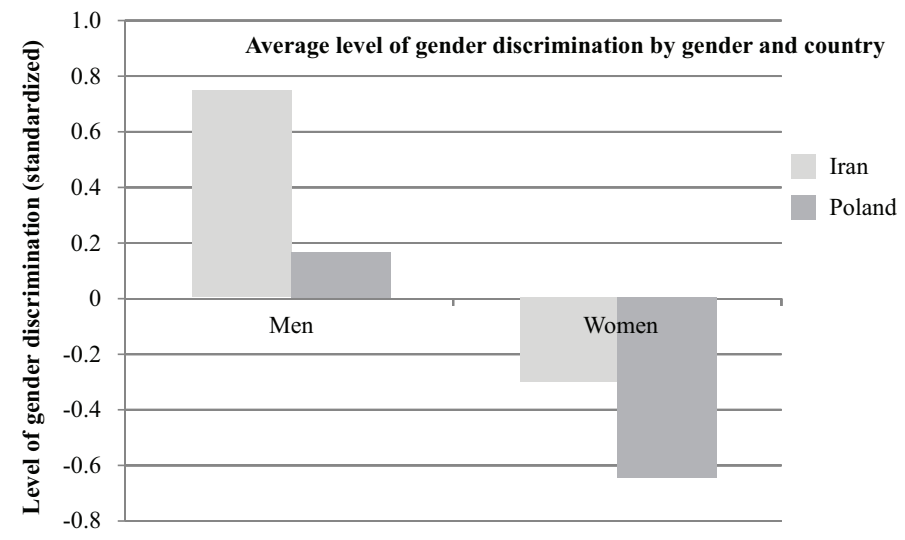

Figure 4. Responses to a statement "When jobs are at scarce men have more right to a job than women"

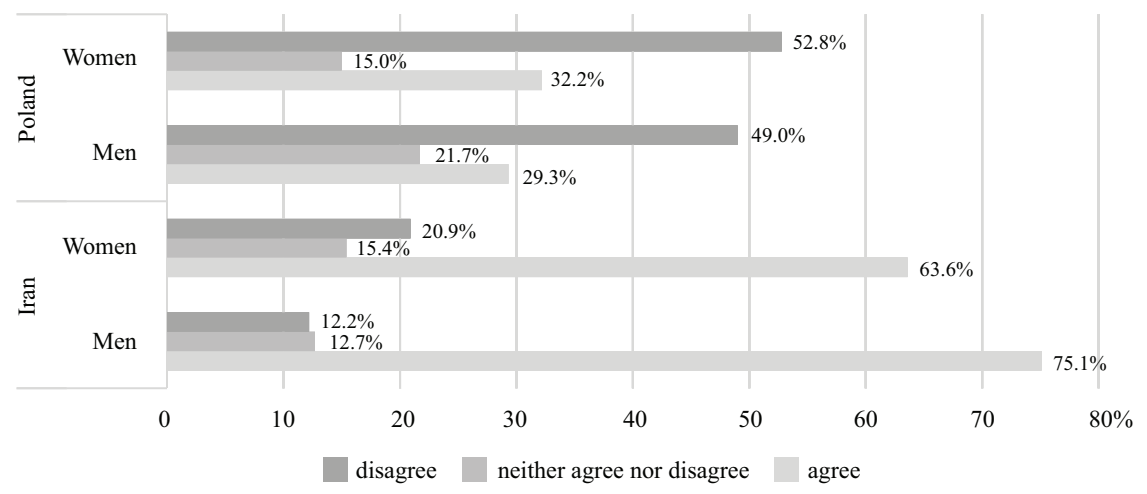

Figure 5. Responses to a statement "Men make better business executives than women"

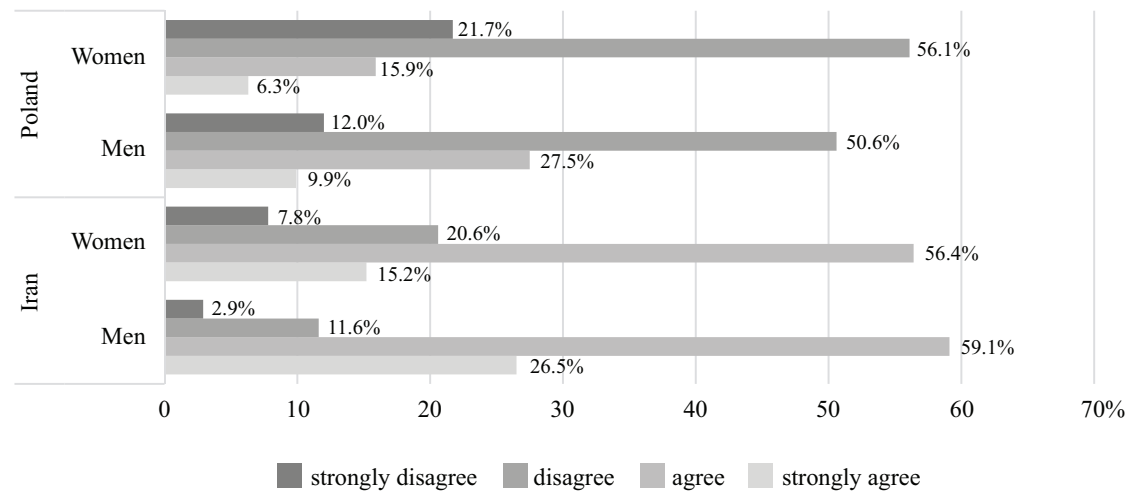


Men in Iran are perceived as more suitable for the role of business executives - fitting the stereotype of a male manager and female subordinate fulfilling orders. In Poland sympathy for the gender segregation is visible more among men, among whom one in three respondents agreed representatives of their own gender would be better at top positions.

Figure 6. Responses to a statement "Men make better political leaders than women"

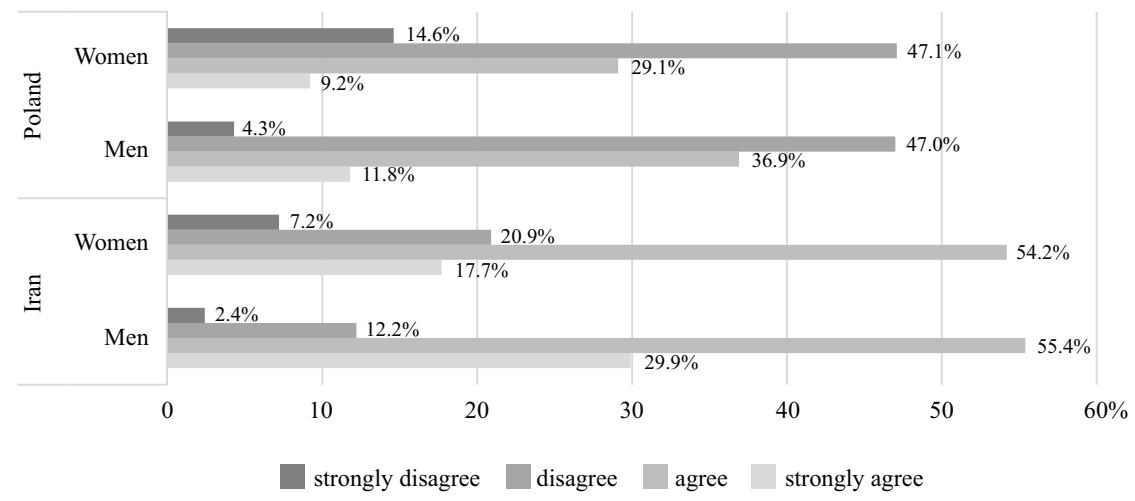

Again, Iranian respondents were more favourable toward the prospect of male political leaders, which somehow is visible currently in the Iranian society, where barely $3 \%$ of parliamentary seats are held by women, and only one in eight managers is female. Responses among Polish respondents were more or less divided by half. Showing that there is growing acceptance for women in political decision-making roles.

Figure 7. Responses to a statement "University education is more important for boys"

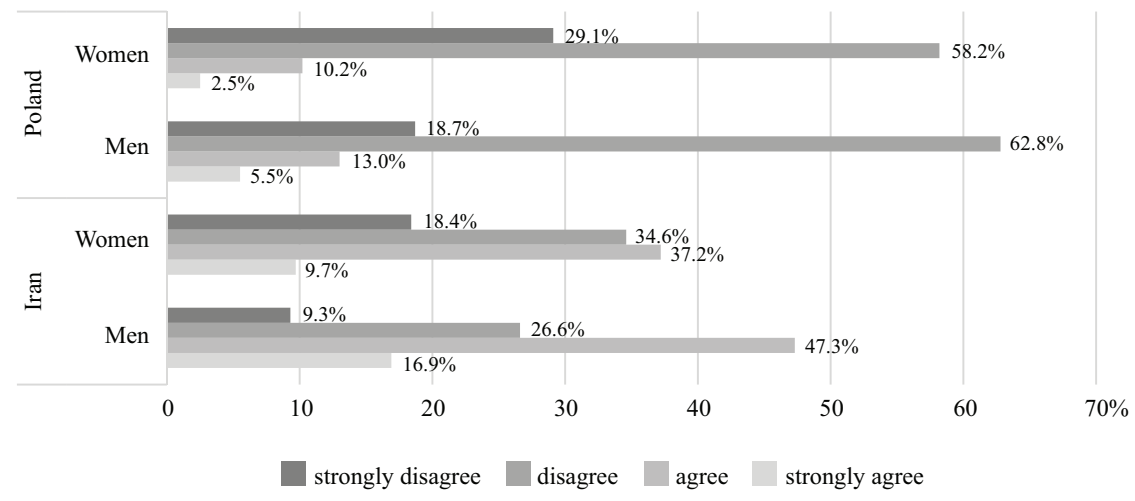

Perceiving university education as more important for male students shows a higher level of discrimination among respondents who might regard women's education as a waste of resources since their role would be to care for home of children. In Poland there is visible disagreement toward such inequality. Over $80 \%$ of both female and male respondents expressed their egalitarian attitude toward roles of men and women in the society. 


\section{SUMMARY}

As historically proved, gender differences in the work and family dimensions have been present invariably for the whole past centuries. The gender lens reveals social constraints, employment segregation, and pay gap imposed on women, and reinforced by men and women through their daily lives. These find simple rationalisations for discriminatory practices in the public sphere, workplace and at the privacy of their homes. Inequalities cut across all dimensions of sustainable development - social, economic and environmental and pose obstacles to all goals. Inequalities exist both within and between countries (Imbierowicz, 2012). Women often lack access to decent work opportunities and face occupational segregation and gender wage gaps. They are underrepresented in political, economic decision-making processes and academic career.

Poland and Iran differ in terms of their gender gaps - and in terms of the outcomes stemming from that disparity in many areas. In both countries the majority of university students are female. However, the majority of the workforce in Iran is formed by males, which is not the case in Poland where gender gap in the workforce is relatively low. Iran managed to close the education gap, while in Poland education gap is in favour of women. Still, there might be different motivations behind the university education enrolment among Polish and Iranian women on an individual level. Nonetheless, through admission to and graduation from university women from both countries seek to be more employable, and to improve their earning potential and social status (Rezai-Rashti \& Moghadam, 2011). In many cases these advantages of higher education attainment would be associated with delayed marriage and a lower rate of reproduction on one hand, and with better employment and enhanced social and gender awareness on the other.

Women's life choices are believed to be dictated by their personal perception of the traditional family model (Fortin, 2005). Attitudes concerning females' education, marriage, maternity or employment are developing over years, and are influenced by their families. Among these specific features are education and religiosity of parents, social sentiments or barriers created by public institutions. And only later they are offset with person's motivations, priorities and personal ambitions.

Through the literature review authors aimed at presenting the situation of women in Iran and Poland in terms of their educational and employment opportunities. In both cases the origins and consequences of observable gender disparities might be different and strongly depend on cultural issues governing these societies. Social constraints imposed by religion play a crucial role in how strong the gender-related stereotypes in these societies are. Stereotypes significantly hinder women's opportunities in Poland and Iran, provide rationale for discriminatory behaviours and attitudes, and allow for maintaining gender gaps in most areas of public and private spheres.

The analysis of the reviewed literature and the World Value Survey responses allow to establish that women's professional prospects in Poland and Iran might be affected by both cultural factors and to some extent - level of gender discrimination. It is, however crucial to understand that in ethical and social terms lower level of gender disparity stimulates and strengthens basic human rights. In economic terms, closing of the gender gap through enhanced access to education, advances the quantity and quality of human capital fuelled by the potential of women (Siegel, 2005). Such a situation, as a consequence, increases social and economic development by improving productivity and bringing in progressive benefits (Financial Tribune, 2017).

\section{Literature}

Afshar, H. (1995). Women and the Politics of Fundamentalism in Iran, in H. Afshar (ed.), Women and Politics in the Third World. London: Routledge, 121-141.

Algan, Y., \& Cahuc, P. (2004). Job Protection and Family Policies: The Macho Hypothesis. Discussion Paper IZA DP No. 1192, Eurequa-Université de Paris I. Retrieved from: https://hal-sciencespo.archives-ouvertes. fr/hal-01065504 
Baranowska, A. (2007). Views and preferences regarding economic model of the family, in: Kotowska, I. E., et. al. (eds.) Aktywność zawodowa i edukacyjna a obowiazki rodzinne w Polsce w świetle badań empirycznych [Professional and educational activity and family obligations in Poland in the light of empirical research]. Instytut Badań nad Gospodarką Rynkową, Warsaw, 404-422.

Barro, R., \& Lee, J. (1994). Sources of Economic Growth. Carnegie-Rochester Conference Series on Public Policy, 40, 1-46.

Baturo, A., \& Gray, J. (2018). When do family ties matter? the duration of female suffrage and Women's path to high political office. Political Research Quarterly, 71(3), 695-709.

Bauer, J. (1985). Sexuality and the Moral „Construction” of Women in an Islamic Society. Anthropological Quarterly, 58(3), 120-129.

Behrman, J., Foster, A., Rosenzweig, M., \& Vashishtha, P. (1999). Women's Schooling, Home Teaching, and Economic Growth. Journal of Political Economy, 107(4), 682-714.

Betteridge, A. (1983). To Veil or not to veil: A Matter of Protest or policy, in Nashat, G. (ed.) Women and Revolution in Iran. Boulder, CO: Westwind.

Bielby, D., \& Bielby, W. (1984). Work Commitment, Sex-Role Attitudes, and Women's Employment. American Sociological Review, 49(2), 234-247.

Bielby, W., \& Bielby, D. (1989). Family Ties: Balancing Commitments to Work and Family in Dual Earner Households. American Sociological Review, 54(5), 776-789.

Blackden, C. M., \& Bhanu, C. (1999). Gender, Growth, and Poverty Reduction: Special Program of Assistance for Africa. Status Report on Poverty in Sub-Saharan Africa. Working Papers, World Bank - Technical Papers.

Brannon, E. M. (2002). The development of ordinal numerical knowledge in infancy. Cognition, 83(3), 223-240.

Budworth, M., \& Mann, S. (2010). Becoming a leader: the challenge of modesty for women. Journal of Management Development, 29(2), 177-186.

Burkova, R. (2017). It's a men's club. Discrimination Against Women in Iran's Job Market. Human Rights Watch. Retrieved from: https://www.hrw.org/report/2017/05/25/its-mens-club/discrimination-against-womenirans-job-market

Cagatay, N., \& Ozler, S. (1995). Feminisation of the labour force: The effects of long-term development and structural adjustment. World Development, 23(11), 1883-1894.

Chiao, J. Y., Bowman, N. E., \& Gill, H. (2008). The political gender gap: Gender bias in facial inferences that predict voting behavior. PLOS ONE, 3(10), e3666.

Davis, N. J., \& Robinson, R.V. (1991). Men's and Women's Consciousness of Gender Inequality - Austria, West Germany, Great Britain, and the United States. Sociologic Review, 56(1), 72-84.

Deaux, K., \& Emswiller, T. (1974). Explanations of successful performance on sex-linked tasks: What is skill for the male is luck for the female. Journal of Personality and Social Psychology, 29, 80-85.

Deaux, K., \& Lewis, L. L. (1984). Structure of gender stereotypes: Interrelationships among components and gender label. Journal of Personality and Social Psychology, 46(5), 991-1004.

Dobosz, K. (2009). Situation of Women on Labour Market in Poland. Economics \& Competition Policy. Labour Market in EU and in the World, Katedra Mikroekonomii Uniwersytetu Szczecińskiego, 5(14), 154-118.

Ferrant, G. (2015). How Do Gender Inequalities Hinder Development? Cross-Country Evidence. Annals of Economics and Statistics. 117-118.

Financial Tribune. (2017, July 3). Women overshadowed in Iranian Labour Market. Retrieved from: https:// financialtribune.com/articles/domestic-economy/67601/women-overshadowed-in-iranian-labor-market

Fortin, N. (2005). Gender role attitudes and the labour-market outcomes of women across OECD countries. Oxford Review of Economic Policy, 2.1(3), 416-438.

Gąciarz, B. (2011). Women in the workplace in Poland. International Journal of Sociology, 41(3), 68-94.

Galor, O. \& Weil, D.N, (1996). The gender gap, fertility, and growth. American Economic Review, American Economic Association, 86(3), 374-387.

Ge, S., Isaac, E., \& Miller, A. (2018, November). Elite Schools and Opting-In: Effects of College Selectivity on Career and Family Outcomes, NBER Working Paper No. 25315.

Goldberg, P. A. (1968). Are women prejudiced against women? Transactions, 5, 28-30.

Goldin, C., \& Katz, L.F. (2002). The power of the pill: Oral contraceptives and women's career and marriage decisions. Journal of Political Economy, 110(4), 730-770.

Haeri, S. (2013). No end in sight: politics, paradox and gender policies in Iran. Boston University Law Review, 93(3), 1049-1062.

Hakura, D., Hussain, M., Newial, M., Thakoor, V., \& Yang, F. (2016). Inequality, Gender Gaps and Economic Growth: Comparative Evidence for Sub-Saharan Africa. IMF working paper, WP/16/11.

Hedges, L. V., \& Nowell, A. (1995). Sex differences in mental test scores, variability, and numbers of highscoring individuals. Science, 269(5220), 41-45. 
Hellerstein, J. K., Neumark D., \& Troske, K.R. (2002). Market forces and sex discrimination. The Journal of Human Resources, 37(2), 353-80.

Hisrich, R. D., Peters, M. P., \& Shepherd, D. A. (2005). Entrepreneurship (6th ed.). New York: McGraw-Hill/Irwin.

Human Rights Watch (2015). World Report 2015: Iran, Events of 2014. Retreived from: https://www.hrw.org/ world-report/2015/country-chapters/iran

Imbierowicz, A. (2012) Matka Polka w defensywie? Przemiany mitu i jego wpływ na sytuację kobiet w polskim społeczeństwie. Ogrody Nauk i Sztuk, 2, 430-442. Retrieved from: http://bazhum.muzhp.pl/media// files/Ogrody_Nauk_i_Sztuk/Ogrody_Nauk_i_Sztuk-r2012 t2/Ogrody_Nauk_i_Sztuk-r2012-t2-s430-442/Ogrody_Nauk_i_Sztuk-r2012-t2-s430-442.pdf

Inglehart, R., Haerpfer, C., Moreno, A. et al. (eds.). (2014). World Values Survey: Round Five - Country-Pooled Datafile, Version: www.worldvaluessurvey.org/WVSDocumentationWV5.jsp

International Monetary Fund. (2018). Islamic Republic of Iran: Selected Issues. IMF Country Report No. 18/94.

Jaimie, S., Sullivan, P., Chan Halbrendt, C., \& Qingbin, W. (1998). An Exploratory Study of How Rural Female Entrepreneurs View Success. University of Vermont Publication.

Jaumotte, F. (2004). Labour Force Participation of Women: Empirical Evidence on the Role of Policy and Other Determinants in OECD Countries. OECD Economic Studies, 2003(2), 51-108.

Kazemipour, S. (1999). A pattern in determining the socio-economic status of people and measuring social mobility based on a case study in Tehran. Journal of Social Sciences Letter, 14(14), 139-172.

Kiser, A. I. T. (2015). Workplace and leadership perceptions between men and women. Gender in Management, 30(8), 598-612.

Kompa, K., \& Witkowska, D. (2018). Factors affecting men's and women's earnings in Poland. Economic Research-Ekonomska Istraživanja, 31(1), 252-269.

Kopycińska, D., \& Kryńska, E. (2016). Wage Inequalities between Men and Women in Poland - a Justified Differentiation or Accepted Wage Discrimination of Women? Economics and Sociology, 9(4), 222-242.

Król, D. (2002). Wybrane uwarunkowania, korelaty i konsekwencje stereotypów płci. Nieopublikowana rozprawa doktorska. Faculty of Psychology, University of Warsaw. Supervisor: prof. dr hab. Grażyna Wieczorkowska.

Lagerlöf, N. (2003). Gender Equality and Long-Run Growth. Journal of Economic Growth, 8(4), 403-426.

Llorent-Bedmar, V., Llorent-Vaquero, M., \& Navarro-Granados, M. (2017). Towards gender equality in Moroccan universities: Female university teachers from a gender perspective. Women's Studies International Forum, 64, 34-40.

Machin, S., \& Pekkarinen, T. (2008). Global sex differences in test score variability. Science, 322(5906), 1331-1332.

Magda, I., Kiełczewska, A., \& Brandt, N. (2018, March). The "Family 500+" child allowance and female labour supply in Poland. Institute for Structural Research. IBS working paper 01/2018.

Mandal, E. (2000). Podmiotowe i interpersonalne konsekwencje stereotypów związanych z płcią. Prace Naukowe Uniwersytetu Ślaskiego w Katowicach, 0208-6336(1856), 237-268.

Moghadam, F. (2009). Undercounting Women's Work in Iran. Iranian Studies, 42(1), 81-95.

Mulligan, C., \& Rubinstein, Y. (2008). Selection, Investment, and Women's Relative Wages over Time. The Quarterly Journal of Economics, 123(3), 1061-1110.

Nagore Garcia, A. 2017. Gender Differences in Unemployment Dynamics and Initial Wages over the Business Cycle. LISER, 2017, Working Papers.

OECD (2017). Better Life Index: Poland. Retrieved from: http://www.oecdbetterlifeindex.org/countries/poland/

Polish Statistical Bureau (2017). Szkolnictwo wyższe w roku akademickim 2016/2017. Retrieved from: http:// stat.gov.pl/obszary-tematyczne/edukacja/edukacja/szkolnictwo-wyzsze-w-roku-akademickim-20172018-danewstepne, $8,5 . \mathrm{html}$

Polish Statistical Bureau. (2014). Szkoły wyższe i ich finanse w 2014 roku - aneks studenci i kierunki studiów. Retrieved from: http://stat.gov.pl/obszary-tematyczne/edukacja/

Polish Statistical Bureau. (2017a). Szkoty wyższe i ich finanse w 2017 roku - aneks studenci i kierunki studiów. Retrieved from: http://stat.gov.pl/obszary-tematyczne/edukacja/

Poya, M. (1999). Women, work and Islamism: ideology and resistance in Iran. New York and London: Zed Books.

Probert, B. (2005). 'I just couldn't fit it in': Gender and unequal outcomes in academic careers. Gender, Work \& Organisation, 12(1), 50-72.

Ramazani, R. (ed.). (2001). Iran at the Crossroads. New York: Palgrave Macmillan.

Reskin, B. R., McBrier, D. B. \& Kmec, J. A. (1999). The Determinants and Consequences of Workplace Sex and Race Composition. Annual Review of Sociology, 25(1), 335-361.

Rezai-Rashti, G., \& Moghadam, V. (2011). Women and higher education in Iran: What are the implications for employment and the "marriage market"? International Review of Education, 57(3/4), 419-441. 
Rostami-Povey, E. (2016). Women's Education and Employment in Iran, in S. Takhar (ed.) Gender and Race Matter: Global Perspectives on Being a Woman. Advances in Gender Research, 21, 63-83.

Roszkowska, S., \& Majchrowska, A. (2014). Premia z wykształcenia i doświadczenia zawodowego według płci w Polsce. Instytut Ekonomiczny Warszawa, Materiaty i Studia, 302.

Rueden, C. von, Alami, S., Kaplan, H., \& Gurven, M. (2018). Sex differences in political leadership in an egalitarian society. Evolution and Human Behavior, 39(4), 402-411.

Salehi-Isfahani, D. (2005). Human resources in Iran: potentials and challenges. Iranian Studies, 38(1), $117-147$.

Sedghi, H. (2007). Women and Politics in Iran: Veiling, Unveiling, and Reveiling. Cambridge University Press: Cambridge. Retrieved from: https://www.sssup.it/UploadDocs/14639_7_R_Women_and_Politics_in_Iran_ Veiling_Unveiling_and_Reveiling_Hamideh_Sedghi.pdf

Shavarini, M. K. (2006). The Paradox of Higher Education in the Lives of Iranian Women. International Journal of Middle East Studies, 38(2), 189-211.

Shavarini, M. K. (2005). The feminisation of Iranian higher education. Review of Education, 51, 329-347.

Siegel, E. (2005). The Gender gap and Growth: Measures, Models and the Unexplained. University of Copenhagen, 1-19.

Siemieńska, R. (1996). Gendered perceptions: women in the labour market in Poland. Women's History Review, 5(4), 553-566.

Szelewa, D. (2011). The policy on gender equality in Poland. Policy Department C: Citizens' Rights and Constitutional Affairs. European Parliament.

Tait, R. (2012, August 20). Anger as Iran bans women from universities. The Telegraph. Retrieved from: https:// www.telegraph.co.uk/news/worldnews/middleeast/iran/9487761/Anger-as-Iran-bans-women-from-universities. html

Teheran Times (2018, June 30). Fierce competition: Iran's university entrance exam held. Retrieved from: https:// www.tehrantimes.com/news/424879/Fierce-competition-Iran-s-university-entrance-exam-held

Thornton, A., Alwin, D.F., \& Camburn, D. (1983). Causes and consequences of sex-role attitudes and attitude change. American Sociological Review, 48(2), 211-227.

UNESCO (2018). Education: Percentage of female graduates by level of tertiary education. Retrieved from: http://data.uis.unesco.org

United Nations (2017). Population age structure in 2017 report. Retrieved from http://data.un.org

van der Lippe, T., \& van Dijk, L. (2002). Comparative Research on Women's Employment. Annual Review of Sociology, 28(1), 221-241.

Vella, F. (1994). Gender Roles and Human Capital Investment: The Relationship between Traditional Attitudes and Female Labour Market Performance. Economica, 61(242), 191-211.

Verick, S. (2014). Female labour force participation in developing countries. IZA World of Labour 2014: 87. Retrieved from: https://wol.iza.org/articles/female-labor-force-participation-in-developing-countries/long

Walczewska S. (ed.). (1992). Głos mają kobiety. Teksty feministyczne. Fundacja Kobieca eFKa, Kraków.

Wieczorkowska-Nejtardt, G. (1997). Czy kobiety czują się gorsze od mężczyzn w matematyce? in: Siemieńska, R. (ed.) Portrety kobiet $i$ mężczyzn w środkach masowego przekazu oraz podręcznikach szkolnych. Warszawa: Scholar.

Wieczorkowska-Wierzbińska, G. (2018). Zarządzanie ludźmi - pytania i odpowiedzi. Warszawa: Wydawnictwa Naukowe WZUW.

Williams, J. E., \& Best, D. L. (1982). Measuring sex stereotypes: a thirty-nation study. Newbury Park, CA: Sage Publications.

Winn, M. K. (2016). Women in Higher Education in Iran: How the Islamic Revolution Contributed to an Increase in Female Enrolment. Global Tides, 10(10).

World Bank. (2004). Gender and economic opportunities in Poland: has transition left women behind? Report no. 29205. Poverty Reduction and Economic Management Unit, Europe and Central Asia Region, Washington, DC: World Bank.

World Economic Forum (2018). Global Gender Gap Report 2018. Retrieved from: http://www3.weforum.org/ docs/WEF_GGGR_2018.pdf

Wysokie Obcasy. (2018, September). Polka Stulecia. Plebiscyt "Wysokich Obcasów” na sto lat polskiej niepodległości. Retrieved from: http://www.wysokieobcasy.pl/wysokie-obcasy/7,166192,23867864,plebisc yt-czytelniczek-wybierz-kobiete-stulecia-uzasadnij.html

Zuo, J., \& Tang, S. (2000). Breadwinner Status and Gender Ideologies of Men and Women regarding Family Roles. Sociological Perspectives, 43(1), 29-43. 


\title{
Two Approaches to Analyzing Data of Project Teams
}

\author{
Krzysztof Nowak* \& Kamila Pietrzak**
}

\begin{abstract}
Summary
In this chapter, we compare and discuss several statistical approaches to analyzing data obtained from team members. As an illustrative example, we analyze data obtained from 636 team members across 87 teams from 8 companies located in Poland using ordinary least squares multiple regression analysis, multiple regression with clustered standard errors, and mixed modeling. In the example, we analyze the relationship between team size and team gender composition concerning team climate. While a model building approach to hypothesis testing yields most similar results for multiple regression an a clustered standard error approach, a multilevel model yields results more similar to OLS regression when testing the significance of individual predictors, suggesting a clustered standard error correction is more prone to a type II error rate when testing model coefficients than an equivalent multilevel model. Finally, the implications of these observations to team data analyses are discussed.
\end{abstract}

Keywords: Leadership, Multilevel analysis, Project teams, Team climate

JEL: M12, C12, C18

\section{INTRODUCTION}

With the increasing prevalence of project-based management, the need to understand team cooperation has never been greater. Team cooperation provides a valuable competitive advantage in the modern market place. It is hard to emulate in the short term as it depends on human and organizational factors. However, choosing and implementing a method for analyzing data collected from teams has to be carefully considered, as it usually requires going beyond the most common statistical methods taught in most introductory statistical courses, as it requires considering the team context of the team member responses.

If we only consider aggregate, team-level variables (an example would be size, average productivity or number of conflicts in a team) and analyze the teams as distinct units, team data can be analyzed using any of the standard statistical methods (analysis of variance or multiple regression, for example) as long as the standard assumptions are met. If we consider team-member variables (ex. gender or age of team members or how each member views the team), we run into a problem, since team members are usually more similar to members of a team they belong to than to members of another team. This similarity violates the principle of independence of observations assumed in ordinary least squares (OLS) regression and is known as nesting. This results in the underestimation of standard errors of regression coefficients and smaller $\mathrm{p}$ values, leading to increased rate of type I error (finding an effect even when it is not present) (Greene, 2003). The problem is exuberated when:

- the teams are large;

- team members tend to be alike, meaning their values of one or more variables are more similar within a team than between teams;

- there is a sizeable average correlation of one or more variables within teams.

\footnotetext{
* Faculty of Management, University of Warsaw, Poland, https://orcid.org/0000-0001-9615-1222

** Faculty of Management, University of Warsaw, Poland, https://orcid.org/0000-0001-7250-7503
} 
Thus, the problem of nesting is especially important when:

- we consider team-level variables, as they are constant within a team;

- when team members rate team characteristics, as we can expect people will tend to give similar ratings of the same team;

- as the teams get larger, so the problem will usually be more meaningful when considering teams of 10 people than pairs of 2 .

There are various methods of dealing with nesting. One approach is to add dichotomous variables indicating each team and thus accounting for a between-team variance. Although this can be a good way of dealing with correlated observations within teams if we have only variables on the team member level, it fails to correct for the inflated standard errors caused by team-level variables. Additionally, we may want to take into consideration the team context, a problem frequently encountered when analyzing group data (Sagan, 2009).

We will concentrate on two other approaches of correcting for nesting: clustered standard errors (Hox, Moerbeek \& Van de Schoot, 2017) and multilevel modeling (Stock \& Watson, 2008). The first is widely used, as it enables one to use a standard regression procedure and is easily performed with some standard statistical software. The second one requires a large sample size at the team level (Snijders, 2005) (as we are estimating team-level model as well as an individual level model) and a more nuanced theoretical understanding of modeling the team and individual-level (Twiskt, 2010). Despite this, it has been gaining popularity in economics and business research, because it allows for testing numerous individuals, and context (team, institution, country et cetera) level relationships simultaneously (Peterson, Arregle \& Martin, 2012). We will compare these to performing a naïve OLS multiple regression, that does not take the problem of nesting into account to examine how the analyses results differ when accounting for nesting.

\section{EXAMPLE OF PROJECT TEAM STUDY}

Research Question: How is the team size and gender composition related to team climate in a sample of companies located in Poland?

\section{Hypotheses:}

Team-member level:

H1. Team member gender is related to team climate.

Team level:

$\mathrm{H} 2$. There is a relationship between team size, team leader gender, and/or percentage of women in the team with team climate.

Interaction of Team-member and team level:

H3. There is a relationship between the interaction of team leader and team member gender with respect to team climate.

\section{JUSTIFICATION OF A RESEARCH QUESTION AND HYPOTHESES}

Team climate. In this study, we were interested in the relations between team climate and the gender composition and size on a sample of project teams located in Poland. We examined team climate as a construct comprising of five dimensions related to those listed by Patrick Lencioni (Lencioni, 2016):

- Trust

- Open discussion of conflict 
- Team involvement

- Personal accountability

- Attention to results

This is not an accident that trust within a team is listed first. It is crucial for effectiveness of work that team members trust each other and trust the leader. Trust provides them with a degree of comfort and safety, and allows each person to focus on his tasks, rather than wasting energy on double checking others' work. It is a cornerstone, on which other elements build the efficient work environment: problem solving, commitment, accountability and goal oriented approach. In the situation of absence of trust, employees are afraid of asking for help in solving a problem, showing weaknesses or even sharing opinions. As a result, the knowledge transfer between team members is limited, and this can impact the work delivered by the group.

Trust leads to the second important dimension of the team climate: open discussion of conflicts. It manifests itself with the readiness to share comments and opinions with other members of the group. In such situations important ideas or warning signals about potential risks for task delivery reach the leader with ease. Simultaneously, ideas are discussed before being accepted by the rest of the team because team members do not fear open conflict with other team members. Both of these factors can positively influence the quality of the delivered product.

Team involvement is directly related to the proactive attitude possible in a team where trust and open discussion of conflicts are the norm. In a team with high involvement, people commit and care about team goals. This also is closely related to a higher personal accountability. This means that team members are personally and willingly taking on the responsibility of finishing a project, task or goal.

Finally, attention to results, meaning how much team members value and pay attention to common team goals as opposed to personal goals that come at the expense of team efforts. This enables the team to work as a whole, ensuring that the tasks relevant to the project are completed in a timely and organized fashion.

Leadership gender and team climate. Leader and team member gender seem to be related to perceived team climate. This can occur due to a combination of factors. Women and men are judged differently by team members and superiors when performing tasks. A selection bias can also be present: it is usually harder for a woman to attain a leadership position, that it is for a man. Thus, she has to display a different set of characteristics than her male counterparts. Another factor may be the support and perceptions of fellow leaders as well as teammates, which may influence the team climate.

An example of how gender composition is related to the team climate comes from a study performed in three multinational companies based in China, on 59 managers and 245 subordinates: 17 female managers and their 69 subordinates and 42 male managers and their 176 subordinates. The results have indicated that avoidance of a conflict perceived by teams was more frequent in male managers than it was in females (Yang \& Li, 2018). It may suggest that female leaders are more focused on team interactions than male leaders, according to authors of the study.

Although leadership style may be different between female and male leaders, their efficiency does not depend on gender. Despite this, female leaders are perceived as less efficient (Appelbaum, Audet \& Miller, 2003). If this expectation is shared by team members, it may bear on the team climate. Failing that external situations also differ, which may have an impact on team climate. When the company performs well, female leaders are rewarded less then male leaders. However, when the company's economic performance is poor female leaders are also punished less (Kulich, Ryan \& Haslam, 2007)

Leaders are perceived to possess features and attitudes more often associated with being a man than with being a woman - namely decision making, assertiveness and the ability for strategic thinking (Wille, 2018; Schein, 1975). Additionally, women in managerial roles are likely (as well 
as male managers) to choose and support men in their way to leadership. Meanwhile, women face challenges with "sticky floors", and a "glass ceiling", on the way. Some challenges may be related with behaviors, such as being too perfectionistic, hesitant with reaching for power, and not building strategic networks (Shambaugh, 2007).

Additionally, research has shown a tendency to evaluate female leaders less favorably than male leaders but this effect was small (Eagly, Makhijani \& Klonsky, 1992). The devaluation was stronger if women were in high manager positions in male dominated environment and when evaluation was performed my men. An interesting phenomenon associated with leadership assignment in femaledominant groups was called the "glass escalator" (Williams, 1992). Men who work in traditionally female professions, such as nursing and education, receive support and even pressure to move to managerial roles. Thus, not only can we can expect more men than women in managerial positions in our sample, but also an interaction effect, where females evaluate the climate of female-lead teams more negatively.

\section{PARTICIPANTS}

The sample consists of 636 employees ( $37 \%$ of them were women from retail, the automotive sector and finance sector). Among 87 teams $22(25 \%)$ had a female leader. The typical (median) team had 6 members (the smallest had 3 and the largest had 33). All team members filled the survey TEAM PLUS, which diagnoses the climate of teamwork assessed by its members using 10-point Likerttype scale, where -5 indicates "completely disagree" and +5 indicates "completely agree".

\section{MATERIALS}

TEAM PLUS TEST is a tool used by managers who want to learn how the team sees themselves. The tool is based on the concept developed and described by P. Lencioni regarding team dysfunctions, which has been described earlier in this chapter. Questions comprising these five dimensions, as well as their distribution in the teams, can be found in the appendix.

\section{STATISTICAL PROCEDURE}

Our study contrasts the results of the analysis of the same data set by 3 methods:

(1) ordinary least squares multiple regression,

(2) multiple regression with clustered standard errors, and

(3) multilevel modeling.

Analyses were carried out for each of the 5 team climate variables separately and were divided into two parts. Answers to the team climate items were all standardized within people to take into account the individual response styles of the team-members. Next, the team climate variables were computed by taking the mean of the items comprising a dimension of team climate (see materials section). Additionally, the TEAM SIZE was transformed with a logarithm transform because we assume team climate changes linearly with every doubling of team size, so an additional person has less of an effect on larger teams than it has on smaller teams. In order to check how the percentage of men and women in the team is related to team climate we centered the percentage of women in the team to a mean of 0 and added the square of that variable to check for non-linear effects.

Testing the hypotheses was first performed using a model-building approach, where the variables were added into three successive models and the significance of the improvement in explaining team climate was assessed using an appropriate statistical test. The FIRST model had only teammember level variables: member's gender, as the predictor. The SECOND model added team-level 
predictors: team leader's gender, the logarithm of team size, and the percentage of females in the team, along with the square of the percentage of female in the team, to test for the effect of gender composition on team climate. The THIRD model added an interaction term of team leader and team member gender to test the interaction hypothesis between team member and team level variables. F test was used for the OLS multiple regression, an F test with an appropriate correction for a covariance structure that accounted for clustering for the regression with clustered standard errors, and a Likelihood ratio Chi-squared test for the multilevel models.

Lastly the coefficient estimates, their standard errors and significance values of the full models in the previous section were compared. Separate tables were created for each of the climate variables. Analyses were performed using the R statistical environment (R Core Team, 2018) with the lme4 (Bates, Maechler, Bolker \& Walker, 2015) package for multilevel modeling and a custom function for computing the clustered standard error correction to match those available via the cluster option in the regress command in the Stata statistical program (StataCorp, 2017).

\section{DESCRIPTIVE STATISTICS}

The descriptive statistics of the predictors can be seen in Table 1. Overall, there was a moderate to high correlation between the predictors. This is expected in the analysis of team data, as all withinteam correlations of team level variables are equal to 1 . On the other hand, member gender is quite highly correlated with the percent of woman in the team. It is quite clear from the descriptive statistics that it is important to consider the problem of team members nested within teams in our example.

Table 1. Descriptive statistics of the predictors

\begin{tabular}{|c|c|c|c|c|c|c|c|}
\hline Level & Variable name & Mean(SD) & Range & & Corre & tions & \\
\hline member & gender & $238(0.37)^{*}$ & $0-1$ & gender & leader gender & $\%$ women & $\%$ women $^{2}$ \\
\hline team & leader gender & $185(0.29)^{*}$ & $0-1$ & 0.58 & - & - & - \\
\hline team & $\%$ of women & $0(1.00)$ & $0.37-0.62$ & 0.50 & 0.48 & - & - \\
\hline team & {$[\% \text { of women }]^{2}$} & $0.10(0.1)$ & $0-0.39$ & 0.50 & 0.48 & - & - \\
\hline team & $\ln (\mathrm{n})$ & $2.16(0.59)$ & $1.10-3.50$ & 0.23 & 0.46 & 0.23 & 0.23 \\
\hline
\end{tabular}

* For the team member and team leader gender, variable number of women, and their proportion the dataset is shown. $0=\operatorname{man}, 1=$ woman.

The distribution of the climate variables within teams is shown in the appendix. The mean of the variables is quite close to 0 , and their standard error is close to .35 , due to the fact that each is constructed as the mean of eight items standardized within individuals.

While the means of the mean team responses are quite evenly dispersed around the mean value, there is a quite high deviation from this value in some of the ratings within a team, this can indicate it is important to examine the team member level and not only the teams at the aggregate level.

\section{HYPOTHESIS TESTING USING OLS REGRESSION, CLUSTERED STANDARD ERRORS AND MULTILEVEL MODELING}

First, let us examine Table 2 in which hypothesis tests were performed by testing OLS multiple regression models against each other. This type of analysis disregards the problem of nesting, but is the simplest of the three to use, as virtually all statistical packages have it built in. As we can 
see, the team member gender (the Member model) is significantly related to open discussion of conflicts, team involvement and personal accountability. Team gender composition and team size (Member + Team model) is significantly related to trust, attention to results and team involvement. Additionally, open discussion of conflicts is significantly related to the interaction of team leader gender and team member gender.

Examining the coefficients of the significant models, it turns out trust is related to the squared term of team gender, with trust being significantly lower in more heterogeneous groups $(\mathrm{B}=-1.12(0.34)$, $t=-3.25, p=0.001)$.

Women are less open to the discussion of conflicts with female leaders $(\mathrm{B}=-0.18(0.05)$, $t=-3.34, p<0.001)$ with this effect being due to women being less open to discussion of conflict within female lead teams than within male led teams $(\mathrm{B}=-0.37(0.12), t=-2.94, p=0.003)$.

Team involvement was higher for teams with a higher percentage of women $(\mathrm{B}=0.25(0.12)$, $t=2.00, p=0.03)$, and was rated as higher by women than it was rated by men $(\mathrm{B}=0.12(0.04)$, $t=2.42, p=0.02)$. The rating of personal accountability within a team was also rated as higher by women than it was rated by men $(\mathrm{B}=0.20(0.05), t=3.85, p<0.001)$. Finally, attention to results was related to a combination of team-level variables, with attention to results being higher within more heterogeneous teams $(\mathrm{B}=1.26(0.39), t=3.24, p=0.001)$, larger groups $(\mathrm{B}=0.14(0.06)$, $t=2.27, p=0.02)$ and lower for teams led by females $(\mathrm{B}=-0.09(0.34), t=-2.01, p=0.04)$.

Table 2. Hypotheses tests using OLS stepwise regression

\begin{tabular}{|c|c|c|c|}
\hline Model & Member & Member + Team & Member x Team \\
\hline Degrees of freedom & 1,624 & 4,620 & 4,619 \\
\hline \multicolumn{4}{|l|}{ Trust } \\
\hline Test & 3.35 & 4.61 & 0.71 \\
\hline$p$ & 0.07 & 0.00 & 0.40 \\
\hline \multicolumn{4}{|c|}{ Open discussion of conflicts } \\
\hline Test & 11.35 & 2.32 & 6.21 \\
\hline$p$ & 0.00 & 0.06 & 0.01 \\
\hline \multicolumn{4}{|l|}{ Team involvement } \\
\hline Test & 5.98 & 4.20 & 1.13 \\
\hline$p$ & 0.01 & 0.00 & 0.29 \\
\hline \multicolumn{4}{|l|}{ Personal accountability } \\
\hline Test & 14.82 & 0.50 & 1.40 \\
\hline$p$ & 0.00 & 0.73 & 0.24 \\
\hline \multicolumn{4}{|l|}{ Attention to results } \\
\hline Test & 0.08 & 4.36 & 1.17 \\
\hline$p$ & 0.77 & 0.00 & 0.28 \\
\hline
\end{tabular}

Note. The statistical test performed was an F test, and the first and second degrees of freedom for each successive test are separated by a comma in the "degrees of freedom" row. 
A very similar pattern emerges when examining the table of tests with a clustered standard error correction. The difference is that the test statistic is smaller, and the values have a higher $p$ value. However, in our case this was not sufficient to push any of the significant models into the area of non-significance, so the results are qualitatively unchanged. Examining the significant model coefficients, it turns out trust is (again) lower in more heterogeneous groups $(\mathrm{B}=-1.12(0.57)$, $t=-1.92, p=0.049)$, women are less willing to openly discuss conflicts than men $(\mathrm{B}=-0.18(0.07)$, $t=-2.48, p=0.01)$ and this effect is due to females being less open to discuss conflict in female led groups $(\mathrm{B}=-0.37(0.15), t=-2.37, p=0.02)$. Team involvement is rated as higher by women than it is by men $(\mathrm{B}=0.12(0.05), t=2.23, p=0.03)$. Females tend to also rate their team higher on personal accountability $(\mathrm{B}=-0.20(0.05), t=3.98, p<0.001)$, and attention to results is higher in teams that are more heterogeneous $(\mathrm{B}=1.26(0.55), t=2.27, p=0.02)$.

Table 3. Hypotheses tests using clustered standard error corrected stepwise regression

\begin{tabular}{|c|c|c|c|}
\hline Model & Member & Member + Team & Member x Team \\
\hline Degrees of freedom & 1,624 & 4,620 & 4,619 \\
\hline \multicolumn{4}{|l|}{ Trust } \\
\hline Test & 1.31 & 2.80 & 0.31 \\
\hline$p$ & 0.25 & 0.03 & 0.58 \\
\hline \multicolumn{4}{|c|}{ Open discussion of conflicts } \\
\hline Test & 6.13 & 0.97 & 3.94 \\
\hline$p$ & 0.01 & 0.42 & 0.05 \\
\hline \multicolumn{4}{|l|}{ Team involvement } \\
\hline Test & 4.95 & 8.69 & 1.07 \\
\hline$p$ & 0.03 & $<0.001$ & 0.3 \\
\hline \multicolumn{4}{|l|}{ Personal accountability } \\
\hline Test & 15.85 & 0.57 & 1.32 \\
\hline$p$ & 0 & 0.68 & 0.25 \\
\hline \multicolumn{4}{|l|}{ Attention to results } \\
\hline Test & 0.05 & 2.27 & 0.65 \\
\hline$p$ & 0.82 & 0.06 & 0.42 \\
\hline
\end{tabular}

Note. The statistical test performed was a Wald F test with a covariance structure correction for clustering, and the first and second degrees of freedom for each successive test are separated by a comma in the "degrees of freedom" row.

Finally, the pattern somewhat changes with the mixed model approach to analyzing team data, although the differences are not drastically big. Trust is no longer related to team gender composition and size, and team involvement is no longer related to member gender. The pattern of females being less inclined to openly discuss conflicts in female than in male led teams persists $(B=-0.34(0.13)$, $t=-2.60, p=0.02)$. Similarly, team involvement is greater in groups that have a higher percentage of women ( $\mathrm{B}=0.25(0.12), t=2.04, p=0.04)$, and, like in the OLS analysis, attention to results is greater in more heterogeneous $\mathrm{B}=1.40(0.58), t=2.40, p=0.01)$ and larger $(\mathrm{B}=0.22(0.10)$, $t=2.30, p=0.02$ ) teams. 
Table 4. Hypotheses tests using multilevel modeling

\begin{tabular}{|c|c|c|c|}
\hline Model & Member & Member+Team & Member x Team \\
\hline Degrees of freedom & 1 & 4 & 1 \\
\hline \multicolumn{4}{|l|}{ Trust } \\
\hline Test & 0.40 & 7.77 & 0.03 \\
\hline$p$ & 0.53 & 0.10 & 0.87 \\
\hline \multicolumn{4}{|c|}{ Open discussion of conflicts } \\
\hline Test & 6.17 & 7.77 & 5.20 \\
\hline$p$ & 0.01 & 0.10 & 0.02 \\
\hline \multicolumn{4}{|l|}{ Team involvement } \\
\hline Test & 2.23 & 14.07 & 1.14 \\
\hline$p$ & 0.14 & 0.01 & 0.29 \\
\hline \multicolumn{4}{|l|}{ Personal accountability } \\
\hline Test & 12.74 & 2.02 & 1.14 \\
\hline$p$ & 0.00 & 0.73 & 0.29 \\
\hline \multicolumn{4}{|l|}{ Attention to results } \\
\hline Test & 0.21 & 10.74 & 0.50 \\
\hline$p$ & 0.65 & 0.03 & 0.48 \\
\hline
\end{tabular}

Note. The statistical test performed was a likelihood ratio Chi-squared.

\section{COMPARING COEFFICIENTS OF THE FULL MODELS}

Tables 5 through 9 compare the regression coefficients of the full (Member $\mathrm{x}$ Team) models estimated using OLS multiple regression, clustered standard errors, and multilevel analysis for each of the team climate variables. This was done to illustrate the differences in the estimated parameters and statistical tests, as this is often how hypothesis testing is done, instead of the above-shown model-comparison method. Here the advantages of a multilevel approach become readily apparent over the clustered standard error correction. In fact, only two parameters found to be significant in the OLS models were not significant in the multilevel model: less open discussion of conflicts in teams with female leaders and less attention to results in teams with a female leader. In fact, the multilevel model had one coefficient that was significant only in this, but not in the other two models: there was a smaller tendency for open discussion of conflict in bigger teams. In contrast, most of the significant parameters found in the OLS regression models, were not significant after applying the clustered standard error correction, and both of those which were also found to be significant in the multilevel models.

As we can see in Table 5, B coefficients of the model are identical in the OLS and clustered standard errors corrected models, the standard error estimates and statistical tests are the only ones that show some variation. Trust was significantly related to the gender heterogeneity in the OLS regression model, as well as in the multilevel model, but not in the clustered standard errors corrected model. This stands in contrast to the model building hypothesis testing. As it was found, it was the clustered standard error model that was related to gender heterogeneity, but not the multilevel model. 
This could be due to a greater sensitivity of model misspecification through adding a non-significant leader gender $\mathrm{x}$ member gender interaction term in the former than in the latter.

Table 5. OLS, clustered standard error corrected coefficients and multilevel coefficients along with statistical tests and significance levels of the member $\mathrm{x}$ team models for the trust variable

\begin{tabular}{|c|c|c|c|c|c|c|c|c|c|}
\hline & \multicolumn{3}{|c|}{ OLS } & \multicolumn{3}{|c|}{ Clustered SE } & \multicolumn{3}{|c|}{ Multilevel } \\
\hline & B & SE & $p$ & B & SE & $p$ & B & SE & $p$ \\
\hline intercept & 0.35 & 0.14 & 0.01 & 0.35 & 0.18 & 0.05 & 0.36 & 0.18 & 0.05 \\
\hline gender & 0.04 & 0.09 & 0.70 & 0.04 & 0.08 & 0.66 & 0.01 & 0.09 & 0.92 \\
\hline leader gender & 0.05 & 0.10 & 0.65 & 0.05 & 0.18 & 0.80 & 0.01 & 0.13 & 0.92 \\
\hline$\%$ women & -0.02 & 0.15 & 0.89 & -0.02 & 0.25 & 0.93 & -0.05 & 0.19 & 0.82 \\
\hline$(\% \text { of women })^{2}$ & -0.99 & 0.38 & 0.01 & -0.99 & 0.65 & 0.13 & -1.05 & 0.51 & 0.04 \\
\hline $\log (n)$ & -0.07 & 0.06 & 0.20 & -0.07 & 0.08 & 0.38 & -0.07 & 0.08 & 0.37 \\
\hline leader gender $\mathrm{x}$ gender & -0.13 & 0.16 & 0.40 & -0.13 & 0.23 & 0.58 & -0.02 & 0.16 & 0.90 \\
\hline
\end{tabular}

Table 6. OLS, clustered standard error corrected coefficients and multilevel coefficients along with statistical tests and significance levels of the member $\mathrm{x}$ team models for the open discussion of conflicts variable

\begin{tabular}{|c|c|c|c|c|c|c|c|c|c|}
\hline & \multicolumn{3}{|c|}{ OLS } & \multicolumn{3}{|c|}{ Clustered SE } & \multicolumn{3}{|c|}{ Multilevel } \\
\hline & B & SE & $p$ & B & SE & $p$ & B & SE & $p$ \\
\hline intercept & 0.11 & 0.12 & 0.38 & 0.11 & 0.18 & 0.56 & 0.27 & 0.16 & 0.11 \\
\hline gender & 0.00 & 0.08 & 1.00 & 0.00 & 0.07 & 1.00 & -0.01 & 0.07 & 0.85 \\
\hline leader gender & 0.24 & 0.09 & 0.01 & 0.24 & 0.12 & 0.05 & 0.17 & 0.12 & 0.15 \\
\hline$\%$ of women & -0.16 & 0.14 & 0.24 & -0.16 & 0.17 & 0.35 & -0.10 & 0.18 & 0.57 \\
\hline$(\% \text { of women })^{2}$ & 0.11 & 0.34 & 0.76 & 0.11 & 0.51 & 0.84 & -0.21 & 0.46 & 0.65 \\
\hline $\log (\mathrm{n})$ & -0.09 & 0.05 & 0.07 & -0.09 & 0.08 & 0.24 & -0.15 & 0.07 & 0.05 \\
\hline leader gender $\mathrm{x}$ gender & -0.34 & 0.14 & 0.01 & -0.34 & 0.17 & 0.05 & -0.31 & 0.14 & 0.02 \\
\hline
\end{tabular}

In all models there was a significant interaction, it is shown in Figure 1 for the OLS and Clustered SE model (the interaction plot for the multilevel model was almost identical, so it is not shown). Women were less ready to openly discuss conflict in female led groups than they were in male-led groups. In the OLS regression case the leader's gender was significantly related to the discussion of conflicts, having members of teams led by females more openly discussing conflicts than it was in teams led by males. This finding is most probably due to artificially low standard errors when disregarding the team structure of the data. On the other hand the number of team members was found to be significantly negatively related to the open discussion of conflicts within the team in the multilevel model, but not in the other two models. 
Figure 1. Interaction plot of open discussion of conflicts in the OLS regression as a function of the interaction of gender and leaders' gender.

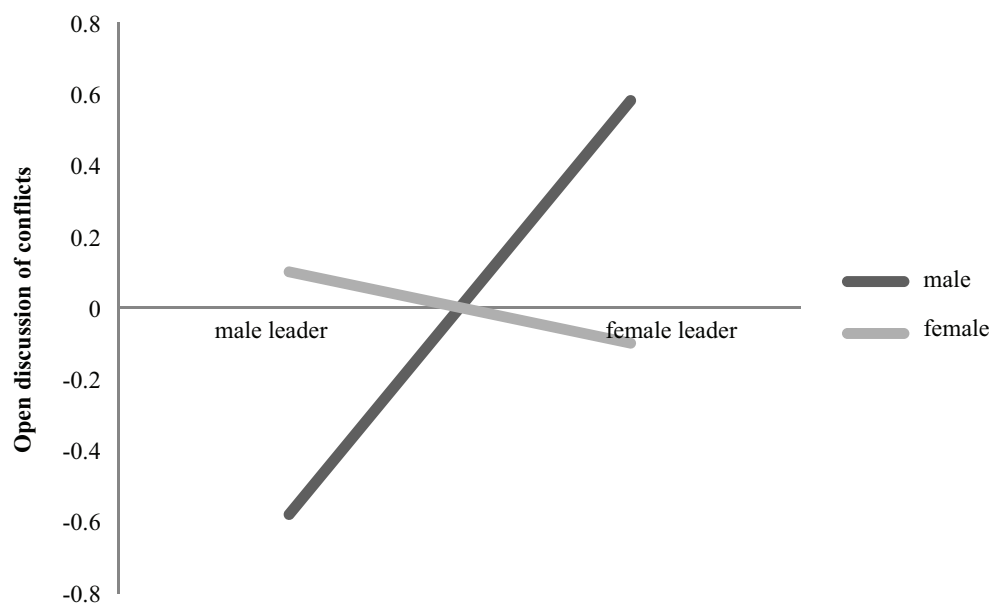

Table 7. OLS, clustered standard error corrected coefficients and multilevel coefficients along with statistical tests and significance levels of the member $\mathrm{x}$ team models for the team involvement variable.

\begin{tabular}{|c|c|c|c|c|c|c|c|c|c|}
\hline & \multicolumn{3}{|c|}{ OLS } & \multicolumn{3}{|c|}{ Clustered SE } & \multicolumn{3}{|c|}{ Multilevel } \\
\hline & B & SE & $p$ & $\mathrm{~B}$ & SE & $p$ & $\mathrm{~B}$ & SE & $p$ \\
\hline intercept & 0.00 & 0.11 & 0.98 & 0.00 & 0.13 & 0.98 & 0.00 & 0.11 & 0.97 \\
\hline gender & -0.07 & 0.07 & 0.35 & -0.07 & 0.07 & 0.35 & -0.06 & 0.07 & 0.36 \\
\hline leader gender & 0.00 & 0.08 & 0.98 & 0.00 & 0.09 & 0.98 & 0.00 & 0.08 & 0.97 \\
\hline$\%$ women & 0.24 & 0.12 & 0.05 & 0.24 & 0.14 & 0.08 & 0.24 & 0.12 & 0.05 \\
\hline$(\% \text { of women })^{2}$ & 0.06 & 0.30 & 0.84 & 0.06 & 0.27 & 0.82 & 0.07 & 0.31 & 0.81 \\
\hline $\log (n)$ & 0.05 & 0.04 & 0.27 & 0.05 & 0.04 & 0.27 & 0.05 & 0.05 & 0.30 \\
\hline leader gender $\mathrm{x}$ gender & 0.13 & 0.12 & 0.29 & 0.13 & 0.13 & 0.30 & 0.12 & 0.12 & 0.32 \\
\hline
\end{tabular}

With a higher percentage of women there was an increased level of involvement both for the OLS regression, as well as the multilevel model. Again, the clustered standard error approach yielded no significant results.

Although gender was found to be significantly related to the rating of personal accountability in the model-building approach, in the full model hypotheses testing there is no significant effect of any variable of the model. This is most probably due to a quite high correlation of team member gender and the percentage of females in the team, which decreases the values of statistical tests for these two variables if they are entered in the same model, although the model itself can significantly explain the dependent variable. 
Table 8. OLS, clustered standard error corrected coefficients and multilevel coefficients along with statistical tests and significance levels of the member $\mathrm{x}$ team models for the personal accountability variable

\begin{tabular}{|c|c|c|c|c|c|c|c|c|c|}
\hline & \multicolumn{3}{|c|}{ OLS } & \multicolumn{3}{|c|}{ Clustered SE } & \multicolumn{3}{|c|}{ Multilevel } \\
\hline & B & SE & $p$ & $\mathrm{~B}$ & SE & $p$ & $\mathrm{~B}$ & SE & $p$ \\
\hline intercept & 0.06 & 0.11 & 0.60 & 0.06 & 0.12 & 0.62 & 0.06 & 0.13 & 0.66 \\
\hline gender & 0.11 & 0.08 & 0.14 & 0.11 & 0.06 & 0.08 & 0.12 & 0.07 & 0.12 \\
\hline leader gender & -0.02 & 0.09 & 0.85 & -0.02 & 0.09 & 0.85 & -0.01 & 0.10 & 0.94 \\
\hline$\%$ of women & 0.10 & 0.13 & 0.46 & 0.10 & 0.17 & 0.57 & 0.10 & 0.14 & 0.47 \\
\hline$(\% \text { of women })^{2}$ & -0.23 & 0.32 & 0.48 & -0.23 & 0.30 & 0.45 & -0.15 & 0.37 & 0.69 \\
\hline $\log (n)$ & -0.03 & 0.05 & 0.54 & -0.03 & 0.05 & 0.52 & -0.03 & 0.06 & 0.57 \\
\hline leader gender $\mathrm{x}$ gender & 0.16 & 0.13 & 0.24 & 0.16 & 0.14 & 0.25 & 0.14 & 0.13 & 0.30 \\
\hline
\end{tabular}

Note: Significant $\mathrm{p}$ values are shaded.

Table 9. OLS, clustered standard error corrected coefficients and multilevel coefficients along with statistical tests and significance levels of the member $\mathrm{x}$ team models for the attention to results variable

\begin{tabular}{|c|c|c|c|c|c|c|c|c|c|}
\hline & \multicolumn{3}{|c|}{ OLS } & \multicolumn{3}{|c|}{ Clustered SE } & \multicolumn{3}{|c|}{ Multilevel } \\
\hline & B & SE & $p$ & $\mathrm{~B}$ & $\mathrm{SE}$ & $p$ & $\mathrm{~B}$ & SE & $p$ \\
\hline intercept & -0.53 & 0.15 & 0.00 & -0.53 & 0.21 & 0.01 & -0.73 & 0.22 & 0.00 \\
\hline gender & -0.08 & 0.10 & 0.44 & -0.08 & 0.10 & 0.43 & -0.06 & 0.09 & 0.55 \\
\hline leader gender & -0.26 & 0.12 & 0.02 & -0.26 & 0.21 & 0.22 & -0.16 & 0.16 & 0.30 \\
\hline$\%$ of women & -0.16 & 0.17 & 0.37 & -0.16 & 0.29 & 0.59 & -0.24 & 0.23 & 0.29 \\
\hline$(\% \text { of women })^{2}$ & 1.06 & 0.43 & 0.01 & 1.06 & 0.60 & 0.08 & 1.28 & 0.61 & 0.04 \\
\hline $\log (n)$ & 0.15 & 0.06 & 0.02 & 0.15 & 0.08 & 0.08 & 0.22 & 0.10 & 0.02 \\
\hline leader gender $\mathrm{x}$ gender & 0.19 & 0.17 & 0.28 & 0.19 & 0.23 & 0.42 & 0.12 & 0.17 & 0.49 \\
\hline
\end{tabular}

Note: Significant $\mathrm{p}$ values are shaded.

Three variables, leader gender, gender heterogeneity, and team size, were found to be significantly related to the attention to results, were non-significant after correcting for the clustered nature of the data. Two of them were also significant in the multilevel model. As the gender heterogeneity was grater and as the team size increased the attention to results also grew.

\section{DISCUSSION OF RESULTS}

The model building approach and comparison of the full model coefficients confirmed hypotheses $\mathrm{H} 2$ and $\mathrm{H} 3$, when used with any of the methods: OLS with clustered standard errors or multilevel modeling. However, the only one which confirmed H1 was a model-building approach. This is not surprising, as team member gender is highly correlated to team gender composition, so including 
the team-level variable could mask the relationship of member gender to team climate. A result that was consistent in the analyses was that trust was lower in more gender heterogeneous groups, open discussion of conflict was related to the interaction of leader and member gender, women rated the team as having a higher personal accountability and that a greater gender heterogeneity, as well as possibly a greater team size, was positively related to attention to results. Very few significant results were found in the full model coefficient comparison approach, as opposed to the model building approach when the clustered standard error correction was applied to regular OLS estimates, indicating that the approach can be overly conservative compared to multilevel modeling when adding non-significant predictors.

\section{CLOSING REMARKS}

In this example two approaches to dealing with team data were explored and compared to a standard ordinary least squares regression approach. Depending on how the researcher wants to conduct hypotheses tests, each has its advantages. If the researcher intends to use a model comparison approach and wants to only examine the coefficients of the significant models, a clustered standard error approach seems to quite closely resemble that of an OLS regression.

Contrarily, if a researcher wants to perform hypotheses tests based on a full model derived from theory and only focuses on a coefficient tests, a multilevel approach seems more appropriate as a clustered SE approach in this case seemed to be underpowered yielding very few significant coefficients. Furthermore, all of the effects found in the clustered SE approach were also found when using the multilevel analysis. The multilevel coefficient tests were not only very similar to the uncorrected OLS coefficient tests, but also reviled an additional effect, suggesting that one can find additional effects when performing a multilevel model, which is unlikely using the clustered standard error correction to OLS parameters.

\section{Literature}

Appelbaum, S. H., Audet, L., \& Miller, J. C. (2003). Gender and leadership? Leadership and gender? A journey through the landscape of theories. Leadership \& Organization Development Journal, 24(1), 43-51, http:// dx.doi.org/10.1108/01437730310457320

Bates, D., Maechler. M., Bolker, B., \& Walker, S. (2015). Fitting Linear Mixed-Effects Models using lme4. Journal of Statistical Software, 67(1), 1-48, http://dx.doi.org/10.18637/jss.v067.i01

Cullen, J. B., Parboteeah, K. P., \& Hoegl, M. (2004). Cross-national differences in managers‘ willingness to justify ethically suspect behaviors: A test of institutional anomie theory. Academy of Management Journal, 47(3), 411-421, http://dx.doi.org/10.2307/20159590

Eagly, A. H., Makhijani, M. G., \& Klonsky, B. G. (1992). Gender and the evaluation of leaders: A meta-analysis. Psychology Bulletin, 111, 3-22, http://dx.doi.org/10.1037/0033-2909.111.1.3

Greene, W. H. (2003). Econometric analysis. Pearson Education India.

Hox, J. J., Moerbeek, M. A, \& Van de Schoot, R. (2017). Multilevel analysis: Techniques and applications, Routledge, http://dx.doi.org//10.4324/9781315650982

Lencioni P. (2016). Przezwyciężanie pięciu dysfunkcji pracy zespolowej: praktyczny przewodnik dla liderów, menedżerów, moderatorów, Warszawa: MT Biznes.

Kulich, C., Ryan, M. K., \& Haslam, S. A. (2007). Where is the romance for women leaders? The effects of gender on leadership attributions and performance based pay, Applied Psychology, 56, 582-601, http:// dx.doi.org/10.1111/j.1464-0597.2007.00305.x

Peterson, M. F., Arregle, J.-L., \& Martin, X. (2012). Multilevel models in international business research. Journal of International Business Studies, 43(5), 451-457.

R Core Team (2018). R: A language and environment for statistical computing. R Foundation for Statistical Computing, Vienna, Austria. Retrieved from https://www.R-project.org/ (19.10.2018)

Sagan, A. (2009). Wielopoziomowe analizy strukturalne w analizie postępowania konsumentów - porównanie modeli pomiarowych. Zeszyty Naukowe Nr 756 Uniwersytetu Ekonomicznego w Krakowie. 
Schein, V. E. (1975). Relationships between sex role stereotypes and requisite management characteristics among female managers. Journal of Applied Psychology, 60, 340-344, http://dx.doi.org/10.1037/h0076637

Shambaugh, R. (2007). It's not a glass ceiling, it's a sticky floor: Free yourself from the hidden behaviors sabotaging your career success. New York, NY: McGraw Hill.

Snijders, T. A. (2005). Power and sample size in multilevel modeling. Encyclopedia of statistics in behavioral science, 3, 1570-1573.

StataCorp (2017). Stata Statistical Software: Release 15. College Station, TX: StataCorp LLC.

Stock, J. H. \& Watson, M. W. (2008). Heteroskedasticity-robust standard errors for fixed effects panel data regression. Econometrica, 76(1), 155-174, http://dx.doi.org/10.1111/j.0012-9682.2008.00821.x

Twiskt, J. W. R. (2010). Analiza wielopoziomowa - przykłady zastosowań (Applied Multilevel Analysis). Oficyna Wydawnicza SGH.

Wieczorkowska G. (1993). Pułapki statystyczne. In Z. Smoleńska (Ed.) Badania nad rozwojem w okresie dorastania. (pp. 211-234). Warszawa: Instytut Psychologii PAN.

Wille, B., Wiernik, B. M., Vergauwe, J., Vrijdags, A., T, N., \& Trbovic, N. (2018). Personality characteristics of male and female executives: Distinct pathways to success? Journal of Vocational Behavior.

Williams Ch. L., (1992). The Glass Escalator: Hidden Advantages for Men in the „Female” Professions, Social Problems, 39(3), 253-267, http://dx.doi.org/10.2307/3096961

Yang, I., \& Li, L. M. (2018). 'It is not fair that you do not know we have problems': Perceptual distance and the consequences of male leaders' conflict avoidance behaviours. European Management Journal, 36(1), 105-116. doi:10.1016/j.emj.2017.03.013 


\section{APPENDIX}

Trust

- In this team we know about non-business interests of other people in this group

- In this team, we trust ourselves as people, not just as collaborators

- I'm calm about complying with ethical standards by other team members

- I am not afraid of openly expressing difficult views in this team, because I know that it will not be used against me

- By submitting a request or task to another member of this team I am calm about the quality of the work I have provided.

- By forwarding a request or task to another member of this team, I am confident that I will do it on time.

- If any of this team fails to meet the deadline for completing the task or makes a mistake, it immediately informs the persons affected by this work.

- Team members are eager to ask their colleagues for advice, knowing that they will receive support and will not be assessed as incompetent.

Open discussion of conflict:

- In the team we can openly disagree with each other in the discussion knowing that it will not negatively affect the relationship between us

- When an unclear situation arises, interested people in the team openly and with commitment discuss it

- During the team meetings, participants boldly present their reasons, even if others see things differently

- The leader talks openly about emerging team conflicts, encouraging discussion of them

- Every member of this team regularly receives feedback from others.

- After completing each larger task, we make sure that we give each other feedback

- In our team, by providing feedback, we call specific events and situations

- In our team, we provide ourselves feedback directly after the event it concerns.

Team involvement:

- At the team's meetings you can see a genuine commitment to making decisions for all participants

- We have a way of making decisions as a team

- When making important decisions about the team, we make sure that everyone can express their opinion

- Members of this team are actively looking for ways to get involved in matters that concern them.

- When a decision is made, everyone is involved in its implementation, even if initially they were advocates of another solution.

- We have a clear view of the direction our team is approaching

- We adapt efficiently to change the way the team goal is achieved, even when it requires effort

- In our team we are committed to the implementation of the decision, even knowing that it can change.

Personal accountability:

- In this team, each task has a specific person who is responsible for it

- I am convinced that people in this team feel genuinely responsible for the implementation of their tasks in the highest quality and on time 
- The members of this team are actively looking for the sense and purpose of the tasks that have been commissioned to them

- I see that the members of this team are constantly improving ways to do their job

- Each team member feels co-responsible for the group's results as a whole

- When the task carried out by one of the team members is threatened with failure, I can see how others help him with involvement

- The leader is not the only source of discipline - the team members are mutually responsible

- Everyone knows what is currently a priority in the work of the other team member

Attention to results:

- We regularly monitor how current the task of each of us brings the team closer to its goal

- We regularly look at the results achieved by the team as a whole

- We regularly compare the level of implementation of our tasks with fixed indicators

- We have as a team a tool to monitor the progress of our work

- We get feedback on the quality of our work from internal or external clients

- We improve our work based on feedback from internal and external clients

- Team members consciously and confidently make concessions in matters that matter to them if it serves the good of the team

- The team celebrates common successes and experiences a lot of failure 


\title{
Employees' Predispositions to Routinised Work: Measurement Issues
}

\author{
Grażyna Wieczorkowska-Wierzbińska* \& Wojciech Karczewski**
}

\begin{abstract}
Summary
We dream of a job that makes us most productive, comfortable and satisfied. But often we focus on salary, job status and ignore the mismatch between job requirements and our psychophysiological predisposition. In the long run can pay the high costs of the mismatch, so the measurement of employees' psychophysiological predispositions is a crucial problem. In the first part of the paper we examine the definition of basic concepts: the job's predisposition and degree of work routinization. The second part of the paper addresses the problems of questionnaire measurement on example of 3 questionnaires: NEOFFI, SSA, Gallup's Clifton StrengthsFinder Assessment. In the empirical part we present the results of measurement of the 2 predispositions (METICULOUSNESS and ADAPTABILITY) important for prediction psychophysiological costs in performing the highly routinized work. The analyses of the data $(\mathrm{N}=1132$ employees of different corporations +4748 colleagues of theirs $)$ have shown: (1) the necessity of eliminating distortions related to the response style by data ipsatization; (2) the significant differences in ADAPTABILITY and METICULOUSNESS between self vs. other -descriptions; (3) the negative relationship between ADAPTABILITY and METICULOUSNESS scores.
\end{abstract}

Keywords: Job routinization, NEO-FFI, Gallup's Clifton StrengthsFinder Assessment

JEL: M12, C12, C18

\section{INTRODUCTION: PROBLEMS WITH CONCEPTS DEFINITION}

The development of management science is based on progress achieved in the basic sciences: economy, psychology, law, and sociology. Similarly to medicine, which has its roots in biology, chemistry, physics, as well as in psychology, management science generates new research questions stimulating the advancements of disciplines fundamental to it.

Management is said to be a discipline of knowledge and practice, hence - just like in medicine - the diagnosis should play a fundamental role. The problem of the diagnosis is important to the extent that the subject of our research is complex organisms which, contrary to inanimate objects, are characterised by possible opposite reactions to stressor. Stress factors for people or organisations may cause either negative or positive (enhancing) effects. The most interesting is antifragility (Taleb, 2012) $=$ property of systems that means an increase in ability to resist (robustness) or recover from failure (resilience).

Some believe that every scientific work should begin from providing precise definitions of the terms "proceduralised work" and "predispositions". The definition of a term(Formal concept) requires the specification of the conditions necessary and sufficient for a given object to be recognised as an example of the concept. Let us illustrate this on the example of a square, defined as a geometric figure that meets two conditions: [w1] has 4 equal sides, and [w2] 4 90-degree angles. The first condition is necessary but not sufficient. All squares meet this condition but so do rhombuses, thus, it is not a sufficient condition. All squares fit the w1 and w2 conditions, and no nonsquares fit both of them. So using a formal concept of SQUARE we have only 2 degrees of belongings of exemplars: 1 for all squares and 0 for all nonsquares.

\footnotetext{
* Faculty of Management, University of Warsaw, Poland, https://orcid.org/0000-0002-3307-1679

** Faculty of Management, University of Warsaw, Poland, https://orcid.org/0000-0002-0672-7513
} 
In social sciences and in everyday life we don't use formal concepts but natural ones (categories) that cannot be defined with equal precision. Natural concepts are described by the most typical exemplar called a prototype.

Even concept SQUARE is used by people in everyday life as a natural one. We can categorize shapes of carpets using more than 2 values by saying that one carpet is more SQUARE like than the other, but the third one cannot be described as a square. So using a natural concept of SQUARE we have more degrees of belongings of exemplars. We can say that carpet \#1 is more SQUARE like (degree of belonging $=0.8$ ) than the carpet \#2 (degree of belonging $=0.6$ ) other, but the third one cannot be described as a square (degree of belonging $=0$ ). The prototype of a natural concept of a square is a figure that meets both formal requirements. Different object can be more or less different from the prototype.

Analogically we have a prototype of proceduralised work (with the highest degree of routinisation) is assembly line work, where every movement of the worker is precisely programmed. Different jobs can be compared with this prototype.

\section{DEGREE OF ROUTINISATION OF WORK}

As we said before we can not specify precise conditions for work to be considered as proceduralised ${ }^{1}$ or not (2 values), but we can compare different jobs on the dimension of routinisation.

Procedures often describe sequences of actions that the employee has no right to change. Processes with a medium degree of routinisation are applied in project management methodologies and good practice collections (e.g., PMBOK, Prince2, and ITIL). Work with a low degree of proceduralisation/routinisation is usually mentioned in the context of organisations operating in a very unstable environment, often requiring unforeseen actions to be taken e.g., consulting companies, hospitals, and law firms (Pava, 1983). Such work requires solving problems that are unstructured (to a greater or lesser extent).

The performance of simple procedures may lead to an unpleasant monotony. If excitation evoked by monotonous stimuli exceeds a certain level, it is switched to inhibition, which also leads to extending the response time and weakening vigilance. Drowsiness is an example of the protective inhibition of the cerebral cortex caused by monotonous stimuli. The monotony level of work is comprised of both the characteristics of the environment and the work process. On the other hand, repetitive elements can give a pleasant "rest". At this point, it is also worth calling to mind studies (Monahan, Murphy \& Zajonc, 2000) comparing the impact of a single exposure of 25 stimuli with the fivefold exposure of 5 stimuli. They demonstrated that repeating stimulation gives rise to a temporary generalised improvement of the affective state. This study may explain the positive impact of that meditation, the recitation of litanies, or listening to song choruses has on our mind. The repetition of both sounds and movements gives rise to a relaxation response. Moreover, this also explains the positive impact of music and dance on our wellbeing.

Carrying out procedures may also have a similar effect. Some employees actually prefer the stabilisation and security associated with them not having to make decisions concerning their work. Some prefer routines, repetition, and specific and set out methods of work rather than change, diversity or decision-making. Other employees, on the other hand, have more satisfaction from being able to decide about their duties. In our studies where three groups of employees with higher education were asked if they find chaos, too much information, or monotony more tiring, most respondents $[55 \%, 77 \%$, and $54 \%$, respectively] pointed to monotony as being more tedious.

1 Similarly much time has been spent on vain attempts to precisely define motivation, personality, and leadership. 
Decisions concerning what, how, and in which order we do things are constantly being made by us. What time we are going to have Sunday lunch, when we are going to do the cleaning, go shopping, or our next holiday destination... Some people simplify their lives by repeating the same decisions and sequences of actions, while others keep on starting over. Routinised (simplified and implemented) action schemata require much less energy than continually discovering new and previously unknown solutions (Pleskac \&Werhsbale, 2014). A measure of the individual propensity for developing and implementing routine choices in life is important as it allows us to gain a better understanding of (Gersick \& Hackman, 1990; Weick, 1979) and to better predict the adaptation process to the organisational routines imposed on employees (Laureiro-Martinez, 2014).

\section{PREDISPOSITIONS}

When assessing potential employees, we use various different terms: ability, skill, qualifications, competences, predispositions, and preferences. We make inferences about qualifications based on past achievements, whereas, when it comes to competences, we emphasise the prediction of future achievements. Abilities designate the speed of learning - some people master instruments more quickly, others mathematics, and still others master a dance choreographic movement sequence faster than others do. Thanks to practice, persons of different abilities may NOT differ in terms of their skills, although the less talented are unlikely to become masters in their art but can still be excellent in their craft. We still know too little about the genetic determinants of the differences in predispositions, but epigenetics shows how important the influence of the environment is on gene expression. The easiest way to become a murderer is if conducive factors, both of a biological and environmental nature, appear at the same time.

Having predispositions to perform a certain type of work means that our properties allow us to carry out this job with lower psychological costs than those incurred by mismatched persons. Predispositions can also include biologically determined temperament properties such as reactivity, defined as the relation of the strength of reaction to the strength of the stimulus, resistance to being overburdened, and the need for various types of stimulation - motor, intellectual, social, etc. It is on their basis that individual differences in processing information and organising actions are shaped. The former are referred to as cognitive styles or thinking styles, the latter as styles of action. As it is difficult to separate behaviour from our thoughts, thus, it is justified to talk of cognitive behavioural styles or styles of activeness.

One of the dimensions of a point working style (Wieczorkowska, 1992; Wieczorkowska \& Burnstein, 1999) is a fondness for routinisation, which may be an indicator of good work organisation but also be a necessity resulting from lower energy levels designated by temperament.

\section{QUESTIONNAIRE METHODS OF THE MEASUREMENT OF PREDISPOSITIONS}

The well-known expression of Gordon Allport: "If you want to know something about a person, why not first ask him?", triggered a plethora of different self-descriptive techniques measuring a variety of psychological traits. The internet is also a place where we can find many professional companies offering such diagnoses.

One such example is the popular questionnaire rooted in the Five-Factor Model of Personality that was developed on the basis of lexical studies. The short version of the NEO-FFI inventory contains 60 questions allowing a respondent to be described in terms of 5 dimensions: neuroticism, extraversion, openness to experience, agreeableness, and conscientiousness. Theoretically, we can try to predict the predispositions of an employee to proceduralised work on the level of their personality 
- using the responses to questions in the openness to experience and conscientiousness scales. People with low results in the openness to experience scale and scoring high in conscientiousness should feel more comfortable with proceduralised work. The NEO-FFI questionnaire consists of first-person singular imperative sentences, which may be problematic if the respondent lacks the relevant experience. Taking, for example, the sentence stating "I often try new and exotic meals", it may be negated by both those who do not like novelty and those who would like to experiment with exotic meals but have not yet had the chance to. However, the biggest problem is the lack of uniformity of both theoretical constructs. In the set measuring openness to experience, as many as $1 / 4$ of the questions concern interests in art/poetry. "Conscientiousness", another scale of the NEO-FFI, entails both the need for achievements and responsibility, and pedantry. This lack of heterogeneity makes it difficult to imagine a person who would obtain a high/low result on the scale. Allport had already pointed this problem out, stating that the factors obtained in the analysis are dimensions of an averaged personality that is completely abstract, and of no use to a psychologist wanting to probe the personality of specific persons. It is difficult to reject a questionnaire measure until a better method of measurement is found, but we do have to bear in mind that when measuring the properties of persons using tests similar to the NEO-FFI, we are tearing apart the relationship with the behavioural observation level, and are analysing statistical abstracts. The proponents of such a method of measurement will argue that the NEO-FFI scales have high reliability (homogeneity) indexes measured using Cronbach's alpha, forgetting that it fails to guarantee the single-factoredness of scales. It is very easy to obtain a high alpha if we take a sufficiently large number of nonnegatively correlated questions.

Apart from questionnaires containing single sentences/questions, there are also tools available that require the person being diagnosed to select one of two options. There is, by way of example, the Survey on Styles of Activity (SSA) made up of items comprising opposing descriptions of the behaviours of two persons: A and B, and the following questions: "Would your behaviour/feelings in this situation be more similar to A, mostly to A, to B, or mostly to B?" The respondent can also choose the "It's difficult to say" response, which is treated as the mid-point on the scale.

This way of formulating questions seems to have undeniable advantages because high/low results are obtained by respondents who point to person $\mathrm{A}$ in half of the items, and to person $\mathrm{B}$ in the rest of the items, which eliminates the effects of the tendency towards acquiescence. What is important is that SSA questions are directly related to the organisation of actions, thanks to which it is very easy to imagine the behaviour of a person who has obtained high/low results on the scale.

Information about somebody different, person A, or person B, behaving in a certain way somehow legitimises this behaviour, which weakens the effect of the social approval variable. One difficulty in phrasing questions containing binary choices is the fact that not all interesting aspects can be presented in the form of a simple alternative.

The main SSA psychometric requirement was for the developed scales to meet measurement model assumptions, thus, mainly for them to be single-factor, even at the cost of a substantial reduction in the number of questions.

\section{LIMITATION OF QUESTIONNAIRE TECHNIQUES}

When creating various questionnaire tools, we forget that it has already been demonstrated in a series of studies that we are often unconscious of the influences to which we succumb, however, this does not stop us from being convinced that we are perfectly capable of accurately pointing to the reasons behind our thoughts, feelings, and behaviours. Self-descriptions refer to knowledge about the Self. For some people, their responses to questionnaire questions result from their deliberations 
on the matter, while for others, who have never spared a thought about it, their responses are created "on-line". We differ in terms of our abilities and our propensity to self-reflect, alike, and it is these differences that affect the measurement accuracy. We can go through life without any insight into the mechanisms underpinning our behaviours. Looking at ourselves introspectively, from the point of view of a detached observer, to many of us, unfortunately, seems to be an artificial and completely unnecessary task. In effect, we are unaware of the defence mechanisms that distort our Self-image. We perceive others much more accurately.

Exactly how useful the analysis of self-descriptions is depends on many factors. Responses may be relatively more reliable if questions refer to overt attitudes and the person being diagnosed is not interested in making a good impression, is motivated to gain insight into their own predispositions, and has the propensity to self-reflect and self-observe. Persons allowing themselves to be diagnosed, often creating their own image, present themselves in such a way as to protect their self-esteem and meet the perceived expectations of the employer.

Another example is questionnaires measuring emotional intelligence through self-description. Self-descriptive techniques concerning emotional abilities can be compared to the questions being asked in a school intelligence test, that is: "Do you think that you're intelligent?". Task-oriented evaluations of intelligence evoke much more trust in us. The only problem is that, although it is easy to test mathematical abilities, emotional abilities are mainly manifest in the use of contextual information, mainly non-verbal communication, which are not even supplied by audiovisual tools, not mentioning questionnaires based on verbal communication.

\section{IMPORTANCE OF RESPONSE STYLE TO QUESTIONS}

In the study described in detail in the doctoral dissertation of Karczewski (2019) employees from different corporations responded ${ }^{1}$ to 102 self-descriptive questions and provided the e-mail addresses of at least 3 colleagues who know them well and who agreed to provide some information about them by answering the same questions. After the data cleaning procedure described in the doctoral dissertation, the subject of analysis were the responses of 1132 (44\% male) persons being diagnosed and of $\mathbf{4 7 4 8}$ colleagues of theirs.

The theoretical framework for the measurement was Gallup's Clifton StrengthsFinder assessment, based on the premise that 5 characteristic talents can be identified for each employee. The 177-item questionnaire measuring 34 talents was developed in the 1980s by Donald O. Clifton and his former student M. Buckingham. The copyrights to it were purchased by the Gallup Institute, which maintains on its website that over 20 million persons have so far received the talent assessments. The 102-item instrument based on Gallup's Clifton StrengthsFinder assessment is available on the Polish market.

The subject of our analysis is the indicators of two "talents": meticulousness (discipline in Gallup's wording) and adaptability, each built on the basis of the responses to 3 questions. The scale of responses depends on whether the questions were answered by the person who was assessing themselves (focus: SELF) or by the person who was assessing their colleague (focus: he/she).

Tables 1 and 2 show the distribution of responses from the point of view of each of the groups:

1 They were asked not to spend more than 10 seconds on each question. 
Table 1. METICULOUSNESS: distribution of responses to relevant questions for the self-description (focus: SELF) and for the description of colleagues (focus: he/she)

\begin{tabular}{|c|c|c|c|c|c|c|}
\hline \multirow[b]{2}{*}{ Answer } & \multicolumn{2}{|c|}{$\begin{array}{c}\text { Frequently pay attention } \\
\text { to detail }\end{array}$} & \multicolumn{2}{|c|}{$\begin{array}{l}\text { I like creating detailed } \\
\text { action plans }\end{array}$} & \multicolumn{2}{|c|}{$\begin{array}{c}\text { I often think: This has to be put } \\
\text { in order, the actions have to be } \\
\text { planned step-by-step }\end{array}$} \\
\hline & Self & he/she & Self & he/she & Self & he/she \\
\hline 1 & 18.4 & 20.0 & 14.9 & 24.0 & 17.0 & 34.4 \\
\hline 2 & 43.8 & 40.0 & 38.3 & 39.5 & 52.2 & 48.3 \\
\hline 3 & 23.1 & 23.6 & 24.6 & 20.9 & 20.3 & 10.5 \\
\hline 4 & 12.7 & 14.7 & 18.1 & 13.4 & 9.0 & 5.6 \\
\hline 5 & 1.9 & 1.7 & 4.1 & 2.3 & 1.5 & 1.2 \\
\hline
\end{tabular}

Response scale:

For SELF: 1 - Strongly describes me, 2 - Describes me well, 3 - Neither yes, nor no, 4 - Doesn't describe me, 5 - Doesn't describe me at all

For him/her: 1 - Strongly describes them, 2 - Describes them well, 3 - Neither yes, nor no, 4 - Doesn't describe them, 5 - Doesn't describe them at all

Table 2. ADAPTABILITY: distribution of responses to relevant questions for the self-description (focus: SELF) and for the description of colleagues (focus: he/she)

\begin{tabular}{|c|c|c|c|c|c|c|}
\hline \multirow[b]{2}{*}{ Answer } & \multicolumn{2}{|c|}{$\begin{array}{l}\text { I easily adapt to changing } \\
\text { circumstances }\end{array}$} & \multicolumn{2}{|c|}{$\begin{array}{l}\text { I like doing many things at } \\
\text { once - I'm inspired by new } \\
\text { circumstances }\end{array}$} & \multicolumn{2}{|c|}{$\begin{array}{l}\text { New circumstances are there to } \\
\text { adjust to them - I always treat } \\
\text { change as something natural }\end{array}$} \\
\hline & Self & he/she & Self & he/she & Self & he/she \\
\hline 1 & 26.7 & 27.1 & 19.0 & 18.4 & 22.7 & 20.9 \\
\hline 2 & 49.7 & 47.2 & 42.6 & 39.6 & 54.5 & 48.1 \\
\hline 3 & 16.3 & 15.5 & 21.1 & 24.4 & 16.4 & 19.6 \\
\hline 4 & 6.8 & 9.2 & 14.2 & 15.3 & 6.0 & 10.1 \\
\hline 5 & 0.5 & 1.0 & 3.1 & 2.2 & 0.4 & 1.3 \\
\hline
\end{tabular}

Response scale:

For SELF: 1 - Strongly describes me 2 - Describes me well 3 - Neither yes, nor no, 4 - Doesn't describe me, 5 - Doesn't describe me at all For him/her: 1 - Strongly describes them, 2 - Describes them well, 3 - Neither yes, nor no, 4 - Doesn't describe them, 5 - Doesn't describe them at all

The responses to the above questions allow indicators to be built and (it would seem) for talents to be diagnosed. Unfortunately, such a standard analysis fails to factor in the respondent response style, which distorts the results.

We forget that the responses of the respondents to the questions posed are not always the result of the transformation of the inner assessment into the response scale prepared by the researcher. In order to answer closed-ended questions, the respondent has to transpose their "private" assessment into the response scale supplied by the researchers, for example: two, three, five, seven-... point (see Figure 1). 
Figure 1. Sample response scales for closed-ended questions. The deprived of content response of "Difficult to say" should be placed at the end of the scale but then it is often recoded into a median value

\begin{tabular}{|l|l|l|l|l|l|l|}
\hline 1 & 2 & 3 & 4 & 5 & 6 & disagree \\
\hline $\begin{array}{l}\text { Strongly } \\
\text { agree }\end{array}$ & agree & $\begin{array}{l}\text { Slightly } \\
\text { agree }\end{array}$ & $\begin{array}{l}\text { Slightly } \\
\text { disagree }\end{array}$ & $\begin{array}{l}\text { Strongly } \\
\text { disagree }\end{array}$ & $\begin{array}{l}\text { Difficult } \\
\text { to say }\end{array}$ \\
\hline
\end{tabular}

\begin{tabular}{|l|l|l|l|l|}
\hline 1 & 2 & 3 & 4 & \\
\hline $\begin{array}{l}\text { Strongly } \\
\text { agree }\end{array}$ & agree & disagree & $\begin{array}{l}\text { Strongly } \\
\text { disagree }\end{array}$ & $\begin{array}{l}\text { Difficult } \\
\text { to say }\end{array}$ \\
\hline
\end{tabular}

\begin{tabular}{|l|l|l|}
\hline 1 & 2 & \\
\hline agree & disagree & $\begin{array}{l}\text { Difficult } \\
\text { to say }\end{array}$ \\
\hline
\end{tabular}

\begin{tabular}{|l|l|}
\hline 1 & 2 \\
\hline agree & disagree \\
\hline
\end{tabular}

Are the persons responding to closed-ended questions not at all bothered about the response scale prepared for them by the investigator? Of course not! We asked the respondents to rank 6 possible response scales for a specific question, ranging from: their MOST preferred (ranked as 1) to their LEAST preferred (ranked as 6).

As we expected, there were different preferences even in such a homogenous sample as University of Warsaw students. A 7-point scale that includes a midpoint and an available "don't know" response was selected as the most preferred scale by almost $\mathbf{3 5 \%}$, and as the least preferred by over $\mathbf{2 6 \%}$. A 2-point scale was chosen as the most preferred by almost $\mathbf{1 6 \%}$, and as the least preferred by over $\mathbf{4 8 \%}$. Preferences with regard to the response scale may depend on the types of questions being put, but also be a characteristic of the respondent, in other words, depend slightly on the object that is currently being assessed. We can then speak of a response STYLE.

The transformation of the inner opinion into a scale with only two responses may be the most difficult. These appeal to respondents inclined to perceive the world dichotomically (which may but does not have to be linked to a lower level of education), and to those who consider the question matter of little importance. Dichotomous questions are not well received by "cognitively complex" respondents who feel forced to choose between two extremes, which do not give across their views fully. That is when they usually get discouraged from responding to questions phrased in this way. Researchers often include a midpoint on the scale ("Slightly agree/disagree", "neither agree nor disagree", etc.), which provides an escape from assuming an opinion. Research has shown that the absence of a midpoint answer does not increase the number of responses that are devoid of content, hence, its inclusion on the scale is pointless.

A respondent's answers may be affected by the need for social approval, manifest in the tendency to use positive response categories (acquiescence response style), or, on the contrary, the need to present oneself as being nonconformist, expressed in the tendency to use negative response categories (dis acquiescence response style) (Harzing, 2006). Some only pick the extremes 
of a response scale (extreme response style), which may be interpreted as having an intolerance of ambiguity or a sign of more weakly articulated cognitive structures. Extreme responses concern important, emotionally engaging objects. Failing to take the response style differences into account may lead to distorted findings, which has been demonstrated in comparative studies of Polish and German teenagers (Wieczorkowska \& Smoleńska, 1993), response comparisons of Italian and Japanese respondents in ISSP surveys (Wieczorkowska, Wierzbiński \& Kuźmińska, 2013), and in marketing research alike (Baumgartner \& Steenkamp, 2001).

\section{NECESSITY OF IPSATIZATION}

There is no reason to assume that the responses to survey questions were not distorted by the response style of the person answering the question. In order to factor in the "use of the response scale" by the responding person, the simplest transformation is the IPSATIZATION of results, in other words, presenting the responses to the questions posed in the form of distances from a set point on a scale and the mean from the responses to all the questions.

To illustrate this, let us compare raw and ipsatised results of two respondents: Eve and Adam, who obtained the following results on the meticulousness and adaptability scale

\begin{tabular}{ccc}
\hline raw results & Meticulousness & Adaptability \\
\hline Eve & 2 & 3 \\
Adam & 5 & 4 \\
\hline
\end{tabular}

When comparing the raw numbers on the scale, we will find that Adam is both more orderly (his score is higher on the meticulousness dimension) and more flexible (his score is higher on the adaptability dimension) than Eve. If, however, we calculate that they used the response scale differently because the mean response to 102 questions for Eve was 2.5, and came to 4.5 for Adam, hen,

\begin{tabular}{cccc}
\hline raw results & meticulousness & adaptability & average use of scale \\
\hline Eve & $2-2.5=\mathbf{- 0 . 5}$ & $3-2.5=\mathbf{0 . 5}$ & 2.5 \\
Adam & $5-4.5=\mathbf{0 . 5}$ & $4-4.5=\mathbf{- 0 . 5}$ & 4.5 \\
\hline
\end{tabular}

comparing the ipsatised results, we will say that Adam is more orderly but less flexible than Eve.

In the studies described by Karczewski, the average of the responses to the 102 questions was calculated and named the SCALE indicator. The dominant tendency was "ascribing the possession of talents, since the self-descriptions averaged $3.74(\mathrm{~s}=0.3 \mathrm{~N}=1132)$. The colleague description average was even higher.

Figure 2 below presents the distributions for this indicator, showing considerable interpersonal differentiation in the way the response scale was used (for the lower $10 \%$, the average was smaller than 3.36 , for the upper $10 \%$, it was greater than 4.11 ). 
Figure 2.

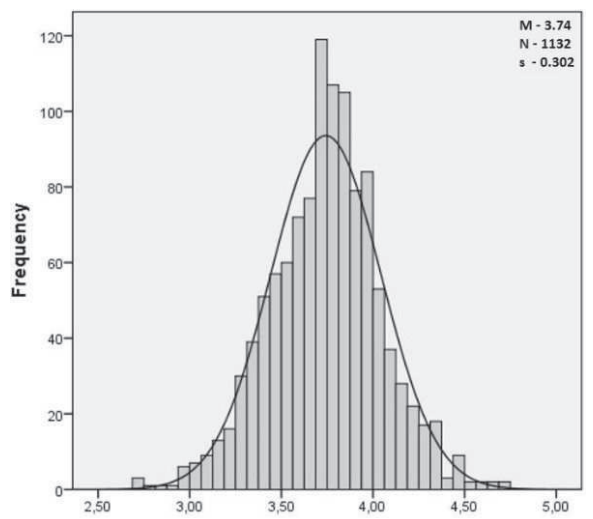

Let us now compare the distributions, Cronbach's alphas, and correlation coefficients between the two indicators created for

- $\quad$ self-descriptions $\mathrm{N}=1132$

- colleague descriptions $\mathrm{N}=4748$

The doctoral dissertation of Karczewski also presented analyses after the aggregation of the object of assessment (average rating of at least 3 colleagues $\mathrm{N}=1132$ ), but this issue was omitted from it due to the volume limitations.

A comparison of the results of both these indicators (raw values vs ipsatised values) reveals that the variable is "more continuous" after ipsatisation, meaning that it accepts more values, which is not, by any means, of trivial significance when we want to divide the group according to positional measures (see ordered distributions - figures 3-6, the distributions for adaptability look similar).

The release of values of the METICULOUSNESS and ADAPTABILITY indicators from the effect of the response style gave rise to a higher degree of correlation of questions creating the same factor indicated by Cronbach's alpha (see Table 4).

Figure 3. Meticulousness - self-descriptions (after ipsatiZation)

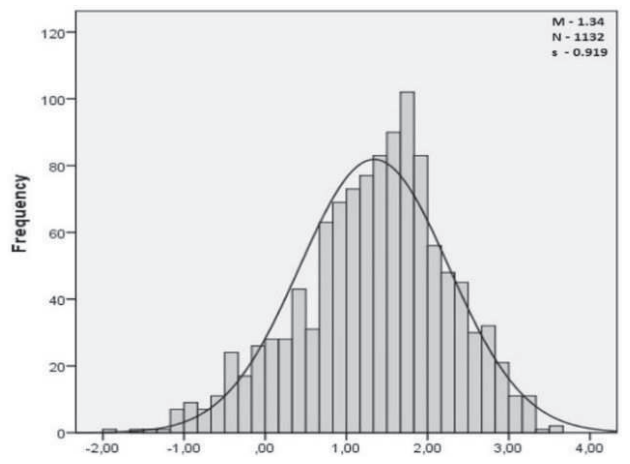

Figure 4. Meticulousness - colleague descriptions (after ipsatiZation)

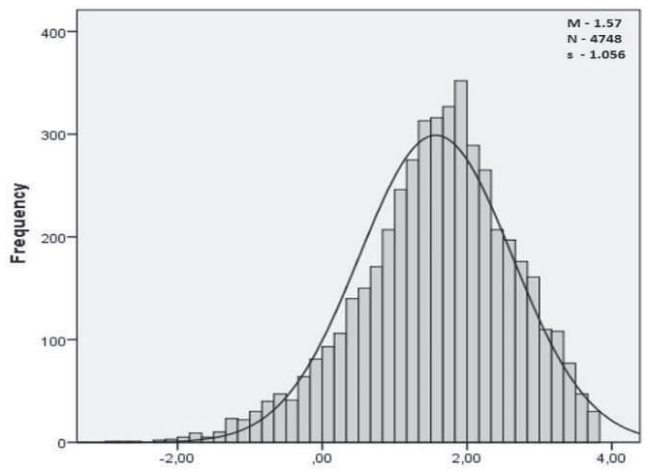


Figure 5. Meticulousness - self-descriptions (before ipsatiZation)

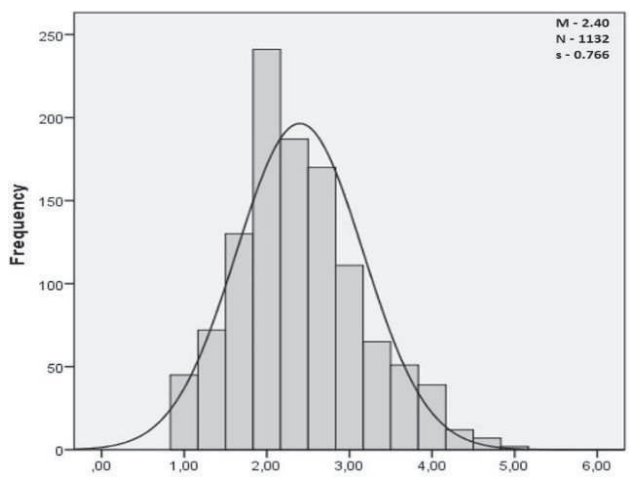

Figure 6. Meticulousness - colleague descriptions (before ipsatiZation)

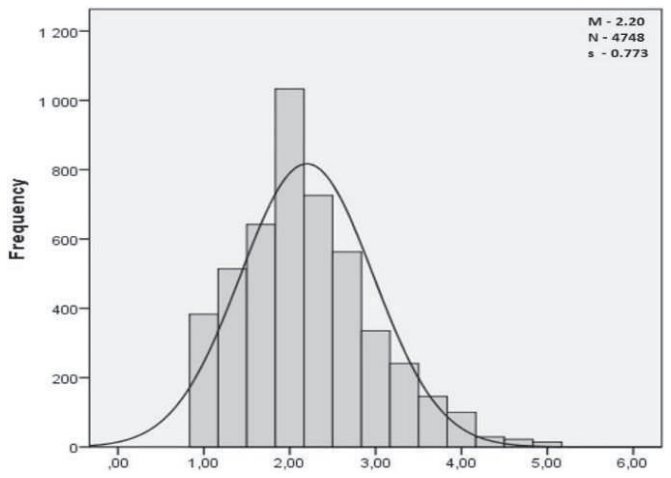

Table 4. The effect of ipsatization on Cronbach's alpha for both scales

\begin{tabular}{llcc}
\hline \multirow{2}{*}{ assessment dimension } & \multicolumn{1}{c}{$\begin{array}{c}\text { data } \\
\text { type }\end{array}$} & $\begin{array}{c}\text { self-description } \\
\mathrm{N}=1132\end{array}$ & $\begin{array}{c}\text { colleague description } \\
\mathrm{N}=4748\end{array}$ \\
\hline $\begin{array}{l}\text { ADAPTABILITY } \\
3 \text { questions }\end{array}$ & $\mathrm{Raw}$ & 0.644 & 0.713 \\
\cline { 2 - 4 } $\begin{array}{l}\text { METICULOUSNESS } \\
3 \text { questions }\end{array}$ & after ipsatization & 0.781 & 0.852 \\
\hline
\end{tabular}

The most important difference, however, concerns the correlation between the two "talents". According to the theory, we could predict that the focus on meticulousness may reduce adaptability, which seems to confirm the not very high but significantly negative correlation coefficient for selfdescriptions $r=-0.101$. However, already in the colleague assessments, all the "talents" are positively correlated with the remaining talents. Seeing the significantly positive correlation coefficient of $\mathrm{r}=+0.16$, we could conclude that meticulousness is conducive to adaptability.

The ipsatisation of results, on the other hand, gives us unequivocal conclusions that are also consistent with the theory (see Table 5)

Table 5. The correlation coefficient between meticulousness and adaptability (all coefficients are statistically significant)

\begin{tabular}{lcc}
\hline data type & $\begin{array}{c}\text { self-description } \\
\mathrm{N}=1132\end{array}$ & $\begin{array}{c}\text { colleague description } \\
\mathrm{N}=4748\end{array}$ \\
\hline Raw & -0.101 & 0.16 \\
after ipsatisation & -0.357 & -0.263 \\
\hline
\end{tabular}

Conclusion - in order for Gallup's diagnosis of talents performed on over 20 million employees to be to used in further research, the results should be freed from the distorting impact of the 
"response style". The rank results for an individual will not change - the ipsatization of 34 talents is a linear transformation and, therefore, it retains the rank order of raw data. It is, however, necessary if we want to compare, for instance, the talents of two employees.

\section{NON-QUESTIONNAIRE METHODS OF MEASUREMENT OF PREDISPOSITIONS}

It can be presumed that psychometric instruments based on self-description turned out to be a blind alley in science, as evidenced by the absence of any progress in psychometry in recent decades, but we must remember that although self-description is a highly imperfect measurement tool, it is, however, better than no instrument at all.

Measurement flaws are a problem that disqualifies our results only if we fail to see them. If we are aware of the inevitable distortions that our self-descriptions are subject to, we can take steps to make appropriate adjustments.

A subtler method of diagnosis could be analysing the non-verbal indicators like facial expressions, body movements, or changes in the way a person speaks, or the continuous capture of physiological measurements throughout the performance of various types of tasks. Such observations may be valuable because, compared to self-description: many non-verbal behaviours are less subject to conscious control and censorship. Non-verbal behaviours can be measured without turning the attention of the person being diagnosed to that fact that measurements are being taken.

We have to remember, however, that:

Physiological measurements, like the heart rate, and the galvanic skin response, are indicators of the general level of arousal, without differentiating between the types. New possibilities that are provided by neuroimaging do not yet allow for its mass application.

The comparison of non-verbal reactions of various people does not make much sense because the interpersonal differences are very large in this extent. The non-verbal expressions of some people are very limited but very vivid for others. Comparisons can be made only "within a person", similarly to polygraph tests where the recording of physiological changes are not compared to any external "standards", just to the differences "within a person" when they give TRUE or FALSE responses to questions with a known and unknown correct answer. Knowing the recording of physiological reactions accompanying these answers that are characteristic of a given person, we can try to predict when a person is lying. Computer software can now monitor the pupil size and alert us once the vigilance of the person being monitored falls.

When observing a respondent completing a questionnaire, we can sometimes notice signs of mental/emotional withdrawal: "What stupid questions these are! How much more of this is there?". This is an indicator of low involvement, which indicates a low level of psychological realism, and it poses a greater threat to the accuracy of diagnoses than a low situational realism ${ }^{1}$. That is why the use of diagnostic games is so valuable, where everything that is happening is real, important, and affects our thoughts, feelings, and behaviours. In this setting nobody can say that they are bored any more.

A series of tasks were developed at the Department of Managerial Psychology and Sociology during which several things are measured, e.g. resistance to boredom and distractors, speed of differentiation, level of concentration under time and or pressure. We should remember, however, that a diagnosis of predispositions should not be based on a single outcome but on the speed of learning and the subjective evaluation of psychological costs involved in carrying out a given type of task.

\footnotetext{
Situational (mundane) realism refers to the extent to which the experimental situation is similar to situations people are likely to encounter outside of the laboratory. Psychological (experimental) realism is the extent to which situations created in social psychology experiments are real and impactful to participants (compare: Aronson \& Wieczorkowska, 2001).
} 
If our goal is, for instance, to diagnose the ability to categorise, so vital in times of an excessive choice of products and information, the speed at which a person masters it is imperative. It is also important to remember that our behaviour changes depending on whether we are playing against a computer or another person. Repeatedly replicated studies using the "ULIMATUM" game requiring the acceptance or rejection of the proposal to share $\$ 10$ between players have shown that we will accept any amount, no matter how small, from a computer but only an amount that is considered as "fair" from a person. The neuroimaging studies of the players demonstrated that the low offers given by a person activate areas "responsible for" negative emotions. The stronger the stimulation of this area, compared to the area involved in the "pursuit of goals", the greater the probability of rejection of such an offer. These dependencies were not found when it came to playing against a computer. It follows from this that it is worth introducing interactions with other people to diagnostic games, even in the form of a simulation of a conversation through a communicator.

\section{SUMMARY}

Just like the breakthrough in medicine came not through new theories but through the advancement of technology, so too will be the case when it comes to management science. All that remains is to wait patiently, working intensely with the tools currently available to us. A good diagnostic instrument can help us gain a greater self-awareness of our predispositions and, in so doing, better understand the costs incurred by us when doing our work. There are professions that can be carried out only in point (Wieczorkowska, 1992) form: sequentially and precisely, such as that of a surgeon or a pharmacist. In other professions, like journalism, different action styles may give equally good results. Sometimes different elements of complex works require different predispositions. In the work of a professor, both introverts and extraverts are awarded bonuses. Can it be presumed that a diagnosed propensity for routinisation is an indication to choose proceduralised work? Reluctance to routinisation in employment in the liberal professions as well as teleworking may end with a motivational paralysis. Writers waiting for inspiration or attempting to write several books at once vs those that sit down to write every day at a set time are a good example for the analysis of the consequences of how well-matched a person is. The lack of external restrictions in liberal professions requires self-meticulousness, thus, the ability to establish routines is extremely valuable. A moderately ill-match of predispositions/preferences to the environmental requirements may stimulate development, while a completely ill match is tantamount to stagnation. Another thing worth keeping in mind is that significant bonuses and penalties may modify the action style. Experimental studies have shown that respondents can adjust their behaviour to the instructions to exercise greater or less precision in carrying out a command. However, the differences appear on the level of the subjectively assessed costs by them. The effectiveness of a style of action depends both on the environmental requirements and on the energy capacity set out by temperament. Not being well-matched results in overload, which is manifest in a lower wellbeing on the emotional and cognitive level alike.

Therefore, the way we do our work does not depend solely on what we like. Oftentimes we have no choice. It is estimated that only $20 \%$ of the sellers of advanced technologies actually like having contacts with clients. Employee predispositions/preferences were taken into account in one of the sales firms where sellers were having 2 to 3 meetings per week with clients. Instead of settling accounts with employees separately, they work in a team. This allows those sellers who like having contact with people to carry out many more meetings with clients, leaving the two other sellers to prepare the meeting documentation and any new offers. This is a positive example of how an accurate diagnosis of employee predispositions has led to the reorganisation of work in a manner that enhanced both employee productivity and satisfaction. 


\section{Literature}

Aronson, E., \& Wieczorkowska, G. (2001). Kontrola naszych myśli i uczuć. Warszawa: Santorski.

Baumgartner, H., \& Steenkamp, J. B. (2001). Response Styles in Marketing Research: A Cross-National Investigation. Journal of Marketing Research, 38(2), 143-156, https://doi.org/10.1509/jmkr.38.2.143.18840.

Gersick, C. J., Hackman, R. J. (1990). Habitual routines in task-performing groups. Organizational Behavior and Human Decision Processes, 47(1), 65-97, https://doi.org/10.1016/0749-5978(90)90047-D.

Harzing, A. W. (2006). Response Styles in Cross-national Survey Research: 26-country Study. International Journal of Cross Cultural Management, 6(2), 243-266, http://dx.doi.org/10.1177/1470595806066332.

Karczewski, W. (2019). Predyspozycje do wykonywania pracy wysoko zrutynizowanej. Rekomendacje dla zarzadzania zasobami ludzkimi (Unpublished doctoral dissertation) Warszawa: University of Warsaw.

Laureiro-Martinez, D. (2014). Cognitive Control Capabilities, Routinization Propensity and Decision Making Performance. Organization Science, 25(4), 1111-1133, https://doi.org/10.1287/orsc.2014.0899.

Monahan, J. L., Murphy, S. T., Zajonc, R. B. (2000). Subliminal mere exposure: Specific, general, and diffuse effects. Psychological Science, 11(6), 462-466, https://doi.org/10.1111/1467-9280.00289.

Pava, C.H.P. (1983). Designing managerial and professional work for high performance: A sociotechnical approach. National Productivity Review, 2(2), 126-135, https://doi.org/10.1002/npr.4040020204.

Pleskac, T. J., \& Wershbale, A. (2014). Making assessments while taking repeated risks: A pattern of multiple response pathways. Journal of Experimental Psychology: General, 143(1), 142-162, http://dx.doi.org/10.1037/ $\mathrm{a} 0031106$.

Weick, K. E. (1979). The social psychology of organizing. New York: McGraw-Hill

Wieczorkowska, G., \& Smoleńska, M. Z. (1993). Kryteria wartościowania u młodzieży w latach 1985-1990. Psychologia Wychowawcza, 2, 122-131.

Wieczorkowska, G., \& Burnstein, E. (1999). Adapting to the transition from Socialism to Capitalism in Poland: The Role of Search Costs and Screening Strategies in Social Change. Psychological Science, 10(2), 98-105, https://doi.org/10.1111/1467-9280.00115.

Wieczorkowska-Siarkiewicz, G. (1992). Punktowe i przedziałowe reprezentacje celu. Uwarunkowania $i$ konsekwencje. Warszawa: University of Warsaw.

Wieczorkowska-Wierzbińska, G., Wierzbiński, J., \& Kuźmińska, A. (2014). Porównywalność danych sondażowych zebranych w różnych krajach. Psychologia Społeczna, 2(29), 128-143, doi: 10.7366/1896180020142901. 


\title{
The Investigation of a Weak Form of the Efficient Market Hypothesis: Evidence From Stock Markets in the European Union
}

\author{
Jacek Karasiński*
}

\begin{abstract}
Summary
The purpose of this article is to examine whether returns of main indexes of selected stock exchanges in the European Union are subject to the random walk model proposed by L. Bacheliere in 1900, which is considered by many researchers to be a synonym of a weak form of the efficient market. The research was conducted for the main indexes of eight selected European stock exchanges representing markets of a different capitalisation. In order to check whether the level of informational efficiency was stable in a whole research period, namely in the years 2000-2017, the research period was divided into three equal six years sub-periods. To test a weak form of the efficient market hypothesis (EMH), four different tests of returns distribution normality were done for daily, weekly, monthly and quarterly intervals. The conducted study allowed for rejecting the null hypothesis saying that returns are subject to the random walk model proposed by L. Bacheliere which leads to normal distribution. Moreover, some significant differences between the research periods occurred. Nonetheless as the random walk model seems to be too strict even for the biggest European markets, it is proposed to test whether the returns can be subject to other stable distributions like the Pareto distribution, which gives higher probability to extremely low and high returns of what resembles actual price fluctuations of financial markets.
\end{abstract}

Keywords: Efficient market hypothesis, Weak form efficiency, Stock markets, The European Union, Random walk

JEL: E44, G10, G14

\section{INTRODUCTION}

The high formalization of information transmission mechanisms on the regulated markets in the European Union aids a common and equal access to information, as well as safety and transparency of trading (Dziawgo, 2011). The mechanisms of the information transmission mentioned are to the greatest extent responsible for informational efficiency of the market, as on the efficient market the prices change due to new information and the situation expected by investors in the future. Moreover, on the efficient market the prices stay unchanged until the new, economically significant information is published (Czekaj, 2014). The abovementioned results from the definition of the efficient market proposed by E. Fama (1970), which states that available information is fully reflected by the prices. What is more E. Fama (1970) distinguished three types of informational market efficiency depending on the set of information - namely a weak, semi-strong and strong informational market efficiency. The weak form of the efficient market hypothesis (EMH) formulated by E. Fama (1970) and M. C. Jensen (1978) states that the current prices of financial assets reflect historical information and the expected situation, which means that the current prices vary randomly in a way impossible to predict (Kilon and Jamróz, 2015). The first model of the stochastic process of stock prices fluctuation, called a random walk model, was proposed by L. Bacheliere in 1900 . His model is considered by many researchers to be a synonym of informational efficiency of the market in a weak form, which indicates that the short-term returns fluctuations are random and fully reflect any information at any time (Czekaj, 2014).

The aim of this paper is to examine whether returns of the main indexes of selected European stock exchanges are efficient in a weak form. Taking into account that the random walk model

\footnotetext{
Faculty of Management, University of Warsaw, Poland, https://orcid.org/0000-0003-4326-5044, e-mail: jkarasinski@ wz.uw.edu.pl
} 
of L. Bacheliere from 1900 leads to a normal distribution, in order to check whether the selected indexes were efficient in a weak form, four chosen tests of returns distribution normality were done for four different quotation intervals. As is typical for the research on market efficiency, the null hypothesis was that the markets were efficient. The research was conducted for the main indexes of eight selected stock exchanges in the European Union representing markets of a different capitalisation. In order to check whether the level of informational efficiency was stable in a whole research period, namely in the years 2000-2017, the research period was divided into three equal six years sub-periods.

\section{RESEARCH ON THE WEAK FORM OF THE EFFICIENT MARKET HYPOTHESIS}

The stock markets' weak form efficiency tests are willingly conducted on many markets all over the world. There are several main reasons for the large number of studies related to the stock markets' weak form efficiency testing. First, the markets are changing and thereupon their informational efficiency is changing as well. What is more, new markets come into being. Secondly, data necessary to conduct weak form efficiency tests is widely and easily accessible. Any researcher can easily examine the informational efficiency of any market in the world. Thirdly, weak form informational efficiency tests can be run quickly for many different shares, indexes and markets once the researcher possesses advanced statistical and econometric knowledge.

In order to test the weak form efficient market hypothesis, which is far more often tested than the semi-strong and strong one, the researchers conduct tests which can be divided into three different groups. The first group pertains to tests based on technical analysis. These methods use tools provided by technical analysis to predict the prices of financial assets. When the predictions are accurate, the hypothesis of the weak form efficient market is rejected. The second group relates to random walk testing and usually the researchers use autocorrelation tests, runs tests and unit root tests. When the returns are not subject to random walk, the hypothesis of the weak form efficient market is rejected. The third group pertains to searching for calendar and seasonal effects. When some regular calendar and seasonal effects are spotted, the hypothesis of the weak form efficient market is rejected (Czekaj, 2014).

The research of M. R. Borges (2010) can be an example of a study devoted to different European markets. She investigated weak form informational efficiency for stock market indexes in the UK, France, Germany, Spain, Greece and Portugal, from January 1993 to December 2007 using runs tests and joint variance ratio tests. Results varied depending on the country and stock returns frequency. The hypothesis of the weak form market efficiency was rejected on daily data for Portugal and Greece as well as for France and the UK on weekly data. The hypothesis wasn't rejected for Germany and Spain. A Spanish market turned out to be the most efficient one. A comprehensive research of fifteen European emerging stock markets conducted by G. Smith (2012) in the period from February 2000 to December 2009 for daily data used rolling window variance ratio tests based on returns and signs with wild bootstrapped p-values. The results reached varied across the countries. The most efficient ones were the Turkish, UK, Hungarian and Polish markets. The least efficient ones were the Ukrainian, Maltese and Estonian stock markets. J. Kilon and P. Jamróz (2015) made an attempt to answer the question of whether for the Warsaw Stock Exchange the weak form of the efficient market hypothesis can be considered true, and what its informational efficiency looks like compared to selected stock exchanges of Baltic Sea countries. The researchers performed autocorrelation tests, series tests and unit root tests in the period from January 2000 to December 2014 for nine different stock indexes including four Polish ones and five from different Baltic Sea countries. The results reached indicate some inefficiencies for all markets examined, however they do not permit to completely reject the hypothesis of a weak 
form efficiency. The main conclusion made by the authors is that the selected active investment strategies can be successful for some groups of shares on all markets examined. It especially pertains to indexes containing small and medium-sized companies, which confirms the results of other studies.

With regard to studies on the weak form efficiency of stock markets from other parts of the world, W. Abdmoulah (2010) examined eleven Arab stock markets in a ten year period ending in March 2009 using the GARCH-M $(1,1)$ approach. Results of the research indicate that all markets show high sensitivity to past shocks and are found to be weak form inefficient. What is more, no significant improvement of market informational efficiency can be seen. The author advises that in order to enhance the Arab markets' efficiency, some actions like liquidity improvement, enhancement of investment culture and spreading of institutional trading need to be undertaken. M. A. M. Al Janabi, A. Hatemi and M. Irandoust (2010) examined whether the Gulf Cooperation Council (GCC) stock markets are informationally efficient with regard to oil and gold price shocks during the period 2006-2008. The empirical findings revealed that the GCC equity markets are informationally efficient with regard to gold and oil price indexes. The main objective of the study by S. Arshad, S. A. R. Rizvi, G. M. Ghani and J. Duasa (2016) was to examine the weak form efficiency of Organization of Islamic Conference (OIC) member stock markets. The research was conducted for 11 markets and covered the period of 1998-2012. The main conclusion was that the overall efficiency varied across the countries for the short and long term, it was however improving over the years examined. The weak form market efficiency comparison of Islamic and non-Islamic stock indices made by O. M. Al-Khazali, G. Leduc and M. S. Alsayed (2016) indicated that overall the non-Islamic indices were more efficient than their Islamic counterparts. Nevertheless, during the periods of bearish stock markets all indices showed the same level of efficiency. In four subperiods of bullish and bearish stock markets over the period from 1997 to 2012 the study applied the automatic portmanteau test, the test for the martingale difference hypothesis as well as the automatic variance ratio test.

J. Appiah-Kusi and K. Menyah (2003) investigated the weak form pricing efficiency of eleven African stock markets. Results received varied across the countries. Markets in Nigeria, South Africa, Botswana, Ghana, Ivory Coast and Swaziland are not consistent with weak form efficiency in contrast to markets in Egypt, Kenya, Zimbabwe, Mauritius and Morocco. Another study by M. A. Magnusson and B. Wydick (2002) related to the African markets tested informational efficiency of the eight largest African markets using random walk tests. Results were compared with similar tests on emerging stock markets in South-East Asia and Latin America. Results reached indicate that the emerging African stock markets are more efficient in comparison to other emerging stock markets.

J. H. Kim and A. Shamsuddin (2008) tested weak form efficiency for a group of Asian markets using multiple variance ratio tests based on the wild bootstrap and signs. Hong Kong, Japanese, Korean and Taiwanese markets turned out to be efficient in the weak form. The results received showed that Singaporean and Thai markets have become efficient after the Asian crisis. The weak form efficiency hypothesis had to be rejected for Indonesia, Malaysia and the Philippines. Another research related to Asian markets by E. J. A. Lima and B. M. Tabak (2004) tests the random walk hypothesis for China, Hong Kong and Singapore. The results indicate that Chinese and Hong Kong Class A shares are weak form efficient in opposite to Singapore and Chinese Class B stocks. The authors suggest that liquidity and market capitalization may play a role in explaining results of weak form efficiency tests. The influence of the financial crisis on East Asian markets was examined by S.A.R. Rizvi and S. Arshad (2016). They applied the multifractal detrended fluctuation analysis to derive the efficiency measure for comparative analysis of crisis periods with pre-crisis and postcrisis periods. They found that the financial crisis had a negative impact on the weak form market 
efficiency. They also found that the crisis impact varied based on the economic structure of the economies.

Many studies on the weak form efficiency of markets testing random walk use autocorrelation tests, runs tests and unit root tests. However, results of studies focused on prices stationarity testing using unit root tests have low informational value. What is more, commonly used autocorrelation tests have been developed under the assumption of linearity and normality of the returns analysed. Because of that, when returns are not normally distributed, or a given study does not provide any information on returns normality, the results of autocorrelation tests have to be treated with caution (Czekaj, 2014).

\section{RESEARCH METHOD}

As it was already mentioned, the first model of stochastic process of stock prices fluctuation called a random walk model proposed by L. Bacheliere in 1900 is considered by many researchers to be a synonym of informational efficiency of the market in a weak form. It can be described by the following equation:

$$
y_{t}=y_{t-1}+\varepsilon_{t}, \quad \varepsilon_{t} i d d(0,1),
$$

where $y_{t-1}$ is price in the period $t-1, y_{t}$ is the price in the period $t$ and $\varepsilon_{t}$ is a random component reflecting the influence of new information on the price change. The main indication of the model is that the short-term returns fluctuations are random, and the prices immediately reflect accessible information. After proper transformation of the formula presented above, a density function of the normal distribution is received, which means that if the returns are subject to random walk model they have to be normally distributed (Czekaj, 2014).

$$
P(t, i)=\sqrt{\frac{2}{t \pi}} \exp \left(-\frac{\left(i-\frac{t}{2}\right)^{2}}{t}\right) d i
$$

In order to achieve the goal of this study, the selected tests of returns normality were conducted, namely the Kolmogorov-Smirnov test, the Lilliefors test, the Shapiro-Wilk test and the D'AgostinoPearson test. The null hypothesis stated that the empirical returns distribution $F$ was compatible with the normal distribution $N\left(\hat{u}, \hat{\sigma}^{\in}\right)$. It was rejected for the benefit of the alternative hypothesis stating that the empirical returns distribution $F$ was not compatible with the normal distribution $N(\hat{u}, \hat{\sigma} \in)$ when the p-value resulting from the normality test was less than the significance level of $\alpha=0.05$.

$$
\begin{aligned}
& H_{0}: F=N\left(\hat{u}, \hat{\sigma}^{\in}\right), \\
& H_{1}: F \neq N\left(\hat{u}, \hat{\sigma}^{\in}\right) .
\end{aligned}
$$

The research was conducted for the main indexes of eight selected stock exchanges in the European Union, representing markets of a different capitalisation. The selected indexes are presented in table 1. In order to check whether the level of informational efficiency was stable in a whole research period, namely in the years 2000-2017, the research period was divided into three equal six years sub-periods. The first sub-period was 2000-2005, the second one was 2006-2011 and the third one was 2012-2017. Moreover, the normality tests were performed for four different quotation intervals, namely for daily, weekly, monthly and quarterly intervals. 
Table 1. Main indexes of selected stock exchanges in the European Union

\begin{tabular}{|c|c|c|c|c|c|}
\hline Index & Stock exchange & Country & Index & Stock exchange & Country \\
\hline ATX & Vienna Stock Exchange & Austria & HEX & Helsinki Stock Exchange & Finland \\
\hline BUX & Budapest Stock Exchange & Hungary & IBEX 35 & Madrid Stock Exchange & Spain \\
\hline DAX & Frankfurt Stock Exchange & Germany & OMXS30 & Stockholm Stock Exchange & Sweden \\
\hline FTSE 100 & London Stock Exchange & UK & WIG & Warsaw Stock Exchange & Poland \\
\hline
\end{tabular}

Source: Own elaboration.

All necessary data pertaining to quotations of indexes has been obtained from the website stooq. pl. Statistical tests of returns distributions normality have been performed in PQStat, a statistical software.

\section{EMPIRICAL RESULTS}

The results of the normality tests for returns distributions of selected indexes in specified subperiods for four different quotation intervals are presented in table 3. Cases in which there were no grounds to reject the null hypothesis (empirical returns distribution was compatible with the normal distribution) are bolded and marked as H0. Cases in which the null hypothesis had to be rejected at the significance level of $\alpha=0.05$ are marked as H1. In order to make the analysis of the results easier, in table 2, the percentage of cases in which there were no grounds to reject the null hypothesis is presented. It's worth adding that the table 2 aggregates cases in which there were no grounds for rejecting the null hypothesis for many indexes, but still divides them into specified sub-periods.

The results indicate that in almost all cases of daily intervals, the null hypothesis had to be rejected for the benefit of the alternative one. Only in the case of BUX index from the Budapest Stock Exchange in Hungary in the period 2000-2005, according to the Kolmogorov-Smirnov test, daily returns seemed to be distributed normally. In the following research periods the indications of the Kolmogorov-Smirnov test for the BUX index were different. The next main conclusion, which can be easily made on the basis of the results reached, is that the percentage of cases in which there were no grounds to reject the null hypothesis increased along with the decrease of the returns frequency.

Table 2. Percentage of cases in which there were no grounds to reject the null hypothesis

\begin{tabular}{|c|c|c|c|c|c|c|c|c|c|c|c|c|c|c|c|c|}
\hline \multirow{2}{*}{$\frac{\text { Test }}{\text { Period }}$} & \multicolumn{4}{|c|}{ Kolmogorov-Smirnov \% } & \multicolumn{4}{|c|}{ Lilliefors \% } & \multicolumn{4}{|c|}{ Shapiro-Wilk \% } & \multicolumn{4}{|c|}{ D'Agostino-Pearson \% } \\
\hline & d. & w. & $\mathrm{m}$. & q. & d. & w. & $\mathrm{m}$. & q. & d. & w. & $\mathrm{m}$. & q. & d. & w. & $\mathrm{m}$. & q. \\
\hline $2000-2005$ & 13 & 100 & 100 & 100 & 0 & 50 & 100 & 88 & 0 & 25 & 75 & 88 & 0 & 25 & 75 & 88 \\
\hline $2006-2011$ & 0 & 0 & 100 & 100 & 0 & 0 & 63 & 100 & 0 & 0 & 50 & 88 & 0 & 0 & 38 & 100 \\
\hline 2012-2017 & 0 & 100 & 100 & 100 & 0 & 75 & 63 & 75 & 0 & 13 & 75 & 100 & 0 & 25 & 75 & 100 \\
\hline
\end{tabular}

Source: Own elaboration.

The conclusions are in line with the conclusions of J. Czekaj (2014) made on the basis of results reached in the research conducted on the Warsaw Stock Exchange. The phenomenon observed mainly the results from the growing sample of returns, namely when the frequency of returns is 


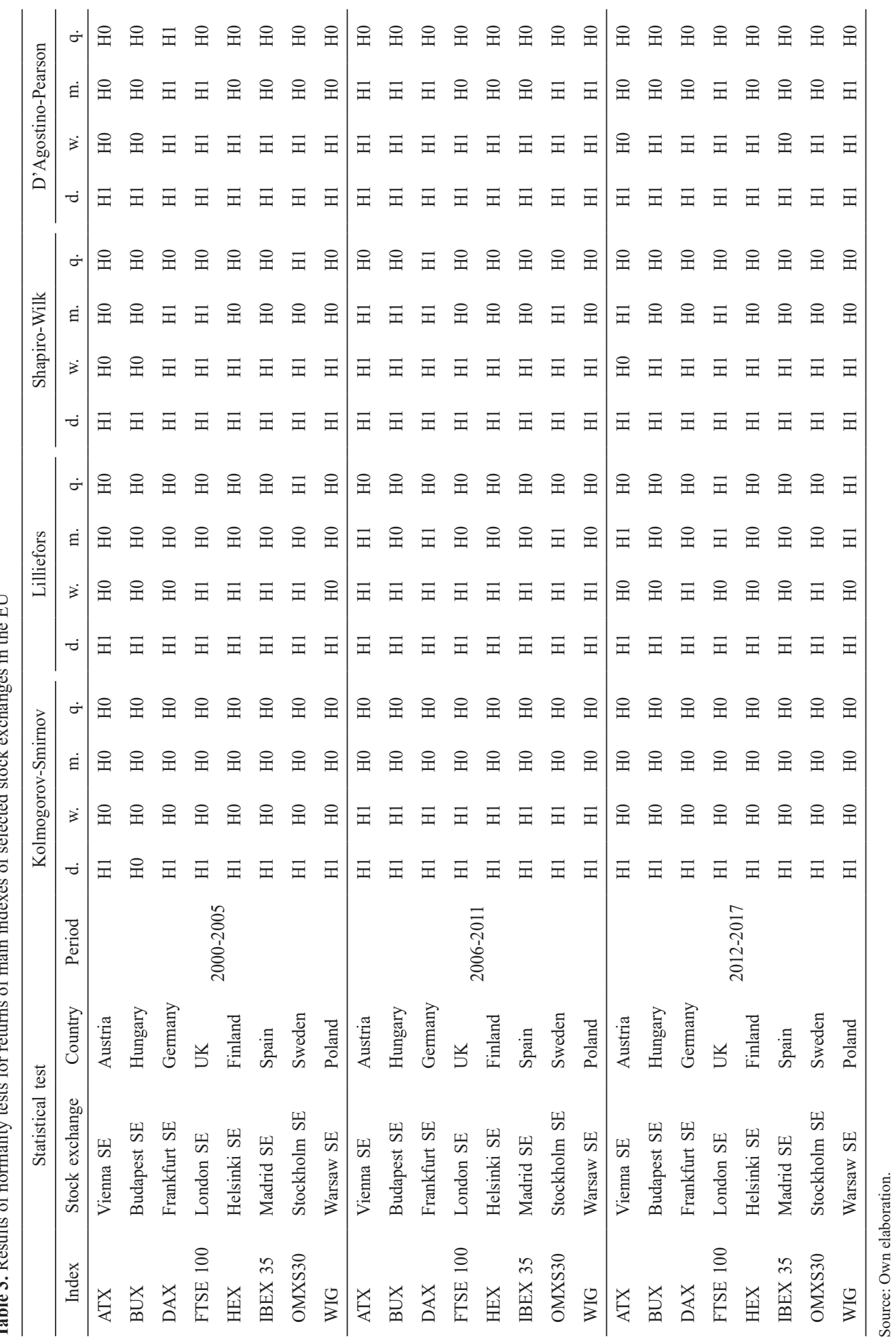


higher, the sample is bigger and when the sample is bigger, there is more evidence to reject the null hypothesis.

Looking at the percentage of cases in which there were no grounds to reject the null hypothesis in particular sub-periods, it is easy to notice some differences between them. Firstly, in contrast to the periods 2000-2005 and 2012-2017, the period 2006-2011 has no efficient stock indexes for weekly intervals according to all four statistical tests. For monthly intervals, the period 2006-2011 has fewer cases of null hypothesis rejections or their percentage is the same as in the case of two other periods. This phenomenon can result from the global financial crisis which began in 2007, and which could influence the informational efficiency of the financial markets. It's also worth to add that overall the percentage of the null hypothesis rejections is noticeably lower in the case of the Kolmogorov-Smirnov test and the Lilliefors test. It results from the nature of the statistical tests applied. The Kolmogorov-Smirnov test and the Lilliefors test both are from the same group of nonparametric tests of distributions compatibility, verifying the distance between the empirical cumulative distribution function and the normal one. The third test used, namely the Shapiro-Wilk test, belongs to the group of tests based on the statistical measures of position quantile-quantile. The fourth test used, namely the D'Agostino-Pearson test, is based on a special feature of the normal distribution, i.e. skewness and kurtosis equal to zero.

Taking into account that the measures were done for each of the eight indexes, four intervals, three sub-periods, and that four different test were applied, the total number of tests done for each index was fourty-eight. The BUX index from the Budapest Stock Exchange in Hungary had the greatest number of not rejected null hypotheses, namely twenty-nine. The fewest number of not rejected null hypotheses belonged to the DAX index from the Frankfurt Stock Exchange in Germany, and their number was twenty.

\section{CONCLUSIONS}

The results of the research show that in the case of almost all indexes for daily returns frequency, and the higher one the hypothesis of normally distributed returns, has to be rejected. In result they cannot be considered as being subject to the random walk model of L. Bacheliere from 1900, and the markets cannot be considered weak form efficient as well. The results are in line with these of J. Czekaj (2014), reached in the research done on the Warsaw Stock Exchange. Additionally, in his research, J. Czekaj (2014) presented the kurtosis of returns distributions which is commonly used in financial econometrics to characterise the tails. It turned out that the tails of returns distributions were fat and that was why the normal distribution seemed not to be good for describing the dynamics of financial asset prices fluctuations. As the normal distribution belongs to a group of stable distributions, it is proposed to test whether the returns can be subject to other stable distributions like the Pareto distribution, which gives higher probability to extremely low and high returns which resembles actual price fluctuations on financial markets.

\section{Literature}

Abdmoulah, W. (2010). Testing the evolving efficiency of Arab stock markets. International Review of Financial Analysis, 19(1), 25-34. doi:10.1016/j.irfa.2009.11.004

Al Janabi, M. A. M., Hatemi-J, A. \& Irandoust, M. (2010). An empirical investigation of the informational efficiency of the GCC equity markets: Evidence from bootstrap simulation. International Review of Financial Analysis, 19(1), 47-54. doi:10.1016/j.irfa.2009.11.002

Al-Khazali, O. M., Leduc, G., \& Alsayed, M. S. (2016). A Market Efficiency Comparison of Islamic and Non-Islamic Stock Indices. Emerging Markets Finance and Trade, 52(7), 1587-1605. doi:10.1080/15404 96X.2014.998572 
Appiah-Kusi, J. \& Menyah, K. (2003). Return predictability in African stock markets. Review of Financial Economics, 12(3), 247-270. doi:10.1016/S1058-3300(02)00073-3

Arshad, S., Rizvi, S. A. R., Ghani, G. M., \& Duasa, J. (2016). Investigating stock market efficiency: A look at OIC member countries. Research in International Business and Finance, 36, 402-413. doi:10.1016/j. ribaf.2015.09.026

Borges, M. R. (2010). Efficient market hypothesis in European stock markets. European Journal of Finance, 16(7), 711-726. doi:10.1080/1351847X.2010.495477

Czekaj, J. (2014). Efektywność giełdowego rynku akcji w Polsce z perspektywy dwudziestolecia. Warszawa: Polskie Wydawnictwo Ekonomiczne.

Dziawgo, D. (2011). Relacje inwestorskie. Ewolucja, funkcjonowanie, wyzwania. Warszawa: Wydawnictwo Naukowe PWN.

Fama, E. F. (1970). Efficient Capital Markets: A Review of Theory and Empirical Work. Journal of Finance, 25(2), 383-417. doi:10.2307/2325486

Jensen, M. C. (1978). Some Anomalous Evidence Regarding Market Efficiency. Journal of Financial Economics, 6(2-3), 95-101. doi: 10.1016/0304-405X(78)90025-9

Kilon, J. \& Jamróz, P. (2015). Informational (in)efficiency of the Polish Stock Exchange. Procedia - Social and Behavioral Sciences, 213, 390-396. doi: 10.1016/j.sbspro.2015.11.556

Kim, J. H. \& Shamsuddin, A. (2008). Are Asian stock markets efficient? evidence from new multiple variance ratio tests. Journal of Empirical Finance, 15(3), 518-532. doi:10.1016/j.jempfin.2007.07.001

Lima, E. J. A. \& Tabak, B. M. (2004). Tests of the random walk hypothesis for equity markets: Evidence from China, Hong Kong and Singapore. Applied Economics Letters, 11(4), 255-258. doi:10.1080/135048 50410001674911

Magnusson, M. A. \& Wydick, B. (2002). How efficient are Africa's emerging stock markets? Journal of Development Studies, 38(4), 141-156. doi:10.1080/00220380412331322441

Rizvi, S. A. R. \& Arshad, S. (2016). How does crisis affect efficiency? An empirical study of East Asian markets. Borsa Istanbul Review, 16(1), 1-8. doi:10.1016/j.bir.2015.12.003

Smith, G. (2012). The changing and relative efficiency of European emerging stock markets. European Journal of Finance, 18(8), 689-708. doi:10.1080/1351847X.2011.628682 
PART 2: LITERATURE REVIEW/S 



\title{
The Challenges of Knowledge Workers Management
}

\author{
Lukasz Pietrzak*
}

\begin{abstract}
Summary
The paper focuses on factors which influence productivity and creativity of knowledge workers but it also treats about managing teams made up of knowledge workers. Main topics that have been analyzed include workers autonomy, rewarding, motivation, communication, organizational climate, organizational structure, team building, organizational processes, specialization and also clear responsibility allocation. In order to combine great results with knowledge workers satisfaction, it is necessary for managers to be well familiarized with mentioned topics and to know how to use them.
\end{abstract}

Keywords: management, Knowledge worker, Productivity, Creativity, IT industry

JEL: M1, M15, M5, M54

\section{INTRODUCTION}

Today, the number of knowledge workers constantly increases. They constitute about $40 \%$ of the whole world's workforce (Drucker, 2002). People whose advantages are knowledge and learning capabilities and who focus on quality are vital for organizations to build competitive advantage (Oskarsdottir, 2017).

In the 20th century the most valuable asset of a company was its production equipment, while in the 21 st century it is and it will be knowledge workers. (Drucker, 1999). Today's managers face a great deal of challenges connected with managing knowledge workers. However, workers also expect a lot from their employees and managers. Thus, it is crucial for people managing workers to know how to do it well and efficiently. It is easy to lose a good worker by making simple mistakes but it is extremely difficult to employ a very good one. Therefore, every manager has to know the challenges that come with managing knowledge workers and factors which foster workers' efficiency, creativity and motivation.

\section{KNOWLEDGE WORKER}

A knowledge worker is a person, who does her work with everything she learned during systematic education (ideas, theories, definitions) unlike person who uses manual skills or physical strength (Drucker, 2005). According to another definition, knowledge workers are workers who focus on creating, distributing and making use of the knowledge. They possess very well developed specialist knowledge, wide and strong experience or good education (Davenport, 2005). Natalie Waters (2012) defines knowledge workers as those who use their minds rather than hands to create value.

The first person who noticed the aspect of knowledge in the activities performed by manual workers was Frederick Winslow Taylor (1856-1915). He believed that knowledge meant the way simple movements were put together as a whole, how they were organized and performed. Drucker (1999) even claimed that all economic and social achievements of the 20th century were based, to some extent, on the use of Taylor's method and its refinements. However, methods used to organize manual workers work are not applicable to knowledge workers (Oskarsdottir, 2017).

\footnotetext{
Faculty of Management, University of Warsaw, Poland, https://orcid.org/0000-0003-0057-6088, e-mail: pietrzak.lukasz@ gmail.com
} 
The paper describes three categories of topics connected with work organization of knowledge workers. They are as follows: knowledge workers productivity, knowledge workers creativity and management of teams made up of knowledge workers.

\section{Knowledge Worker Productivity}

According to Drucker (1999), six major factors that influence knowledge worker productivity include:

1. Knowing and understanding the assigned tasks.

2. Independence and autonomy.

3. Innovation as an integral part of the work.

4. Continuous self-improvement and knowledge sharing.

5. High-quality results of the work.

6. Treating knowledge workers as assets of an organization rather than costs.

Smith (2005) in his research of 72 companies from the high-tech sector states that knowledge workers productivity, and consequently the entire company's productivity, is defined by the speed of the new products and services introduction which, in turn, depends on the company's capability to create knowledge.

Oskarsdottir (2017) determines that four main challenges connected with the issue of low knowledge workers productivity from the point of view of organizations involve:

1. The need for gaining information and worker interdependence.

2. Motivation, work engagement and health.

3. Organizational structure and changes in organizations.

4. The nature of knowledge work.

While, eight main challenges connected with the issue of low knowledge workers productivity from the point of view of workers include (Oskarsdottir, 2017):

1. Too heavy demands and insufficient resources.

2. Self-improvement and self-awareness of one's capabilities and needs.

3. Effectiveness.

4. Setting and achieving goals.

5. Full potential fulfillment.

6. More productive thinking.

7. Positive relations and collaborations with coworkers.

8. Motivation.

From the perspective of organizations, the productivity of knowledge workers will increase when the workers perform tasks that create value for the organizations. However, the productivity will decrease if (Oskarsdottir, 2017):

1. The workers perform tasks that do not create value for organizations.

2. The workers perform tasks ineffectively due to lack of knowledge sharing and cooperation with other workers.

3. The workers perform tasks ineffectively because their organization does not cater to their needs.

From the perspective of knowledge workers themselves their productivity will increase when the workers can perform tasks that create value for the organizations effectively and when they can realize their full potential. Nevertheless, the productivity will fall when (Oskarsdottir, 2017) personal worker resources deplete which results in exhaustion and stress and the workers perform activities that do not create value.

Janz (2003) claims that the higher the level of cooperative learning in an organization, the higher the work productivity and the workers' satisfaction form their tasks. There are three characteristics 
of the cooperative learning process (Janz, 2003): positive interdependence, encouraging interactions between team members and group process. He also states that the factors which have a positive influence on the level of cooperative learning are (Janz, 2003) autonomy and organizational climate.

Among the entrepreneurs mistakes in creating the organizational climate that may cause adverse consequences we can list (Glinka, Pasieczny, 2015):

1. Advocating values and norms that are hard to accept by workers or even deemed inappropriate by them.

2. Official advocacy of values and norms that entrepreneurs themselves do not conform to.

3. No connection between advocated norms and behaviors and the system of worker promotion, development and rewarding.

It is worth mentioning that the success of project teams also depends on the number of knowledge workers that make up those teams. The bigger the number of knowledge workers in a project team, the higher the team's productivity (Waters, 2012). Waters claims in his research that a project will be successful if the percentage of knowledge workers in a project team approximates to 63 percent.

\section{Knowledge Worker Creativity}

Similarly to productivity, knowledge workers creativity is one of the factors that determine the success of enterprises and drive their innovation. Knowledge workers creativity depends to a large extent on their knowledge, and this knowledge and its organization in enterprises is a complicated issue. That complexity allows, on the one hand, to gain a competitive advantage of a given company over another, and on the other hand, it involves difficulties in knowledge management (Henard, 2008).

According to Henard (2008), the most fundamental knowledge level, that is the basis for the knowledge pyramid, is the acquired knowledge. This type of knowledge consists of information that is available to others and which also regards issues not directly related to the organization in which the worker is currently working. This knowledge is collected by the worker throughout his whole career and consists of past experience, knowledge sharing with coworkers, trainings and readings. The next level is the unique knowledge (Henard, 2008). It is based on the acquired knowledge but requires more advanced cognitive abilities from the worker. It is the knowledge that is created by making new knowledge combinations that have not been previously noticed by the worker.

The top of the knowledge pyramid is occupied by the creative knowledge (Henard, 2008). It is based on the acquired and unique knowledge and depends on how deep and wide these types of knowledge are. However, creative knowledge is the main source of innovative ideas. This type of thinking goes beyond making connections and combinations between several sources of information. Creative knowledge is about creating completely new ideas and innovative solutions to problems for which there have not been any known solutions so far. An organization that has knowledge workers with this level of thinking may establish a competitive advantage over other organizations.

David Henard (2008) believes that in order to develop creative knowledge in an organization, the following actions should be taken:

1. Allowing workers to deepen and broaden their acquired knowledge.

2. Allowing workers to have contact with different sources of knowledge, also outside the organization.

3. Promoting knowledge sharing practices and training workers in the areas of seeking knowledge outside the organization, e.g. clients product offering.

4. Rewarding the workers who contribute to the expanse of creative abilities in the organization and eliminating bad practices even by penalizing those workers who do not want to share their knowledge.

5. Placing the role of knowledge and creativity high in the organization hierarchy.

6. Knowledge workers should periodically become responsible for a new area for them. 
According to Smith (2005), the organization's creativity manifests itself in the organization's ability to create new knowledge. The key factors that affect this are (Smith, 2005):

1. The level of knowledge of the organization's top management and knowledge workers.

2. Networking between the top management of the organization and the key workers.

3. An organizational climate that supports or suppresses the ability to create new knowledge.

\section{The Management of Teams Consisting of Knowledge Workers}

In order to organize the work of knowledge workers optimally, one should pay attention not only to the individual person, but to the entire team. The work of knowledge workers should be restructured and organized as part of the system (Drucker, 1999).

The issue of recruitment and selection of persons for the project team as well as the choice of the appropriate manager of such a team has a critical impact on the success of the project (Wi, 2009). Hyeongkon Wi (2009) proposed a model for the objective evaluation of candidates' knowledge and their selection for project teams. Worker's knowledge consists of two main elements (Wi, 2009): personal knowledge and knowledge from the worker's network of contacts.

Worker's knowledge assessment process is carried out according to the following algorithm (Wi, 2009):

1. Collecting keywords describing the project.

2. Assessing the level of knowledge of each worker as the sum of comparisons of each keyword describing the project with the keywords appearing in the publications of the researcher (reports, documents, patents, books, etc.) and his network connections resulting from co-creation of these documents.

The project team is selected from among those with the best results, and the team leader is the person who has the best overall score on both knowledge and network connections. In addition to selecting a team leader, the issue of team management is equally important. According to Pearce (2004), when managing knowledge workers, traditional team management by one person is less effective than sharing the leadership among the team members.

Factors that may indicate the need for shared leadership are (Pearce, 2004): a large interdependence of workers in the team, implementation of tasks that require a lot of creativity and implementation of tasks that are complicated.

A very important issue for any organization is the issue of workers turnover. The costs of new recruitments are high for the organization and the resignation of knowledge workers is also associated with the loss of knowledge, and thus the loss of competitive advantage of the organization (Jayasingam, 2016). Moreover, the assumption that knowledge can be separated from the knowledge worker is an erroneous assumption (Howe and Levin, 2007). Therefore, organizations should focus on motivating workers to remain in the organization. According to Jayasingam (2016), workers who display a high degree of emotional commitment to the organization are less likely to change their job.

Factors that have a positive impact on the degree of knowledge worker's emotional commitment to the organization, and hence, the reduction of departures from the organization, are (Jayasingam, 2016): worker appreciation, knowledge sharing culture, autonomy in the performed tasks, management support and fair rewarding and promotions for good performance.

With regard to building knowledge worker's emotional commitment to the organization, Glinka and Pasieczny (2015) indicated that the issue of motivating is one of the most difficult challenges that managers face, regardless of the size of the organization. They believe a good motivation system should include elements from the group of material factors such as salary, bonuses and office equipment, as well as from the group of immaterial factors such as recognition and enabling self-development. Additionally, a two-factor theory of motivation consisting of hygiene factors and motivators should be considered (Herzberg, 1987). 


\section{CONCLUSIONS}

Knowledge workers require a specific approach and they should be managed by specific techniques. The nature of knowledge workers work differs from that of manual workers. Manual workers methods developed over decades do not apply to knowledge workers. Knowledge workers are expected to deliver high-quality work and creativity in creating new knowledge, products and solutions. The tasks they perform are usually complicated ones which require constant development, qualifications improvement and continuous new knowledge acquisition in a rapidly changing environment.

The key aspects that a knowledge workers manager must pay attention to are:

1. A proper definition of tasks and objectives. It is very important to instruct and set tasks, so the worker does everything to bring profit to the organization. It is necessary to eliminate or significantly reduce the tasks that waste the time of knowledge workers. It is imperative to hand over such tasks to workers with lower competencies who are less expensive. However, there cannot be too many tasks entrusted to workers since it would lead to significant losses in workers internal resources, productivity and job satisfaction.

2. Knowledge workers autonomy. Knowledge workers in order to work effectively need a lot of autonomy in their work. The autonomy has also a positive impact on their job satisfaction as well as the perceived level of trust in them, which is crucial for retaining workers in the organization. What is more, the nature of knowledge workers work requires from them to have specialist knowledge and create new knowledge. As specialists in a given field they should be responsible for making all of the decisions in terms of tasks.

3. Climate and organizational culture.An organization should create a climate that encourages and supports cooperation, knowledge sharing and team work. Open and positive atmosphere, the acceptance of the risk resulting from taking up innovative topics and the mutual support provided by workers and the organization have a large impact on the productivity of workers as well as on the level of their job satisfaction.

4. Supporting development, innovation and creative thinking. Knowledge workers are usually motivated to self-develop and gain knowledge. However, it is important that the organization support these initiatives by giving workers opportunities to get certificates, participate in trainings, conferences and funded studies. In addition to expanding workers creativity in this way, workers themselves may consider these initiatives as ways in which the organization cares for them, invests in them and treats them as an asset rather than as a cost. The bonus system in the organization should also be structured in such a way as to reward team activities, successes and knowledge sharing.

5. A proper structure of the team. While building teams, it is worth taking into account the fact that higher productivity is reached by teams with a higher number of knowledge workers. In addition, the evaluation of recruited workers should not only include the verification of their personal knowledge but also their network of contacts. In particular, people holding managerial positions should have a good network of contacts as well as large knowledge in a given area. In case of teams composed almost entirely of knowledge workers and in which there is a high degree of interdependence and the need for high creativity in the implementation of complex tasks, it is worth establishing a shared leadership in the team.

6. Motivation systems. Workers in order to work effectively need proper motivation. Motivation is crucial for them to feel job satisfaction and not to leave the organization. Minimizing the number of knowledge workers departures is important since workers who leave an organization take with them their knowledge and competencies that, despite knowledge management systems, are very difficult to record in a formal way and which are important for the competitive advantage of the organization. That is why it is important to properly appreciate workers whether in the aspect 
of remuneration, facilitating and financing their development and ensuring proper working conditions - either in terms of office conditions, flexible working forms or home office work. Telecommuting may also have a positive impact on workers productivity and may increase their commitment. It is also important to remember about immaterial motivators. Sometimes appreciating the contribution of each worker and telling him that he has done a "good job" can be as important to him as an additional bonus.

7. Creating appropriate working conditions. Workers will be satisfied and work efficiently if they have the appropriate conditions and a high level of personal resources: emotional, physical, social and cognitive. Therefore, it is important that workers are full of energy, do sports and engage in positive relationships. The organization should promote and support such activities. What is more, the proper organization of office space, focusing on silence and the lack of factors that distract knowledge workers is equally important.

\section{Literature}

Clear, F. (2005). Teleworking practice in small and medium-sized firms: management style and worker autonomy. New Technology, Work and Employment, 20(3), 218-233, doi.org/10.1111/j/1468-005X.2005.00155.x.

Collins, C. (2017). Examining strategic fit and misfit in the management of knowledge workers. ILR Review, Sage Journals, 70(2), 308-335, doi.org/10.1177/0019793916654481.

Corso, M. (2006). Managing dispersed workers: the new challenge in Knowledge Management. Technovation, 26(5-6), 583-594. doi.org/10.1016/j.technovation.2005.02.003.

Davenport, T. H. (2005). Thinking for a Living: How to get better performance and results from knowledge workers. Boston: Harvard Business School Press.

Elliman, T., Eatock, T., Spencer, N. (2005). Modelling knowledge worker behaviour in business process studies. Journal of Enterprise Information Management, 18(1), 79-94. (5-6), 583-594. doi.org/10.1016/j.technovation.2005.02.003.

Drucker, P. (1999). Knowledge-worker productivity: The biggest challenge. California Management Review, 41(2), 79-94, doi.org/10.2307//41165987.

Felstead, A. (2017). Assesing the growth of remote working and its consequences for effort, well-being and work-life balance. New Technology, Work and Employment.

Glinka, B. i Pasieczny, J. (2015). Tworzenie Przedsiębiorstwa. Szanse, realizacja, rozwój. Warszawa: Wydawnictwa Uniwersytetu Warszawskiego.

Henard, D. (2008). Making knowledge workers more creative. Research - Technology Management, 51(2), 40-46, doi.org/10.1080/08956308.2008.11657494.

Herzberg, F. I. (1987). One more time: How do you motivate employees?, Harvard Business Review, 65(5), 109-120.

Howe, P. E., and Levin, M. C. (2007). Knowledge management is all about people, Pennsylvania CPA Journal.

Janz, B. (2003). Understanding the Antecedents of Effective Knowledge Management: The Importance of a Knowledge - Centered Culture. Decision Sciences, Journal (DSI), 14(2), 351-384, doi.org/10.1111/15405915.02328.

Jayasingam, S. (2016). Instilling affective commitment: insights on what makes knowledge workers want to stay. Management Research Review, 39(3), 266-288, doi.org/10.1108/MRR-03-2014-0060.

Oskarsdottir, H. (2017). A Soft Systems Approach to Knowledge Worker Productivity - Analysis of the Problem Situation. Economies, 5(3), 28, doi.org/10.3390/economies5030028.

Pearce, C. (2004). The future of leadership: Combining vertical and shared leadership to transform knowledge work. Academy of Management Executive, 18(1), 47-59, www.jstor.org/sable/4166034.

Smith, K. (2005). Esixting knowledge, knowledge creation capability, and the rate of new product introduction in high-technology firms. Academy of Management Journal, 48(2), 346-357, doi.org10.2037/20159660.

Waters, N. (2012). An Empirical Study of Large-Sized Companies With Knowledge Work Teams and Their Impacts on Project Team Performance. Enginnering Management Journal, 24(2), 54-62, doi.org/10.1080/ 10429247.201211431936.

Wi, H. (2009). A team formation model based on knowledge and collaboration. Science Direct, 36(5), 9121 -9134, doi.org/10.1016/j.eswa.2008.12.031. 


\title{
Quality Systems at Universities in Academics' Perception: A Systematic Literature Review
}

\begin{abstract}
Agnieszka Lęgocka*
Summary

New public management, as well as institutional and market pressure, brought business-like requirements to HEIs. Their implementation resulted in profound changes in university governance. This paper presents a systematic literature review of the scholars' perception of a quality system introduced by new public management and the corporatization of universities. The implications of the new practices and discourses for academic identity, university governance, power-balance, as well as the role of a scholar are investigated. The findings reveal that the underlying values and university culture stay in tension with managerialist ideology. The presence of the institutional logics approach in a university context was also examined. It enabled to analyze whether it was used in the context of providing insight into the academics' perception of quality assurance systems.
\end{abstract}

Keywords: Institutional logics, University governance, Quality systems

JEL: Classification: M14

\section{INTRODUCTION}

Policies and regulations on both, the national and supranational level, are designed to build a knowledge society and to bring more transparency, accountability and legitimacy into the university. The provision of various legal requirements is a sign of changing and raising expectations of governments and society towards universities in recent decades. They had to transform from a republic of scholars delivering independent thought and educating elites, to providers of ready-touse knowledge and skills for a high percentage of the population. In addition, they had to conduct research of tangible practical application within a shorter timetable and for short-term profits, as well as to cooperate with external stakeholders in ways and to the degree of which they never experienced before. New ways of financing these institutions were introduced. The pressure of accountability and value for money was increased, which lead to the reduction of stable state financing in place of grants for which one has to compete for. Those transformations lead to profound changes in terms of the role and identity of a university and entail rethinking its mission, strategy, functions, structure and objectives. Those expectations and legal requirements that the university needed to fulfill resulted in, among others, developing and implementing internal quality assurance systems.

It may be argued that such systems in principle should advance the quality culture in the organization, enable to deliver valuable information for the stakeholders - especially academic teachers and University authorities - of the current state of art of the quality of teaching and research; therefore become a crucial instrument for organization's self-improvement. However, it may be questioned whether that is the case. What exactly does quality mean? How the definition of quality can be actually an arena of political struggle? What is the impact of quality systems on crucial agents participating in its inception and development? What is the opportunity cost that these agents pay for their involvement in the system? What is there to gain on the university level,

\footnotetext{
Faculty of Management, University of Warsaw, Poland, https://orcid.org/0000-0002-5501-9767, e-mail: ALegocka@ wz.uw.edu.pl
} 
faculty level, and personal level? Who (if anyone) and why is interested in the actual evaluation of the quality system and its improvement?

As the quality assurance system is to deliver more data on performance and level of excellence in teaching and research, one may ask: is it used, and if so - how, in order to benefit university governance? Is it perceived as a useful tool, or rather an obstacle generating a lot of unnecessary workload and documents? Where to place quality systems on a landscape that has university autonomy on an operational and strategic level on the one end, and subordination to the state through established policies and goals on the other? Finally, in the light of that dichotomy, how do the agents provide meaning, values and rationality to their actions concerning quality systems?

This paper aims of to investigate to what extent answers to the questions listed above were already provided and to draw conclusions on what is currently known about the topic. Therefore the analysis of 58 papers on quality assurance, university governance and institutional logics is presented. In particular, I will be looking for those theoretical approaches and research findings that broaden the knowledge of academics' motivation towards participation in quality assurance activities and their understanding of its meaning and goals. The three focal issues investigated in the paper are quality assurance, university governance and institutional logics.

I acknowledge the Stensaker (2007) stance that regards the notion of quality assurance as fulfilling the requirement for being considered as a Wittgenstein's notion of" a family of meaning". The concept of quality assurance used in HEIs, having a variety of overlapping similarities, escapes the attempts to capture all of them in a definition. Therefore, it is treated in this paper as a natural, fuzzy concept and no attempt to define it is made.

The definition of university governance adopted for the paper is the one proposed Shattock (2006): "Governance is defined as the constitutional forms and processes through which universities govern their affairs.(...) extending right through the institution from a governing body, down through senates and academic boards to faculty boards and departmental meetings and it regards governance as being effective when these levels of governance work together productively" (Shattock, 2006, p. 1). When we treat teaching and research as core activities of universities, "we have to believe that the organs of governance which coordinate, incentivize and sometimes direct these activities carry equal weight in the governance of the institution as a whole even if they may not have the final decision on the fundamental strategic and financial issues. This might lead us to see the university governance, not from the top of the basis of who governs who, but part of the organizational law of the institution"(Shattock, 2006, p. 1).

The decision of encompassing university governance was undertaken to enable including a wider perspective of the current paradigm shift in university governance modes. Firstly, that may be very valuable for interpreting the academics' views on quality systems regarding a broader spectrum of current changes, one of which is university governance. Secondly, quality systems are frequently interpreted as a part of a new mode of governance. Therefore it was purposeful to investigate whether there is any research concerning the relation between the perception of governance and quality systems. The institutional logics perspective is one of the analytical approaches that enable one to capture and interpret clashes and tensions between a set of interlinked values, beliefs, rules and assumptions - a broader belief system (logic) providing explanations for the sense-making and actions of people. The paper investigates whether this analytical approach has been used in the context of quality assurance systems at universities, provided that there may be some collisions of logics.

To foster future research and contribute to the insight into current knowledge, the paper was structured as follows. The research method is explained, keyword string is specified, and the eligibility, as well as exclusion criteria, are given. Having presented the general overview of 
the evolvement of the research issue through time, the 58 selected papers that met the criteria are introduced and studied. On the basis of this analysis, the articles are organised into 4 major strands: quality assurance, academic values, university governance and institutional logics. Some of the main topics are divided into subtopics, when cogent. Summary of the findings embracing all strands show that quality a) along with the new managerialism leads to undermining traditional academic values b) is seen as a form of, mistrust and regulatory tool with limited (if any) interest of academics and impact on core academic activities c) is one of the factors leading to substitution of academics' participation in governance by various coping strategies. Subsequently, the contribution of the paper in terms of identifying knowledge gap is presented. The conclusion is drawn that employing institutional logics perspective to analyse quality assurance systems' perception is a research gap. On account of a small number of quantitative studies, longitudinal studies and cross-country comparisons, the need for employing a wider range of research method than qualitative ones is also recognised. The concluding section presents the limitation of the paper.

\section{RESEARCH METHODS}

The systematic literature review methodology applied in this paper follows the procedure proposed by Briner and Denyer (2012). The review methodology began from searching the following keywords representing three components of the research problem: a) internal assurance or internal system(s) and university/universities, b) institutional logic, and c) university governance. The search in the SCOPUS database revealed that there are no papers which would employ both analytical frameworks to quality assurance systems. What is more, there are no papers that would employ only institutional logics to quality assurance systems. Therefore, it seems that those theoretical approaches have not been jointly applied to quality assurance systems, which provides an interesting research gap to explore.

The query used in the SCOPUS database was the following: "institutional logic*" OR "university governance" OR "quality assurance" AND Universit* AND NOT "health care" AND NOT "product development". The phrase Universit* was added to narrow the number of records concerning quality and to receive the most relevant ones. Since a number of the records received was connected with health care and product development, the query was modified to exclude them. This research returned 4,323 documents.

The search was then restricted to

- "Subject Area": Business, management and accounting", "Social sciences" and "Economics, econometrics and finance";

- "document type": "Article" and "Article in press";

- "Source type": "Journals";

- "Language": "English".

That limited the number of records to 1346 . No restriction on the search regarding time limit was put.

\section{OVERVIEW OF THE RECORDS}

The earliest paper was from 1973. Until 1992 up to two papers a year were published, and since 1993 the number of papers started to rise to reach 136 in 2017. The papers published between 1973 and 1992 were covering such topics as quality assurance in various fields, and university governance. After Friedland and Alford (1991) publication on institutional logics followed. The first paper that links quality assurance systems with autonomy is from 1993 and states that "if university autonomy 
is essential for the proper functioning of universities, then quality control and management are essential prerequisites for autonomy." (Berg, 1993, p. 18).

Three of the papers identified by the keywords present a systematic literature review. One concentrates on the literature on university governance published in the United States between 1970 and 1990 (Ordorika, 2014). Said paper arranges the articles into four analytical perspectives (organizational/functional, organizational/interpretative, societal/functional and societal/interpretative). It argues that all of the existing theories are insufficient, especially in terms of understanding the change in higher education institutions and in the position and role of the state (Ordorika, 2014). The second systematic literature review provides a comparison of theoretical models of academic governance in the context of Connell's Southern theory by indicating differences and similarities between the US, England and Australia (Rowlands, Ngo, 2018). The third one provides a bibliometric analysis of papers concerning quality assurance for concluding that quality assurance of teaching and learning is becoming a speciality in the interdisciplinary field of higher education research (Steinhardt et al., 2017). No SLR concerning quality assurance was found.

\section{ELIGIBILITY CRITERIA}

The 1346 papers were read and evaluated according to the criteria presented below. That process enabled to select only those papers that will allow to gain more insight into the research questions and therefore were evaluated as relevant. The final number of papers decreased to 58 .

During the selection process the following criteria were adopted:

The paper covers

1. Quality assurance systems or some of their aspects in the light of academics' perception and assessment of it;

2. The impact of quality assurance system on the academics regarding their career development and roles played at the university;

3. The conflict of motivations, roles and expectations that the academics face, especially concerning quality assurance systems and/or university governance;

4. The meaning, value and associations that the academics have towards quality assurance systems;

5. The present conflicting or competing requirements concerning various aspects of university functioning on the personal and/or university or state level.

Therefore, the papers covering the following topics were excluded:

1. The other stakeholders view such as students, and social and business partners on quality assurance system or/and university governance;

2. The comparison of various university governance and quality assurance systems models;

3. The measurements of the effectiveness of specific quality solutions at universities, for example distant learning.

\section{FINDINGS}

The further presentation of the analysis of the findings is structured around four main themes that were the result of thematic analysis performed: quality assurance, governance, institutional logics and academic values. Additional subtopics appear if justified. The conclusions drawn together from the analysis of these three sections are presented afterwards. 


\section{OVERVIEW OF THE SELECTED PAPERS}

The figure presenting the distribution of the selected papers over time is presented.

Fig. 1. The distribution of papers selected for the SLR over time.

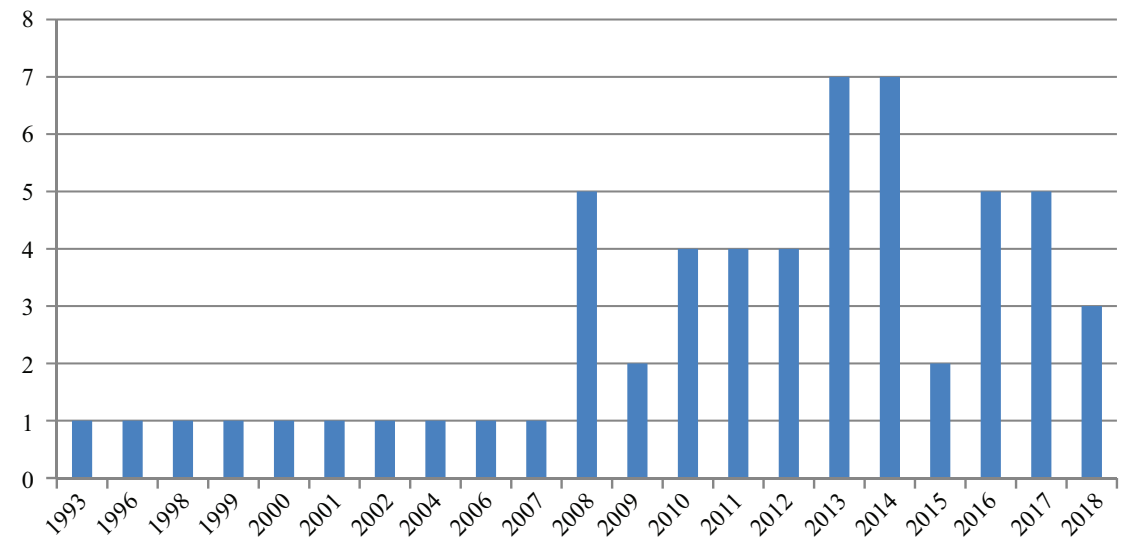

The list of journals with the number of papers included in the SLR are presented in the attachment.

Below the table presenting the analytical method used in empirical papers is presented. Out of 58 selected articles, 14 are conceptual, with no empirical data. Majority of the rest (39) is qualitative. Sample sizes vary - from 5 to 135; however, most of the samples consist of 20 to 50 interviewees. There are only 8 papers that employ a quantitative approach. Three papers use both qualitative, and quantitative method, so the count data are not mutually exclusive.

Table 1. Analytical method used in empirical papers

\begin{tabular}{lc}
\hline \multicolumn{1}{c}{ Method } & Number of Times used \\
\hline $\begin{array}{l}\text { Qualitative } \\
\text { (case studies, interview analysis, content analysis, secondary data analysis) } \\
\text { Quantitative }\end{array}$ & 39 \\
descriptive statistics & 2 \\
t-test & 1 \\
factor analysis & 1 \\
SEM & 1 \\
hierarchical cluster analysis & 1 \\
GEE regression & 1 \\
non-parametric statistical tests & 1 \\
\hline
\end{tabular}

Note: of the 58 papers, 14 are conceptual. 


\section{QUALITY ASSURANCE}

Among the 58 studies that met the eligibility criteria, only 21 papers were identified as strictly related to quality assurance and its perception by academic teachers and researchers. Most of them presented qualitative studies showing a negative attitude towards quality assurance.

\section{a) academics stances towards quality assurance systems}

The prevailing attitude of academics towards quality system is negative. External audits are perceived as "bureaucratic practice that has little impact on their work" (Cheng, 2010, p. 259), and quality assurance is seen as a form of implementing new public management, a form of discipline (Anderson, 2006; Lukas, 2014). Individuals are frustrated with "the neoliberal reforms in general, and assessment policies in particular" (Raaper, 2016, p. 175), and are struggling to understand the regulations. In addition, they are sometimes dissociating themselves from those practices and feel no ownership of the process. Academics do not reject the concept of quality assurance as such. The way it is shaped and implemented however is seen as incompatible with their work, concentrating on process rather than the content, and as a way to implement sanctions, leading to undesirable consequences such as academics' feeling the need to "play the game" (Vidovich and Porter, 1999, p. 574) and being tempted to "massage the figures" (Teelken, Lomas, 2009, p. 268). Nonetheless, the notion of quality as excellence is valued by academics. The one imposed by the quality assurance systems however, is either incompatible with it in any meaningful way or very vague (Mårtensson et al., 2012; Stamelos and Kavasakalis, 2011) and seen as "instrumental, minimalist, and mediocre" (Anderson, 2006, p. 171). Therefore all the quantitative measures that are required of academics are not leading to getting insight into quality (Anderson, 2006). "Quality" is seen as a way to discipline and control (Vidovich and Porter, 1999; Houston and Paewai, 2013), as well as a way to introduce fundamental changes in universities and lead to treating them as "simply another marketable commodity" (Alderman, 1996, p.184). Quality assurance is of no great interest and lacks academics involvement, which leads to high rates of suspending one's opinions concerning such systems. Self-assessment reports are often seen as not being a result of internal discussion and cooperation, and the final reports are not analysed critically (Veiga et al., 2013). As Bamber and Anderson (2012, p. 15) argue "evaluation which is rooted in academic practice within a specific discipline may be difficult to quantify, but it is just this type of evaluation which will lead to an enhancement. Evaluation which is focused on institutional performativity, on the other hand, may, at best, obtain little more than superficial compliance. At worst, it will be simply ignored". The label of "quality" is bestowed upon the university by external actors as if it was their property (Houston and Paewai, 2013). The academics are often excluded from narratives concerning quality policies and strategies (Smith, 2008), nor are they the real beneficiaries of the system as such. As Houston and Paewai (2013, p. 274) write: "only universities, academic units, academic staff and disciplines have the potential to use the information yielded by quality assurance to improve teaching, learning and research. However, the analysis shows that these groups are positioned as passive recipients of quality assurance system designs. The design and implementation of quality assurance occur at a distance from teaching, learning and research"(Houston and Paewai, 2013, p. 274).

Evaluations are seen as too frequent and overwhelming and therefore disrupting other activities such as teaching and research. They are sometimes seen as a waste of public money (Lucas, 2014; Veiga et al., 2013), ineffective, superficial and "measuring that which is measurable, and ignoring that which is useful" (Anderson 2006, p.168). The positive influence of quality assurance is not often noted by academics (Veiga et al., 2013; Wang, 2014) as it may be used against them as if it was a part of a power-knowledge regime. They are unable to contribute to quality improvements (Houston and Paewai, 2013) and are often de-coupled from academic life (Mårtensson, 2014). 
Lucas (2014, p. 218) analyses "incidents of resistance to the quality assurance processes relating to research and teaching in higher education in the UK" and shows that this opposition led to crucial changes within the polities and quality assurance practices in the UK. The author employs a Foucauldian framework devised by Hyatt (2013) with "modes of legitimation" including "authorisation, rationalisation and moral evaluation as three important concepts by which to investigate texts"(Lucas, 2014, p. 219). The two "critical cases" examined lead to the conclusion that

- the quality assurance methodology is not scientific, unable to influence the quality of teaching and research positively (rationale is questionable);

- needlessly increases the financial costs of the university and negatively influences the motivation to work since the continuous changes in quality assurance methodology undermine the possibility to measure changes across time (rationale is questionable);

- leads to such human costs as disorganisation of career development, working overtime with no financial compensation, sleepless nights, and disengages the individuals from the processes, limiting their actions to responses to external incentives (moral purpose is questionable).

Raaper (2016) argues that the frustration of academics may be connected with the changes in the aims of universities that are visible in every aspect of its functioning. Said changes entail losing control over such important aspect of their work as assessment: "academics feel as if they are tied to something that is used not only for educational purposes but also for wider neoliberal technologies of government such as auditing, monitoring and quality assurance mechanisms. It, therefore, appears as though (...) phrases that reflected confusion with assessment policies, and unhappiness with neoliberal reforms in higher education, reveal wider processes in relation to student assessment turning into a technology of government that functions as part of the neoliberal policy context and that increasingly scrutinises academics and their work for the sake of institutional market position" (Raaper, 2016, p. 182).

The 'atomization' and dissociation of academics in cases when quality assurance procedure is resulting in losing supervision over the curriculum is studied by Brady and Bates (2016). As the academics' role is switching from working together as a community negotiating the curriculum to alienated researchers appointed to deliver a given module, their attitude towards the curriculum and the organisation as a whole changes significantly. They feel as if they were a "cog in a wheel", "powerless, disconnected from the organisation or both" (Brady and Bates, 2016, p. 166).

Contrary to the finding presented above, the academics perception of quality assurance is positive in Finland and seen as a "means to administer their everyday life as long as academics' autonomy to their work is cherished and controlling mechanisms are avoided"(Husko and Ursin, 2017, p. 868). One of the reasons may be that the Finnish system preserved the autonomy both on the university level and the fact that the "roots of the Finnish evaluation tradition lie on the idea of Humboldtian university" (Husko and Ursin, 2017, p. 867-868).

The findings summarized above represented the following countries: the United Kingdom, Portugal, China, Estonia, Finland, Greece, Spain, Vietnam, Australia, New Zealand. Only two papers presented comparative cross-country research: (the United Kingdom and the Netherlands, Hong Kong and Singapore). One paper did not specify in what country the research was performed.

\section{b) stances towards quality assurance systems: cross-country comparisons}

There are not many papers that compare the academics perception of quality assurance across at least two countries. Not many differences between countries have been identified. Teelken and Lomas (2009) argue that UK respondents connote quality assurance with quality control and are more inclined to a negative evaluation of the concept as such. Dutch respondents feel that their implicit 
norm of quality of research and teaching is not reflected in the current practices. They are also more explicit in looking for ways allowing them not to comply with the quality management system.

Quality assurance mechanisms introduced in Hong Kong and Singapore were designed to make the universities more competitive on a global education market and in fact, led to raising the position of their universities in the global ranking. Hong Kong academics found the research review process more intrusive and directive than the teaching one. On the one hand, a prevailing number of respondents evaluated research assessment as having some or a high impact ( $85 \%$ in Hong Kong and $97 \%$ in Singapore). On the other hand, the number of negative views was twice as much in Hong Kong. Regarding teaching assessment - twice as many positive views as negative ones were given in Hong Kong, and two-thirds of the views were positive in Singapore. The advantages of the assurance systems were connected with the belief that the quality system enhances research culture, quality and productivity in research and "the feedback is used constructively to improve (...) teaching" (Currie et al., 2008, p. 73). The negative ones were connected with the opinion that local and Chinese research is not likely to be published in top journals, as well as a high competitiveness and lack of trust in science. In addition, the "unreliability of the evaluations as some academics, lower their assessment standards to be more popular and hence achieve better student feedback".(Currie et al., 2008, p. 73). Currie et al. (2008, p. 83) conclude that "the greater the link to funding and compliance, the greater the possibility that academics will resent the intrusion, and a culture of mistrust rather than trust will begin to develop between them and the university of higher educational system managers, whether at the local, state or national level". Their findings show that the researchers are already more reluctant towards quality assurance than managers.

The positive correlation between the participation in quality assessment and the perception of the system as an improvement tool was found by Trullen and Rodríguez (2013). In addition, a negative correlation between the participation in such assessment and the perception of the system as an instrumental one (for example justifying budget cuts) was found. What is more, the perception of the system influences the level of identification with the program being assessed, as well as whether one is participating in the quality assessment. "Faculty who participate in quality assessments will be more likely to identify with the programme being assessed. Viewing quality assessments as motivated by improvement reasons will positively affect faculty identification with the programme being assessed and viewing quality assessments as motivated by instrumental reasons will negatively affect faculty identification with the programme being assessed" (Trullen and Rodríguez, 2013, p. 681-682).

\section{ACADEMIC VALUES}

Due to thematic focus on academic values a few papers were identified.

The longitudinal data analysis performed from the sixties to the nineties in Australian universities and colleges concerning how the academics perceive their roles reveal that they value: "the freedom to do original work; a flexible work schedule; independence and autonomy; the opportunity to make a contribution to knowledge; the social aspects of the job; the salary; and prestige associated with being an academic" (Adams, 1998, p. 427).

The author claims that the factors that may undercut academics motivation and job satisfaction are an erosion of that core values and satisfaction of academic work caused by legislation or regulation. If what is considered "a marginal work" such as additional activities besides research and teaching will be growing, it may affect the essential values and expectations of academic culture (Adams, 1998).

Other authors see referring to values while explaining academics reluctance to accept some policies as "simplistic explanations attributing lack of adherence to ideas of academic freedom (...) 
[which] cover up a lack of research-based understandings of why academics act as they do" (Brew et al., 2017, p. 379).

They argue that the diversity of academics' responses to university policies and strategic initiatives may be interpreted and understood partially at least by using the Archer's (2007) modes of reflexivity. Those responses were interpreted within the framework of those modes, mediated by career aspirations. In addition, one's perception of what is desirable enables us to understand why policies sometimes fail, and do not lead to the desired outcomes. For instance, on the one hand, the meta-reflexivity mode which is "characterised by internal conversations critical of one's internal conversations and on the look-out for a difference in the social world around them" (Brew et al., 2017, p. 380) is the crucial one when implementing a new policy and most helpful for the organisation. On the other hand, academics exhibiting traces of fractured-reflexivity ("internal conversations intensify distress and disorientation rather than leading to purposeful courses of action") need professional help in accepting changes (Brew et al., 2017, p. 380). Therefore, it is the organisation's responsibility to address the personal model of reflexivity of an academic and adjust the message concerning the new requirements to it.

Parker (2011, p. 440) provides a list of focal values that the university is expected to fulfil nowadays:

- "knowledge as a driver of national economic development;

- universities services and products as key national export commodities;

- the primacy of knowledge for industry application;

- employable graduate output;

- operational values for money, efficiency, and effectiveness;

- fee-for-service and market competitive deliverables".

Those values are enforced onto universities and become another level of tension between what is expected by academics and what is expected by the governments, society and top-decision makers at universities. That entails the profound changes in the perception of a role of an academic, the "unique roles of an independent, professional, expert educators and research scholars operating in collegial association and co-decision-making with the university in which they were members"(Parker 2011, p. 444). This is being gradually replaced by defining them as "teaching, research and administrative employees in the university, subject to its strategic objectives and direction, and driven and evaluated by corporate KPIs that drill down from university to faculty, to school, to individual levels." (Parker 2011, p. 444).

\section{UNIVERSITY GOVERNANCE}

Twenty-five papers concerning university governance have been identified on the basis of their thematic focus. . Their main topics are the shifts in power balance and academic autonomy due to managerialism at universities (Bleiklie and Kogan, 2007; Carvalho and Videira, 2017; Giroux et al., 2015; Kolsaker, 2008; Parker, 2011; Salter and Tapper, 2000; Taylor 2013), as well as the decline in academic participation in governance (Dowling-Hetherington, 2013; Lapworth, 2004; Shattock, 2002; Shattock, 2013; Vidovich and Curie, 2010). Quality assurance as an example of a practice that plays a role in that transformation undermining traditional academic values is frequently listed or discussed in more details (Bleiklie and Kogan, 2007; Salter and Tapper, 2000; Azman et at., 2012).

\section{a) The interplay of autonomy, mistrust and modes of governance}

The shift from the classic notion of the university seen as a republic of scholars towards the university perceived as a stakeholder organisation is analysed by Bleiklie and Kogan (2007). The difference between them is mainly concentrated around the way the institutional autonomy and 
academic freedom are considered. The first notion entails that institutional autonomy and academic freedom are interlinked - "which means that leadership and decision making are based on collegial decisions made by independent scholars" (Bleiklie and Kogan, 2007, p. 477). Traditionally, the collegial approach lies at the core and central place in the decision-making process and is a value "underpinning academic life" (Dowling-Hetherington, 2013, p.220). The fact that the faculty's influence on the decision-making process is decreasing is very often regarded as a disillusionment (Dowling-Hetherington, 2013). The second notion treats academic freedom as a voice of one of the many stakeholders whose interest the decision makers are to protect. The authors argue, that "a powerful force lending support to the growth of managerialism has been the assertion of quite penetrative quality assurance procedures that replace the hitherto 'trustful' relationships between academics and their institutions as they believe in 'transparency' has replaced the trust in expert and professional knowledge"(Bleiklie and Kogan, 2007, p. 480).

However, the implementation of quality assurance systems (as an element of managerialism) does not necessarily entail excluding scholars" autonomy, as "the general ideological pressure in individual countries is mediated through specific national policies based on experiences and issues that constitute powerful political, legal and financial operating conditions" (Bleiklie and Kogan, 2007, p. 480). Therefore, the relations between the four principles: professional self-regulation, sensitive democracy, bureaucratic steering, and corporate management specify the organisational ideas and lead to varying across "time and across institutions and educational systems" (Bleiklie and Kogan, 2007, p. 485).

Shattock (2013) explains the arrival of quality assurance officers in terms of filling the void after the decline of academics participation in governance, and states that "university governance and management are falling into the hands of 'management teams' that are less and less either accountable to, or working in partnership with, the rest of the components of the institution" (Shattock, 2013, p. 230). This is also an argument raised by Vidovich and Curie (2010) as a result of their analysis of the Australian and UK national governance policy that lead them to the conclusion that the recent development in said area increases mistrust across the sector. Some of the solutions proposed are a flexible model of governance (Lapworth, 2004), promoting academics participation in areas in which they "have better information and incentives than administrators of trustees" (Brown, 2001, p. 130), as well as a model of shared governance (Taylor, 2013) "reframing faculty senates-in-practice from political to collaborative entities" in order to break " the competitive stalemate" (Gallos, 2009, p. 137).

A typology of three ideal types of universities (the state-centered model, market-oriented model, and academic self-governance) with empirically observable indicators is presented to enable "trace and operationalise the extent and direction of policy change or persistence in European higher education systems." (Dobbins et al., 2011, p. 679). In addition, in other papers the proposals for changes are to be found. Shattock argues that "shared governance" emerging in the USA is the most advantageous model of university governance while "the corporate model is no more desirable or effective in modern conditions than the consensual model implied by academic dominance of the governing process" (Shattock, 2002, p. 236). Trakman (2008), on the other hand, argues against "a one-size-fits-all-model" and identifies and evaluates "five primary models of board-level governance in universities: (1) faculty; (2) corporate; (3) trustee governance; (4) stakeholder; and (5) amalgam models of governance." (Trakman, 2008, p. 63).

Parker (2011) argues that the new mode of university governance that is replacing the collegial, consultative model is a rebirth of scientific management from a century ago with its promotion of a centralised style of governance. 


\section{b) Quality assurance systems impact on performance and behaviour}

The "issues of behavioural consequences of quantitative performance measurement in universities" is studied by Frost and Brockmann (2014, p. 27). They argue that while the implementation of performance indicators increased the academic research output, it also brought dysfunctional effects and thus led to "a performance paradox" (Frost and Brockmann, 2014, p. 27). The causal patterns of that paradox are "inaccurate reports on scholars' performances; lack of congruence between political goals and performance indicators in use; de-contextualization of knowledge; ambiguity and myopia" (Frost and Brockmann, 2014, p. 33). They lead to such behaviours and actions as gaming, pigeonholing, cherry-picking, salami-slicing, measure fixation and publication inflation. In the long run, the creativity, innovativeness and progress in science are impeded and scientific curiosity suppressed by adopting the strategy of playing safe. Franco-Santos et al. (2017) concludes that "current transition towards enhanced control governance with increasing reliance on hard performance measures and targets for academics may lead to dysfunctionalities rather than the intended improvements"(Franco-Santos et al., 2017, p. 724).

A typology of a regulator as an ally, threat and obstacle was proposed by Gray and Silbey (2014). The goal of said article was to provide a framework for understanding the response of actors within the organisation to the new university requirements.

Maassen searches for an explanation of the university's governance paradox - "the more university leaders take on and operate in line with the reform agenda's underlying ideologies, the less effective they appear to be in realising the reform intentions". (Maassen, 2017, p. 290). He argues that the reforms treat universities as if they were of the same substance as other organisations, especially business ones, to which incentives build upon economic reasoning and financial effectiveness should appeal. However, universities' integral and indispensable goal is prestige maximisation, which is gained by academics publishing in top journals, gaining grants and scientific prizes. The success rate of said activities and outcomes can never be predicted beforehand and is easily governed directly by leadership. It is the autonomy and flexibility of academics which needs to be preserved in order to create an appropriate environment for researchers. Too direct and perceptible control will probably hinder researchers and discourage them from searching employment in such universities (Maassen, 2017). Autonomy, creativity and an unstable environment are characteristics for lowstructured roles such as researchers and general knowledge workers (Franco-Santos et al., 2017). Collegial governance is positively related to the well-being and low-stress levels of academics not having leadership responsibilities, while high-level control governance is leading to a high level of stress for that group. However, the relation between the type of governance and welfare of staff is different for non-academic employees and scholars having leadership responsibilities. The first group prefers control governance, and the latter feels well in both types of governance. The reason may be that the non-academic staff has already experienced business-like job arrangements and hasn't been acquainted with other possibilities, and "when academics ascend to leadership positions, it appears that the needs and expectations of the role position change their outlook and sentiment towards governance"(Franco-Santos et al., 2017, p. 724).

The frictions between professors and university governance at a German university have been investigated by Lueg (2018) as well. Their response to strategy papers concerning Europeanization was mostly negative. They considered it a superfluous initiative and were detached form university governance. A smaller group of professors possessed a more critically-supportive stance. What is more, the governance-detached professors claimed their actions are in no way affected by this strategic initiative, and that they were promoting said attitude among junior staff as well. Therefore, their stance was undermining the leadership, which, surprisingly, sometimes justified the resistance of professors. To sum up, "both narrative and counter-narrative find legitimacy, and thereby impede 
organisational change" and "this has implications for how positioning and power are understood in a university facing a change process: organisational and counter-narrative cannot be considered pure dichotomies" (Lueg, 2018, p. 15).

Kolsaker (2008) argues that despite the very negative and pessimistic accounts of the impact of managerialism on scholars, they are rather positive and pragmatic about the changes. She employs a Foucauldian epistemology to study their attitude and concludes that power has not been taken away from them, as well as that academics are in no retreat, but instead that "managerialism has simply changed the ways in which power is exercised in English universities today". (Kolsaker, 2008, p. 516).

The reform of higher education institutions in Singapore and Malaysia carried out in the name of corporatisation did not lead to a transformation of university management but raised the level of pressure the scholars' experience (Mok, 2008). A comparative study of nine universities from Australia, the UK, Belgium, the Netherlands and Malaysia provides insight into the factors and the various levels of their influence in each of the countries on universities. The five influencing forces are

- the government sector;

- the state government/other funding bodies/local industry/local councils;

- global competitions;

- collegial managerialism, autonomy and academic culture;

- and internal management.

The conclusion concerning the fourth factor is that any governance system should embrace the "collegial and autonomous culture" in the case of all universities studied except the Malaysian one, in which the level of control is very high and "collegiality and academic freedom are either nonexistent or within the confines of this control" (Christopher, 2012, p. 345).

An impact of "national and institutional features of governance and management" on quality assurance policies, procedures and actual improvement was studied by Sarrico et al. (2013, p. 375) in four Portuguese universities and polytechnic institutions. The real impact of the system is rather questionable, but still, the system is perceived as a necessity. It is to some extent accepted that lecturers are under the pressure of gathering data, building information systems, as well as allocating some of their time to growing managerial and administrative tasks by deducing that time from research and teaching. This however also leads to perceiving quality as "producing measure and reports, and people are conscious that nothing will essentially change because of that". (Sarrico et al., 2013, p. 386).

\section{INSTITUTIONAL LOGICS}

The conflict of logics in various areas of higher education is investigated in 11 papers. However, none of them explores whether quality assurance is an arena of plural institutional logics conflict or coexistence. Institutional logics are discussed in the context of university management, leadership (Howells et al., 2014), and governance (Blaschke et al., 2014); medical profession (Dunn and Jones, 2010); R\&D collaboration between universities and industry (Bjerregaard (2010); market logic entering the university realm (Bjerregaard, 2010; Berman, 2012); excellence treated as a part of institutional logics and institutional myth (O'Connor and O'Hagan, 2016); "ideal" models of institutional logics aligned with Triple Helix activities (Cai, 2015); defensive mechanism concerning responding to stakeholders' critique of university (Mampaey and Huisman,2016); identifying values and multiple logics in Chinese doctoral education system (Zheng et at., 2018); and academics coping mechanisms for competing logics of science and business (David et al., 2018, p. 386). 
Blaschke et al., (2014) explores the relation between governance, leadership and managerialism as not necessary in conflict, but coexisting and corresponding due to complementary sequences of micro patterns such as agenda building, critical reflection and debriefing with one of the micro patterns - devising being attributed to management and government only. The authors argue that the core activities of a university, research and science, are decoupled from managerialism: "despite the shift towards business-like leadership and management styles in universities, the academic authority over teaching and research largely prevails". (Blaschke et al., 2014, p. 726).

A cross-case analysis of mission statements of three universities in the USA provided an insight into the relation of 'industry' logics (referenced to "market forces, economic development and workforce skills"; Upton et al., 2017, p. 98) and 'social institution' logic' ("which draws legitimacy from social goals as well as "traditional academic ideals"”; Upton et al., 2017, p. 98). According to these findings, those logics generally coexist and are mutually dependent. Only in some areas (such as student recruitment) are they apt to lead to tensions or conflicts. According to Upton et al. (2017), the analyzed mission cannot be fully understood without employing two of the logics simultaneously. Therefore the conclusion is that they are no longer two truly separate logics, but one hybridized one.

Dunn and Jones (2010) discuss two logics (care and science) that are central to the medical profession "supported by distinct groups and interest, fluctuate over time, and create dynamic tensions about how to educate future professionals" (Dunn and Jones, 2010, p. 114). The paper examines reasons why professions may be prone to be "the subject of multiple logics". It also gives arguments for why such a plurality may regulate conflicts if the logics stay in balance, as well as identifies "shifts in the attention to and emphasis on particular logics in a profession." (Dunn and Jones, 2010, p. 114).

The impact of changing institutional logics on R\&D collaboration between universities and the industry resulting in adapting scientific values by firms and entrepreneurial ones by the university has been explored by Bjerregaard (2010). Berman (2012) proposed a model for explaining how the environmental changes may encourage the growth of impact of a logic that is not a dominant one. Howells et al. (2014) discusses what leadership skills should be employed in times of paradigm shifts and plural institutional logics.

A concept of excellence crucial for the evaluation of university faculty is being analysed by O'Connor and O'Hagan (2016). The findings unfold that excellence that is not as gender-neutral and objective notion as is often assumed to be. Therefore the credibility of it and the legitimacy of an organisation that is built upon that notion are questioned (O'Connor and O'Hagan, 2016).

Relations between stakeholders and the university in terms of responding to the stakeholders' critique are analyzed by Mampaey and Huisman (2016) to propose that "in HEIs where a particular logic is salient, conflict-reducing strategies will be deployed in response to stakeholders who criticize that logic whereas conflict-inducing strategies will be deployed in situations where other logics are criticized"(Mampaey and Huisman, 2016, p. 2227). They argue that it is not uncommon, however not often researched, that the university may choose to deny responding to a critique in order not to acknowledge it. It also explains why universities are not keen on building a strong relationship with stakeholders if both sides do not share the same values and institutional logic.

\section{CONCLUSIONS}

This article has explored the changes that the introduction of quality assurance - one of the manifestations of university corporatisation and neo liberal ideology - brought to HEIs and its impact on academics. 
As the concept of quality assurance is as such not refuted by scholars, its implementation, procedures and actions that the system entails are seen as having a "hidden agenda" in the background - serving not the university and its scholars, but external stakeholders. Its true essence is believed to be of disciplining nature, with little or no impact on improvements in terms of quality of teaching or research, but with high costs on academics' time, motivation and career development. The methodology of the system is sometimes seen as not scientific, overwhelmingly bureaucratic and not compatible with the role of an academic for whom the core activities are research and teaching. The system as such is of no interest for most scholars.

The revision of traditional values, power balance, academic freedom and autonomy perceived by academics is frequently regarded as a disillusionment and a threat of losing the most core underpinnings of academic life. Quality assurance is seen as a game that one needs to play. The attitude of lack of ownership of the process is occurring, as well as the belief that the system actually does not entail many improvements but is a source of control and discipline. In the light of the current changes, the academics are reported as declining in participation in governance, and the void is being replaced by quality assurance officers that lead the university even further towards corporatisation. The ideas of accountability, values for money and transparency are paradoxically resulting in an outgrowth of mistrust, tension, raising the level of pressure on academics and developing various coping strategies such as decoupling or mimetic isomorphism (Blaschke et al., 2014; Parker, 2011; Lueg, 2018).

The traditional role of an academic for whom research and teaching are the essential activities is being undermined by the necessity of assigning time for time-consuming administrative and managerial tasks with no concrete payoffs.

Research shows that role conflict, and role ambiguity are dysfunctional factors influencing one's effectiveness and job satisfaction (Rizzo et al., 1970) and although sometimes inevitable should be minimised (Floyd and Lane, 2000). What is more, it's the administrative part of the job, and the awareness of being controlled that tend to be the most negative job experience, as Williams et al., (1991) claims. The generally unfavourable perception of the quality system could also be interpreted in terms of those findings.

Another possible contribution to the previous research could be investigating if research on quality assurance is an area prone to interest conflicts, and if so, to what extent and how to ensure maintaining a neutral stand.

Nonetheless, the question can be asked whether the overly negative perception of quality assurance linking the system to restraining academic freedom and autonomy is inevitable. As Bleiklie and Kogan (2007) point out, "the general ideological pressure in individual countries is mediated through specific national policies" (Bleiklie and Kogan, 2007, p. 458) and do not have to entail diminishing academic autonomy. There are, however, not many comparative studies across various countries to investigate that. Another question is whether the prevailing attitudes will be preserved, or whether the interplay of managerialism and traditional view of a university will lead to some kind of a merge in the long run. Are decoupling, gaming, questionable research practices and other coping strategies to become an irremovable part of the picture, or just a temporary solution? There is a need for longitudinal research in that field in order to establish that. Is the case of quality assurance perception an arena on which two institutional logics collide? This remains to be unknown since no papers exploring that approach have been identified in this SLR.

Upton et al. (2017) state that not much attention so far has been given to conceptualise and analyse institutional logics at the university level, as well as that "the complexity of relationships among multiple logics remains less well understood than the ascendancy of one over the other" (Upton et al. 2017, p. 90). The authors also argue that "the concept of hybrid or blended logics suggests a promising framework for understanding how universities can and do manage and exploit tensions in 
their missions" Upton et al. 2017, p. 100). and that if "appropriately applied, the findings could serve as another tool in universities' multifaceted response to institutional complexity" (Upton et al. 2017, p. 101). Upon the conducted research, it may be stated that using the institutional logics analytical framework for analysing quality assurance perception and efficiency in bringing improvements to universities is a research gap. It however also showcases as a promising area of contributing insight to "universities' multifaceted response to institutional complexity" (Upton, 2017, p. 101).

In terms of analytical methods used in the selected papers, it is worth noticing, that most of the research was based on qualitative methods and small sample sizes (between 20-50 interviewees). A quantitative approach and significantly bigger sample sizes were used only eight times including three papers with a mixed approach. For that reason, the recommendation to employ quantitative methods more frequently is concluding the list of research gaps identified in this paper.

\section{LIMITATIONS}

The systematic literature review presented here has its limitations. One of it is restraining the search to one database only. Another one is that it could be useful to add managerialism or new public management to the search words to receive a broader set of papers. The results of the papers' analysis show that the list of identified papers should be treated as a starting point for additional research since the chosen keywords did not identify a lot of valuable papers. All generalisations presented in the papers should be accepted with care, as the conclusions of papers presented were mostly drawn on qualitative studies, small sample sizes and studies bound to the specific culture and organisations.

The paper presents the perception of quality systems of one stakeholders only; therefore, to broaden the perspective the analysis of other stakeholders should follow in further research. Including their view could enable to give answers to such question how does the perception of quality assurance systems differ among various groups of stakeholders.

\section{Literature}

Adams, D. (1998). Examining the fabric of academic life: An analysis of three decades of research on the perceptions of Australian academics about their roles. Higher Education, 36(4), 421-435. https://doi. org/10.1023/A:1003423628962

Ala-Vähälä, T. (2016). Reception of the quality assurance commitments of the Bologna process in Finnish higher education institutions. Quality in Higher Education, 22(2), 103-116. https://doi.org/10.1080/13538 322.2016.1195966

Alderman, G. (1996). Audit, assessment and academic autonomy. Higher Education Quarterly, 50(3), 178-192. https://doi.org/10.1111/j.1468-2273.1996.tb01700.x

Anderson, G. (2006). Assuring quality/resisting quality assurance: Academics' responses to 'quality' in some Australian universities. Quality in Higher Education, 12(2), 161-173. https://doi.org/10.1080/13538320600916767

Archer, M.S. (2007). Making our way through the world: Human reflexivity and social mobility. Cambridge: Cambridge University Press.

Azman, N. (2012). Malaysian public universities governance system: A compromise between collegiality, autonomy and corporate management approaches. International Journal of Knowledge, Culture and Change Management, 11(5), 115-133.

Bamber, V., Anderson, S. (2012). Evaluating learning and teaching: Institutional needs and individual practices. International Journal for Academic Development, 17(1), 5-18. https://doi.org/10.1080/1360144X.2011.586459

Berg, C. (1993). University autonomy and quality assurance. Higher Education in Europe, 18(3), 18-26. https:// doi.org/10.1080/0379772930180303

Berman, E.P. (2012). Explaining the move toward the market in US academic science: How institutional logics can change without institutional entrepreneurs. Theory and Society, 41(3), 261-299. https://doi.org/10.1007/ s11186-012-9167-7 
Bjerregaard, T. (2010). Industry and academia in convergence: Micro-institutional dimensions of R\&D collaboration. Technovation, 30(2), 100-108. https://doi.org/10.1016/j.technovation.2009.11.002

Blaschke, S., Frost, J., Hattke, F. (2014). Towards a micro foundation of leadership, governance, and management in universities. Higher Education, 68(5), 711-732. https://doi.org/10.1007/s10734-014-9740-2

Bleiklie, I., Kogan, M. (2007). Organization and governance of universities. Higher Education Policy, 20(4), 477-493. https://doi.org/10.1057/palgrave.hep.8300167

Brady, N., Bates, A. (2016). The standards paradox: How quality assurance regimes can subvert teaching and learning in higher education. European Educational Research Journal, 15(2), 155-174. https://doi. org/10.1177/1474904115617484

Brew A., Boud D., Lucas L., Crawford K. (2017). Responding to university policies and initiatives: the role of reflexivity in the mid-career academic. Journal of Higher Education Policy and Management, 39(40), 378-389. https://doi.org/10.1080/1360080X.2017.1330819

Briner R. B., Denyer D. (2012). Systematic Review and Evidence Synthesis as a Practice and Scholarship Tool. In D. M. Rousseau (Ed.), Oxford Handbook of Evidence-Based Management: Companies, Classrooms and Research (pp. 112-129), Oxford University Press. https://doi.org/10.1093/oxfordhb/9780199763986.013.0007

Brown Jr., W. O. (2001). Faculty participation in university governance and the effects on university performance. Journal of Economic Behavior and Organization, 44(2), 129-143.

Cai, Y. (2015). What contextual factors shape 'innovation in innovation'? Integration of insights from the Triple Helix and the institutional logics perspective. Social Science Information, 54(3), 299-326. https:// doi.org/10.1177/0539018415583527

Carvalho, T., Videira, P. (2017). Losing autonomy? Restructuring higher education institutions governance and relations between teaching and non-teaching staff. Studies in Higher Education, 44(4), 762-773. https://doi. org/10.1080/03075079.2017.1401059

Cheng, M. (2010). Audit cultures and quality assurance mechanisms in England: A study of their perceived impact on the work of academics. Teaching in Higher Education, 15(3), 259-271. 10.1080/13562511003740817

Christopher, J., (2012). Governance Paradigms of Public Universities: An international comparative study. Tertiary Education and Management, 18(4), 335-351. https://dx.doi.org/10.1080/13583883.2012.724705

Currie, J., Vidovich, L., Yang, R. (2008). Countability not answerability? Accountability in Hong Kong and Singapore universities. Asia Pacific Journal of Education, 28(1), 67-85. https://doi.org/10.1080/02188790701845972

David, F., van der Sijde, P., van den Besselaar, P. (2018). Academics coping with business logic: A study at Indonesian universities. Journal of Engineering and Technology Management - JET-M, 48, 91-108, doi. org.10.1016/j.engtecman.2018.07.002

Dobbins, M., Knill, C., Vögtle, E. M. (2011). An analytical framework for the cross-country comparison of higher education governance. Higher Education, 62(5), 665-683. https://doi.org/10.1007/s10734-011-9412-4

Dowling-Hetherington, L. (2013). The Changing Shape of University Decision-Making Processes and the Consequences for Faculty Participation in Ireland. Tertiary Education and Management, 19(3), 219-232. https:// doi.org/10.1080/13583883.2013.790071

Dunn, M. B., Jones, C. (2010). Institutional logics and institutional pluralism: The contestation of care and science logics in medical education, 1967-2005. Administrative Science Quarterly, 55(1), 114-149. https:// doi.org/10.2189/asqu.2010.55.1.114

Floyd, S.W., Lane, P.J. (2000). Strategizing throughout the Organization: Managing Role Conflict in Strategic Renewal. The Academy of Management Review, 25(1), 154-177. https://doi.org/10.2307/259268

Franco-Santos, M., Nalick, M., Rivera-Torres, P., Gomez-Mejia, L. (2017). Governance and Well-being in Academia: Negative Consequences of Applying an Agency Theory Logic in Higher Education. British Journal of Management, 28(4), 711-730. https://doi.org/10.1111/1467-8551.12249

Frost, J., Brockmann, J. (2014). When qualitative productivity is equated with quantitative productivity: scholars caught in a performance paradox [Wenn Qualität von Forschung, Lehre und Bildung mit quantitativer Produktivität gleichgesetzt wird - im Leistungsparadoxon gefangene Wissenschaftler]. Zeitschrift fur Erziehungswissenschaft, 17(6), 25-45.

https://doi.org/10.1007/s11618-014-0572-8

Gallos, J. V. (2009). Reframing shared governance: Rediscovering the soul of campus collaboration. Journal of Management Inquiry, 18(2), 136-138. https://doi.org/10.1177/1056492608326326

Giroux, D., Karmis, D., Rouillard, C. (2015). Between the managerial and the democratic university: Governance structure and academic freedom as sites of political struggle. Studies in Social Justice, 9(2), https:// doi.org/142-158. 10.26522/ssj.v9i2.1149

Gray, G. C., Silbey, S. S. (2014). Governing inside the organization: Interpreting regulation and compliance. American Journal of Sociology, 120(1), 96-145. 
Houston, D., Paewai, S. (2013). Knowledge, power and meanings shaping quality assurance in higher education: A systemic critique. Quality in Higher Education, 19(3), 261-282. https://doi.org/10.1080/13538322 .2013 .849786

Howells, J.R.L., Karataş-Özkan, M., Yavuz, Ç., Atiq, M. (2014). University management and organisational change: A dynamic institutional perspective. Cambridge Journal of Regions, Economy and Society, 7(2), 251-270. https://doi.org/10.1093/cjres/rsu005

Huusko, M., Ursin, J. (2010). Why (not) assess? Views from the academic departments of Finnish Universities. Assessment and Evaluation in Higher Education, 35(7), 859-869. https://doi.org/10.1080/02602930903125264

Hyatt, D. (2013). The critical policy discourse analysis frame: Helping doctoral students engage with the educational policy analysis. Teaching in Higher Education, 18(8), 833-845. https://doi.org/10.1080/1356 2517.2013.795935

Kolsaker, A. (2008). Academic professionalism in the managerialist era: A study of English universities. Studies in Higher Education, 33(5), 513-525. https://doi.org/10.1080/03075070802372885

Lapworth, S. (2004). Arresting decline in shared governance: Towards a flexible model for academic participation. Higher Education Quarterly, 58(4), 299-314. https://doi.org/10.1111/j.1468-2273.2004.00275.x

Lucas, L. (2014). Academic resistance to quality assurance processes in higher education in the UK. Policy and Society, 33(3), 215-224. https://doi.org/10.1016/j.polsoc.2014.09.006

Lueg, K. (2018). Organizational changes towards a European academic field. A case study of frictions in the narratives of Europeanization at a German university from an institutional perspective. Innovation, 31, 454-503, https://doi.org/10.1080/13511610.2018.1490637

Maassen, P., (2017). The university's governance paradox. Higher Education Quarterly, 71(3), 290-298. https:// doi.org/10.1111/hequ. 12125

Mampaey, J., Huisman, J. (2016). Defensive stakeholder management in European universities: an institutional logics perspective. Studies in Higher Education, 41(12), 2218-2231. https://doi.org/10.1080/03075079.201 5.1029904

Mårtensson, K., Roxå, T., Stensaker, B. (2014). From quality assurance to quality practices: an investigation of strong microcultures in teaching and learning. Studies in Higher Education, 39(4), 534-545. https://doi. org/10.1080/03075079.2012.709493

Mok, K. H. (2008). Singapore's global education hub ambitions: University governance change and transnational higher Education. International Journal of Educational Management, 22(6), 527-546. https://doi. org/10.1108/09513540810895444

O'Connor, P., O'Hagan, C. (2016). Excellence in university academic staff evaluation: a problematic reality? Studies in Higher Education, 41(11), 1943-1957. https://doi.org/10.1080/03075079.2014.1000292

Ordorika, I. (2014). Governance and change in higher education: The debate between classical political sociology, new institutionalism and critical theories. Bordon, 66(1), 107- https://doi.org/10.13042/Bordon.2014.66107

Parker, L. (2011). University corporatisation: Driving redefinition. Critical Perspectives on Accounting, 22(4), 434-450. https://doi.org/10.1016/j.cpa.2010.11.002

Raaper, R. (2016). Academic perceptions of higher education assessment processes in neoliberal academia. Critical Studies in Education, 57(2), 175-190. https://doi.org/10.1080/17508487.2015.1019901

Rizzo, J.R., House, R.J., Lirtzman, S.I. (1970). Role Conflict and Ambiguity in Complex Organizations. Administrative Science Quarterly, 15(2), 150-163. http://dx.doi.org/10.2307/2391486

Salter, B., Tapper, T. (2000) The politics of governance in higher education: The case of quality assurance. Political Studies, 48(1), 66-87. https://doi.org/10.1111/1467-9248.00251

Sarrico, C.S., Veiga, A., Amaral, A. (2013). The long road-how evolving institutional governance mechanisms are changing the face of quality in Portuguese higher education. Educational Assessment, Evaluation and Accountability, 25(4), 375-391. https://doi.org/10.1007/s11092-013-9174-x

Shattock, M. (2002). Re-balancing modern concepts of university governance. Higher Education Quarterly, 56(3), 235-244. https://doi.org/10.1111/1468-2273.00215

Shattock, M., (2006). Managing Good Governance in Higher Education. Maidenhead: OpenUniversity Press.

Shattock, M. (2013). University governance, leadership and management in a decade of diversification and uncertainty. Higher Education Quarterly, 67(3), 217-233. https://doi.org/10.1111/hequ.12017

Smith, K. (2008). 'Who do you think you're talking to?' - The discourse of learning and teaching strategies. Higher Education, 56(4), 395-406. https://doi.org/10.1007/s10734-007-9100-6

Stamelos, G., Kavasakalis, A. (2011). The public debate on a quality assurance system for Greek universities. Quality in Higher Education, 17(3), 353-368. https://doi.org/10.1080/13538322.2011.628807

Steinhardt, I., Schneijderberg, C., Götze, N., Baumann, J., Krücken, G. (2017). Mapping the quality assurance of teaching and learning in higher education: the emergence of a specialty? Higher Education, 74(2), 221-237. https://doi.org/10.1007/s10734-016-0045-5 
Stensaker, B. (2007). Quality as fashion: Exploring the translation of a management idea into higher education. In M. J. Rosa, B. Stensaker, \& D. F. Westerheijden (Eds.), Quality assurance in higher education trends in regulation, translation and transformation (pp. 99-118). Dordrecht, Netherlands: Springer. https://doi. org/10.1007/978-1-4020-6012-0_4

Taylor, M. (2013). Shared Governance in the Modern University. Higher Education Quarterly, 67(1), 80-94. https://doi.org/10.1111/hequ.12003

Teelken, C., Lomas, C., L. (2009). How to strike the right balance between quality assurance and quality control in the perceptions of individual lecturers": A comparison of UK and Dutch higher education institutions. Tertiary Education and Management, 15(3), 259-275. https://doi.org/10.1080/13583880903073016

Trakman, L. (2008). Modelling university governance. Higher Education Quarterly, 62(1-2), 63-83. https://doi. org/10.1111/j.1468-2273.2008.00384.x

Trullen, J., Rodríguez, S. (2013). Faculty perceptions of instrumental and improvement reasons behind quality assessments in higher education: the roles of participation and identification. Studies in Higher Education, 38(5), 678-692. https://doi.org/10.1080/03075079.2011.590587

Upton, S., Warshaw, J. B., (2017). Evidence of hybrid institutional logics in the US public research university. Journal of Higher Education Policy and Management, 39(1), 89-103. https://doi.org/10.1080/136008 0X.2017.1254380

Veiga, A., Rosa, M. J., Dias, D., Amaral, A. (2013). Why is it difficult to grasp the impacts of the Portuguese quality assurance system? European Journal of Education, 48(3), 454-470. https://doi.org/10.1111/ejed.12040

Vidovich, L., Currie, J. (2011). Governance and trust in higher education. Studies in Higher Education, 36(1), 43-56. https://doi.org/10.1080/03075070903469580

Vidovich, L., Porter, P. (1999). Quality policy in Australian higher education of the 1990s: University perspectives. Journal of Education Policy, 14(6), 567-586. https://doi.org/10.1080/026809399286099

Wang, L. (2014). Quality assurance in higher education in China: Control, accountability and freedom. Policy and Society, 33 (3), 253-262. https://doi.org/10.1023/A:1014616110418

Williams, K. J, Suls, J., Alliger G. M., Learner, S. M., Wan C. K. (1991). Multiple role juggling and daily mood states in working mothers: an experience sampling study. Journal of Applied Psychology, 76(5), 664-74. http://dx.doi.org/10.1037/0021-9010.76.5.664

Zheng, G., Shen, W., Cai, Y. (2018). Institutional logics of Chinese doctoral education system. Higher Education, 76(1), 753-770, https://doi.org/10.1007/s10734-018-0236-3 


\section{APPENDIX}

List of journals and number of papers included in the SLR

\begin{tabular}{|c|c|}
\hline Journal & Number of papers \\
\hline Higher Education Quarterly & 7 \\
\hline Studies in Higher Education & 5 \\
\hline Higher Education & 4 \\
\hline Quality in Higher Education & 3 \\
\hline Studies in Higher Education & 2 \\
\hline Journal of Higher Education Policy and Management & 2 \\
\hline Policy and Society & 2 \\
\hline Asia Pacific Journal of Education & 1 \\
\hline Critical Studies in Education & 1 \\
\hline Economy and Society & 1 \\
\hline European Educational Research Journal & 1 \\
\hline Higher Education & 1 \\
\hline Innovation & 1 \\
\hline International Journal of Educational Management & 1 \\
\hline Journal of Engineering and Technology Management - JET-M & 1 \\
\hline Tertiary Education and Management & 1 \\
\hline Administrative Science Quarterly & 1 \\
\hline American Journal of Sociology, & 1 \\
\hline Assessment and Evaluation in Higher Education & 1 \\
\hline British Journal of Management & 1 \\
\hline Critical Perspectives on Accounting & 1 \\
\hline Educational Assessment, Evaluation and Accountability & 1 \\
\hline European Journal of Education & 1 \\
\hline Higher Education in Europe & 1 \\
\hline Higher Education Policy & 1 \\
\hline International Journal for Academic Development & 1 \\
\hline International Journal of Knowledge, Culture and Change Management & 1 \\
\hline Journal of Economic Behavior and Organization & 1 \\
\hline Journal of Education Policy & 1 \\
\hline Journal of Management Inquiry & 1 \\
\hline Political Studies & 1 \\
\hline Quality in Higher Education, & 1 \\
\hline Social Science Information & 1 \\
\hline Studies in Social Justice, & 1 \\
\hline Teaching in Higher Education & 1 \\
\hline Technovation & 1 \\
\hline Tertiary Education and Management & 2 \\
\hline Theory and Society & 1 \\
\hline Zeitschrift fur Erziehungswissenschaft & 1 \\
\hline Total & 58 \\
\hline
\end{tabular}




\title{
Perspectives for More Inclusive and Impactful Fair Trade. Analysis of the Handloom Industry in Nepal
}

\author{
Karolina Osterczuk*
}

\begin{abstract}
Summary
Fair trade movement is keeping evolving and developing new, more impactful practices, dedicated to multi-faceted support of producers and protection of natural environment. Hand looming is a disappearing craft of a high cultural value and a traditional profession providing income to a significant amount of people from the global south. The industry relies on a support of local non-profit organizations, the same as the artisans who hand wave. The article explores the possibilities for international, fair collaboration within the global community of conscious fashion and sustainable design, which benefits both sides: the craftsmen and the designers.
\end{abstract}

Keywords: fair trade, social innovation, craftsmanship, sustainable design

JEL: Q01, F16, M14, O15

\section{INTRODUCTION}

The fair trade movement was established in the 1960s and strengthened in the 70s. Its aim was to ensure fair salaries and decent working conditions for discriminated producers and farmers from developing countries. By the definition, it is a "commercial network of production-distributionconsumption oriented towards interdependent, sustainable development" (Audebrand \& Pauchant, 2009). Fair trade is a component of "the new forces of market construction, coordination and regulation, which link social movements, commodities and policies in new global networks". It is the most dynamic, market-based practice to create social change and to transform globalization into a fair model. More advanced initiatives from the fair trade movement are aimed at multi-faceted support, providing decent income, skills training, education and new effective and ecologically friendly technologies. A meaningful difference is the basic assumption, that smallholders can become leaders of their community and support it towards a sustainable development. Empowerment is practiced for example by the coffee trader Bean Voyage, which declares that "trade is not just an exchange of goods (...), but the investment in holistic sustainability of the people and planet" (https:// beanvoyage.com/pages/about). So called "care trade" is an expanding idea of changing the existing trade system and another form of social enterprise with an international range. As a third party in the fair and care trade movement, they service a large group of consumers, who pay attention to the origin of purchased goods and consider themselves conscious buyers. Even though the mainstream economy convinces us that consumers seek the lowest possible prices and the maximization of individual gains, the image of a consumer has been changing from an egocentric profit maker, to a person who is aware of consumption's cost and actively "votes with his money" by choosing ethically made, eco-friendly products; even for a higher price. Conscious fashion and sustainable design are concepts which have gained a lot of popularity and become movements followed by responsible consumers. Transforming globalization provides new possibilities of development for a disadvantaged global south. Said possibilities are based on a commercial exchange and economic inclusion, not a charity or financial aid.

* Faculty of Management, University of Warsaw, Poland, https://orcid.org/0000-0003-2189-3170, e-mail: karolina.osterczuk@gmail.com 
Hand crafted fabric is a very unique product on today's market, which makes it an attractive exported good, produced by small workshops and craftsmen. At the same time, it provides a source of income to a significant amount of people from the global south and has been an economical trampoline to discriminated members of society like women and low castes. The responsible textiles value chain is an object of research and interest for NGOs and experts, because of its impact on rural development. It has a strong potential for advanced fair trade initiatives to bring change and offer to the market a desired product. Fashion enterprises, like Mayamiko, build their core marketing strategy around the origin of their products, which allows them to create a responsible image.

Insights provided by the theory of transformative globalization suggests the collaborative model of development, through fair trade and empowerment of local organizations and open access to modern technologies. This leads to independent and sustainable growth. Social innovation is understood as "the development and delivery of new ideas and solutions (products, services, models, modes of provision, processes) at different socio-structural levels that intentionally seek to change power relations and improve human capabilities, as well as the processes via which these solutions are carried out" (Chiappero-Martinetti, Ziegler \& Budd, 2017). According to researchers, only a participatory initiative creates social change, not a temporary action, which is not continued after the foreign actor's disappearance (Chandra, 2018). Involvement of local leaders and organizations is crucial for any initiative aspiring to create a positive impact. The Nepali non-profit sector is very well developed, supports society on many levels, as well the craftsmanship and producers of handmade fabrics and textiles. It holds important insights about handcrafted goods and the industry, while also acting as a safety bumper between producers and the market. It protects members of the value chain from exploitation and supports their development (Adhikari, Shrestha, Dorji, Lemke, $\&$ Subedee, 2018).

The Indian NGO, Dastkar, declared themselves to "strongly believe in craft as a social, cultural and economic force, that despite being marginalized due to urbanization and industrialization, has enormous strength and potential and has thus a vital role to play within the economic mainstream of the country" (Adhikari, Shrestha, Dorji, Lemke, \& Subedee, 2018). Craft skills are passed down from generation to generation. Craftsmanship is strongly rooted in local culture, while traditional professions create authenticity of the society and support its perception of identity. According to the UNCTAD handbook for artisans from developing economies, a very important issue is whether they can adapt their products to meet the requirements of the global markets or not, because the purchasing power of local markets is too limited to support them (International Trade Centre, 1991). At the same time the 'handmade' label in western countries is actually having its renaissance. In the opposite of machine produced and all equal goods, those created by humans are considered to have a touch of soul and uniqueness of imperfection.

One of the ways to raise competitiveness of local products is to improve its design - in both, an aesthetical as well as a practical meaning. Collaborations between the designer and the craftsman and a combination of modern design with traditional craft can be a source of innovation and skills training. Product development is considered to be one of the strategies for scaling the impact of social enterprise in a developing economy (Bocken, Fil, Prabhu, 2016). In order to maintain financial sustainability and to bring change to the community, SE must keep on adapting to market requirements. There are potential threats in such dynamic, trend sensitive industries like fashion and design, to which textiles producers are directly dependent. The important factor however is the responsible approach to the project. As Victor Papanek emphasized already over 30 years ago, the object of design will carry with it the moral, social and environmental consequences. Design is a multifaceted process that goes far beyond aesthetics.

Having the above in mind, a cognitive excursion to a textile craft in Nepal was planned and took place with a group of six people, including students and academics of industrial design 
and management. The aim was to recognize opportunities and threats, which design and production of textiles goods can carry, as well to get familiar with the cultural context of it.

The following article analyzes the collected information and supplements it with a literature review in order to search for opportunities of more impactful and inclusive fair trade with textile craftsmanship. It has been suggested by researchers that it represents a social innovative approach due to its developmental application.

\section{RESEARCH METHOD}

The article is based on the field observations and informal interviews, made during the cognitive excursion to Nepal, as well on existing literature related to craftsmanship's developmental role and social innovation theory. The local textiles industry was analyzed through the perspective of a stakeholder map and value chain. An explorative journey program involved visiting places and meeting actors engaged at various levels of handmade textiles production, as well those indirectly affecting the industry. The whole process of fabric production was acknowledged - from harvesting plants, to final product sewing. Identifying human and institutional resources contributed to a better understanding of the craftsmen community (Starnawska, 2016). Research and excursion were dominated by a human center approach. Various intellectual tools were engaged - design thinking, ideation and brainstorming - in order to synthesize information and compare the current observations of participants. A photographic documentation and journey map in a smartphone application served as a systematization of collected data.

\section{INDUSTRY AND THE STAKEHOLDERS}

After tourism, the textile and carpet industry is the biggest sector of the Nepali economy, offering a source of employment and income of households. According to WITS, in 2015 over $43 \%$ of exported textiles were sold to India, and over $19 \%$ to the United States. The goods are mostly handcrafted, produced by small business or house workshops. Woven on handlooms and decorated by hand block printing or embroidery. Very typical fabrics are hemp, cotton and nettle, as well wool, pashmina and Dhaka (WITS, 2015).

The garment industry is the second largest item of export in Nepal after the woolen carpet. It earned one-third of the total export income, and directly employed 90,000 people, supporting the livelihood of 450,000 persons (Sapkota, 2010). The industry benefited from the Multi-Fiber Arrangement (MFA), but the quota has ended in 2004, causing a significant downfall in export (Fair Wear Foudation, 2013). The developmental objective in Nepal, according to a UN report, is to improve citizens' livelihoods through the creation of employment possibilities. Unemployment is very high, $46 \%$ of Nepal's youth labor force in the age group 20-24 is underutilized (Nepal Labour Force Survey, 2008). Agriculture provides a livelihood for over $80 \%$ of the population and over $85 \%$ of the population lives in rural areas, where harvesting of natural fabrics is significant.

Craftsmanship of textiles and fabrics is deeply rooted in Nepali society, which passes the knowledge from generation to generation, in order to keep remembered traditional technics of handwork. Existence and quality of the life of artisans is dependent on market trends and fast changing customer needs, to which it is not always easy to keep up. To support this important part of Nepali heritage, many organizations have arisen, and craftsmanship gained a place in academic education. When considering any activity related to it, this specific network must be noticed and incorporated into plans. Figure 1 presents a framework for recognizing local stakeholders. A stakeholder is understood here according to Freeman's definition (1984) as "any group or individual who can affect or is affected by the achievement of the organization objectives". This means that any market activity involving craftsmanship has or may have a certain level of relationship to groups of actors listed below. 
In the bottom part of stakeholder map appear actors who bear the direct consequence of the manual production of textiles. They are mostly professionals, like tailors or weavers, but also farmers cultivating a plant, from which the fibers are obtained, as well as processors who prepare a thread, by winding it on a foot-driven reel. The "environment" category (which is related to livelihood and market operation (Haigh \& Griffiths, 2009)), includes natural resources, used for fabric production, and environmental degradation, like pollution, caused by the production. Quality of life of the community of people (e.g. those who take water in the vicinity of dye works or families of craftspeople) depends on the fabric production. They are considered to be stakeholders, whose rights are crucial for any socially responsible initiative.

Figure 1. Stakeholder map

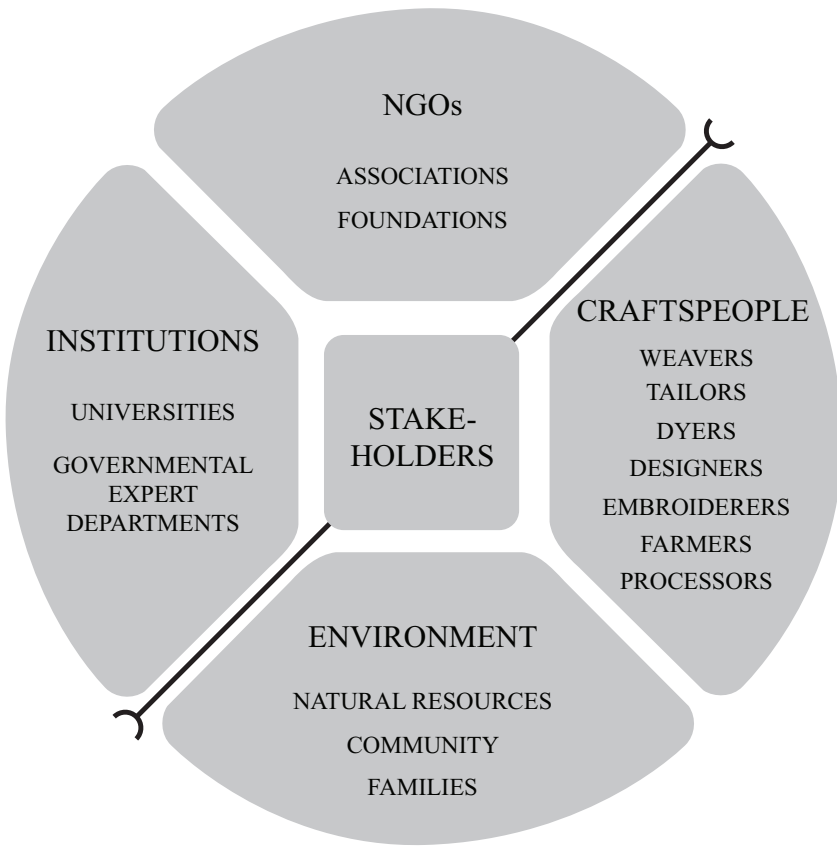

On the other side there groups of local experts, institutional resources and organizations influencing the craft textiles industry, e.g. associations connecting small producers, stimulating their development and providing access to income. This also includes local researchers and knowledge centers that hold valuable information. Such a division covers most of the groups dealing with craftsmanship and became a starting base for planning interviews and observations made for the purpose of this research during the cognitive excursion.

\section{COGNITIVE EXCURSION SUMMARY}

The cognitive excursion to Nepal took place in order to investigate the local textiles industry and recognize the potential for social innovativeness in the field of craftsmanship. In order to achieve it, participants followed a value chain of the fabric's manufacturing and investigated the production process with its ecological and social consequences, but also the potential for responsible design. Special attention was given to a cultural and structural context, in order to recognize the level of 
social awareness, activism, and the ability to accommodate new ideas, as well to find out about structural supportiveness for social innovation.

The team was created out of students and academics of industrial design and management, altogether 6 people. Students, who were gathering material for their final thesis projects, played the role of designers - explorers, equipped with postcolonial theory, cameras and notebooks filled with everyday reflections. They were searching not only for the inspiration, but also for the social consequences of their design. The journey took 16 days and was dedicated to gain an overall view of the textiles industry and to understand the role that craftsmanship plays in it. Moreover, to answer the question - what are the conditions for innovativeness in the field? The table below includes all the visited places, sorted by the type of their activity.

Table 1. Objects of field research

\begin{tabular}{|c|c|c|c|c|c|c|c|c|c|}
\hline \multicolumn{2}{|c|}{ Fabrics and textiles } & \multirow{2}{*}{\multicolumn{2}{|c|}{$\begin{array}{l}\text { Dye houses } \\
\text { Dye house1, } \\
\text { screen printing, } \\
\text { embroidery }\end{array}$}} & \multirow{2}{*}{\multicolumn{2}{|c|}{$\begin{array}{ll}\text { Education center } \\
11 \quad \text { Kathmandu } \\
& \text { University of } \\
& \text { Arts KUART }\end{array}$}} & \multicolumn{2}{|c|}{ Shoe manufactures } & \multicolumn{2}{|c|}{$\begin{array}{c}\text { Non-governmental } \\
\text { organizations }\end{array}$} \\
\hline 1 & $\begin{array}{l}\text { Nepal Apparels } \\
\text { Natural Fibers } \\
\text { weaving house }\end{array}$ & & & & & 12 & $\begin{array}{l}\text { Handmade shoe } \\
\text { house }\end{array}$ & 15 & Sabah Nepal \\
\hline 2 & NANF tailoring & 9 & Dye house 2 & & & 13 & $\begin{array}{l}\text { Handmade shoe } \\
\text { house }\end{array}$ & 16 & $\begin{array}{l}\text { Conscious } \\
\text { Impact }\end{array}$ \\
\hline 3 & $\begin{array}{l}\text { Sabah } \\
\text { manufacture }\end{array}$ & 10 & $\begin{array}{l}\text { Automatic dye } \\
\text { house }\end{array}$ & & & & $\begin{array}{l}\text { Handmade shoe } \\
\text { house }\end{array}$ & 17 & Mahaguthi \\
\hline 4 & $\begin{array}{l}\text { Kushma } \\
\text { weaving house }\end{array}$ & & & & & & & 18 & FNCSI \\
\hline 5 & $\begin{array}{l}\text { Kushma home } \\
\text { based weaving } \\
\text { house }\end{array}$ & & & & & & & & \\
\hline 6 & $\begin{array}{l}\text { Nitya Traditional } \\
\text { Tex }\end{array}$ & & & & & & & & \\
\hline 7 & $\begin{array}{l}\text { Wool electric } \\
\text { manufacture }\end{array}$ & & & & & & & & \\
\hline
\end{tabular}

3-16 November 2017.

The program was made in order to meet actors affected by the textiles industry and organizations supporting them or interacting with them. Below a brief explanation:

1. The category "Fabrics" includes: handloom, sewing, embroidery and screen printing workshops

2. Dye houses - where fabrics are dyed;

3. Sabah Nepal - Cooperative representing home-based workers;

4. FNCSI - Association uniting small and cottage industry;

5. Mahaguti Foundation - supporting artisanship;

6. University of Art and Design - source of local design knowledge

Observations were made in 7 manufactures related to weaving fabrics (mostly handcrafts, several equipped with electric machines), 3 footwear manufactures, 3 dyes workshops, embroidery, screen printing and tailoring workshops. Interviews in the form of informal conversations were conducted with farmers, processors and craftsmen employed and self-employed, one business owner, members of non-profit organizations and academics from a local school of design. The variety of visited 
places gave a quite wide view on textiles production possibilities and the overall condition of the industry. It must be noticed, that the majority of the workshops and manufactures were located near the cities, in the most developed regions, around Kathmandu Valley (distance up to $30 \mathrm{~km}$ ), in Pokhara and in Kushma, which is a distanced of $60 \mathrm{~km}$ to the city.

During the journey, there was a smartphone map application in use, which allowed to mark visited places and to attach basic data about them. A detailed photographic documentation has been made, which later was organized by design students and matched with locations, notes and swatches of materials. They were encouraged to recognize available technologies, production parameters, capacity, working conditions, to spot ecological threats and to be sensitive to local culture and tradition. Three workshops were held for the participants of the excursion, dedicated to summarizing and briefly concluding the recently acquired knowledge. The team got involved in so-called "ecoideation" in order to generate ideas helpful to reduce the negative impact of the product (Bocken, Rana, \& Short, 2015). Brainstorming was focused on identifying environmental and social issues related to the textile industry of Nepal. It defined some of the assumptions for product design workshops, during which it was decided for example to use only natural color fabrics in order to minimize the river's pollution and expose a natural beauty of the fabric. After returning to the country, students created products and services, which consider minimizing the environmental effect and maximizing the benefit of local society.

\section{ANALYSIS AND CONCLUSIONS}

The field research, supported with a literature review, brought some findings worth deepening about the current situation of the craftsman society. Below is presented a responsible SWOT analysis of the handloom and handcrafted textiles industry, which includes information related to social and environmental issues. The analysis can be perceived through not only a business perspective, but also as an insight for strategic planning of social innovativeness within the field of craftsmanship.

Table 2. SWOT analysis

\begin{tabular}{|c|c|c|c|}
\hline Strengths & Weaknesses & Opportunities & Threats \\
\hline $\begin{array}{l}\text { Variety of traditional } \\
\text { textiles products }\end{array}$ & Pollution from dye houses & $\begin{array}{l}\text { Rising demand for } \\
\text { handcrafted and fair trade } \\
\text { products in developed } \\
\text { countries }\end{array}$ & $\begin{array}{l}\text { Loss of traditional patterns } \\
\text { and cultural identity }\end{array}$ \\
\hline Uniqueness of handicrafts & $\begin{array}{l}\text { Pollution from processing } \\
\text { fibers }\end{array}$ & $\begin{array}{l}\text { E-commerce as a channel } \\
\text { of sales }\end{array}$ & Logistics \\
\hline Developed retail structure & Lack of modern technology & $\begin{array}{l}\text { Space for collaboration } \\
\text { with world fashion and } \\
\text { design. Meeting global } \\
\text { requirements }\end{array}$ & $\begin{array}{l}\text { Disappearance of craft } \\
\text { practice }\end{array}$ \\
\hline $\begin{array}{l}\text { Variety of NGOs supporting } \\
\text { the industry }\end{array}$ & $\begin{array}{l}\text { Sex discrimination on } \\
\text { managerial levels }\end{array}$ & Product design & $\begin{array}{l}\text { Inadequate quality of } \\
\text { products }\end{array}$ \\
\hline Use of local resources & $\begin{array}{l}\text { Limited access to skills } \\
\text { training }\end{array}$ & $\begin{array}{l}\text { Low cost technological } \\
\text { improvements }\end{array}$ & $\begin{array}{l}\text { Competition from } \\
\text { neighboring countries like } \\
\text { India and China }\end{array}$ \\
\hline $\begin{array}{l}\text { Inclusion of home-based } \\
\text { workers, women and } \\
\text { marginalized groups }\end{array}$ & Poor infrastructure & Employment in rural areas & $\begin{array}{l}\text { Unstable, protectionist } \\
\text { tax policy of developed } \\
\text { countries }\end{array}$ \\
\hline
\end{tabular}


Table 2. (cont.)

\begin{tabular}{llll}
\hline \multicolumn{1}{c}{ Strengths } & \multicolumn{1}{c}{ Weaknesses } & \multicolumn{1}{c}{ Opportunities } & \multicolumn{1}{c}{ Threats } \\
\hline $\begin{array}{l}\text { Inexpensive technology and } \\
\text { innovation }\end{array}$ & Exploitation by middleman & $\begin{array}{l}\text { Scaling the impact of local } \\
\text { NGOs }\end{array}$ & Dependency on export \\
\hline $\begin{array}{l}\text { Social acceptance for } \\
\text { women and low casts in } \\
\text { textiles industry }\end{array}$ & Little ecological awareness & $\begin{array}{l}\text { Popularization of renewable } \\
\text { energy and sustainable } \\
\text { technology of fabric's } \\
\text { production }\end{array}$ & Export restrictions \\
\hline $\begin{array}{l}\text { Openness for foreign } \\
\text { collaboration }\end{array}$ & $\begin{array}{l}\text { Communication and } \\
\text { marketing skills }\end{array}$ & Niche B2B market & \\
\hline
\end{tabular}

The textiles craftsmanship in Nepal creates a range of opportunities for social impact within the frameworks of inclusive trade, employment and self employment, social and gender equality, technology development and implementation, entrepreneurial and professional education, as well all the innovations related to environment protection. Local producers and traders are still somewhat connected with the world market, however retail structures are well developed and there exists a supportive network of non-governmental organizations, as well as an enthusiastic approach to new ideas. Collaboration between global fashion, design and craftsmanship in a developing economy is beneficial for both sides. Uncertainty however appears on a few levels: standards of communication, reliability of product quality, market suitability considering the offer for the EU and US and access to modern technological advancements, which all together decide on the competitiveness of craftsmanship in comparison to industrial textiles producers. Product development is an opportunity for handcrafted products to meet the needs of global markets. In addition, it opens the space for creative innovativeness and improvements on both social and commercial levels. At the same time, handmade is considered to be luxurious and attractive, which makes the textile craftsmanship still a promising field.

Tradition of textiles and fabrics in Nepal has a long history and the assortment is wide - starting from raw, strong materials (e.g. made of hemp), ending on labor-intensive pattern Dhaka, which is used for soft clothing for festive occasions. The majority of produced fabrics is made of natural fibers. Hemp and Himalayan nettle (allo) are locally resourced, which grow widely in high altitudes. Unfortunately available basic technology is not sufficient to produce thin threads, which makes the offer less competitive, in comparison to China or India.

The value chain of the fabric's production is long and includes many middlemen, which can be a source of exploitation and offers little control over the producer's income. Usually village level traders, who buy the harvested plant from village collectors, or spools of thread from thread makers, have no access to national and international level manufacturers, nor to consumers. This is due to factors like poor accessibility and limited livelihood opportunities (Adhikari, Shrestha, Dorji, Lemke \& Subedee, 2018). Local NGOs connect craftsmen and farmers to the market in order to stabilize their profits and exclude the exploitive factor. Craftsmanship is a source of income to a significant amount of people from developing countries. According to a capabilities approach, society can only evolve when the potential of all the people is released and everyone has a freedom to decide consciously about his or her own future (Sen, 2003). The inclusive value chain is a program which applies Sen's theory into practice. Nepal is a society of a caste system, which was adapted from Hindus immigrants arriving from India since the Muslim invasion in the XIV century. To this day the system is a source of inequalities inherited from generation to generation. Traditionally, castes are associated with specific occupations and economical statuses - Brahman and Chhetri are most privileged and born to participate in politics, administration and the military. On the contrary, there 
are occupational castes (tailors, weavers, shoemakers, blacksmiths, etc.) and Dalit (untouchables), who receive lower income, worse access to education and less of social privileges (Dor, 1967). However development and an open market have brought new possibilities of income generation and mobility between occupations, strengthened by a better access to education (Hamid, 2018).

While the textiles industry became a way to social promotion through entrepreneurship, this is however still not available to everyone. Reality puts additional limitations, like poor or no secure infrastructure, limited access to communication technology and discrimination within the community. Those issues are being tackled by non-profit organizations supporting fair trade and craftsmanship, which reach communities marginalized because of their place of residence or social status. Years of experience in creating social impact made local organizations a repository of knowledge and the third sector in Nepal - very well developed. There are over 40 thousand NGOs in existence in Nepal (Social Welfare Council, 2014). A perfect example to analyze is an innovative program implemented by the Business Association of Home Based Workers (SABAH) in Naugat, a mountain region in fair the far west of Nepal. Through an establishment of community owned enterprise producing local resource-based textiles - the traditional allo (nettle) - organizations tended to bring new economical possibilities to the region. The basic assumption was equal accessibility for everyone, regardless affiliation to social caste or gender. In the past, access to the allo business was often denied to women, whose knowledge and potential was underestimated. To avoid the issue this time around, the community owned an enterprise established for a new, high quality nettle production entirely owned by women. As a result, women got empowered, improved their skills and gained independence. The whole region benefited significantly from this shift - many new small businesses have arisen, technology has improved, and pollution decreased (Adhikari, Shrestha, Dorji, Lemke $\&$ Subedee, 2018). Textiles production is a domain in which the activity of women and other marginalized groups is socially accepted, making it a relatively safe tool of empowerment.

In the Nepali handmade industry one might observe the phenomena of negating one's own culture - imported products are expected to be better than the native ones. During the observations in one of the workshops, there a label "made in England, Fabrique in China" found, even though the whole manual work was done in Nepal. The owner, when asked, has explained, that it is because retailers value less products made in Nepal. This is a popular approach in the times of cosmopolitan trends, the global village and the need to belong to a dominant culture. An interesting point of view shows a Hindu sociologist, Bhabha, H. K., 2004, studying western culture, who feels that her early worldview was dominated by the trend of post-colonial countries, widely accepted adoration for foreign culture, art and literature and a devaluation of native treasures. When working with craftsmen, it is important to support their culture and traditions and to strengthen their sense of worth and pride. International collaboration can be beneficial for awareness of identity, as „Cultures recognize themselves through their projections of 'otherness', the dissidence from representatives of different cultures" (Bhabha, 2004). The problematic is a lack of acceptance from outside or devaluation of traditional products. The import of mass-produced goods from giant neighbors, such as China and India, negatively affects craftsmanship. This is the case for as long as they are striving to be market competitors, as opposed to being alternatives.

One of the biggest threats for the craftsmanship practice is the fact of its complete disappearance due to a lack of continuity and loss of skills and knowledge (as it almost happened for example in the UK). A low income, the devaluation of skills as well as a low social status of the profession are factors that decrease the amount of hand wavers, even though many rural regions have no alternative workplaces. Craftsmanship is not only worth protection, but also needs sustainable development in order to empower marginalized groups and regions. As a field of social innovation, it tackles issues of the poorest. It also protects those left behind during the fast industrialization, which typically has grown in most developed regions, while having negatively affected rural areas. 
Textiles production causes environmental pollution and there is a need for technological modernization in a sustainable spirit - sewers, solar energy, ecological stoves, recycling. During the visits to the dye houses, the problem of environmental pollution was observed - chemical dyes, together with water, are purred straight to the rivers near which the dye workshops are located. The second problem is the burning of waste to warm the water - wood or coal are scarce products, it is common to make a fire with available waste, including plastic. Combustion points were located in the immediate vicinity of residential houses, exposing neighbors to toxic smoke. Naturally colored fabrics are a less toxic, however slightly cheaper artificial dyes, in bright colors, imported from China and India, are more attractive to customers and their choice defines the supply. Researchers have noticed another issue - the process of fibers extraction involves harmful substances, which might be easily replaced - "Use of ash in place of caustic soda reduced negative health impacts like allergies, coughing, and gastritis and was more environmentally friendly" - which is an example of low-cost, locally available, innovative improvement (Adhikari, Shrestha, Dorji, Lemke, \& Subedee, 2018). Simply by skill training, local NGOs bring change and development to the rural industry. The process of yarn harvesting and processing is very traditional, but ineffective, and not practiced anymore by craftsmen from more developed regions who have access to modern technologies (Subedee, Chaudhary, Uprety, \& Dorji, 2018). At the same time, when considering the import of technology, there appears another problem, which should be noticed - building dependencies between the technology provider and its users. However, in an emerging economy, low-cost innovations contribute strongly to a sustainable development (GIZ, 2013). Already in the 60's, the South-African designer Selby Mvusi stressed that the low-income societies must have access to technology (Magaziner, 2018). There is a need for more responsible and ecological craftsmanship powered by the achievements of modern knowledge.

Due to transformative globalization theory, development through fair trade, empowerment and access to technology, is most beneficial and leads to independent and sustainable growth. Local organizations supporting craftsmanship emphasize the importance of connecting the private sector with rural communities. Fair trade entities, sensitive to social issues, are desirable partners of projects for socio-economic development. International collaboration can significantly support local activities and „local ownership” (Chandra, 2018). It is a way to scale the impact of existing initiatives, which have a knowhow and experience in causing social change. Leverage of existing resources is most beneficial and suggested by researchers.

For the future research, the author wishes to work on the above issues on participatory bases, with involvement of local stakeholders, in order to elaborate frameworks for international fair trade, which will be more accessible for responsible entrepreneurs on the one hand, and more inclusive for marginalized producers on the other.

Special thanks to dr Anna Szwaja, dr Andrzej Śmiatek and dr Krzysztof Bogomaz from WFP Krakow, for participation in the cognitive excursion and working with their students on a thesis related to sustainable design in Nepal.

\section{Literature}

Adhikari, L., Shrestha, A. J., Dorji, T., Lemke, E., \& Subedee, B. R. (2018). Transforming the Lives of Mountain Women Through the Himalayan Nettle Value Chain: A Case Study from Darchula, Far West Nepal. Mountain Research and Development, 38(1), 4-13. https://doi.org/10.1659/MRD-JOURNAL-D-17-00074.1 Audebrand, L. K. \& Pauchant, T. C. J. (2009). Can the Fair Trade Movement Enrich Traditional Business Ethics? A Historical Study of Its Founders in Mexico. Netherlands: Springer, 87.

Bhabha, H. (2004). The Location of Culture. London, New York: Routledge Classics. 
Bocken N., Fil A., Prabhu J. (2016). Scaling up social businesses in developing markets. Journal of Cleaner Production, 139, 295-308. https://doi.org/10.1016/j.jclepro.2016.08.045

Bocken, N. M. P., Rana, P., \& Short, S. W. (2015). Value mapping for sustainable business thinking. Journal of Industrial and Production Engineering, 32(1), 88-102. https://doi.org/10.1080/21681015.2014.1000399

Bradley, S. W., Mcmullen, J. S., Artz, K., \& Simiyu, E. M. (2012). Capital is not enough: Innovation in developing economies. Journal of Management Studies, 49(4), 684-717.

Brown, T., Wyatt, J. (2010) Design thinking for social innovation. Stanford Social Innovation Review. Development Outreach, 12(1), 29-43. doi.org/10.1596/1020-797X_12_1_29

Chandra, Y. (2017). Social entrepreneurship as emancipatory work. Journal of Business Venturing, vol. 32(6), 657-673. https://doi.org/10.1016/j.jbusvent.2017.08.004

Chandra, Y. (2018). New narratives of development work? Making sense of social entrepreneurs development narratives across time and economies. World Development, 107, 306-326. https://doi.org/10.1016/j.worlddev.2018.02.033

Chiappero-Martinetti, E., Ziegler, R., Budd, C. H., Social Innovation and the Capability Approach-Introduction to the Special Issue, Journal of Human Development and Capabilities, 18(2), 141-147.

Dawson, P., \& Daniel, L. (2010). Understanding social innovation: a provisional framework. International Journal of Technology Management, 51(1). https://doi.org/10.1504/IJTM.2010.033125

Dey, P., \& Steyaert, C. (2016). Rethinking the Space of Ethics in Social Entrepreneurship: Power, Subjectivity, and Practices of Freedom. Journal of Business Ethics, 133(4), 627-641. https://doi.org/10.1007/s10551-014-2450-y

Dor, B., B. (1967). People of Nepal. Kathmandu: Ratna Pustak Bhandar.

Elia, G., \& Margherita, A. (2018). Can we solve wicked problems? A conceptual framework and a collective intelligence system to support problem analysis and solution design for complex social issues. Technological Forecasting and Social Change, 133(October 2017), 279-286. https://doi.org/10.1016/j.techfore.2018.03.010

Fair Wear Foudation, Country Study Nepal, June 2013.

Fontaine, Ch., Haarman, A., Schmid, S., (2006). The stakeholder theory. https://pdfs.semanticscholar.org/606a /828294dafd62aeda92a77bd7e5d0a39af56f.pdf

Freeman, R.E (1984). Strategic Management: A stakeholder Approach. Journal of Management Studies, 29(2) $10.1017 /$ CBO9781139192675

GIZ [German Corporation for International Cooperation]. 2013. Value Chain Development by the Private Sector in Africa: Lessons Learnt and Guidance Notes. Germany. http://www.plugintheworld.com/mobisol/wp-content/ uploads/2014/01/Value-chain-development-by-the-private-sector-in-Africa. pdf; accessed in September 2018.

Haigh, N. and Griffiths, A. (2009), The natural environment as a primary stakeholder: The case of climate change. Business Strategy and the Environment, 18(6), 347-359.

Hamid A., Changing Pattern of Relationships - Caste Vs Occupations. The Thumb Print - A magazine from the East. http://www.thethumbprintmag.com/changing-pattern-of-relationships-between-caste-and-occupations/ Accessed on August 2018.

Hanington, B., Martin B. (2012). Universal Methods of Design: 100 Ways to Research Complex Problems. Beverly, MA: Rockport Publishers.

Hillgren, P. A., Seravalli, A., \& Emilson, A. (2011). Prototyping and infrastructuring in design for social innovation. CoDesign, 7(3-4), 169-183, https://doi.org/10.1080/15710882.2011.630474

Mair, J., \& Martí, I. (2006). Social entrepreneurship research: A source of explanation, prediction, and delight. Journal of World Business, 41(1), 36-44, https://doi.org/10.1016/j.jwb.2005.09.002

Mills, D. (2000). Introduction to Action Research: Social Research for Social Change, American Anthropologist, 102(3). doi: 10.1525/aa.2000.102.3.659

Mormina, M. (2018). Science, Technology and Innovation as Social Goods for Development: Rethinking Research Capacity Building from Sen's Capabilities Approach. Science and Engineering Ethics. https://oi. org/10.1007/s11948-018-0037-1

Magaziner, D. (2018). The Foundation: Design, Time, and Possibility in 1960s Nairobi. Comparative Studies in Society and History, 60(3), 599-628, doi:10.1017/S0010417518000208

Nepal Labour Force Survey NLFS. (2008). Central Bureau of Statistics, http:/www.ilo.org/surveydata/index. $\mathrm{php} / \mathrm{catalog} / 1357 /$ study-description

Papanek, V. (2012). Dizanj dla realnego świata. Łódź: Recto Verso.

Perrini, F., Vurro, C., \& Costanzo, L. A. (2010). A process-based view of social entrepreneurship: From opportunity identification to scaling-up social change in the case of San Patrignano. Entrepreneurship and Regional Development, 22(6), 515-534. https://doi.org/10.1080/08985626.2010.488402

Reijonen, E. K. (2012). Enhancing the capabilities of small producers in developing countries to meet global challenges: an investigation into the contribution of international craft development initiatives. Open Access Institutional Repository by Robert Gordon University, https://openair.rgu.ac.uk/handle/10059/573 
Santos, F. M. (2012). A Positive Theory of Social Entrepreneurship. Journal of Business Ethics, 111(3), 335-351. https://doi.org/10.1007/s10551-012-1413-4

Sapir, E. (1924). Culture, Genuine and Spurious. American Journal of Sociology, 29(4), 401-429.

Sapkota, Ch. (2010). Demise of Garment Sector, Republica.

Selloni, D., Corubolo, M. (2017). Design for Social Enterprises: How Design Thinking Can Support Social Innovation within Social Enterprises. Design Journal, 20(6): 775-794. https://doi.org/10.1080/14606925.2 017.1372931

Sen, A. (2003). Development as capability expansion, Readings in Human Development, New Delhi and New York, Oxford University Press, 41-58.

Social Welfare Council (SWC). (2014).

Starnawska, M. (2016). Identyfikowanie zasobów i lokalnych potrzeb w preprzedsiębiorczej fazie inicjatyw spotecznych. Animacja społeczna - praca nad zmianq. Gdańsk-Gdynia-Sopot: MMediterranean Politics, 26-37.

Stephan, U., Patterson, M., Kelly, C., \& Mair, J. (2016). Organizations Driving Positive Social Change: A Review and an Integrative Framework of Change Processes. Journal of Management, 42(5), 1250-1281. https:// doi.org/10.1177/0149206316633268

Stott, N., \& Tracey, P. (2018). Organizing and innovating in poor places. Innovation: Management, Policy and Practice, 20(1), 1-17.

Subedee, B. R., Chaudhary, R. P., Uprety, Y., \& Dorji, T. (2018). Socio-ecological perspectives of Himalayan Giant Nettle (Girardinia diversifolia (Link) Friis) in Nepal. Journal of Natural Fibers, 00(00), 1-9. https:// doi.org/10.1080/15440478.2018.1458684

Trzcieniecki J. (1979), Projektowanie systemów zarzadzania, Warszawa:PWN.

WITS -https://wits.worldbank.org/CountryProfile/en/Country/NPL/Year/2015/Summary

Young, W., \& Tilley, F. (2006). Can businesses move beyond efficiency? The shift toward effectiveness and equity in the corporate sustainability debate. Business Strategy and the Environment, 15(6), 402-415. https:// doi.org/10.1002/bse. 510

Ziegler, R., Schulz, S., Richter, L., \& Schreck, M. (2014). Following Gandhi: Social entrepreneurship as a non-violent way of communicating sustainability challenges. Sustainability (Switzerland), 6(2), 1018-1036. 


\title{
Refugees or Immigrants - How Does it Matter for Entrepreneurship? Systematic Review of Refugee Entrepreneurship Literature Inspired by the Immigrant Entrepreneurship Research
}

\author{
Nina Lazarczyk-Bilal ${ }^{*}$
}

\begin{abstract}
Summary
This literature review answers the research question of how being a refugee or an immigrant affects entrepreneurial experience. It aims to examine the differences between refugees and immigrants in the light of immigrant entrepreneurship literature and emerging refugee entrepreneurship research. The analysis of the selected 41 peer reviewed papers within the framework of the eight dominant theories in immigrant entrepreneurship literature, including the field pertaining to refugees, implies that being a refugee has a rather negative impact on the entrepreneurial experience as compared to being an immigrant. Nonetheless, the literature on refugee entrepreneurship or their general labor market integration is rather scarce in number of applied theories and conducted studies in comparison to the immigrant entrepreneurship area and leaves vast room for future research.
\end{abstract}

Keywords: Immigrant entrepreneurship, Refugee entrepreneurship, Refugee labor market integration, Small business

JEL: L26, F22, O15, J15

\section{INTRODUCTION}

The number of forcibly displaced people around the world has reached 68,5 mln people (UNHCR 2018), which is more than the whole population of France. Out of $68,5 \mathrm{mln}$, about $40 \mathrm{mln}$ people are internally displaced migrants - those who have had to leave their home due to various reasons, but have stayed within the borders of their country. About 25,4 million people worldwide are refugees (UNHCR 2018) - people who have fled their country because of war or persecution. In 2015, about 1255600 refugees from Asia and northern Africa managed to cross the borders of the European Union. Since it is only the beginning of huge migrations, the EU member states have to look for adequate solutions in order to help accommodate as many newcomers as possible. Needless to say, refugees, often traumatized, have to settle down in a completely new socio-cultural and economic context. They need to find an apartment, learn the local language, adapt to the new culture and most importantly support themselves financially. Only after the massive influx of Asians and Africans to the EU, the need to integrate so many refugees into local labor markets has drawn much more scholarly attention to the refugee entrepreneurship research. This research is still rather new territory for academics who can be immensely inspired by the vast body of literature on immigrant entrepreneurship.

I hereby address the research question: How does being a refugee or an immigrant affect one's entrepreneurial experience? In other words, I would like to examine the difference between those who were forced to flee their home country due to war or the fear of persecution and those who voluntary moved to another country in the light of entrepreneurship. This paper aims to present a systematic literature review on refugee entrepreneurship in the context of immigrant entrepreneurship. It is divided into five sections. In the following section I present the search process conducted in Scopus, one of the biggest abstract and citation databases of peer-reviewed literature and its results related

\footnotetext{
Faculty of Management, University of Warsaw, Poland, https://orcid.org/0000-0003-4020-027X, e-mail: lazarczyk.nina@, gmail.com
} 
to refugee and immigrant entrepreneurship literature. In the third part, I present the general concept of immigrant entrepreneurship and explain the terms "refugee" and "immigrant". In chapter four, I discuss similarities and differences between refugees and immigrants in light of entrepreneurship and the general labor market integration literature. I analyze those similarities and differences using the dominant theoretical frameworks within the immigrant entrepreneurship research. Finally, I present conclusions and limitations, which may serve as a source of inspiration for future research in the refugee entrepreneurship field.

\section{LITERATURE SEARCH METHODOLOGY}

In order to find the peer-reviewed articles on refugee entrepreneurship, I used the Scopus electronic database where I restricted the search to three subject areas (social sciences; business, management and accounting; economics, econometrics), articles and articles in press, peer-reviewed journals and English language. First, I defined the following search stream (refugee* OR asylum-seeker* W/6 entrepr* OR "small business" OR "self*employ*" OR "economic adaptation" OR "labo*r integration" OR "labo*r market" OR "career adaptability"), which returned 145 papers. I sorted the obtained results according to the number of highest citations. After an initial review I have selected 50 articles, and after further scrutiny I have decided to discuss in detail 19 papers which I find relevant for the topic. Most importantly, only 6 papers related directly to the topic of refugee entrepreneurship, whereas others concerned refugee labor market integration.

Having realized that the literature devoted solely to refugees or asylum-seekers is scarce, I have decided to try another set of key words focusing on immigrant entrepreneurship (*migrant* OR ethnic* W/6 entrepr* OR "small business" OR "self*employ*" OR "economic adaptation" OR "labo*r integration"). The search stream restricted to the same criteria as the previous one returned 1,670 articles. Once again I sorted them according to the highest number of citations. After an initial revision I chose 117 papers, and eventually decided to concentrate on 22 articles in this review.

In total, I have analyzed in detail 41 papers, which date from 1986 to 2018. Studies conducted in the selected papers examine the phenomenon of immigrant/refugee entrepreneurship or broader labor market integration in the US (18), the Netherlands (6), the UK (4), Norway (3), Canada (2), Belgium (2), Sweden (1), Denmark (1), EU (1), Australia (1), Turkey (1), Ghana (1) and Lebanon (1). Most of the selected papers focus on North America, Europe and Australia; whereas only 2 papers concern Africa and Asia and both of them analyze the phenomenon of refugee entrepreneurship. Within refugee related papers, 9 studies adopted a quantitative method, 8 studies used qualitative method, 1 study applied mixed method approach and 1 paper was a policy review.

In the following section I first explain the concept of immigrant entrepreneurship; secondly, I discuss the terms "refugee" and "immigrant" and signal basic differences between refugees and immigrants, which are likely to impact their entrepreneurship experience or general labor market integration.

\section{REFUGEE OR IMMIGRANT ENTREPRENEURSHIP?}

Among scholars there is no consensus on what entrepreneurship is, but most often the body of literature of our interest defines it as self-employment, start of one's own business or further development of an already existing company (Fong, Busch, Armour, Heffron, \& Chanmugam, 2008). Setting up and running one's own company in a new country is not an easy task, especially for immigrants or refugees who need to get familiar with the new system. Research implies that, since migration per se is an act of courage that already proves an entrepreneurial attitude, immigrants or refugees should be more likely to start their own venture (Bizri, 2017). Indeed, the substantial 
part of research indicates that immigrants become entrepreneurs proportionately more often than natives in the host countries (Bizri, 2017; Dheer, 2018). This is why many academics consider the phenomenon of immigrant entrepreneurship to be a separate research area (R. C. Kloosterman, 2003; Ley, 2006; Portes, Haller, \& Guarnizo, 2002a; Sahin, Nijkamp, \& Stough, 2011; Waldinger, 1989). However, the refugee entrepreneurship literature has not yet become a distinct research field, but has rather stayed a part of the broader literature on immigrants. This is quite surprising if one takes into account the history of refugee regime and the special legal status of refugees regulated in the 1951 Convention Relating to the Status of Refugees, the so called Refugee Convention. The convention defines a refugee as a person who has a "well-founded fear of persecution for reasons of race, religion, nationality, membership of a particular social group or political opinion, is outside the country of his nationality and is unable or, owing to such fear, is unwilling to avail himself of the protection of that country; or who, not having a nationality and being outside the country of his former habitual residence as a result of such events, is unable or, owing to such fear, is unwilling to return to it" (1951 Convention Relating to the Status of Refugees).

While the concept of the term "refugee" has been legally defined, the term "immigrant" does not have a single straightforward meaning and requires further definition depending on the context. On the one hand, it constitutes a very broad category of all the people who move from one country to another with an intention to settle down there. On the other hand, it often implies that migrants leave their country on a voluntary basis in order to improve their living standards, whereas refugees are forced to flee because of the fear of persecution (Gold, 1988, 1992). Consequently, immigrants have the opportunity to plan their life in a new country, for example bringing with them some start-up capital to set up a small business in the host country, whereas refugees do not have the ability to prepare for refuge, and thus do not possess any extra funds to start a business (Gold, 1988). Nevertheless, the recent influx of asylum-seekers to the EU has shown that refugees also plan their journey to Europe and save substantial sums of money to pay smugglers for their transit to the EU through the Mediterranean. Research shows that longdistance mobility requires sufficient resources, which can be organized by relatively well off people who have a certain social and financial situation (Omata, 2017). This is also one of the reasons why scholars acknowledge that making a clear distinction between voluntary and forced migration becomes problematic nowadays (Omata, 2017; Waite, 2017). Although drawing a stark line between voluntary and forced migration seems to be ambivalent, it is still possible to identify several general differences between refugees and immigrants (Gold, 1992; Wauters \& Lambrecht, 2006b). In the following chapter I will discuss the similarities and differences between refugees and immigrants in the context of the dominant theories within immigrant and refugee entrepreneurship literature.

\section{REFUGEES OR IMMIGRANTS: HOW DOES IT MATTER FOR ENTREPRENEURSHIP?}

Immigrant entrepreneurship has become a well developed research area contrary to refugee entrepreneurship, which is extremely poor in terms of theoretical frameworks and conducted studies (Alrawadieh et al., 2019; Bizri, 2017; Ruiz \& Vargas-Silva, 2017; Wauters \& Lambrecht, 2008). The immigrant entrepreneurship literature offers many theories as to why immigrants set up their own businesses in the host country. Some of these theoretical frameworks have been used either directly or indirectly in the literature on refugee labor market integration or refugee entrepreneurship. Below, I will compare refugees and immigrants discussing the dominant perspectives used in the immigrant entrepreneurship and refugee entrepreneurship research: human capital theory, social capital theory, culture theory, disadvantage theory, social network theory, transnationalism, interactive model of ethnic entrepreneurship and mixed embeddedness. 


\section{Human capital and Social capital theory}

The most basic explanations of immigrant entrepreneurship relate to human capital or social capital theory. The human capital theory helps to understand entrepreneurial experience by investigating individual characteristics, educational background, skills etc. immigrants have gained on their own, either back home or in a host country (Vinogradov \& Kolvereid, 2007). In other words, such factors as age, gender, household composition, number of years of formal education, previous job experience, or language proficiency determine labor market integration (Bach \& Carroll-Seguin, 1986; Potocky-Tripodi, 2004). For instance, findings from Belgium indicate that male refugees who have entrepreneurial role models in the family and have been previously self-employed are much more likely to become entrepreneurs (Wauters \& Lambrecht, 2006b). The social capital theory goes beyond personal characteristics focusing on the non-material goods in the immigrant community such as for example trust or helpfulness, which play an important role in undertaking entrepreneurial activities (Timothy Bates, 1997; Tomothy Bates, 1994; Deakins, Ishaq, Smallbone, Whittam, \& Wyper, 2007; Sahin et al., 2011). Similarly, a study based on ecology theory indicates that individual features, family relations and counseling play an important role in refugee entrepreneurship (Fong et al., 2008).

\section{Culture theory}

Since immigrants constitute a big and diverse group of people, many researchers argue that cultural differences between them explain why some migrants are more likely to start business activity than others. There is a substantial body of research on immigrant entrepreneurship inspired by Hofstede's five cultural dimensions (power distance, individualism versus collectivism, masculinity versus femininity, uncertainty avoidance, and long or short-term orientation) which explains the entrepreneurial attitude between different groups of migrants (Chand \& Ghorbani, 2011; Frederking, 2004; Li, 2001a; Vinogradov \& Kolvereid, 2007). For example, cultural approach argues that some cultures like for example Jews, Chinese or Japanese are more prone to start a business venture, however, in case of refugees it helps to understand only the choices of refugees who deliberately start their own company despite having promising job offers in the market (Gold, 1988). In short, the cultural perspective does not explain well the entrepreneurial activities of refugees who decide to set up their own business as a last resort to make money for a living (Gold, 1988).

\section{Disadvantage theory}

Disadvantage theory argues that since immigrants have lower job prospects due to being at a disadvantaged position in the labor market in comparison to the host society, and for this reason decide to open a small business (Gold, 1988). Their inferior position in the job market usually stems from language barriers, lack of locally recognized skills, lack of adequate qualifications, complex bureaucracy, or discrimination. The disadvantage perspective is very helpful in understanding decisions of both immigrants and refugees who set up business activity. In the following sections I will discuss further similarities and differences between immigrant and refugee entrepreneurs using the disadvantage framework. First, in light of the entrepreneurship perspective, I will examine similarities between immigrants and refugees who face language problems, do not possess necessary diplomas, are usually overwhelmed by bureaucracy in the host country, and fall victim to discrimination. Secondly, I will analyze the differences between immigrants and refugees focusing on legal and economic status, mobility aspects and the likelihood of psychological trauma. 


\section{Similarities between refugee and immigrant entrepreneurs in the light of disadvantage theory}

Disadvantage theory argues that immigrants who are usually worse off at the start in comparison to the host society members decide to open their own company as a last resort to make money in order to make a living. Nonetheless, it is not an easy process since they face such obstacles as language barriers and lack of locally recognized qualifications (Li, 2001a; Raijman \& Tienda, 2000). Similarly, language barriers, lack of recognized skills and high uncertainty about the future are faced by refugees who enter the entrepreneurial pathway (Alrawadieh, Karayilan, \& Cetin, 2019; Colic-Peisker \& Tilbury, 2006; Wauters \& Lambrecht, 2006b). Additionally, lack of funds, overwhelming bureaucracy, and lack of belief in one's own entrepreneurial potential are much more often mentioned by refugees than immigrants as obstacles to start business activity (Connor, 2019; Wauters \& Lambrecht, 2006b). Broadly speaking, these factors hinder refugees' access not only to entrepreneurship, but to the labor market in general (Bucken-Knapp, Fakih, \& Spehar, 2019). Last but not least, both refugees and immigrants suffer from discrimination in the job market, which results in either difficulties in finding a job or lower income (Alrawadieh et al., 2018a; Bucken-Knapp et al., 2019; Li, 2001b; Minor \& Cameo, 2018; Raijman \& Tienda, 2000). For example, a study conducted in the US shows that the latter concerns particularly refugees from subSaharan Africa, Latin America, and the Caribbean as well as female migrants or refugees (Minor \& Cameo, 2018).

\section{Differences between refugee and immigrant entrepreneurs in the light of disadvantage theory}

The legal status, which entails other consequences for refugee rights in the host country, is the most important differentiating factor between the refugees and immigrants. In the host countries, which are signatories to the 1951 Geneva Convention, refugees who either apply for asylum or have been already granted asylum have a different legal status from immigrants who are dependent on visa regimen, and thus the future of their stay is usually less secure. Refugees become asylum-seekers from the moment they apply for asylum in a host country signatory to the Geneva Convention, which entails legal consequences regulating many aspects of their stay in a country of arrival such as work permit, job training opportunities, economic status as well as freedom of mobility.

One of the significant issues for newly arrived refugees is the possibility to get employed as fast as possible and make money for living expenses. According to Article 17 of the Refugee Convention, the basic human right to work should be granted to those who are legally recognized as refugees. Depending on the host country newcomers usually have to wait for work permit for several months or longer, which negatively affects their future career, and makes their everyday life much less predictable. Research shows that refugees have a worse start in their job career in comparison to immigrants due to the long asylum procedure, and thus longer unemployment period (Bakker, Dagevos, \& Engbersen, 2017). The disadvantaged situation of refugees in relation to both immigrants and natives has its own name in the literature, namely the 'refugee entry effect' or the 'refugee gap'(Bakker et al., 2017; Dustmann, Fasani, Frattini, Minale, \& Schonberg, 2017). Research carried out in the Netherlands and the EU indicates that only after 15 to 20 years the 'refugee gap' ceases to exist or gets much smaller in relation to immigrants (Bakker et al., 2017; Dustmann et al., 2017). Other research findings from the United Kingdom show that 8 and 15 months from the successful end of asylum procedure refugees are still at a disadvantaged position in the job market in comparison to immigrants, while after 21 months the employment situation of refugees improves and does not differ significantly from the one of recent immigrants (Ruiz \& Vargas-Silva, 2017). In addition, depending on the internal regulations of the host country, refugees should be entitled to additional financial support, language classes or job trainings, which are not necessarily available for free for immigrants (Gold, 1992). Nonetheless, the state support may be counterproductive in 
making refugees more dependent on external help and less willing to take full responsibility for their life (Gold, 1988).

Another difference between immigrants and refugees, which goes in line with the disadvantage theory, is that refugees have more restricted freedom of mobility than immigrants. To some extent refugees may have influence over the country of destination (Ruiz \& Vargas-Silva, 2017); however, once they settle down in the host country and apply for asylum, their mobility may be officially limited to the borders of an administrative unit. On one hand, providing asylum-seekers with accommodation, healthcare, social security and education is a substantial burden for municipalities' budgets. Hence, the limited mobility of asylum-seekers seems to be a reasonable solution for municipalities, which invest resources in the integration of recent refugees (Godøy, 2017). On the other hand, research shows that limited mobility of refugees who live in economically poorer labor areas may have a negative impact on their remuneration even years later (Godøy, 2017). Future research should examine to what extent these findings are generalizable on the wider refugee and immigrant population (Godøy, 2017).

Last but not least, research indicates that fleeing the war zone or running away from the persecution refugees are more likely to suffer from psychological trauma than immigrants (FullerLove, Lim, \& Akehurst, 2006; Gold, 1988). On the top of that, tensions back home tend to continue in the country of asylum (Wauters \& Lambrecht, 2008).

\section{Social network theory and Transnationalism}

Social network theory focuses on the role of social relationships in setting up business activity within immigrant or refugee communities. There is no consensus in the literature on the role of social networks in the case of refugees. Some studies indicate that since refugees arrive from different destinations and do not have the ability to take part in long-term chain migration, they are less likely than immigrants to create effective social networks (Colic-Peisker \& Tilbury, 2006; Gold, 1988, 1992; Wauters \& Lambrecht, 2006a). Additionally, refugees mostly cannot go back to their country of origin and take advantage of transnational links to start a business, whereas for immigrants it is very common to import goods or mobilize money for business development in their home country (Gold, 1988; Portes, Haller, \& Guarnizo, 2002b). Other findings point out that refugees form social networks in the host country or establish transnational relationships with their home country in order to undertake entrepreneurial activities (Bizri, 2017; Omata, 2017). However, these are studies conducted in non-Western countries - Ghana and Lebanon - where there is a whole different context necessary to take into account to make further generalizations.

\section{Interactive model of ethnic entrepreneurship and Mixed embeddedness}

Waldinger with co-authors offer the interactive model of ethnic entrepreneurship, which takes into consideration the existing opportunity structure and group characteristics, in other words market opportunities and access to entrepreneurship as well as human capital and social network (Fernandez \& Kim, 1998; Kim, Hurh, \& Fernandez, 1989; R. C. Kloosterman, 2010; Waldinger, 1995). Kloosterman goes even further claiming that the development of enterprise does not take place in a socio-economic vacuum, but is determined by the political and economic context (Jones \& Ram, 2007; R. C. Kloosterman, 2010; R. Kloosterman, Van Der Leun, \& Rath, 1999; Robert Kloosterman, 2006; Robert Kloosterman \& Rath, 2010). Kloosterman introduces the concept of mixed embeddedness, which encompasses micro-level of the individual entrepreneur, meso-level of the local opportunity and macro-institutional level (R. C. Kloosterman, 2010).

The theoretical frameworks developed by Waldinger and Kloosterman within the immigrant entrepreneurship literature have been used in one of the most important studies on refugee 
entrepreneurship in order to examine why so few refugees become self-employed in Belgium (Wauters \& Lambrecht, 2008). The interactive model of ethnic business development and mixed embeddedness helped to group the obstacles refugees face when entering the entrepreneurial pathway into three variables: market opportunities and access to entrepreneurship, human capital and social networks, and institutional and societal environment (Wauters \& Lambrecht, 2008). The results show that not many refugees decide to start a small business because of lack of recognized qualifications, lack of necessary competences or insufficient funds for the start, and institutional barriers. The authors argue that these barriers are more troublesome for refugees than immigrants. Interestingly, a previous study conducted by the same researchers showed that some refugee entrepreneurs do not set up business activity to take advantage of the existing market opportunity, but to get integrated into the host society (Wauters \& Lambrecht, 2006b).

\section{CONCLUSION}

The research question I addressed in this literature review is: How does being a refugee or an immigrant affect entrepreneurial experience? The aim of the paper was to examine differences between those who were forced to flee their home country due to the fear of persecution and those who voluntary moved to another country in the light of immigrant entrepreneurship literature and emerging refugee entrepreneurship research. The search results showed that the literature on refugee entrepreneurship or their general labor market integration (145 papers) is scarce in number of applied theories and conducted studies in comparison to the immigrant entrepreneurship area (1,670 papers). In total, I have analyzed 41 peer-reviewed papers retrieved from the Scopus database. 22 papers focus on immigrant entrepreneurship, whereas 19 relate to refugees. Only 6 papers concern explicitly the topic of the refugee entrepreneurship, 2 of which refer to refugees in Ghana and Lebanon. Otherwise, the majority of papers examine the entrepreneurship or labor market integration of immigrants and refugees in the Western hemisphere. 9 studies adopted a quantitative method, 8 studies used qualitative method, 1 study applied mixed method approach and 1 paper was a policy review.

The analysis of the selected papers within the framework of the eight dominant theories - human capital, social capital, culture, disadvantage, social network, transnationalism, interactive model of ethnic entrepreneurship and mixed embeddedness - in immigrant entrepreneurship literature emerging also in the refugee related field implies that being a refugee has a rather negative impact on the entrepreneurial experience in comparison to being an immigrant. As a matter of fact, both refugees and immigrants face similar obstacles in access to the host labor market such as the lack of recognized diplomas and lack of adequate skills, which push them into an entrepreneurial pathway. Nevertheless, insufficient funds for the start of the business and institutional barriers discourage them from starting their own business. The findings of the reviewed studies argue that refugees are more likely to suffer from these barriers than immigrants.

The fundamental difference distinguishing refugees from immigrants lies in the legal status of refugees, which guarantees them a more secure stay in the host country in comparison to immigrants who are dependent on the less predictable visa regime. The legal status of an asylum-seeker or a refugee also entails other rights such as access to additional financial assistance from the state, language classes, or job trainings, which are not necessarily available for immigrants. Nonetheless, such an additional support from the state may have a dependency effect on refugees who rely more on the state support than on their own initiative. Research findings point out the phenomenon of 'refugee entry effect' or a 'refugee gap', which means that refugees suffer from a longer unemployment period due to asylum procedure. In addition, after applying for asylum, refugees may have a restricted freedom of mobility being restrained only to the borders of a certain administrative 
unit within a host country. Such a limited mobility can have a long-term effect on lower wages of refugees in their future career. There is no consensus on the role of social networks in the case of refugees, however, studies conducted on the refugees seeking asylum in the Western hemisphere imply that they are less likely to create and benefit from social networks because of two reasons. Usually they do not have the experience of long-term chain migration characteristic for immigrants and they cannot go back to their home country due to an ongoing war or fear of persecution. Last but not least, refugees who fled their home country because of war or fear of persecution are more likely than immigrants to suffer from psychological trauma, and what is more, tensions back home tend to continue in the country of asylum.

To summarize, the literature review implies that being a refugee has a rather negative impact on the entrepreneurial experience in comparison to being an immigrant. While it is possible to make general distinctions between refugees and immigrants, one needs to bear in mind that neither refugees nor immigrants constitute a homogenous group. There is great diversity among refugees depending on many factors such as, for example, their socio-economic background, country of origin, circumstances under which they left their home country etc. In light of the labor market integration or entrepreneurship discussion it is also of paramount importance where refugees apply for asylum. Even just within the EU there are so many differences between internal refugee policies that the situation of newcomers may vary from country to country (Dustmann et al., 2017). Therefore, future research should focus further on examining refugee labor market integration and their entrepreneurship in more countries bearing in mind the contextual aspects of the host countries. For this purpose, the development of the mixed embeddedness theory taking into account the micro, meso and macro level of entrepreneurship related factors seems to be a good point of departure.

\section{Literature}

Alrawadieh, Z., Karayilan, E., \& Cetin, G. (2019). Understanding the challenges of refugee entrepreneurship in tourism and hospitality. The Service Industries Journal, 39(9-10), 717-740. http://doi.org/10.1080/0264 2069.2018.1440550

Bach, R. L., \& Carroll-Seguin, R. (1986). Labor force participation, household composition and sponsorship among Southeast Asian Refugees. International Migration Review, 20(2), 381-404.

Bakker, L., Dagevos, J., \& Engbersen, G. (2017). Explaining the refugee gap: a longitudinal study on labour market participation of refugees in the Netherlands. Journal of Ethnic and Migration Studies, 43(11), 1775-1791. http://doi.org/10.1080/1369183X.2016.1251835

Bates, T. (1994). Social Resources Generated by Group Support Networks May Not Be Beneficial to Asian Immigratrant-Owned Small Businesses. Social Forces, 72(3), 671-689.

Bates, T. (1997). Financing small business creation: The case of Chinese and Korean immigrant entrepreneurs. Journal of Business Venturing, 12(2), 109-124. http://doi.org/10.1016/S0883-9026(96)00054-7

Bizri, R. M. (2017). Refugee-entrepreneurship: a social capital perspective. Entrepreneurship \& Regional Development, 5626, 1-22. http://doi.org/10.1080/08985626.2017.1364787

Bucken-Knapp, G., Fakih, Z., \& Spehar, A. (2019). Talking about Integration: The Voices of Syrian Refugees Taking Part in Introduction Programmes for Integration into Swedish Society. International Migration, 57(2), 221-234. http://doi.org/10.1111/imig.12440

Chand, M., \& Ghorbani, M. (2011). National culture, networks and ethnic entrepreneurship: A comparison of the Indian and Chinese immigrants in the US. International Business Review, 20(6), 593-606. http://doi. org/10.1016/j.ibusrev.2011.02.009

Colic-Peisker, V., \& Tilbury, F. (2006). Employment Niches for Recent Refugees: Segmented labour Market in Twenty-first Century Australia. Journal of Refugee Studies, 19(2), 203-229. http://doi.org/10.1093/jrs /fej016

Connor, P. (2018). Explaining the Refugee Gap: Economic Outcomes of Refugees versus Other Immigrants, Journal of Refugee Studies, 23(3), 377-397. http://doi.org/10.1093/jrs/feq025

Convention Relating to the Status of Refugees, https://www.unhcr.org/1951-refugee-convention.html. 
Deakins, D., Ishaq, M., Smallbone, D., Whittam, G., \& Wyper, J. (2007). Ethnic minority businesses in Scotland and the role of social capital. International Small Business Journal, 25(3), 307-326. http://doi. org/10.1177/0266242607076530

Dheer, R. (2018). Entrepreneurship by immigrants: a review of existing literature and directions for future research. International Entrepreneurship and Management Journal, 14, 555-614. http://doi.org/10.1007/ s11365-018-0506-7

Dustmann, C., Fasani, F., Frattini, T., Minale, L., \& Schonberg, U. (2017). On the economic and politics of refugee migration. Economic Policy, (July 2017), 497-550.

Fernandez, M., \& Kim, K. C. (1998). Self-employment rates of Asian immigrant groups: an analysis of intragroup and intergroup differences. The International Migration Review, 32(3), 654-681. http://doi. org/10.2307/2547767

Fong, R., Busch, N. B., Armour, M., Heffron, L. C., \& Chanmugam, A. (2008). Pathways to Self-Sufficiency: Successful Entrepreneurship for Refugees. Journal of Ethnic \& Cultural Diversity in Social Work, 16(1-2), 127-159. http://doi.org/10.1300/J051v16n01

Frederking, L. C. (2004). A cross-national study of culture, organization and entrepreneurship in three neighbourhoods. Entrepreneurship and Regional Development, 16(3), 197-215. http://doi.org/10.1080/0898562042000197126

Fuller-Love, N., Lim, L., \& Akehurst, G. (2006). Guest editorial: Female and ethnic minority entrepreneurship, 2, 429-439. http://doi.org/10.1007/s11365-006-0007-y

Godøy, A. (2017). Local labor markets and earnings of refugee immigrants. Empirical Economics, 52(1), 31-58. http://doi.org/10.1007/s00181-016-1067-7

Gold, S. J. (1988). Refugees and small business: The case of Soviet Jews and Vietnamese. Ethnic and Racial Studies, 11(4), 411-438. http://doi.org/10.1080/01419870.1988.9993613

Gold, S. J. (1992). The employment potential for refugee entrepreneurship: Soviet Jews and Vietnamese in California. Policy Studies Review, 11(2), 176-186.

Jones, T., \& Ram, M. (2007). Re-embedding the ethnic business agenda. Work, Employment and Society, 21(3), 439-457. http://doi.org/10.1177/0950017007080007

Kim, K. C., Hurh, W. M., \& Fernandez, M. (1989). Intra-group differences in business participation: three Asian immigrant groups. The International Migration Review, 23(1), 73-95. http://doi.org/10.2307/2546183

Kloosterman, R. (2006). Mixed Embeddedness as a Conceptual Framework for Exploring Immigrant Entrepreneurship, EUREX Lecture Nr. 8.

Kloosterman, R. C. (2003). Creating opportunities. Policies aimed at increasing openings for immigrant entrepreneurs in the Netherlands. Entrepreneurship and Regional Development, 15(2), 167-181. http://doi. org/10.1080/0898562032000075159

Kloosterman, R. C. (2010). Matching opportunities with resources: A framework for analysing (migrant) entrepreneurship from a mixed embeddedness perspective. Entrepreneurship and Regional Development, 22(1), 25-45. http://doi.org/10.1080/08985620903220488

Kloosterman, R., \& Rath, J. (2010). Journal of Ethnic and Immigrant entrepreneurs in advanced economies: Mixed embeddedness further explored Immigrant entrepreneurs in advanced economies : mixed embeddedness further explored. Journal of Ethnic and Migration Studies, 9451(April 2012), 37-41. http://doi. org/10.1080/1369183002004156

Kloosterman, R., Van Der Leun, J., \& Rath, J. (1999). Mixed Embeddedness: (In)formal Economic Activities and Immigrant Businesses in the Netherlands. International Journal of Urban and Regional Research, 23(2), 252-266. http://doi.org/10.1111/1468-2427.00194

Ley, D. (2006). Explaining variations in business performance among immigrant entrepreneurs in Canada. Journal of Ethnic and Migration Studies, 32(5), 743-764. http://doi.org/10.1080/13691830600704123

Li, P. S. (2001b). Immigrants' Propensity to Self-Employment: Evidence from Canada. Social Sciences, 35(4). http://doi.org/10.1111/j.1747-7379.2001.tb00054.x

Minor, O. M., \& Cameo, M. (2018). A Comparison of Wages by Gender and Region of Origin for Newly Arrived Refugees in the USA. Journal of International Migration and Integration, 19(3), 813-828. http:// doi.org/10.1007/s12134-018-0581-1

Omata, N. (2017). Who takes advantage of mobility? Exploring the nexus between refugees' movement, livelihoods and socioeconomic status in West Africa. African Geographical Review, 6812, 1-11. http://doi.org $/ 10.1080 / 19376812.2017 .1350987$

Portes, A., Haller, W. J., \& Guarnizo, L. E. (2002a). Transnational Entrepreneurs: An Alternative Form of Immigrant Economic Adaptation Author (s): Alejandro Portes, Luis Eduardo Guarnizo and William J. Haller Published by: American Sociological Association Stable URL: http:/www.jstor.org/stable/3088. American Sociological Review, 67(2), 278-298. 
Portes, A., Haller, W. J., \& Guarnizo, L. E. (2002b). Transnational Entrepreneurs : An Alternative Form of Immigrant Economic Adaptation Author (s): Alejandro Portes, Luis Eduardo Guarnizo and William J. Haller Published by: American Sociological Association Stable URL: http://www.jstor.org/stable/3088. American Sociological Review, 67(2), 278-298.

Potocky-Tripodi, M. (2004). The Role of Social Capital in Immigrant and Refugee Adaptation. Journal of Social Service Research, 31(1), 59-91. http://doi.org/10.1300/J079v31n01

Raijman, R., \& Tienda, M. (2000). Immigrants' Pathways to Business Ownership: A Comparative Ethnic Perspective. International Migration Review, 34(3), 682. http://doi.org/10.2307/2675941

Ruiz, I., \& Vargas-Silva, C. (2017). Are Refugees' Labour Market Outcomes Different from Those of Other Migrants? Evidence from the United Kingdom in the 2005-2007 Period. Population, Space and Place, 23(6). http://doi.org/10.1002/psp.2049

Sahin, M., Nijkamp, P., \& Stough, R. (2011). Impact of urban conditions on firm performance of migrant entrepreneurs: A comparative Dutch-US study. Annals of Regional Science, 46(3), 661-689. http://doi. org/10.1007/s00168-009-0351-2

United Nations Refugee Agency, https://www.unhcr.org/.

Vinogradov, E., \& Kolvereid, L. (2007). Cultural background, human capital and self-employment rates among immigrants in Norway. Entrepreneurship and Regional Development, 19(4), 359-376. http://doi. org/10.1080/08985620701223213

Waite, L. (2017). Asylum seekers and the labour market: Spaces of discomfort and hostility. Social Policy and Society, 16(4), 669-679. http://doi.org/10.1017/S1474746417000173

Waldinger, R. (1989). Structural Opportunity or Ethnic Advantage? Immigrant Business Development in New York. International Migration Review, 23(1), 48. http://doi.org/10.2307/2546182

Waldinger, R. (1995). The 'other side' of embeddedness: a case-study of the interplay of economy and ethnicity. Ethnic and Racial Studies. 18(3), 555-580. http://doi.org/10.1080/01419870.1995.9993879

Wauters, B., \& Lambrecht, J. (2006a). Refugee entrepreneurship in Belgium: Potential and practice, 509-525. http://doi.org/10.1007/s11365-006-0008-x

Wauters, B., \& Lambrecht, P. J. (2008). Barriers to Refugee Entrepreneurship in Belgium: Towards an Explanatory Model. Journal of Ethnic and Migration Studies, 34(6), 895-915. http://doi.org/10.1080/13691830802211190 


\title{
Developing Employee Adaptive Behaviors by Organizational Employability Culture in the Flexible Human Resource Management. Scholars' Perspective
}

\author{
Leila Shoraka*
}

\begin{abstract}
Summary
This study aims to present the role of employability culture in shaping employees' employability as an adaptive reaction to the effects of flexible human resource management in modern organizations. In addition, we check whether these phenomena are described in scientific studies, regardless of the conditions in which the business environment operates in a given country. Therefore, this article presents a review of the literature on this subject, in Iran. This study is a systematic literature review (SLR) that investigated this subject from 1997 to 2018 published in databases such as Scopus, Web of Science, Science Direct, and Iranian databases such as SID, MAGIRAN, CIVILICA, and NOORMAG. The result showed the important role of employability culture in shaping employees' employability as an adaptive reaction to the effects of flexible human resource management. In addition, it has been shown that there are very few items describing this issue in Iranian publications. This is due to the relatively low competitive conditions of the business environment in which the companies of this country operate. It can be assumed that depending on the advancement of the economy, scholars, to varying degrees, concentrate on the phenomena that are the subject of analysis of their publications. They most clearly respond to current problems and even with a certain delay in relation to their issues.

This approach of the employer is very beneficial from the point of view of the effective use of employee competencies in the labor market and avoiding the unfavorable phenomenon of unemployment.
\end{abstract}

Keywords: Employability, Employability culture, Flexible human resource management

JEL: M12, M53

\section{INTRODUCTION}

In modern organizations, issues of people management have become a source of competitive advantage. Organizations are looking for ways to gain a competitive advantage for their survival, which causes uncertainty in organizations. The result is a negative impact on work engagement and individual actions (Sekhar et al., 2018). Thanks to a properly constructed portfolio of employee competencies, the organization can respond to the client's needs on an ongoing basis. To make this possible, it is necessary to apply the principles of flexible human resource management.

According to Michie and Sheehan-Quinn (2001), flexible human resource management acts as a core role for competitiveness. Flexibility is the dynamic ability of the organization to respond actively to a competitive environment that is changing (Sanchez, 1995; Bhattacharya, Gibson, Doty, 2005; Ngo \& Loi, 2008). Flexible human resource management offers organizations a capacity to recognize change, adapt to this change, obtain knowledge, keep superiority of organizations and introduce new ideas (Sekhar, Patwardhan, \& Vyas, 2018). Flexible human resource management in organizations uses strategies such as downsizing or "planned elimination of positions or jobs" (Cascio 1993, p. 95). Therefore, it causes the change of rules of cooperation between the employee

Ferdowsi University of Mashhad, Iran \& Faculty of Management, University of Warsaw, Poland, https://orcid.org/00000003-0071-716X, e-mail: yashoraka@yahoo.com 
and the employer (Psychological contract). The main consequence is short-term employment. Therefore, the employee has to adapt to the new situation and face employment insecurity based on long-term employment. Employee adaptive behavior consists of building employability. This means that an employee may find employment at another company when they lose their job. The question arises whether employers can help employees shape these adaptive behaviors.

Research shows that there are organizations that implement solutions based on the so-called employability culture. This approach of the employer is very beneficial from the point of view of the effective use of employee competencies in the labor market. It also avoids the unfavorable phenomenon of unemployment.

The aim of the article is to present the role of employability culture in shaping employees' employability as an adaptive reaction to the effects of flexible human resource management.

In addition, we will check whether these phenomena are described in scientific studies, regardless of the conditions in which the business environment operates in a given country. Therefore, this article presents a review of the literature on this subject, published in Iran, a country with relatively low competitiveness, and low flexibility of people management ${ }^{1}$.

According to the Global Competitiveness Index (2016-17), the absence of labor market efficiency is rank 134 out of 138 and Index places "inefficient government bureaucracy" as the third most problematic issue for doing business in Iran ${ }^{2}$. The labor force participation rate is $40.3 \%$ and the rate of unemployment is $12.1 \%{ }^{3}$. The aim is to check whether an adaptive reaction to the effects of flexible human resource management, regardless of their intensity in the environment, are noticed and described in the scientific studies.

The articles were found by searching keywords in the major databases such as a Web of Science, Scopus and Science Direct. Unrelated reviews regarding other aspects of flexible human resource management, employability culture and employability, were deleted. Only articles, which related to the subject area of Business and Management, were considered. The focus of this study is to demonstrate the effect of organizational employability culture on employability in flexible human resource management, by considering all document types (Articles, Conference papers, Book chapters, Reviews \& Articles in press) and eliminating duplicated results of the search. This article also includes the published research in Iran with Persian language, by searching keywords in the major Iranian databases such as SID, MAGIRAN, NOORMAG, CIVILICA.

The article is structured in five sections. The first section presents the definition, determinants, and role of flexible human resource management in organizations. The second section provides definitions, types, measurement, and determinants of employability. The third section offers the theory of employability culture. The fourth section states the conclusions.

\section{FLEXIBLE HUMAN RESOURCES MANAGEMENT - LITERATURE REVIEW}

Below is the literature review on flexible human resources management, appearing in scientific studies of developed countries (Table 1) and in Iran (Table 2). The articles that did not focus on employment perspective are eliminated.

Available: https://www.bti-project.org/de/berichte/laenderberichte/detail/itc/IRN/, Accessed 15.02.2019

Available: http://www3.weforum.org/docs/GCR2016-2017/05 FullReport/ The Global Competitiveness Report 20162017_FINAL.pdf, Accessed 15.02.2019

3 Available: http://amarkar.ir/main/kilm, Accessed 14.02.2017 
Table 1. Search results for Flexible Human Resource Management

\begin{tabular}{lcc}
\hline & Keyword & Flexible Human Resource Management (the focus on employment perspective) \\
\cline { 2 - 3 } Database & The result of the search & Eliminated \\
\hline Scopus & 177 & 349 \\
Web of Science & 56 & 256 \\
Science Direct & 296 & 34 \\
\hline
\end{tabular}

Source: own elaboration.

Table 2. Search results for Flexible of Human Resource Management (Persian literature)

\begin{tabular}{lcc}
\hline & Keyword & Flexible Human Resource Management (the focus on employment perspective) \\
\cline { 2 - 3 } Database & Included & Eliminated \\
MAGIRAN & 6 & 3 \\
CIVILICA & 12 & 12 \\
NOORMAG & 11 & 10 \\
\hline
\end{tabular}

Source: own elaboration.

\section{DEFINITIONS AND DETERMINANTS}

The topic of flexibility in human resource management was raised in the 1990s to empower organizations in overcoming in the various and changing of the recently competitive environment. Flexibility supports an organization in adapting to different and alternative demands from the environment (Snow \& Snell, 1993; Wright \& Boswell, 2002; Ngo \& Loi, 2008). Milliman, Von Glinow \& Nathan (1991) claimed that flexible human resource (FHR) is an aptitude for human resource management (HRM) systems to adjust and react appropriately to changes of the internal and external environment (Peiró, García-Montalvo \& Gracia, 2002). Flexibility is defined as the 'golden triangle', merging with the flexible labor market, a powerful social security net that confirms 'protected mobility' and dynamic labor market policies. It emphasis on improving employability through re-education and lifelong learning (EMCO, 2006; Li \& Zhang, 2015).

Previous researches mentioned diverse scopes of organizational flexibility such as organizational structures, competitive strategies, production method, and human resource management (FHRM) (Atkinson, 1984; Michie \& Sheehan, 2001; Roca-Puig et al, 2005; Swan \& Fox, 2009; Lastra, Martín-Alcázar \& Sánchez-Gardey, 2014). FHRM empowers the organization to create innovative, valuable, exceptional and incomparable resources (Barney, Wright \& Ketchen, 2001; Lastra, MartínAlcázar \& Sánchez-Gardey, 2014). Wright and Snell (1998) mentioned three dimensions for human resource flexibility (HR): employee skill flexibility, employee behavior flexibility, and HR practice flexibility. Employee skill flexibility mentions the uses of a number of potential substitutes to which the abilities can be applied to. Employee behavior flexibility refers to the flexibility that concerns employee behavior. The flexibility of the organization comes to life with employees revealing suitable behavioral characteristics to given situations. These behaviors contain sequences of behavioral actions expected by an employee. HR practice flexibility refers that they can be adapted and are practical across a variety of conditions. 
Wright and Snell (1998) defined the notions of flexibility in the field of a strategy of Human Resource Management and emphasized the three dimensions of it. They mentioned that human resources could improve the development of a staff with a comprehensive base of skills and behavioral repertoires that is essential to reply to a variety of demands. Therefore, this increases the possibility of the substitute strategies that will be produced within the organizations outside of the official strategic planning process. It also involves the change of a participative organization that empowers the firm to better display and react to changes in the competitive environment. They did however not mention the word of employability but implied improving the ability of employees by the organization.

The flexibility of human resource management is a new word in Iranian literature and has been considered in the recent 10 years. Abasi and his colleagues (2013) investigated the influence of flexibility of human resources in an entrepreneur's organization with the mediating role of adaptation of culture in 180 employees of the Iran Petroleum Industry Research Institute. Data analysis was based on the Structural Equation Modeling (SEM). The result of the research showed that there is a positive relationship between an entrepreneur's organization and the adaptation of culture. The authors showed that there is a relationship between the behavior flexibility, functional flexibility and adaptation of culture, but in their research, they did not observe any relationship between skill flexibility and adaptation of culture.

\section{TYPES AND ROLE FOR THE ORGANIZATIONS}

According to Pawlowska (2017), the flexible management work is directly dependent on the relationship between the features of the environment, the directions of competitiveness, the customer's needs and the organization's offer. The results show a reduction of a higher or lower request for only labor. According to the model presented by Wright and Snell (1998, as cited in Ekelund and Pluta, 2012), the process of the flexibility of human resource management mentions three related constituents. The first one consists of the ability of the all-inclusive system and subsystems of human resource management (for instance employment and selection, payment, assessment and training systems, etc.) to react to the needs of the employment of an organization. It mentions the ability to quickly adapt to processes and implementations. The reaction time of the processes of the progress of human resource management defines the potential to improve an offer in reaction to the customer's needs, which creates a source of competitive advantage for the organizations (Pawlowska, 2017).

The second one consists of flexible human resource management related to the kind and level of competences controlled by the employee of the organization. The third one consists of the cognitivebehavioural flexibility of employees, such as their range of behavioural characters, to which workers can apply effects to the evolving circumstances. They define their skill to adapt, talent to react and behave as necessary under given conditions and the anticipations of the employers (Bhattacharya et al., 2005, as cited in Ekelund and Pluta, 2012).

The flexibility of employees is dependent upon four traits. These consist of the practical aspect, vital for the ability to implement different tasks and roles, and the financial aspect, which indicates employees' reception of instabilities in the level of payment. For flexibility of human resource management, the quantitative and qualitative perspectives are mainly important (Juchnowicz, Wojtczuk-Turek, 2007; Sienkiewicz, 2009; Pawlowska, 2017).

From a quantitative point of view, the flexibility of human resources works to solve the problem of increasing the demand for labor in relation to productivity, for the recent suggestion of the enterprise. The flexibility of human resource management in terms of the quantitative perspective 
leads to the increase of employment in new forms, for example, short-term employment contracts, outsourcing, part-time employment, unusual jobs, work contracting, on-call work, telecommuting and homeworking (Pawlowska, 2017).

The condition is different when the organizations suggest expires and there is no request. Therefore, the organization requires adapting and new employee skills are necessarily based on new technologies. The organization in this situation adapts by using its current employees who receive training, or by replacing the current employees with new employees who possess the required skills. Time is a significant criterion here for organizations that do not have enough time to develop new skills (Pawlowska, 2017). On the other hand, the training of the current employee can be so cost-intensive making it not economically feasible. Here rises the trait of the human resource management in qualitative flexibility, stated by the capacity of organization to update the capability portfolio of its workers.

Ball and De Lange (2015) researched the effect of flexibility of human resource management on the engagement of employees and examined job performance through their lifespan by distributing a questionnaire in multinational companies through 11 countries. In their research, they found that flexibility HRM has a positive relationship with engagement. However, one of their findings, which relates to our topics is the fact that the relationships of flexibility HRM, age with engagement and performance were differing as a function in different national cultures. They examined the relations of flexibility HRM with the consequences influenced by culture, whereby the interaction impact of flexibility HRM with age were moderated by culture. When considering collectivism via unitlevel moderator, the results displayed that in collectivistic countries engagement and performance were poorer. They also mentioned that collectivism carries a moderated role in relation to the use of flexibility HRM with engagement. Although this relations for both low collectivistic and high, collectivistic countries were non-significant. Only in high levels of collectivism, this relation showed significantly. Thus, they mentioned that they did not find any evidence for cultural differences between the countries.

In recent studies from 2018, scholars researched the effect of FHRM, with the aspects of employability, in different cultures with diverse countries such as Sekhar, Patwardhan \& Vyas (2018) researched in 244 Indian IT industries to investigate the effect of work engagement on job performance in FHRM in one Sample Company confirmatory factor analysis (CFA) by using Amos. They mentioned that FHRM should be encouraged for the employee to enhance job performance. The authors cited previous researches and redefined flexibility as the employees' freedom to choose their time of organizational entry and exit, work timetables, and possessing the flexibility for job sharing daily. FHRM systems empower organizations so companies have started to improve individual productivity. Improvement of an organization depends on how they can prepare the motivated and flexible workplace for their employees. They mentioned that FHRM is a strong indicator and is positively related to job performance and employee engagement. The authors suggested that an organization needs to reinvent its culture to adapt with FHRM. In FHRM, organization employees feel more important and the practice ultimately leads to better job performance through engagement.

Purzare and Rahimi (2016) researched on 100 companies in Iran. They wanted to investigate the relationship between dimensions of FHRM and promote competitive advantages by using Structural Equation Modeling - Partial Least Squares Method (SEM-PLS). They defined three dimensions for FHRM. Internal flexibility, behavioral flexibility, and relational flexibility. They displayed internal flexibility and behavioral flexibility has a positive relationship with increasing competitive advantages but they did not find any evidence for the relationship between behavioral flexibility and competitive advantages. Overall FHRM had a direct positive effect on competitive advantage. 


\section{CONSEQUENCES FOR CHANGING BETWEEN EMPLOYER-EMPLOYEE RELATIONS (PSYCHOLOGICAL CONTRACT)}

The nature of the relationship between the employer and the employee results from the psychological contract. This concept was used for the first time by Chris Argyris (1960) and is based on the organization theory of Edgar Schein (1965, for: Adamska, 2011). Currently, the research assumes the definition of Denise Rousseau and Martin Greller, according to which the psychological contract consists of the employees' ideas about the expectations of the employer and expected reactions of the employer to the behavior of employees (Rousseau \& Greller, 2001, for: Wellin, 2010, p. 43). The resulting "treatment expected by people and how they are actually treated can have a very significant impact on the way the job is done" (Makin, Cooper, Cox, 2000, p. 12).

According to the suggestion of McInnis, Meyer and Feldman (2009), a psychological contract is analyzed in terms of content (relational or transactional). The relational contract includes an attitude towards long-term employment and meeting mutual needs. The main values are loyalty and stability, and relationships are generally paternalistic. In the transaction contract between the employer and the employee, there is a para economic exchange of benefits within a strictly defined scope of duties and tasks of both parties. Table 3 shows the differences between relational and transactional psychological contract.

Table 3. Change of the psychological contract between the employer and employee

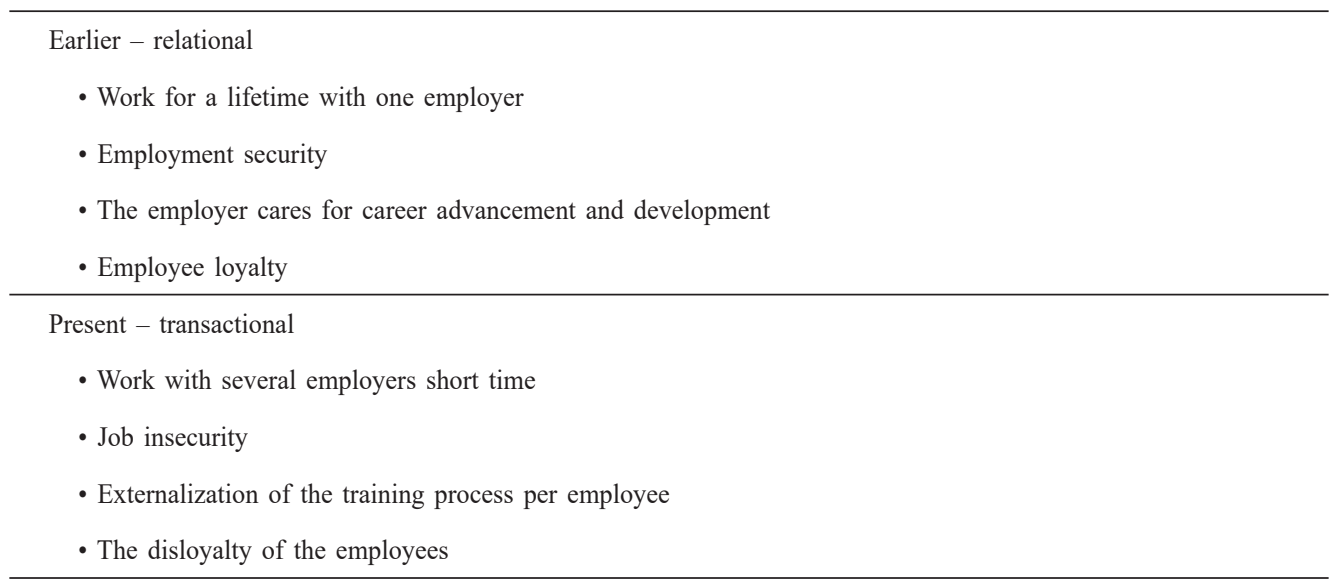

Source: (Pawlowska, 2017).

Van der Heijden, de Lange, Demerouti \& Van der Heijde (2009) researched work experience and ages of employees and mentioned the differences of accepting changes in the psychological contract. They claimed that when changes in the regular job occurred (internal or external) only middle-aged employees react to it. Beginners want to stay at the job without changing it, for the reason that they still have to construct their field of skill. However, for senior employees, the period spent in one job is not impressive.

\section{EMPLOYABILITY - LITERATURE REVIEW}

Below is the literature review on employability, appearing in scientific studies of developed countries (Table 4) and in Iran (Table 5). The articles that did not focus on FHRM in organizations are eliminated. 
Table 4. Search results for Employability in Human Resource Management

\begin{tabular}{lcc}
\hline & Keyword & Employability in Human resource management (the focus on FHRM in organizations) \\
\cline { 2 - 3 } Database & The result of the search & Eliminated \\
\hline Scopus & 7 & 4 \\
Web of Science & 3 & 2 \\
Science Direct & 4 & \\
\hline
\end{tabular}

Source: own elaboration.

Table 5. Search results for Employability in Human Resource Management (Persian Literature)

\begin{tabular}{lcc} 
Database & Keyword & Employability in Human resource management (the focus on FHRM in organizations) \\
\cline { 2 - 3 } SID & Included & Eliminated \\
MAGIRAN & 1 \\
CIVILICA & 0 \\
NOORMAG & 0 \\
\hline
\end{tabular}

Source: own elaboration.

\section{DEFINITIONS AND MEASUREMENT}

Employability is an important requirement for employees who need to compete in a changing environment and labor market (Fugate, Kinicki, \& Ashforth, 2004; Van der Heijde \& Van der Heijden, 2006; Nauta et al., 2009). Employability is defined as "continuous fulfilling, acquiring or creating of work through the optimal use of one's competencies" (Van der Heijde \& Van der Heijden, 2006, p. 453). Workers with these characteristics empower organizations to confront an unstable environment. Changes in the structure of the organization, technology, and job tasks require the employee to obtain new roles, adapt behavior and gain new skills (Chan, 2000; Pulakos, Arad, Donovan, \& Plamondon, 2000; Nauta et al., 2009).

Previous literature mentioned that employability has been raised in the 1990s (Forrier \& Sels, 2003; Nauta et al., 2009), but traces back approximately one century (Gazier, 1998; McQuaid \& Lindsay, 2005; Nauta et al., 2009). Yorke (2004) defined employability as "A set of achievements skills, understandings and personal attributes - that make graduates more likely to gain employment and be successful in their chosen occupations, which benefit themselves, the workforce, the community and the economy". There are three perspectives for employability: the Economic social perspective, the Individual perspective, and the Organizational perspective (Nauta et al., 2009). The Economic - social perspective is defined by diverse abilities of the workers, leading to achievement and employment retention (Finn, 2000; Nauta et al., 2009). It refers to how to recognize the unemployable and employable (McQuaid \& Lindsay, 2005, Nauta et al., 2009). The individual perspective refers to career characteristics, such as adaptability (Fugate et al., 2004; Nauta et al., 2009), mobility (Van Dam, 2005; Nauta et al., 2009), occupational skill (Van der Heijde \& Van der Heijden, 2006; Nauta et al., 2009), occupation development (Sterns \& Dorsett, 1994, Nauta et al., 2009), permanent learning and personal improvement (Hillage \& Pollard, 1998; Rothwell \& Arnold, 2007; Nauta et al., 2009). The organizational perspective defined employability in the functional flexibility of organizations. Improvement in competition, internationalization and technological changes are vital for reacting organizations to come over to change the environment, 
as well as to improve the employee's employability via gaining extensive skills and the tendency to change tasks freely (Guest, 1987; Nauta et al., 2009).

De Vos, Hauw, and Van der Heijden (2011) in their research showed the relation between competency development, career success and employability by examining their model. In their study, both organizational and individual employability were considered. They conducted their research in three departments of a large financial institution in Belgium, and their statistic society consisted of 561 employees. The results were extracted from exploratory factor analysis, by principal component analysis. The authors defined the relationship among career management and employability with comprising individual and organizational influences on competency development. Their research also showed that competency development both relates to domain-specific knowledge, as well as perceptions of occupational organization and flexibility of employees.

Empirical study research conducted by De Cuyper, Van der Heijden \& De Witte (2011) showed the relations among perceived employability and workers' views about obligations of the employer in psychological contract to self-rated performance, job satisfaction, and intention of turnover. They researched in 463 employees in seven Belgian companies. One of the important points of their article was an explanation of the authors about the criticism of perceived employability and the negative relation of continuance commitment.

\section{MEASUREMENT OF EMPLOYABILITY}

Fugate and Kinicki (2008) improved and validated a model for a dispositional measure of employability (DME). Dispositional employability refers to individual differences, which influence individuals to proactive adaptability particular to their careers and work. The authors researched in three studies. In Study 1, they used exploratory factor analysis (EFA) by the Web-based survey. They researched on 292 employees who worked for a web services company in the United States. The authors mentioned five dimensions of adaptive nature of disposal employability (openness to changes at work, work and career proactivity, work and career resilience, work identity and career motivation) and the results of study one supported the context validity of the DME and revealed the five suggested dimensions. In the second study, they used confirmatory factor analysis to investigate validation of study one and to examine the discriminant validity, for example, by constructing independence of the DME's dimensions. In this study, the web-based survey was sent to 321 workers who worked for a technology services company in the southwestern part of the United States. The results of this study validated the discriminant cogency of the five dimensions.

The third study contributed to the whole valuation of dispositional employability's construct validity by using CFA for confirming Study 2 . In this study, the researchers longitudinally examined the DME's predictive validity to find relationships between dispositional employability and positive emotions and affective commitment related to organizational change. They mentioned that dispositional employability has a relationship with positive reactions and affecting commitment to organizational changes. They defined that these effects include open-mindedness for ambiguity, work locus of control, optimism, and self-esteem.

\section{DETERMINANTS}

Fugate, Kinicki \& Ashforth (2004) defined employability as a synergistic set of individual features that is energized and absorbed by an individual's career characteristics. The authors mentioned three dimensions for employability: career identity, social and human capital and personal adaptability that deliver the cognitive motivation and individual characteristics that affect adaptive behaviors 
at work. The authors focused only on the individual employability of the employee and did not consider the role of the interaction between organizations and employees.

Scholarios and her colleagues (2008) interviewed 100 managers in the information and communication technology (ICT) supplier of seven European companies (Germany, Greece, Italy, The Netherlands, Norway, Poland, and UK). This research showed that the approach of most managers of small- and medium-sized enterprises (SMEs) had the tendency of keeping the skill of employees up-to-date which industry needs. The research showed that developed countries in northern European marketplaces had a greater responsiveness to high commitment profits concerning employability career management. The second study of this research limited the interviews to managers of 12 English companies to make a model of encouraging an employer's effect on psychological contracts, and employability career management. The authors believed that flexibility and creativity were important factors, which ICT employees needed. In addition, communication and consultancy skills were important for the up-date employee. In this research, Polish and Greek SME companies had the lowest tendency of employability compared with the other countries. The authors believed the cause to be the countries' political situation at the research time. This research was only limited to small and medium sized companies, so future research on the other companies is needed.

Presti, Tornroos \& Pluvianoin (2018) the preprint version of their article, compared 254 Italian, and 254 Finnish employees by using a questionnaire to search for employability orientation as a mediator with relations between psychological well-being at work, and self-esteem. The authors with considering different labor markets and cultures (based on Hofstede's theory) between Italy and Finland. They claimed that self-esteem, especially between Italian workers, positively predicted employability orientation, and that employability was a mediator in the trait of power for these countries. The same accounts for job satisfaction, and emotional fatigue for Italy, and in the case of psychological indicators for Finland.

In one research in Iran, Aghapour and her colleagues (2015) showed the role of key skills in employability of university students. They mentioned that academic skills, individual skills, and business skills shape employability in individuals. The authors conducted their studies on 310 students of an MA degree or Ph.D. and used a questionnaire. The result of this research showed that the contribution of these three skills in employability was not equal. Business skill was the most effective in the shaping of employability, and the academic skills had the least effect on individual employability.

\section{EMPLOYABILITY CULTURE - LITERATURE REVIEW}

Below is the literature review on employability culture, appearing in scientific studies of developed countries (Table 6) and in Iran (Table 7). The articles that did not focus on FHRM in organizations are eliminated.

Table 6. Search results Employability culture in Flexible human resource management

\begin{tabular}{lcc}
\hline & Keyword & Employability culture (the focus on FHRM in organizations) \\
\cline { 2 - 3 } Database & Total & Eliminated \\
\hline Scopus & 9 & 4 \\
Web of Science & 158 & 129 \\
Science Direct & 46 & 14 \\
\hline
\end{tabular}

Source: own elaboration. 
Table 7. Search results for Employability culture in Flexible human resource management (Persian Literature)

\begin{tabular}{lcc} 
& Keyword & Employability culture (the focus on FHRM in organizations) \\
\cline { 2 - 3 } Database & Included & Eliminated \\
\hline SID & 0 & \\
MAGIRAN & 0 & \\
CIVILICA & 0 & \\
NOORMAG & 0 & \\
\hline
\end{tabular}

Source: own elaboration.

In this section, we provide a brief overview of theoretical background used to investigate employability culture in human resource management in 3 sections: In Early Employability culture - FHRM Research (1990-2010), Employability culture - FHRM Research (2011- up to now) and Employability culture - FHRM research in IRAN (in Persian).

\section{ORGANIZATIONAL CULTURE AND HUMAN RESOURCE MANAGEMENT ARE INTEGRATED WITH EACH OTHER}

It is considered that one of the foundations of competitive advantage for an organization is organizational culture (Barney, 1986; Ngo \& Loi, 2008). Organizational culture is formed by human resource management (Brockbank 1999; Lau \& Ngo 2004; Ngo \& Loi, 2008). Previous researches claimed that there is a positive relationship between the reaction of employee and organizational changes when advancement oriented culture is considered (Tierney, 1999; Van Dam, Oreg \& Schyns, 2008; Nauta et al., 2009).

Marion Estienne (1997) claimed that the culture of the organization is compatible with employability. The culture of organizations is suitable for recent forms of employability. It have been specified by its achievement in challenging and enabling its employee, stimulating them, and prepare their requirements for belongingness in the economizing environment. She suggested improving the model of Harrison's classification and added employability culture as the fifth alternative to this model. She believed that two main specifications of organizational culture are well matched with employability (Estienne, 1997). First, the culture of an organization makes a climate of an experiment for employees to motivate and enable them, as Argyris (1990) also defined as "defensive organizational routines".

Secondly, the culture of organization persuades employability to value learning as a "vehicle for change". Learning and Change are two aspects that should be considered. Managing change and approach to new information to adjust new circumstances has been known as a basis for competitive advantage. She claimed that employability culture in organizations might predominate in individualistic societies. Estienne did not mention any evidence or empirical study.

Nauta and his colleagues (2009) defined the three perspectives on employability (social, individual and organizational employability). They determined the relationships of employability culture with employee employability orientation and turnover intent with the following characteristics: individual characteristics such as career satisfaction and role breadth self-efficacy with standard deviations, and correlation coefficients between the variables under the study. The authors conducted their research on 702 Dutch employees who worked in the health care and welfare sector. Their survey covered measures for understood employability culture of the organization (with eight items that were made by the authors): employability orientation, role breadth self-efficacy, turnover intention, 
career satisfaction, push and pull motives, and demographic characteristics. The result showed that employability culture had positive effects on employability orientation, but a negative relationship with turnover intent and push motives. The authors believed that the success of organizations related to their attitudes and behavior towards employees. If employability culture part of the organizational culture, employees will feel motivated to orient towards their employability and have positive approaches towards job changes in their organizations.

Van der Klink and colleagues (2016) in their discussion paper mentioned a model based on Amartya Sen's capability approach (CA) to integrate a focus on values and reveal the complexity of maintainable employability. The authors claimed that their model considered both personal and organizational employability. (Figure 1)

Figure 1. Model of sustainable employability based on the Capability approach

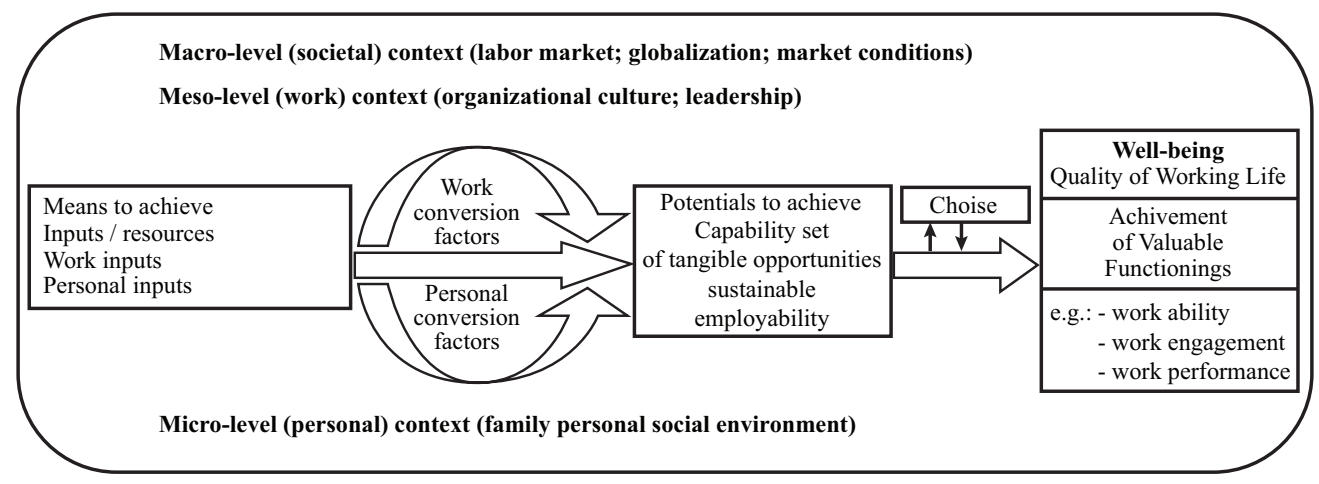

Source: (Van der Klink et al., 2016).

In an organizational employability, their model considers workplaces where the capability set or the accomplishment of specific activity is regulated. Managers evaluate the variety of capabilities that is well matched with the purposes and goals of the organization. The authors believed that their model mentioned the complexity of interactions between employee and their work context, so they suggested that polices of organization and interventions should be advanced in order to be adapted to an employee's certain situation and values. They did not test their model.

De Cuyper, Van der Heijden \& De Witte (2011) explained three default modes. In the first mode perceived employability made non-continuance commitment. In this situation, this perceived employability is based on individual-centered aspect. In the second mode, they focused on employability as social employability, and not on employability organizations. So perceived employability refers to a possibility for changing jobs, with either the current organization or elsewhere. In the third mode continuance commitment concerns perceptions of limited accessibility of jobs, however, perceived employability refers to the whole range of job alternatives. The authors showed that perceived employability has positive relationships to employees' well-being, turnover intention, self-rated performance, and life satisfaction. They also mentioned that psychological contract entitlements have positive relationships with self-rated performance and negatively related to turnover intention. They claimed the relationship between perceived employability and a worker's psychological contract entitlements.

Wong, Rasdi, Abu Samah and Abdul Wahat (2017) mentioned the impact of variables that related to the organization and the moderating role of career approaches on protean vocation between workers. The authors studied on 306 workers in 18 electrical and electronics multinational 
companies (MNCs) in Malaysia. Data was analyzed by partial least squares structural equation modeling (PLS-SEM). The result showed that employability culture and mentoring are necessary to be considered as potential forecasters of employee adaptive behaviors. This research emphasized that by obtaining the required skills and capabilities from the organizational training and improvement programs, workers will become more self-reliant in their careers and accept the "ownership" of career growth. Employees acquire and cultivate a noticeable set of manageable skills and knowledge that raises adaptability in diverse environments instead of insisting on the traditional career development practices organization.

\section{CONCLUSION}

Employability culture plays an important role in modern organizations, which involve high competitiveness and need quick reaction to the customers' needs. Employability supports the development of employees' competencies, their professional flexibility and organizational commitment or engagement. The achievement of organizations in FHRM related to their approaches and behavior towards employees. If employability culture part of the organizational culture, employees will feel motivated to orient towards their employability and have positive behaviors towards job changes in their organizations.

The literature review indicates that there are few publications in Iran on this subject. It can be assumed that depending on the advancement of the economy, scholars, to varying degrees, concentrate on the phenomena that are the subject of analysis of their publications. They most clearly respond to current problems and even with a certain delay in relation to their appearance.

\section{Literature}

Abbasi, R., Babashahi, J., Afkhami Ardakani, M., \& Farahani, D. (2014). The effect of human resource management on entrepreneur of organization: Determinants of the mediating role of adaptive culture. Organizational Culture Management, 11(1), 87-106.

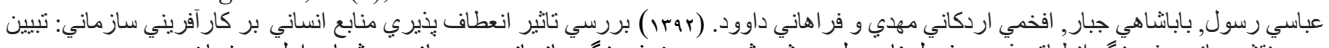

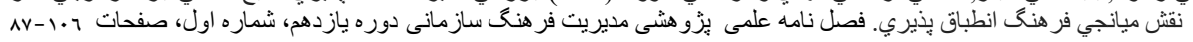

Adamska, K. (2011). Kontrakt psychologiczny w organizacji-Kwestionariusz Kontraktu Psychologicznego. Psychologia Spoleczna, 63(18), 267-283.

Aghapour S., Movahed Mohammadi H., Alambeigi A. (2015). The role of core skills in forming students employability. Quarterly Journal of Research and Planning in Higher Education, 1(71), 41-59.

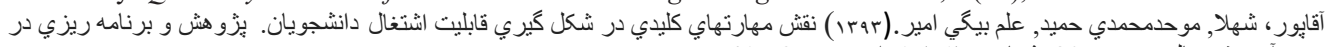

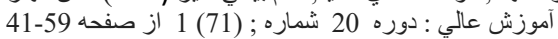

Argyris, C. (1960). Understanding organizational behavior. Homewood (IL): Dorsey Press.

Argyris, C. (1990). Overcoming organizational defenses. Boston, MA: Allyn and Bacon.

Atkinson, J. (1984). The flexible firm and the shape of jobs to come. Labor Market Issues, 5, 26-29.

Atkinson, J. (1984). Manpower strategies for flexible organisations. Personnel management, 16(8), $28-31$.

Bal, P. M., \& De Lange, A. H. (2015). From flexibility human resource management to employee engagement and perceived job performance across the lifespan: A multi sample study. Journal of Occupational and Organizational Psychology, 88(1), 126-154.

Barney, J. B. (1986). Organizational culture: can it be a source of sustained competitive advantage?. Academy of Management Review, 11(3), 656-665.

Berry, J. W. (2005). Acculturation: Living successfully in two cultures. International Journal of Intercultural Relations, 29(6), 697-712.

Bertelsmann Stiftung, BTI 2018 Country Report - Iran. Gütersloh: Bertelsmann Stiftung, Retrieved 2018 from https://www.bti- roject.org/de/berichte/laenderberichte/detail/itc/IRN

Brockbank, W. (1999). If HR were really strategically proactive: Present and future directions in HR's contribution to competitive advantage. Human Resource Management: Published in Cooperation with the School of Business Administration, The University of Michigan and in alliance with the Society of Human Resources Management, 38(4), 337-352. 
Cascio, W. F. (1993). Downsizing: What do we know? What have we learned? Academy of Management Perspectives, 7(1), 95-104.

Chan, S. L. (2000). Information technology in business processes. Business Process Management Journal, 6(3), 224-237.

Dam, K., Oreg, S., \& Schyns, B. (2008). Daily work contexts and resistance to organizational change: The role of leader-member exchange, development climate, and change process characteristics. Applied Psychology, 57(2), 313-334.

De Cuyper, N., Van der Heijden, B. I., \& De Witte, H. (2011). Associations between perceived employability, employee well-being, and its contribution to organizational success: a matter of psychological contracts?. The International Journal of Human Resource Management, 22(07), 1486-1503.

De La Lastra, S. F. P., Martin-Alcazar, F., \& Sanchez-Gardey, G. (2014). Functional flexibility in human resource management systems: Conceptualization and measurement. International Journal of Business Administration, 5(1), 1.

De Vos, A., De Hauw, S., \& Van der Heijden, B. I. (2011). Competency development and career success: The mediating role of employability. Journal of Vocational Behavior, 79(2), 438-447.

Ekelund, B. Z., \& Pluta, P. (2012). Diversity Icebreaker-trening elastycznego zarządzania różnorodnością. Prace Naukowe Uniwersytetu Ekonomicznego we Wrocławiu, (249 Sukces w zarządzaniu kadrami: elastyczność w zarządzaniu kapitałem ludzkim. T. 2, Problemy zarządczo-psychologiczne), 263-272.

EMCO (2006). 'Reinforcing the Mutual Learning Programme', EMCO/23/131106/EN, Brussels, 13 November.

Estiénne, M. (1997). An organizational culture compatible with employability. Industrial and Commercial Training, 29(6), 194-199.

Finn, D. (2000). From full employment to employability: a new deal for Britain's unemployed?. International Journal of Manpower, 21(5), 384-399.

Forrier, A., \& Sels, L. (2003). The concept of employability: A complex mosaic. International Journal of Human Resources Development and Management, 3, 102-124.

Fugate, M., Kinicki, A. J., \& Ashforth, B. E. (2004). Employability: A psycho-social construct, its dimensions, and applications. Journal of Vocational Behavior, 65(1), 14-38.

Fugate, M., \& Kinicki, A. J. (2008). A dispositional approach to employability: Development of a measure and test of implications for employee reactions to organizational change. Journal of Occupational and Organizational Psychology, 81(3), 503-527.

Gazier, B. (Ed.). (1999). Employability: Concepts and Policies: Report 1998 Berlin: Institute for Applied SocioEconomics. Berlin: Institute for Applied Socio-Economics Institute for Applied Socio-Economics.

Guest, D. E. (1987). Human resource management and industrial relations [1]. Journal of Management Studies, 24(5), 503-521.

Heijde, C. M. V. D., \& Van Der Heijden, B. I. (2006). A competence-based and multidimensional operationalization and measurement of employability. Human Resource Management: Published in Cooperation with the School of Business Administration, The University of Michigan and in Alliance with the Society of Human Resources Management, 45(3), 449-476.

Hillage, J., \& Pollard, E. (1998). Employability: developing a framework for policy analysis. London: DfEE.

Klaus Schwab, World Economic Forum. (2016). The Global Competitiveness Report 2016-2017[PDF file]. Retrieved from http://www3.weforum.org/docs/GCR2016-2017/05FullReport/TheGlobalCompetitivenessReport2016-2017_FINAL.pdf

Lau, C. M., \& Ngo, H. Y. (2004). The HR system, organizational culture, and product innovation. International Business Review, 13(6), 685-703.

Li, Y., Zhang, G., Yang, X., \& Li, J. (2015). The influence of collectivist human resource management practices on team-level identification. The International Journal of Human Resource Management, 26(14), 1791-1806.

McInnis, K. J., Meyer, J. P., \& Feldman, S. (2009). Psychological contracts and their implications for commitment: A feature-based approach. Journal of Vocational Behavior, 74(2), 165-180.

Makin, P., Cooper, C., \& Cox, I Ch. (2000).Organizacje a kontrakt psychologiczny. Zarzadzanie ludźmi w pracy, Warszawa: PWN.

McQuaid, R. W., \& Lindsay, C. (2005). The concept of employability. Urban studies, 42(2), 197-219.

Michie, J., \& Sheehan-Quinn, M. (2001). Labor market flexibility, human resource management, and corporate performance. British Journal of Management, 12(4), 287-306.

Milliman, J., Glinow, M. A. V., \& Nathan, M. (1991). Organizational life cycles and strategic international human resource management in multinational companies: Implications for congruence theory. Academy of management Review, 16(2), 318-339.

Ministry of cooperatives labor and social welfare (n.d.). Key indicators of Force labor market [PDF file] Retrieved from February 19, 2017, http://amarkar.ir/main/kilm 
Nauta, A., Van Vianen, A., Van der Heijden, B., Van Dam, K., \& Willemsen, M. (2009). Understanding the factors that promote employability orientation: the impact of employability culture, career satisfaction, and role breadth self-efficacy. Journal of Occupational and Organizational Psychology, 82(2), 233-251.

Nedergaard, P. (2006). Policy learning in the European Union: the case of the European Employment Strategy. Policy Studies, 27(4), 311-323.

Ngo, H. Y., \& Loi, R. (2008). Human resource flexibility, organizational culture and firm performance: An investigation of multinational firms in Hong Kong. The International Journal of Human Resource Management, 19(9), 1654-1666.

Pawłowska, A. (2017). Zatrudnialność pracobiorcy w elastycznym zarządzaniu ludźmi, Warszawa: PWE.

Pawlowska, A. (2017). International Scientific Conference Entrepreneurship For The XXI Century. (III), 16-17 November, Warsaw.

Peiró, J. M., García-Montalvo, J., \& Gracia, F. (2002). How Do Young People Cope with Job Flexibility?. Demographic and Psychological Antecedents of the Resistance to Accept a Job with Non-Preferred Flexibility Features. Applied Psychology, 51(1), 43-66.

Pourzare H, Rahimi F.)2017). The investigate of human resource management effects on competitive advantages. Organizational Resources Management Research, 8(4), 57-82.

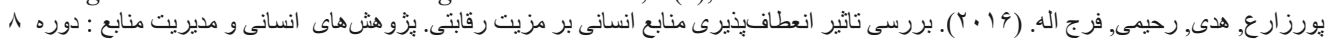

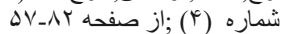

Presti, A. L., Törnroos, K., \& Pluviano, S. (2018). "Because I am worth it and employable": A cross-cultural study on self-esteem and employability orientation as personal resources for psychological well-being at work. Current Psychology, 1-13. DOI:10.1007/s12144-018-9883-x

Pulakos, E. D., Arad, S., Donovan, M. A., \& Plamondon, K. E. (2000). Adaptability in the workplace: Development of a taxonomy of adaptive performance. Journal of Applied Psychology, 85(4), 612.

Roca-Puig, V., Beltrán-Martín, I., Escrig-Tena, A. B., \& Bou-Llusar, J. C. (2005). Strategic flexibility as a moderator of the relationship between commitment to employees and performance in service firms. The International Journal of Human Resource Management, 16(11), 2075-2093.

Rothwell, A., \& Arnold, J. (2007). Self-perceived employability: Development and validation of a scale. Personnel review, 36(1), 23-41.

Samnani, A. K., Boekhorst, J. A., \& Harrison, J. A. (2012). Acculturation strategy and individual outcomes: Cultural diversity implications for human resource management. Human Resource Management Review, 22(4), 323-335.

Schneider, B., Brief, A. P., \& Guzzo, R. A. (1996). Creating a climate and culture for sustainable organizational change. Organizational Dynamics, 24(4), 7-19.

Scholarios, D., Van der Heijden, B. I., Van der Schoot, E., Bozionelos, N., Epitropaki, O., Jedrzejowicz, P., \& Van der Heijde, C. M. (2008). Employability and the psychological contract in European ICT sector SMEs. The International Journal of Human Resource Management, 19(6), 1035-1055.

Sekhar, C., Patwardhan, M., \& Vyas, V. (2018). Linking Work Engagement to Job Performance Through Flexible Human Resource Management. Advances in Developing Human Resources, 20(1), 72-87.

Sienkiewicz, Ł. (2009). Professional flexibility of Poles as determinant of employment decisions, [in:] Juchnowicz M. (ed.). Attitudes of Poles towards work in managing human capital, 67-92.

Snow, C. C., \& Snell, S. A. (1993). Staffing as a strategy. Personnel selection in organizations, 4, 448-478.

Sterns, H. L., \& Dorsett, J. G. (1994). Career development: A lifespan issue. Experimental Aging Research, 20(4), 257-264.

Swan, E., \& Fox, S. (2009). Becoming flexible: Self-flexibility and its pedagogies. British Journal of Management, 20, S149-S159.

Tierney, P. (1999). Work relations as a precursor to a psychological climate for change: The role of workgroup supervisors and peers. Journal of Organizational Change Management, 12(2), 120-134.

Van Dam, K. (2005). Employee attitudes toward job changes: An application and extension of Rusbult and Farrell's investment model. Journal of Occupational and Organizational Psychology, 78(2), 253-272.

Van der Heijden, B. I., de Lange, A. H., Demerouti, E., \& Van der Heijde, C. M. (2009). Age effects on the employability-career success relationship. Journal of Vocational Behavior, 74(2), 156-164.

Van der Klink, J. J., Bültmann, U., Burdorf, A., Schaufeli, W. B., Zijlstra, F. R., Abma, F. I., ... \& Van der Wilt, G. J. (2016). Sustainable employability-definition, conceptualization, and implications: A perspective based on the capability approach. Scandinavian Journal of Work Environment \& Health, 42(1), 71-79.

Wellin, M. (2010). Zarządzanie kontraktem psychologicznym. Zaangażowanie pracowników w zwiększenie wydajności firmy. Warszawa: Oficyna Wolters Kulwer Business.

Wojtczuk-Turek, A. (2007). Flexibility as the key competence of the employee in knowledge organizations, [in:] Flexible human capital management in the organization of knowledge, ed. M. Juchnowicz, Warsaw: Difin. 
Wong, S. C., Mohd Rasdi, R., Abu Samah, B., \& Abdul Wahat, N. W. (2017). Promoting protean career through employability culture and mentoring: Career strategies as moderator. European Journal of Training and Development, 41(3), 277-302.

Wright, M., \& Ketchen Jr, D. J. (2001). The resource-based view of the firm: Ten years after 1991. Journal of Management, 27(6), 625-641.

Wright, P. M., \& Boswell, W. R. (2002). Desegregating HRM: A review and synthesis of micro and macro human resource management research. Journal of Management, 28(3), 247-276.

Wright, P. M., \& Snell, S. A. (1998). Toward a unifying framework for exploring fit and flexibility in strategic human resource management. Academy of Management Review, 23(4), 756-772.

Yorke, M. (2004). Employability in the undergraduate curriculum: Some student Perspectives. European Journal of Education, 39(4), 409-427. 


\title{
The Dark Side of Extra Role Behaviors: Investigating the Link between Extra-role and Counterproductive Behaviors in Organizations using Moral Licensing Theory
}

\begin{abstract}
Atefeh Sodeiri*
Summary

Most researches in the organizational citizenship behaviors (OCBs) field illustrate a wide range of positive outcomes for both employees and organizations. Some studies have investigated the other side of the coin, as well as the dark side of OCBs and the tendencies of these kinds of behaviors to increase deviant and counterproductive work behaviors (CWBs). Nowadays, investigations about counterproductive work behaviors (CWBs) and the finding of their causes is crucial for organizations. Sometimes the causes of CWBs are clarified, but sometimes extra-role behaviors such as OCBs, which have a negative relation with CWBs as well as organizational culture, can contribute to the formation of counterproductive work behaviors (CWBs). In this paper, by considering moral licensing theory and effects of abusive climate in organizations, as well as dysfunctional culture dimensions, I discuss how employees who engage in OCB may subsequently participate in counterproductive work behaviors (CWBs).
\end{abstract}

Keywords: organizational citizenship behavior (OCBs), moral licensing theory, counterproductive work behavior, organizational culture

JEL: M12, O15, J24

Organizational citizenship behaviors (OCBs) as positive behaviors in an organization have been one of the most important subjects in organizational behavior over the past 30 years. During this time, most of the papers were concentrated on the light edge of OCB and positive effects and consequences of OCBs for employees and organizations. There were fewer articles focusing on the dark side of OCBs. In this paper, I will investigate the way in which background culture effects on the tendency of OCBs to conduct unethical and counterproductive work behaviors (CWBs) with an emphasis on the moral licensing theory.

In this regard and according to the systematic review of literature, I acted in accordance with the following steps. Following the structured literature review (SLR) process suggested by Tranfield, Denyer, and Smart (2003). According to this process, in the first step, the research objective should be determined. In this case, the purpose of my study is to showcase how background culture effects on the tendency of OCBs to conduct unethical and counterproductive work behaviors (CWBs) with an emphasis on the moral licensing theory.

To this aim I searched all articles containing the following key words: Organizational citizenship Behavior (OCBs), Moral licensing theory, Counterproductive work behavior, Organizational culture in different databases such Scopus, Oxford Handbooks Online, Science Direct, Emerald, Elsevier and so on. Those databases contained relevant publications in the area of management. In particular Oxford Handbooks Online was related to the OCBs completely. As illustrated in Figure 1, I searched for any articles or documents that contained the terms of "Organizational Citizenship Behaviors" in any place, such as titles, abstracts or keywords. In this step the results were 2729 articles. I then restricted these results by English language and areas of business management, as well as accounting, psychology and social science. After this restriction the number of search results

* Ferdowski University of Mashhad, Iran \& Faculty of Management, University of Warsaw, Poland, is: https://orcid. org/0000-0002-6032-722X, e-mail: atefeh.sodeirijavadi@mail.um.ac.ir 
was approximately 2374. Afterwards I searched the combination of "Organizational Citizenship Behaviors" and "Counterproductive Work Behavior", which reduced the results to 113 documents. Because my paper has an emphasis on the moral licensing theory, I first searched only for "moral licensing theory" which resulted in 32 articles. I then searched this term with the previous keywords, which resulted in just 1 article. Said this article is the most important article related to my work, and according to the "Academic Journal Guide 2018" it is ranked Q1.

In the next step, it was necessary to know about the definition of organizational culture and various dimensions of organizational culture, as well as knowing about different models of organizational culture. This was however not enough, and I should have investigated the effects of various dimensions of culture on OCBs (354 document results), as well as the effects of organizational culture on forming counterproductive behaviors in an organization (37 document results) separately. After investigating these articles, I chose only 28 of them which were most related to my subjects.

Figure 1. Summery of the SLR

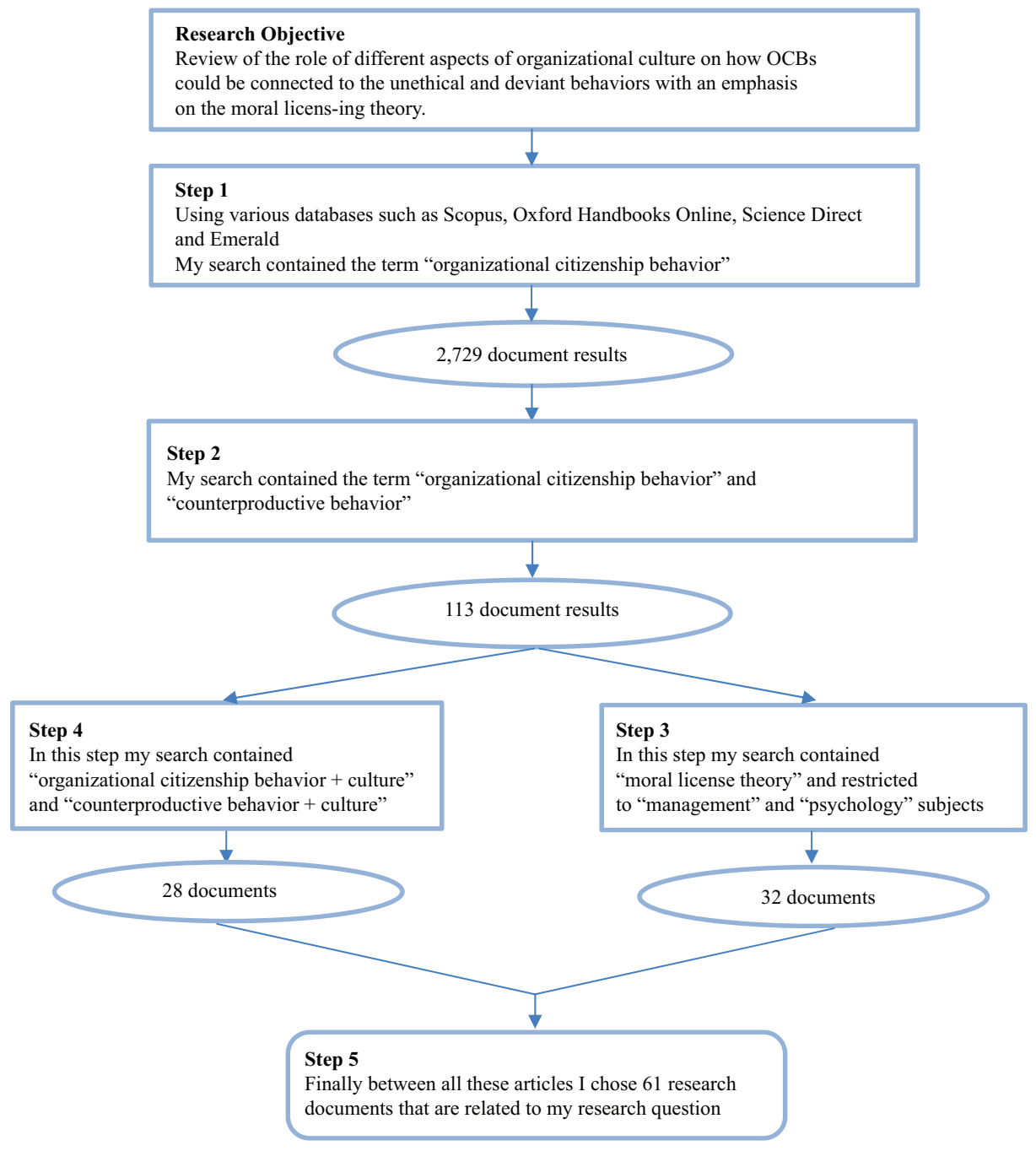




\section{INTRODUCTION}

Employees usually try to contribute positively to the organizational goals. Therefore, employees may go above and beyond of the in-role duties, and they may even engage in extra-role behaviors. Employees can be inclined to engage in such productive behaviors - in-role and extra-role behaviors - because organizations often provide motivations through reward systems or supportive leadership to encourage them toward organizational aims.

Nonetheless, employees may also, at the same time, engage in behaviors that explicitly contradict organizational goals. It is important for organizations and managers to find an explanation for how employees can engage in both - productive and destructive - forms of behaviors. There are various individual and organizational factors to explain this phenomenon. It is clear that productive behaviors not only are effective and efficient for organization, but also lead to improved employee's credit in an organization. In contradiction to the productive behaviors, destructive behaviors not only are detrimental for organizations but also lead to decrease employee's credit in an organization. Since employees do not want to be morally discrediting in their organizations or in view of their colleagues, they try to obtain licenses from various resources such as previous moral behaviors. They do so in order to liberate and allow them to engage in counterproductive work behaviors without worrying about discrediting themselves morally. This study possesses a moral licensing view. It will examine the impact of background culture for explaining how individuals can engage in organizational citizenship behaviors and counterproductive work behavior in an organization at the same time.

Common forms of counterproductive work behavior (CWBs) in organizations consist of ineffective job performance, absenteeism, turnover and unsafe behavior, administrative corruption and so on (Jex \& Britt, 2008).

Counterproductive work behaviors (CWBs) has negative effects on the administrative, economic, social and cultural systems. Therefore, organizational behavior experts are interested in decreasing counterproductive work behaviors because counterproductive work behaviors are disruptive and overpriced in both, a financial fee as well as an emotional fee (Muafi, 2011). To deal with counterproductive work behaviors in the organizations, first, the causes and roots of these behaviors should be identified.

In general, counterproductive work behaviors $(\mathrm{CWBs})$ in the organization are divided in to two general categories: positive counterproductive work behaviors (PCWBs) and negative counterproductive work behaviors (NCWBs) (Appelbaum, Iaconi \& Matousek, 2007).

Depending on the categorizations of counterproductive work behaviors (CWBs) in an organization, typically these behaviors categorize as interpersonal against organizational counterproductive work behavior and mild against severe counterproductive work behavior.

As Figure 2 shows, mild organizational deviant behavior that categorized under the production deviance includes: leaving early, taking excessive beaks, intentionally working slowly and wasting resources. Severe organizational deviant behavior that categorized under the property deviance includes: sabotaging equipment, accepting kickbacks, lying about hours worked and stealing from the company. Mild interpersonal deviant behavior that categorized under the political deviance includes: showing favoritism, gossiping about co-workers, blaming co-workers and competing none beneficially. Severe interpersonal deviant behavior that categorized under the personal aggression includes: sexual harassment, verbal abuse, stealing from co-workers and endangering co-workers (Robinson \& Bennett, 1995).

In contrast, the positive counterproductive work behaviors can be considered as deliberate behaviors that deviate from the standards of a referent group in fair ways. These behaviors are classified under the pro-social behavior such as organizational citizenship behaviors (OCBs), 
whistle-blowing, corporate social responsibility and creativity/innovation (Appelbaum, Iaconi \& Matousek, 2007). All types of pro-social behavior can be classified as positive counterproductive work behavior when they go beyond organizational norms.

Figure 2. Negative deviant workplace behavior

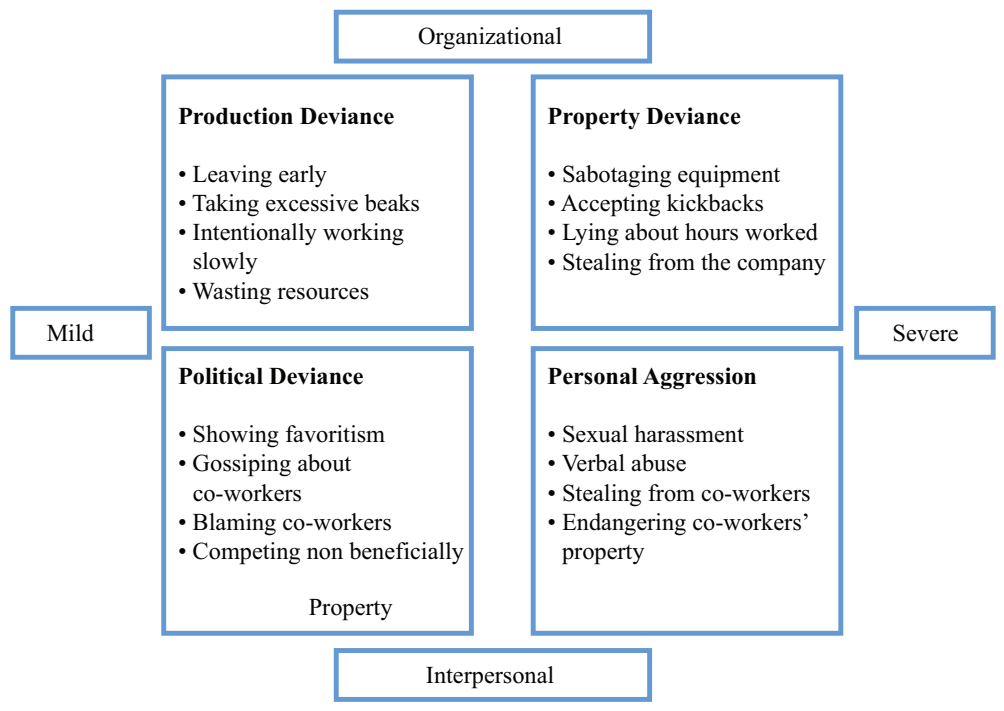

Source: Robinson \& Bennett (1995)

Although most of the researches related to the deviant and counterproductive behavior are often focused on negative deviant workplace behaviors, this research, however, focuses on positive deviant workplace behaviors. This is especially the case for organizational citizenship behavior, as moral behaviors give employees moral licensing in order to engage in counterproductive work behavior.

OCBs are considered behaviors outside of the necessities required of a person at a specific institution, but which will inspire efficiency consecutively of the organization. While OCBs increase the performance of an organization, OCBs behaviors as positive counterproductive work behavior may or may not provide such a goal (Spreitzer \& Sonenshein, 2003). According to the results of empirical studies, employees who usually engage in OCB incline to engage in CWB rarely. Therefore, there is a negative relationship between OCB and CWB. In some cases, positive workplace behaviors such as OCBs provided a moral admirable license for employees to engage in deviant behaviors which are contrary with organizational norms and rules (Klotz \& Bolino, 2013).

In this way, numerous supplementary issues are necessary to be considered. Particularly, (1) there are various types of $\mathrm{OCB}$ and $\mathrm{CWB},(2)$ there are numerous reasons why an employee might engage in $\mathrm{OCB}$ and $\mathrm{CWB}$, and (3) the $\mathrm{OCB}-\mathrm{CWB}$ relationship is probable to be moderated by several variables (Dalal, 2005). According to Dalal (2005), various moderate variables can moderate the relationship between OCBs and CWB. Blanken, van de Ven and Zeelenberg (2015), identified different moderators for the relationship between OCBs and CWBs. One of these moderators of the relationship between OCBs and CWBs is a domain which refers to employees who receive a moral license in a domain. Said employees simultaneously engage in morally questionable behavior in that same domain (specific-domain moral license) or can engage in morally questionable behavior in different domain (cross-domain moral license) (Miller and Effron, 2010). Another moderator 
of the relationship between OCBs and CWBs is related to the real behavior against a proposed behavior. In addition, another moderator which can be considered the most important moderator of the relationship between OCBs and CWBs, is cultural background.

In this study, cultural background is considered as a crucial moderator. This is due to the fact that ethical standards are learned through the process of socialization and therefore are heavily dependent on the cultural environment in which the individual has grown and has been associated with said environment throughout his/her life (Simbrunner \& Schlegelmilch, 2017).

This study will be focused on the influence of cultural background for explaining how individuals can engage in OCBs and CWBs in an organization simultaneously, with consideration of moral licensing theory. In fact, the main question of study is: how do cultural frames influence the transformation of OCBs to deviant behaviors? This study tries to explore how organizational context and cultural background impact an employee's motivations tending from OCBs to CWB while considering the role of moral licensing theory.

\section{LITERATURE REVIEW}

\section{Organizational Citizenship Behavior - Definition}

Nowadays, with growth and complexity of organizations in competitive environments and the importance of behavioral issues in organizations, the attention of organizational behavior researchers is focused on the investigation and identification of causes of both positive and negative organizational work place behaviors. Furthermore, with an increase of unethical and illegal work behaviors in organizations and work places, and according to the researches done (Skyvington, 2014; Klotz \& Bolino, 2013; Yam et al., 2017; Organ, Podsakoff \& MacKenzie, 2005) one of the reasons that has been underestimated in such behaviors are positive counterproductive work behaviors, particularly organizational citizenship behavior (OCBs).

The term "Organizational Citizenship" is identified as an "extra-role" behavior - which is usually not considered by the formal payment system of organizations (Paillé, 2009). They are completely voluntary and vary in the behaviors which are known as intra-role behaviors (Organ, 1988). This was for the first time presented by Organ (1997), who defined Organizational citizenship behaviors (OCBs) as behaviors that are not part of official organizational roles but do affect the organization's performance. In fact OCB is a concept that explains how and why people contribute positively to their organizations beyond their defined work roles (Campbell Pickford \& Joy, 2016).

Usually, OCBs are known as certain behaviors, each of which having certain outcomes for organizations that can affect on the effectiveness of organizations. These behaviors include: altruism which involves helping co-workers; courtesy which is intended to avoiding problems at work, especially with colleagues; conscientiousness which shows that a person is concerned with following rules, being punctual and going beyond minimum organizational necessities; civic virtue which denotes to behaviors that display concern for and commitment to the organization, as well as having constructive involvement in issues of governance and sportsmanship which happens when an employee is willing to tolerate hard circumstances, inconveniences, or other problems at work while keeping their positive outlook with no complains (Halbesleben \& Bellairs, 2018).

\section{Antecedents for Organizational Citizenship Behavior}

Understanding why individuals engage in $\mathrm{OCB}$ has become a progressively important issue in this field for behavior researchers and organizations. In general, researches have considered four antecedents for OCBs: 1) individual (or employee) characteristics which can be divided into two items: moral and dispositional items. Moral item relates to the employee satisfaction, organizational commitment, 
perceptions of fairness, as well as perceptions of leader supportiveness. Dispositional item relates to the friendliness and agreeableness, conscientiousness, positive affectivity, and negative affectivity. 2) Task characteristics relates to the task feedback, task reutilization, and inherently satisfying tasks.

3) Organizational characteristics relates to the group cohesiveness, perceived organizational support, and organizational fairness; and leadership behaviors (Farh, Earley \& Lin, 1997).

In other categories, researchers have identified various motives for OCBs that can be related to the conscious and subconscious decision processors which guides behaviors in work environments (Borman \& Penner, 2001; Hanson \& Borman, 2006). These motives can be divided into two categories: positive OCBs motives and negative OCBs motives (dark OCBs motives), and in this regard conditions under which certain motives emerge (Kim et al., 2013; Penner \& Orom, 2010). Individual perceptions of said conditions, such as the situational context and role cognition (Morrison, 1994) are effective.

Engaging in OCBs with positive motives aimed at serving others may be formed by social values. Those who engage in said behaviors are interested in being helpful and shaping positive relationships with others (Rioux \& Penner, 2001). They are also concerned with the welfare of others and the organization (Bolino \& Turnley, 2005; Grant, 2007), and may be motivated by organizational concern - This is showcased by them being interested in doing well and caring about the company, as well as displaying pride in and commitment to the organization (Rioux \& Penner, 2001).

On the other side, most of the researches have indicated that there are certain context inflections and deviation points upon which OCBs go from positive to negative (Grant \& Schwartz, 2011; Pierce \& Aguinis, 2013). In this way, individuals may engage in OCBs aimed at self-serving and personal goals and desires, such as impressing management which is an effort to impact how someone is perceived by others. In the OCBs milieu, impression management is a way in which employees engage in OCBs with the aim of gaining rewards or promotion or other positive outcomes for themselves (Bolino, 1999; Rosenfeld, Giacalone \& Riordan, 1995). In fact, they engage in visible, recognizable practices of citizenship for instrumental purposes. They can also recognize strategic ways to involve OCBs at times in which they would like to augment their reputations (Salamon \& Deutsch, 2006) and avoid looking bad to their colleagues and supervisors (Rioux \& Penner, 2001).

In addition, behaviors can serve one or numerous motives such as the functional approach to behavior and perceived instrumentality to behavior, the motives of which were drawn from social values, organizational concern (positive motives) and also personal and career aims and desires. The functional approach to behavior is related to behaviors in which personal motives are highlight motives, and individuals engage in OCBs for the achievement of their personal aims and desires. Under said approach, they for example engage in OCBs because they can receive praise from the boss or merely for the cause of ingratiation. There is a perceived instrumentality to behaviors related to those possessing career motives are highlight motives, as well as individuals engaging in OCBs for the achievement of their careers and professional aims and desires. Those individuals for instance engage in OCBs for the purpose of obtaining a better position in the future or promotion at work. It's clear that the opportunity for promotion operates as a goal that can be a motivating factor for employees to engage in OCB. For them, OCBs are considered as instrumental to career success (Halbesleben \& Bellairs, 2018).

\section{Consequence of Organizational Citizenship Behaviors}

Organizational citizenship behaviors (OCBs) have been effected positively by organizational performance and outcomes like service quality (Bettencourt \& Brown, 1997; Bell \& Menguc, 2002), organizational commitment (Podsakoff, McKenzie \& Bommer, 1996), job involvement (Dimitriades, 2007), leader-member exchange (Bhal, 2006; Lo, Ramayah \& Kueh Swee Hui, 2006), 
job satisfaction (Chughtai \& Zafar, 2006; Khalid \& Ali, 2005), improved work spirit, confidence, or cohesiveness and sense of belonging among employees (Farh, Earley \& Lin, 1997).

As has been mentioned, OCBs have different dimensions. Each of these dimensions can bring various outcomes for organizations, by for instance helping behaviors lead to predictive outcomes such as product quality, customer satisfaction, performance quality, operating efficiency and revenue (Podsakoff \& MacKenzie, 1994; Walz \& Niehoff, 1996). Civic virtue behaviors facilitate the involvement of employees in governance's issues, therefore they provide constructive suggestions which may save costs (Campbell Pickford \& Joy, 2016). Civic virtue and sportsmanship on the other hand are negatively related to customer complaints (Podsakoff et al., 2000; Walz \& Niehoff, 1996). Other studies showcased altruism and sportsmanship to increase organizational capacity and to appeal to and retain the best employees. Personnel with altruism behavior help each other in the organization, which leads to healthy interpersonal relationships in organizations. Employees in a healthy work environment and positive work climate rarely wish to leave the organization, therefore a reduction of absenteeism can be considered as another result (Podsakoff \& Mackenzie, 1997; Dash \& Pradhan, 2014).

OCBs have been affected negatively by organizational outcomes as well, such as role overload, stress, work-family conflict, and unreciprocated help that lowers productivity (Bergeron et al., 2014; Bolino \& Turnley, 2005; Flynn, 2003). Employees usually face time constraints, therefore when they spend their time engaging in OCBs, they cannot use said time for task performance (Bergeron, 2007). OCBs, which are morally praiseworthy behaviors, in certain circumstances may lead to immoral behaviors in the organization. This is because engaging in OCB may make them feel psychologically free to engage in CWB as an outcome of going the extra mile. This process can be explained by moral licensing theory (Bolino et al., 2013).

\section{OCBs and Counterproductive Behaviors}

Briefly, OCBs are behaviors which support the wider social and psychological environment in which responsibilities are done in organizations and improve organizational functioning (Organ, 1997; Podsakoff, Ahearne \& MacKenzie, 1997). Counterproductive work behaviors (CWBs) are behaviors which intended to hurt the organization or other members of the organization (Spector \& Fox, 2002). Although OCBs and CWBs have a negative relationship, generally, some researches show that OCB could be related to deviant and unethical behaviors in certain circumstances. Bolino \& Klotz (2015) discuss several causes which explain how OCBs exchange to CWBs, including: Resource depletion - OCBs are part of extra-roles and usually go to the extra mile and beyond a formal job. As a result, employees feel overloaded, stressed, fatigued and emotionally exhausted. In this case, OCBs as resource-depleting behaviors, let employees engage in immoral behaviors such as cheating, harming others, wasting time etc. Injustice and anger - Sometimes OCBs may exchange to CWBs because of injustice and underestimated employee activities; Citizenship pressure - As has been mentioned, OCBs are completely voluntary behaviors, but when employees feel an ongoing force to do more than the necessities of their jobs, OCB may miss its quality and intend to CWB.

\section{Moral Licensing Theory}

Moral licensing theory is based on Nisan and Horenczyk's (1990) moral balance theory, according to which "individuals who behave in a morally laudable way, later feel more justified to perform a morally questionable action" (Blanken \& et al, 2014, p. 232). Another definition of moral licensing is a cognitive preconception, which allows individuals to perform immorally without threatening their self-image of being a moral person (Simbrunner \& Schlegelmilch, 2017). Moral licensing theory uses the relationship between OCBs and CWBs as an explanation. According to Nisan and Horenczyk's 
(1990), moral balance theory contains worthless actions by an individual who has recently behaved morally and is valued less rigorously than the same actions conducted by somebody who has recently behaved immorally. In previous researches two unique ways have been considered to form moral licensing: moral credits and moral credentials (Miller \& Effron, 2010). Moral licensing via moral credits is "a dynamic moral self-concept that fluctuates around an equilibrium point", and moral licensing via moral credential is "one's behavioral history makes morally questionable deeds seem as if they were not transgressions at all" (Yam and et al., 2017, p. 9).

The occurrence of moral license is related to a person's self-concept - with concern to morality that self-concept is based on person's cultural background. While moral license can have various causes from racism, sexism, over selfishness to environmental friendliness, we consider cultural background to be one of the most important causes for moral licensing. On the other hand, conditions can be effective in shaping moral license. In addition, whether a person considers herself/himself as a religious person can be affected by forming moral licensing. (Simbrunner \& Schlegelmilch, 2017).

\section{Licensing to Counterproductive Behaviors: Considering the Role of OCBs}

Based on moral balance theory (Nisan \& Horenczyk, 1990) when individuals engage in voluntary counterproductive or deviant behaviors, their self-concept decreases. Therefor they are motivated to increase their self-concept and tend to create balanced moral equilibrium through positive and good behaviors, which is called moral cleanse (Yam \& et al., 2017). In contrast, when individuals engage in morally admirable behaviors such as OCBs, their self-concept increases and subsequently they allow themselves to behave immorally. As a matter of fact, they grant themselves a moral license to engage in negative behaviors (Klotz \& Bolino, 2013). It should be mentioned that the acquisition of moral license does not always lead to the formation of deviant or counterproductive behaviors. In fact, employees with a moral license don't seek deviant behaviors aggressively, but it can be considered as an opportunity to engage in deviant behaviors.

In the workplace, employees engage in broad performance domains such as task performances, organizational citizenship behaviors and counterproductive work behaviors (Dalal, 2005). Although in many researches (Dalal, 2005) OCBs and CWBs have a negative relation, in the real world, we can see the fact that individuals are engaged in both behaviors at the same time. But the basic question is: how can someone accept a rule and break it simultaneously?

Spector and Fox (2002) express that positive and negative conditions at work influence an individual's emotional reactions, so that positive emotions are related to the OCBs and negative emotions related to the CWB. Similarly, in another paper Spector and Fox (2010) suggest that employees may engage in OCBs and CWBs as a way to deal with under-stimulation and injustice at work. To summarize, these result indicate that both OCBs and CWB may co-occur. In this paper and according to the findings of psychologists, moral licensing theory has been used to explain positive relations of OCBs and CWB.

\section{The Influence of Cultural background on Morally Licensed CWB}

As has been mentioned before, OCBs and the acquisition of moral licenses don't always lead to deviant and CWBs. Special conditions or context can be affected in forming deviant and counterproductive work behaviors. In this regard, organizational culture's dimensions have a critical role in the tendency of OCBs to CWB. This is because organizational culture often has a robust impact on an employee's behavior and attitudes between supervisors and employees. Organizational culture outlines the dos and don'ts of organizational life. Therefore investigation this relationship without taking into account the organizational culture's dimensions would be incomplete. 
Generally, the term of "organizational culture" induces a positive meaning in relation to the organization that is related to effectiveness and efficiency in the organization. The culture of an organization however is made up from many factors which have profound and positive impacts on organizational culture and help to create and reinforce to constructive culture. At the same time, it is important to keep in mind that these impacts can be dysfunctional and negative.

Previous researches on the definitions of organizational culture have concentrated on values. While values are important factors in organizational culture, they often are gained in the family. In fact, organizational culture is the way in which employees receive and interpret conditions and how they respond to these conditions. Therefore, organizational culture, especially those dimensions that related to the OCBs, can be defined by organizational work performance. Schein (1990) defined organizational culture as 1) a pattern of basic assumptions, 2) invented, discovered, or developed by a given group, 3) as it learns to cope with its problems of external adaptation and internal integration, 4) that has worked well enough to be considered valid and, therefore 5) is to be taught to new members as the 6) correct way to perceive, think, and feel in relation to those problems. In Figure 3, different dimensions of organizational culture are presented based on the views of various researchers in the field of culture and organizational culture (Van den Berg \& Wilderom, 2004).

Figure 3. Different dimensions of organizational culture in the views of various researchers

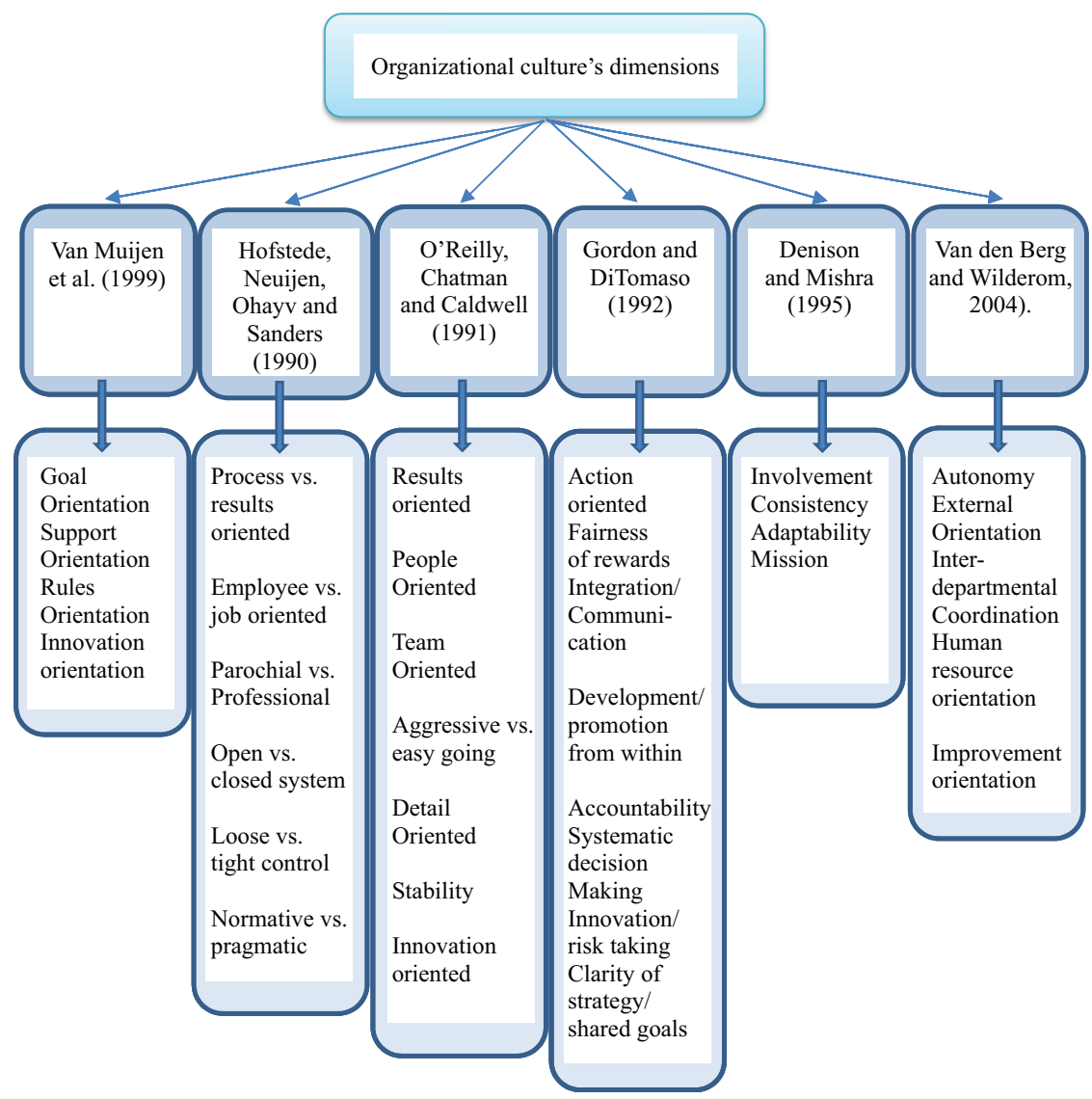


In fact, organizational culture is derived from the characteristics of national culture and administrative organization as well. There are several key organizational culture features that are related to OCBs. Findings show that organizational justice is used to foresee OCBs, so that organizational justice improves employees' trust and encourages them to exhibition OCBs (Jafari \& Bidarian, 2012). Another key organizational culture feature is hierarchy in an organization, which has been considered as power distance in Hofstede's works. In hierarchical organization people from high levels of hierarchy have power to influence. This is putative, however this kind of behavior should reflect fairness. Through time, these relationships may change from instrumental to agreement relationships based on communication satisfaction, trust and faith like covenantal relationships (Graham \& Organ, 1993). According to Earley and Calic (2018), reducing power distance in an organization leads to the tendency of legitimate relations becoming more personal agreement and conciliatory relations being crucial for displaying of OCBs.

In another study, Mohanty and Rath (2012) find that there is a significant correlation between all organizational culture variables (belief and norms, individual autonomy, individual responsibility, conflict tolerance, structure, risk tolerance, and support) and organizational citizenship behavior variables (altruism, conscientiousness, sportsmanship, courtesy and civic virtue). According their results, culture if nurtured can instruct citizenship behaviors in employees within the organization. It can be considered that strengthening the cultural roots of an organization can lead to form citizenship behavior across all sectors in an organization. Therefore strong organizational culture that is characterized by fairness with employees, caring and empathy, employee empowerment, career enriching opportunities, equitable payment and benefits, accurate job-person matching, honesty and ethics and safe working conditions reduce deviant and criminal behavior at the workplace and have a positive impact on formation of OCBs (Elias, 2013).

Despite of positive dimensions of organizational culture and their effects on forming extra role behaviors in an organization and the negative relation of OCBs and CWB, moral licensing theory and an abusive climate in an organization as well as dysfunctional culture dimensions can provide a potential explanation for why individuals are willing to conduct deviant behaviors.

When organizational culture induces to do more with less as an organizational imperative and supervisors expect employees to engage in extra role behaviors and OCBs, OCBs are not completely voluntary. In such situations the employees engage in OCBs because they are worried that their supervisors punish them, or that they lose their job. On the other hand, increasing OCBs reduces their values to the norms, in fact becoming part of organizational culture such that the personal costs (such as time and energy) may overshadow the benefits. When organizational culture induces turning the job into a contest of competitive scales, it leads to employees getting away from work and competition. It also causes friction among workers who want to be seen as the most committed employees. The continuation these conditions can be fragile for employees (Bolino \& et al, 2013; Balthazard, Cooke \& Potter, 2006). When organizational culture is not supportive and puts employees under pressure to engage in OCBs, forcing them to do these behaviors e.g. when their supervisors ruins an employee's vacation, or when the organizational culture is oppositional and supervisors just see the dark sides OCBs and looking for mistakes behavior of employees because they believe that OCBs detract from their in-role performance (Bolino \& et al., 2013; Balthazard, Cooke \& Potter, 2006). All of these can have negative outcomes and lead to deviant and counterproductive work behaviors.

\section{CONCLUSION}

In an organization, employees while engaging in productive behaviors - in-role behaviors and even extra-role behaviors, at the same time may engage in destructive behaviors that are contradicted with organizational goals, rules and norms. In this way, the role of organizational culture is very crucial. 
It is important to know how organizational context and cultural background affect employee's motivations and their tendency from OCBs to CWBs. When organizational culture is not supportive, or the atmosphere of the organization is too competitive, or if managers and supervisors consider OCBs as employee's main duties (Bolino \& et al., 2013; Balthazard, Cooke \& Potter, 2006); all of these things can lead to OCBs turn to CWBs. On the other hand, employees are interested to preserve a consistent level of moral identity and their credit in their organizations or in view of their colleagues, to prevent strict and negative judgment from others (Nisan, 1990). Therefore, they try to obtain ethical permission and moral licenses by relying on OCBs which have been done in the past. This subsequently lets themselves to engage in CWB without worrying about losing their credibility and reputation in the organization.

\section{Literature}

Appelbaum, S. H., Iaconi, G. D., \& Matousek, A. (2007). Positive and negative deviant workplace behaviors: causes, impacts, and solutions. Corporate Governance: The International Journal of Business in Society, 7(5), 586-598.

Balthazard, P. A., Cooke, R. A., \& Potter, R. E. (2006). Dysfunctional culture, dysfunctional organization: Capturing the behavioral norms that form organizational culture and drive performance. Journal of Managerial Psychology, 21(8), 709-732.

Bell, S. J., \& Menguc, B. (2002). The employee-organization relationship, organizational citizenship behaviors, and superior service quality. Journal of Retailing, 78(2), 131-146.

Bergeron, D. M. (2007). The potential paradox of organizational citizenship behavior: Good citizens at what cost?. Academy of Management Review, 32(4), 1078-1095.

Bergeron, D., Ostroff, C., Schroeder, T., \& Block, C. (2014). The dual effects of organizational citizenship behavior: Relationships to research productivity and career outcomes in academe. Human Performance, 27(2), 99-128.

Bettencourt, L. A., \& Brown, S. W. (1997). Contact employees: Relationships among workplace fairness, job satisfaction and prosocial service behaviors. Journal of Retailing, 73(1), 39-61.

Bhal, K. T. (2006). LMX-citizenship behavior relationship: Justice as a mediator. Leadership \& Organization Development Journal, 27(2), 106-117.

Blanken, I., van de Ven, N., Zeelenberg, M., \& Meijers, M. H. (2014). Three attempts to replicate the moral licensing effect. Social Psychology, 45(3), 232.

Blanken, I., van de Ven, N., \& Zeelenberg, M. (2015). A meta-analytic review of moral licensing. Personality and Social Psychology Bulletin, 41(4), 540-558.

Bolino, M. C. (1999). Citizenship and impression management: Good soldiers or good actors?. Academy of Management Review, 24(1), 82-98.

Bolino, M. C., \& Turnley, W. H. (2005). The personal costs of citizenship behavior: the relationship between individual initiative and role overload, job stress, and work-family conflict. Journal of Applied Psychology, 90(4), 740.

Bolino, M. C., Klotz, A. C., Turnley, W. H., \& Harvey, J. (2013). Exploring the dark side of organizational citizenship behavior. Journal of Organizational Behavior, 34(4), 542-559.

Bolino, M. C., \& Klotz, A. C. (2015). The paradox of the unethical organizational citizen: The link between organizational citizenship behavior and unethical behavior at work. Current Opinion in Psychology, 6, 45-49.

Borman, W. C., \& Penner, L. A. (2001). Citizenship performance: Its nature, antecedents, and motives. In B. W. Roberts \& R. Hogan (Eds.), Decade of behavior. Personality psychology in the workplace (pp. 45-61). Washington, DC, US: American Psychological Association.

Campbell Pickford, H., \& Joy, G. (2016). Organisational Citizenship Behaviours: Definitions and Dimensions. Available at: http://eureka.sbs.ox.ac.uk/6265/1/2016-31.pdf

Chughtai, A. A., \& Zafar, S. (2006). Antecedents and consequences of organizational commitment among Pakistani university teachers. Applied HRM Research, 11, 39-64.

Dalal, R. S. (2005). A meta-analysis of the relationship between organizational citizenship behavior and counterproductive work behavior. Journal of Applied Psychology, 90(6), 1241.

Dash, S., \& Pradhan, R. K. (2014). Determinants and consequences of organizational citizenship behavior: A theoretical framework for Indian manufacturing organisations. International Journal of Business and Management Invention, 3(1), 17-27. 
Dimitriades, Z. S. (2007). The influence of service climate and job involvement on customer-oriented organizational citizenship behavior in Greek service organizations: a survey. Employee Relations, 29(5), 469-491.

Earley, P., \& Calic, G. (2018-08-25). A Cultural Perspective on Organizational Citizenship Behavior. In (Ed.), The Oxford Handbook of Organizational Citizenship Behavior: Oxford University Press,. Retrieved 18 Jan. 2019, from http://www.oxfordhandbooks.com/view/10.1093/oxfordhb/9780190219000.001.0001/oxfordhb$-9780190219000-\mathrm{e}-29$.

Elias, S. M. (Ed.). (2013). Deviant and criminal behavior in the workplace. NYU Press.

Farh, J. L., Earley, P. C., \& Lin, S. C. (1997). Impetus for action: A cultural analysis of justice and organizational citizenship behavior in Chinese society. Administrative Science Quarterly, 42(3), 421-444, DOI: $10.2307 / 2393733$

Flynn, F. J. (2003). How much should I give and how often? The effects of generosity and frequency of favor exchange on social status and productivity. Academy of Management Journal, 46(5), 539-553.

Graham, J. W., \& Organ, D. W. (1993). Commitment and the covenantal organization. Journal of Managerial Issues, 5(4), 483-502.

Grant, A. M. (2007). Relational job design and the motivation to make a prosocial difference. Academy of Management Review, 32(2), 393-417.

Grant, A. M., \& Schwartz, B. (2011). Too much of a good thing: The challenge and opportunity of the inverted U. Perspectives on Psychological Science, 6(1), 61-76.

Halbesleben, J., \& Bellairs, T. (2018-08-25). What Are the Motives for Employees to Exhibit Citizenship Behavior?: A Review of Prosocial and Instrumental Predictors of Organizational Citizenship Behavior. In (Ed.), The Oxford Handbook of Organizational Citizenship Behavior. : Oxford University Press,. Retrieved 18 Jan. 2019, from http://www.oxfordhandbooks.com/view/10.1093/oxfordhb/9780190219000.001.0001/oxfordhb$-9780190219000-\mathrm{e}-16$.

Hanson, M. A., \& Borman, W. C. (2006). Citizenship performance: An integrative review and motivational analysis. Performance measurement: Current Perspectives and Future Challenges, 141-173.

Jafari, P., \& Bidarian, S. (2012). The relationship between organizational justice and organizational citizenship behavior. Procedia-Social and Behavioral Sciences, 47, 1815-1820.

Jex, S. M., \& Britt, T. W. (2008). Organizational Psychology: A Scientist-Practitioner Approach (2. Ausg.). Hoboken, New Jersey, Vereinigte Staaten: John Wiley \& Sons.

Khalid, S. A., \& Ali, H. (2005). The effects of organizational citizenship behavior on withdrawal behavior. International Journal of Management and Entrepreneurship, 1(1), 30-40.

Kim, Y. J., Van Dyne, L., Kamdar, D., \& Johnson, R. E. (2013). Why and when do motives matter? An integrative model of motives, role cognitions, and social support as predictors of OCB. Organizational Behavior and Human Decision Processes, 121(2), 231-245.

Klotz, A. C., \& Bolino, M. C. (2013). Citizenship and counterproductive work behavior: A moral licensing view. Academy of Management Review, 38(2), 292-306.

Lo, M. C., Ramayah, T., \& Kueh Swee Hui, J. (2006). An Investigation of Leader Member Exchange Effects on Organizational Citizenship Behavior in Malaysia. Journal of Business \& Management, 12(1), 5-23.

Miller, D. T., \& Effron, D. A. (2010). Psychological license: When it is needed and how it functions. In Advances in experimental social psychology, (Vol. 43, pp. 115-155). Academic Press.

Mohanty, J., \& Rath, B. (2012). Influence of organizational culture on organizational citizenship behavior: A three-sector, Global Journal of Business Research, 6(1), 65-76,.

Morrison, E. W. (1994). Role definitions and organizational citizenship behavior: The importance of the employee>s perspective. Academy of Management Journal, 37(6), 1543-1567.

Muafi, J. (2011). Causes and consequence deviant workplace behavior. International Journal of Innovation, Management and Technology, 2(2), 123-126.

Nisan, M., \& Horenczyk, G. (1990). Moral balance: The effect of prior behaviour on decision in moral conflict. British Journal of Social Psychology, 29(1), 29-42.

Organ, D. W. (1997). Organizational citizenship behavior: It〉s construct clean-up time. Human Performance, $10(2), 85-97$.

Organ, D. W. (1988). Issues in organization and management series. Organizational citizenship behavior: The good soldier syndrome. Lexington, MA, England: Lexington Books/DC Heath and Com.

Organ, D. W., Podsakoff, P. M., \& MacKenzie, S. B. (2005). Organizational citizenship behavior: Its nature, antecedents, and consequences. Thousand Oaks, CA: SAGE Publications.

Paillé, P. (2009). Assessing organizational citizenship behavior in the French context: Evidence for the four-dimensional model. The Journal of Psychology, 143(2), 133-146. 
Penner, L. A., \& Orom, H. (2010). Enduring goodness: A person-by-situation perspective on prosocial behavior. In M. Mikulincer, \& P. R. Shaver (Eds.), Prosocial motives, emotions, and behavior: The better angels of our nature (pp. 55-72). Washington, DC: American Psychological Association.

Pierce, J. R., \& Aguinis, H. (2013). The too-much-of-a-good-thing effect in management. Journal of Management, 39(2), 313-338.

Posdakoff, P. M., \& Mackenzie, S. B. (1994). Organizational citizenship behaviors and sales unit effectiveness. Journal of Marketing Research, 351-363.

Podsakoff, P. M., MacKenzie, S. B., \& Bommer, W. H. (1996). Meta-analysis of the relationships between Kerr and Jermierss substitutes for leadership and employee job attitudes, role perceptions, and performance. Journal of Applied Psychology, 81(4), 380.

Podsakoff, P. M., Ahearne, M., \& MacKenzie, S. B. (1997). Organizational citizenship behavior and the quantity and quality of work group performance. Journal of Applied Psychology, 82(2), 262.

Podsakoff, P. M., \& MacKenzie, S. B. (1997). Impact of organizational citizenship behavior on organizational performance: A review and suggestion for future research. Human Performance, 10(2), 133-151.

Podsakoff, P. M., MacKenzie, S. B., Paine, J. B., \& Bachrach, D. G. (2000). Organizational citizenship behaviors: A critical review of the theoretical and empirical literature and suggestions for future research. Journal of Management, 26(3), 513-563.

Rioux, S. M., \& Penner, L. A. (2001). The causes of organizational citizenship behavior: a motivational analysis. Journal of Applied Psychology, 86(6), 1306.

Robinson, S. L., \& Bennett, R. J. (1995). A typology of deviant workplace behaviors: A multidimensional scaling study. Academy of Management Journal, 38(2), 555-572.

Rosenfeld, P., Giacalone, R. A., \& Riordan, C. A. (1995). Impression management in organizations: Theory, measurement, practice. Van Nostrand Reinhold.

Salamon, S. D., \& Deutsch, Y. (2006). OCB as a handicap: An evolutionary psychological perspective. Journal of Organizational Behavior: The International Journal of Industrial, Occupational and Organizational Psychology and Behavior, 27(2), 185-199.

Schein, E. H. (1990). Organizational Culture, American Psychologist, 45(2), 109-119.

Simbrunner, P., \& Schlegelmilch, B. B. (2017). Moral licensing: a culture-moderated meta-analysis. Management Review Quarterly, 67(4), 201-225.

Skyvington, S. (2014). License to Misbehave: Organizational Citizenship Behavior as a Moral License for Deviant Reactions to Abusive Supervision (Master's thesis, University of Waterloo).

Spector, P. E., \& Fox, S. (2010). Theorizing about the deviant citizen: An attributional explanation of the interplay of organizational citizenship and counterproductive work behavior. Human Resource Management Review, 20(2), 132-143.

Spector, P. E., \& Fox, S. (2002). An emotion-centered model of voluntary work behavior: Some parallels between counterproductive work behavior and organizational citizenship behavior. Human Resource Management Review, 12(2), 269-292.

Spreitzer, G., \& Sonenshein, S. (2003). Positive Deviance and Extraordinary Organizing. In K. S. Cameron, J. E. Dutton, \& R. E. Quinn (Eds.), Positive organizational scholarship: Foundations of a New Discipline (pp. 207-224), San Francisco, USA: Berrett-Koehler Publishers, Inc.

Tranfield, D., Denyer, D., \& Smart, P. (2003). Towards a methodology for developing evidence-informed management knowledge by means of systematic review. British journal of management, 14(3), 207-222.

Van den Berg, P. T., \& Wilderom, C. P. (2004). Defining, measuring, and comparing organisational cultures. Applied Psychology, 53(4), 570-582.

Walz, S. M., \& Niehoff, B. P. (1996, August). Organizational citizenship behaviors and their effect on organizational effectiveness in limited-menu restaurants. In Academy of management proceedings, 1996(1), 307-311). Briarcliff Manor, NY 10510: Academy of Management.

Yam, K. C., Klotz, A. C., He, W., \& Reynolds, S. J. (2017). From good soldiers to psychologically entitled: Examining when and why citizenship behavior leads to deviance. Academy of Management Journal, 60(1), 373-396. 


\title{
The Future of Corporate Bonds - Collateral, Risks, New Legal Regulations
}

\author{
Ewa Ciborowska*
}

\begin{abstract}
Summary
The following article presents corporate bonds as one of the important ways for entrepreneurs to obtain financing. There were presented the risks of corporate bonds investors i.e. disproportion of information and significant risks occurring mainly on the retail investors. Besides the author presented the new regulations of Act on Bonds which ensure greater security of trading on the bond market. The Act is intended to strengthen control over the bond market through dematerialization and registration of all bond issues in the National Depository for Securities (KDPW), which until now existed only for public offers. The research study results included in the article should contribute to filling the significant gap in the literature of the subject and facilitate conducting analysis of corporate bonds market in Poland.
\end{abstract}

Keywords: Bonds, Risk, Securities, Issuers, Collateral

JEL: K22

\section{INTRODUCTION}

Corporate bonds issue is considerably more flexible debt financing method than the bank credit, in which the entrepreneur in the Terms and Conditions of the Issue of Bonds (WEO) defines the rules under which he incurs a liability. The abovementioned advantages made bonds an exceptionally common form of raising capital.

The subject literature referring to the financial markets provides a wide variety of terms defining bonds. In the case of corporate bonds, there is no unambiguous definition of this concept under the applicable law. A corporate bond is a security in the rank of dispersed debt issued by a company conducting business activity in order to collect medium- and long-term loan funds securing the investment activity of the issuer of this instrument (Pawłowski, 2015). This definition should be seen in the context of the economic function of corporate bonds, as the legal nature of bonds as a financial instrument is precisely described by legal acts (Pawłowski, 2015; Pawłowski, 2011). Thus, the bond states the existence of debt of the issuer - entrepreneur - to the purchaser of the bonds - investor (bondholder) (Dybowski \& Pyrzyńska, 2006).

\section{CORPORATE BONDS - LEGAL REGULATIONS}

Enterprises issue bonds in order to raise the capital necessary to carry on the activity, its development or new investments. Bond buyers, in turn, are entitled to receive interest and return capital at maturity of the bonds. Importantly, unlike shares, bonds generally do not give the purchaser any other rights towards the issuer. Therefore, a corporate bond does not include dividend rights or the right to participate and vote in a general meeting. Neither does the acquirer of the bonds become a co-owner of the company. It is worth adding, however, that certain types of corporate bonds may be associated with special rights (e.g. convertible bonds entitle to take up shares issued by the company in exchange for these bonds), including those of a property nature (e.g. participating bonds grant the right to participate in the issuer's profit) and of a corporate nature (where the terms of 
issue provide for a meeting of bondholders, which is entitled to adopt resolutions relevant from the point of view of the bondholders' interests). The bonds are issued in series, divided into a certain number of equal units representing the same property rights (e.g. company $\mathrm{X}$ issues 70 series $\mathrm{A}$ bonds with a nominal value of PLN 10,000 each, thus acquiring PLN 700,000, and 80 series B bonds with a nominal value of PLN 20,000 each, thus acquiring PLN 1,600,000).

\section{Bond issue procedures}

We distinguish the following bond issue modes: ${ }^{1}$

1) non-public placement also referred to as a private or closed issue

2) public issue conducted in accordance with the provisions of the Act on Public Offering and Conditions Governing the Introduction of Financial Instruments to Organized Trading and Public Companies

Private placement mode constitutes an offer to purchase corporate bonds addressed to a group of individually designated addressees in a number not exceeding 149 entities. Literature indicates that a non-public offering of debt securities is conducted through the issuer's declaration of intent to conclude an agreement by way of an offer, invitation to negotiations or a tender limited by a circle of selected investors. In practice, as part of a private placement, the offer is addressed to several or more than a dozen entities with which individual negotiations are conducted (Michalak, 2007).

\section{STATUTORY SECURITIES OF BONDHOLDERS}

In order to secure bondholders in the event of a closed issue, a statutory obligation has been introduced to disclose by the issuer information describing the issue and the issuer's property and financial situation (Cichy, 2012).

Information obligations resulting from the Act on Bonds are one of the collaterals that protect investors: "An issuer conducting business activity for more than one year is obliged to make available, in a purchase proposal, financial statements prepared as at the balance sheet date falling not earlier than 15 months before the date of making the purchase proposal available together with an audit report". Moreover, "in the period between the issue of bonds and the full redemption of bonds, the issuer shall make the annual financial statements and the audit report available to the bondholders". ${ }^{2}$

In the case of a public issue, investors have been secured by a statutory obligation to prepare a prospectus or information memorandum - if the issuer, within 12 months preceding the new issue, placed bonds with a total nominal value not exceeding EUR 2,500,000 or the issued bonds are guaranteed unconditionally and irrevocable by the State Treasury or administrative bodies of EU countries. Both the prospectus and the information memorandum are subject to approval by the Polish Financial Supervision Authority.

\section{RISKS FOR CORPORATE BONDS INVESTORS}

Taking into consideration the existing regulations, it should be pointed out that despite the above described information obligations incumbent on issuers on the bond market, there is an information asymmetry, which is why investors (including financial institutions) are exposed to abuses committed by issuers. The particularly privileged position of corporate bond issuers towards investors in terms of access to information creates a particular risk of moral hazard (Gradoń, 2014).

Article 33 of the Act on Bonds of 15 January 2015 (Journal of Laws of 2015, item 238, as amended).

Article 35 of the Act on Bonds (Journal of Laws 2015, item 238, as amended) 
Moreover, investors are exposed to other types of risk, in particular: interest rate risk, reinvestment risk, early redemption risk, inflation risk, foreign exchange risk and, above all, credit risk and liquidity risk.

Liquidity risk is the most important type of risk and occurs when the issuer of bonds is unable to service the debt incurred by issuing them (i.e. it is unable to meet interest payments on time or fails to meet its commitments at all). On the other hand, the credit risk borne by the bondholder is difficult to estimate, especially in the case of the market in the initial development phase. However, its level depends on two basic factors:

1) the probability of insolvency of the issuer, whereby not only the non-repurchase of the nominal value but also the delay in the payment of interest are treated as insolvency,

2) recovery rate, i.e. the part of the claims that can be recovered in the event of suspension of debt service.

The ratings of credit rating agencies can help to assess credit risk, especially in a context of an increasing number of issuers (Cichy, 2009).

It should be pointed out that, under the current rules, issuers have a great deal of leeway in determining the parameters of the issue, this refers in particular to the definition of nominal value, interest rate level, interest payment, maturity, issue price. Moreover, in the case of corporate bonds, entrepreneurs have more freedom in choosing the form of collateral than in the case of bank credit. According to the Grant Thornton report from June 2018, among the issues introduced on Catalyst in 2017 , covered bonds accounted for $34.2 \%$. The share of unsecured issues in the structure of corporate issues increased to $57.5 \%$ compared to 2016. Until the end of 2017, issuers most often chose pledge (34.3\%) and mortgage (32.8\%) as collateral, the less frequently used form of collateral was assignment of receivables and receivables. ${ }^{3}$

In addition, the Issuer may also undertake to the bondholders to provide non-cash benefits, e.g. conversion of bonds into shares (the so-called convertible bonds) or granting the bondholder a preemptive right to acquire new issue shares (Gradon, 2014).

Bonds may be offered by the issuer in two market areas:

1) non-organized market

2) Catalyst organized market

A non-organized market should be understood as any form of trading in financial instruments which, in the light of the applicable regulations, does not constitute organized trading (Pawłowski, 2015).

The offering of debt securities on the non-organized market is characterized by a lack of transparency and access to information, which in consequence poses a higher risk for investors due to the lack of transparency of the offer. To a large extent, the above lack of transparency is related to the lack of issuer's information standards. The statutory obligation to present annual financial statements with an auditor's opinion is insufficient for a thorough analysis and for taking appropriate decisions by investors. When assessing a non-organized secondary market, the lack of standardization of debt parameters, in particular the nominal value, interest rate, maturity and security method, must be stressed (Pawłowski, 2015).

At the end of the fourth quarter of 2017 , the number of corporate bonds increased by $8.3 \%$, the number of mortgage bonds by $13.3 \%$, and the number of municipal bonds by a record $10.2 \%$. Similarly to 2016, the number of cooperative bonds decreased in 2017 by $5.6 \%$. Excluding Treasury bonds from the analysis, the number of debt instruments listed on Catalyst at the end of 2017 amounted to 567 series, i.e. by 43 series more than in the previous year.

Catalyst Report - Development Summary, GrantThornton Frąckowiak Sp. z o.o. sp. k., Poznań 2017 
According to experts from Aforti Holding S.A., corporate bonds with a total value of PLN 86.5 billion were listed on the Catalyst market at the end of November 2018. Therefore, over the last year, the debt securities market recorded an increase by PLN 14.2 billion, which is a continuation of the upward trend that has been going on for several years.

Figure 1. Structure of value of instruments listed on Catalyst (in PLN) by type of instruments as at 31 December 2017 (excluding treasury bonds)

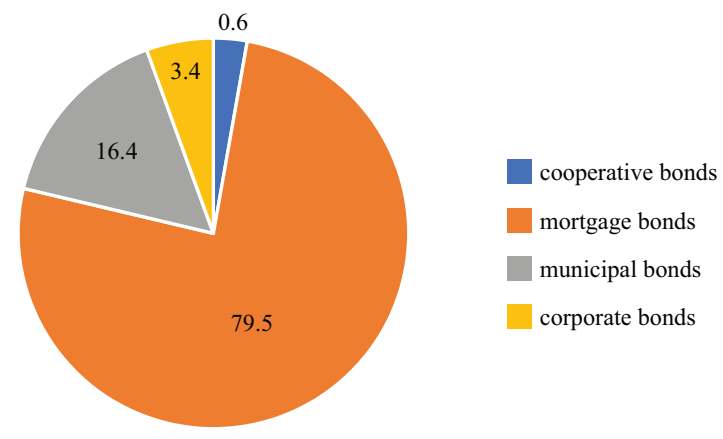

Source: Catalyst - Grant Thornton Frąckowiak Sp. z o.o. Sp. k. report, Poznań 2017

Transparency of the Polish financial instruments market is particularly crucial in the context of the development of the bond market and is steadily increasing due to the changes introduced in regulations. Issuers are obliged to report all significant events affecting their financial, property and economic standing, thus enabling investors to assess the current condition of the issuer in terms of the ability to meet the commitments made to them. When analyzing the Catalyst market, it is impossible to ignore situations in which investors' trust has been undermined. If the issuer allows a situation in which default is unavoidable, lacking reliable information and disregarding the interests of investors at the same time, then the credibility of future issues is reduced and the investment risk of debt securities increases. An event that touched the capital market in 2018, i.e. GetBack's failure to meet its obligations, may raise concerns about the credibility of Catalyst market issuers, let alone companies issuing bonds that are not and will not be traded on the public market.

According to the Grant Thornton Report, bonds listed on the Catalyst market constituted only a part of the debt issued by the company ${ }^{1}$. In Poland, there have already been situations of problems with the repayment of corporate bonds. Therefore, when assessing the Catalyst market, the above situation should not be underestimated, and conclusions should be drawn for the future without, however, assessing the market from the perspective of one issuer.

The above situations indicate the need for greater financial transparency of entities issuing bonds, in particular, according to the author of this article, the scope of financial information provided to investors in purchase proposals and subsequently within the framework of the disclosure obligations set out in the Terms and Condition of Bonds issue should be wide enough for investors to be able to manage investment risk based on the financial data provided. Regular provision of a wider range of financial information throughout the funding period until redemption is crucial for both retail and institutional investors. The statutory obligation to present annual financial statements with an auditor's opinion may not be considered sufficient for investors' decisions, especially in a changing market environment (Pawłowski, 2015). At the same time, observation of the functioning of the secondary non-organized market indicates that this market is also not fully transparent and lack of

$\overline{1}$ Catalyst Report 2017 - Development Summary. GrantThornton Frąckowiak Sp. z o.o. sp. k. 
standardization of issue parameters makes it difficult to compare instruments of different issuers (Piwowar, 2009).

The Polish corporate bond market is dominated by private placements. In 2017, according to Fitch Polska, entrepreneurs issued debt securities worth PLN 14.9 billion, including debt securities in prospectus offers for less than PLN 1.9 billion. It should be noted that Fitch collects data only on those issues, which are communicated to it mainly by brokerage houses, therefore it is estimated that not only the corporate bond market is much larger than the official data, but also the share of public issues is even smaller, clearly below $10 \%$ of the total number of issues ${ }^{2}$.

According to Fitch Polska data, the vast majority of bond issues in Poland are conducted in a private placement mode. This is due to the fact that they are sufficient to carry out institutional issues and small issues addressed to individual investors. Moreover, the existing regulations on private placement have enabled relatively fast and cheap acquisition of financing by issuers.

\section{NEW LEGAL REGULATIONS}

In relation to the strengthening of supervision over the financial market and protection of investors in this market, on 29 November 2018 the Act of 9 November 2018 amending certain acts was signed by the President of the Republic of Poland. The Act is intended to strengthen control over the bond market and introduces key changes, in particular with respect to corporate bond issues. The amendment introduces the obligation to dematerialize and register all bond issues in the National Depository for Securities (KDPW), which until now existed only for public offers.

The Act imposes on the entrepreneurs issuing corporate bonds by way of private placement, for which the issuer does not intend to apply for admission to trading on the regulated market or introduction to the ATS, prior to concluding an agreement for registration of these securities in the depository for securities, concluding an agreement for the performance of the role of an agent for the issue of these securities with an investment company authorized to maintain securities accounts or with a custodian bank. Pursuant to the Act, an agreement on the performance of the role of an issue agent is concluded prior to the commencement of the offer to purchase securities.

In the light of the amended Act on Bonds, the duties of an issue agent include in particular:

1) verification of the issuer's compliance with the requirements concerning the issue of securities, resulting from the provisions of law;

2) verification of the issuer's compliance with the requirements for offering securities resulting from legal regulations;

3) verification that securities and their issuer meet the conditions for registration in the depository for securities set out in the regulations referred to in Article 50.1, as well as whether the rules for handling issuers' obligations ensure proper performance of obligations arising from securities adopted by the National Depository or by a company to which the National Depository has delegated the performance of activities related to tasks referred to in Article 48.1.1 and 48.1.4;

4) creation of a register of persons entitled under securities;

5) acting as an intermediary in the conclusion by the issuer of an agreement concerning the registration of securities in the depository for securities, in particular providing the issuer with the necessary assistance in determining and preparing the documentation necessary for the conclusion of such agreement.

The introduction of the role of an issue agent was aimed at facilitating the process of registration of debt securities in a depository. On the other hand, capital market participants argue that this change

2 https://www.parkiet.com/Obligacje/305129965-Rewolucja-w-sprzedazy-obligacji-firm.html 
may lead to an increase in the cost of issue and, in combination with the obligation to register private placement bonds in KDPW, may result in the reduction or even disappearance of short-term bond issues from the market. These bond market changes enter into force on 1 July 2019.

\section{SUMMARY}

Corporate bonds are one of the important ways for entrepreneurs to obtain financing. To a large extent, in view of the speed and low costs of obtaining financing, the bond market in Poland is growing year by year and this way of obtaining financing is becoming more and more attractive in relation to bank loans or share issues. On the other hand, due to the disproportion of information and significant risks occurring mainly on the retail investors' side, it is important to secure them in an appropriate way, which, however, will not limit private issues and will allow for further development of this market. Let's hope that the amended Act on Bonds will ensure greater security of trading on the bond market and will not reduce private issues.

\section{Literature}

Cichy, J. (2012). Bank spótdzielczy na rynku obligacji Catalyst w Polsce. Współczesna bankowość spółdzielcza. Warszawa: CeDeWu.

Cichy, J. (2009). Rola oceny ratingowej w decyzjach finansowych polskich przedsiębiorstw. Rynki finansowe w rozwoju podmiotów gospodarczych. Warszawa: Difin.

Dybowski, T. Pyrzyńska, A. (2006). Świadczenie pieniężne. Prawo zobowiązań - część ogólna. System prawa prywatnego. Warszawa: C.H. Beck.

Gradoń, W. (2014). Emisja obligacji korporacyjnych a ryzyko uczestników rynku korporacyjnego. Katowice: Wydawnictwo Uniwersytetu Ekonomicznego w Katowicach.

Michalak, A. (2007). Finansowanie inwestycji w teorii i praktyce. Warszawa: PWN.

Pagano, M. Jappelli, T. (2013) Financial Integration in Europe. In The Evidence and Impact of Financial Globalization. Oxford: Elsevier Inc.

Pawłowski, M. (2015). Rynek obligacji korporacyjnych w Polsce „Uwarunkowania i perspektywy rozwoju” Warszawa: CeDeWu.pl.

Pawłowski, M. (2011). Rynek krótkoterminowych papierów dłużnych przedsiębiorstw w Polsce. Zeszyty Naukowe Uniwersytetu Szczecińskiego Nr 639, Finanse. Rynki finansowe. Ubezpieczenia. Nr 37, Kraków: Drukarnia Wydawnicza im. W.L. Anczyca SA.

Piwowar, M.S. (2009). Corporate and Municipal Bond Market Microstructure in the U.S.; Complex Systems in Finance and Econometrics. New York: Meyers, SpringerScience+Business Media, LCC.

2017 Raport Catalyst - podsumowanie rozwoju. GrantThornton Frąckowiak Sp. z o.o. sp. k. Pozyskano z: https://grantthornton.pl/wp.../Raport-Catalyst-GRANT-THORNTON-18-06-2018.pdf

2017 Raport Fitch Ratings Global Corporate Finance 2017 Transition and Default Study. Special Report. Fitch Ratings 2017. Pozyskano z: https://www.fitchratings.com/site/poland

https://www.parkiet.com/Obligacje/305129965-Rewolucja-w-sprzedazy-obligacji-firm.html 


\title{
Main Barriers of the Implementation of the Blockchain Technology
}

\author{
Jan Zadrożny*
}

\begin{abstract}
Summary
Blockchain is a decentralized and distributed database, where participants can exchange the value of, i.e. information or financial resources without the participation of a trusted third party. Despite of a number of positive features, this technology is not free of defects. The aim of the article is to present the barriers of the discussed technology, which prevent the discussed technology from further dissemination. Therefore, in a first step, the review of basic concepts related to blockchain was conducted. It includes a discussion of key characteristics as well as dominant types of blockchain. Afterwards, the author presents barriers of the implementation of the blockchain technology: technical, socio-organizational and legal. Blockchain gained its popularity thanks to the bitcoin cryptocurrency, which was launched in 2009 as a consequence of the global financial crisis. Since then, the technology has gone a long way of evolution and development, and its use goes far beyond only the financial sector. Therefore, the article is not focused on the strengths and weaknesses of the bitcoin blockchain network, as this has already been the subject of many other publications (i.e. Yli-Huumo et al., 2016; Koteska et al., 2017), but aims to highlight barriers of its deployment. Consequently, the limitations faced by bitcoin blockchain or, more broadly, the world of cryptocurrencies, have been passed in this article advisedly.
\end{abstract}

Keywords: Blockchain technology, Distributed ledger, Limitations, Barriers, Innovation, BCT

JEL: 031, O33

\section{INTRODUCTION}

Blockchain does not belong to a technology that is easy to understand (Holotescu, 2018). This is due to the fact that it is associated with using an advanced cryptography. Despite of the early stage of development of the discussed technology, the community focused on the blockchain technology has created its own specialized language. Said language may pose difficulties for people who are just in the initial stage of starting their adventure with it. This all leads to a misunderstanding of the BCT concept, which can be exemplified by using the virtual bitcoin currency as a synonym of blockchain. While bitcoin is a cryptocurrency that works by using this technology, however, the blockchain also works without using Bitcoin. Having above in mind, in order to conduct an analysis of barriers, a basic review of the concepts is needed to understand the principles of the discussed problem.

Conceptual principles of operation of blockchain technology go back to 2009, when a person or group of people under the pseudonym of Satoshi Nakamoto issued a breakthrough article about the concept of a payment system. Said payment system in its assumptions aimed to enable the transaction of two entities directly to each other (P2P), without the participation or involvement of financial institutions (Nakamoto, 2008). The described methodology based on the bitcoin cryptocurrency was launched in 2009 and as it turned out - it caused a whole avalanche of events that led to the emergence and dynamic development of the entire ecosystem of blockchain technology extending far beyond the financial sector. Currently, the application of blockchain technology is observed in various sectors of the economy, i.e. logistics and supply chain (Francisco and Swanson, 2018), insurance, health care or the Internet of Things (IOT) (Khan and Salah, 2017), and even in state administration. A model example of implementation in the public sphere may be seen in Estonia, which, thanks to the use of blockchain, enables its citizens to vote electronically (Piech and Zyga,

\footnotetext{
Faculty of Management, University of Warsaw, Poland, orcid.org/0000-0002-9796-808X, e-mail: zadrozny.jan@gmail. com
} 
2018). In the local government council elections in 2017, nearly $32 \%$ of all voters decided to take advantage of e-voting (Estonian National Electoral Committee, 2017). This proves the legitimacy of implementing such a system, and may also be a remedy for relatively low voter turnout in our country (Korycki, 2017).

The given analysis carries the hallmarks of literature studies along with the use of deductive reasoning, according to the principles of the art of methodological correctness which strive to combine different techniques that happen to be complementary to each other (Apanowicz, 2002). Additionally, interviews and direct conversations with blockchain practitioners were also conducted. At the beginning of the article, the elementary concepts related to the discussed problem were explained simultaneously with the indication of the most important features of the technology. In the next step, on the basis of the literature review, the characteristics of the network types were made, with particular emphasis on the differences between individual functionalities. The central point of the work, which is also a contribution of the paper, is the presentation of barriers limiting the implementation of blockchain technology. The entire study closed by the summary.

\section{PROBLEM OF BYZANTINE GENERALS}

Blockchain technology solves the problem of Byzantine fault (Zheng et al., 2017), which previously was not possible with the help of well-known IT programs. The problem is built around an imaginary thought structure according to which the Byzantine army surrounds the city, and the general stands in front of the decision to attack or withdraw the army. The information is about to be given to the other generals by the messenger. If the assault is carried out at the right time, the conquest of the city will be possible. However, the difficulty can emerge if some of the generals turn out to be traitors who will intentionally pass a false message. Therefore, there is a need of creating a mechanism of action that will allow for the transmission of a proper message, even if a traitor participates in it. The solution to this problem is proposed by the blockchain technology, thanks to the use of the consensus.

\section{CONSENSUS}

The previous methods of confirming the occurrence of the situation referred to the establishing of a trusted third party that acted as an impartial body. The consensus mechanism eliminates this need, as the approval and joining of new blocks to the chain is performed by the blockchain network nodes. Therefore, the consensus can be defined as a mechanism of the agreement between nodes, thanks to which it is possible to add further information to the chain. Various types of algorithms can be used to achieve a consensus, such as (Bashir, 2017):

(1) The Nakamoto consensus, commonly used in the world of cryptocurrencies. It is a protocol that is used by the most popular cryptocurrencies such as bitcoin or ethereum that use proof of work (POW).

(2) The tolerance-based Byzantine fault - it is focused on performing voting rounds by nodes, which after reaching them reach a consensus. These types of protocols are most often used in private networks.

\section{KEY FEATURES OF BLOCKCHAIN}

This means that blockchain can be defined as a database where participants can exchange value (i.e. information, money) without the participation of a trusted third party. Therefore, initially blockchain was used in the world of cryptocurrencies, where members of the community made 
transactions directly among themselves. As rightly noted by A. Antonopoulous, there has been a shift from trusting people to trusting math (Antonopoulos, 2014). In this way, no institution in the world is responsible for such a constituted, public database. It is worth mentioning that the blockchain uses an advanced cryptography, resistant to hacking attacks and forgery.

The most important features of blockchain technology are presented in Table 1.

Table 1. Key characteristics of blockchain

\begin{tabular}{|c|c|}
\hline Features & Characterictics \\
\hline decentralization & $\begin{array}{l}\text { The block chain can be copied by any node in the network, which causes its } \\
\text { decentralization. Blockchain does not belong to any central infrastructure, therefore it will } \\
\text { work in the event of a breakdown or hacking attack. }\end{array}$ \\
\hline transparency & $\begin{array}{l}\text { Members have access to information contained in the block as well as in its entire } \\
\text { history. }\end{array}$ \\
\hline data security & Chain blocks are saved using advanced cryptography, so that stored data is secure. \\
\hline $\begin{array}{l}\text { operation based on } \\
\text { consensus }\end{array}$ & $\begin{array}{l}\text { Adding a block of information to the chain is possible when all relevant entities confirm } \\
\text { the correctness of the information. }\end{array}$ \\
\hline $\begin{array}{l}\text { chronological and timely } \\
\text { recording of data blocks }\end{array}$ & $\begin{array}{l}\text { The added blocks are marked with time, thanks to which they remain chronological in the } \\
\text { timeline. This allows for tracking the information chain without central records. }\end{array}$ \\
\hline durability & It is practically impossible to revoke the accepted information. \\
\hline digital record & $\begin{array}{l}\text { The information contained in the blockchain is digitized, which means that there is no } \\
\text { need to use the paper version. }\end{array}$ \\
\hline $\begin{array}{l}\text { reduction of third party } \\
\text { participation }\end{array}$ & $\begin{array}{l}\text { Based on the peer-to-peer principle of P2P. Network members interact with each other } \\
\text { without the intermediation of third parties, i.e. a central server. }\end{array}$ \\
\hline near real time & Blockchain allows you to settle and add new information almost in real time. \\
\hline
\end{tabular}

Table based on: Berryhill et al., 2018

\section{TYPES OF BLOCKCHAIN}

Blockchain technology was created as a result of the financial crisis, as an alternative to the prevailing financial system that did not work out (Biedrzycki, 2017). Therefore, it was initially used only by the bitcoin cryptocurrency, available to all users of the network. Cryptographic encryption and consensus protocol ensure that the information in the chain is reliable. Anyone who has access to the internet can become a member of the community and decide on the future of cryptocurrencies. Since that moment, other solutions have been created, which evolved with the development of the entire ecosystem. There are three main types of blockchain: public, private and consortium (Buterin, 2015). This division is extremely important because its choice determines the level of access and functionality.

\section{Public blockchain}

Access to the source code is open, which means that all network users can obtain access to it. Thanks to this, possible security imperfections can be identified and corrected by the community. In addition, the network is anonymous, decentralized and irrevocable, so it is not possible to make changes to the chain or censor it. This is a very useful feature, especially when network participants do not trust each other. Examples of networks implementing this model are i.e. ethereum or bitcoin. 
Therefore, the virtual currency bitcoin does not have a central authority responsible for its issue, authorization or approval of transactions.

The problem of public blockchains lays in their low efficiency due to high network maintenance costs. It results directly from the consensus based on the proof of work protocol (POW), where the participant of the network provides the computing power of his computer. The algorithm performs a number of mathematical calculations, the aim of which is to find the right sequence of numbers and verify its correctness, which results in adding another block to the chain. Network users compete for that who will be first, because the winner receives a bonus for the created block. To increase their chances, miners ${ }^{1}$ join in groups on the so-called pools. With the increase in the number of miners, the difficulty of extraction increases, which means that the amount of consumed electricity increases (Zambrano, 2017).

According to the Digiconomist's Bitcoin Energy Consumption Index, currently ${ }^{2}$ the annual electricity consumption needed to maintain the bitcoin network is $73.12 \mathrm{TWh}$, which corresponds to $0.33 \%$ of the total world energy consumption. By comparison, it is more or less the same as Austria consumes annually (De Vries, 2018). In return, we receive a highly decentralized network, as well as a high level of security thanks to the enormous support of global computing power. In addition, public networks in commercial applications face numerous problems, i.e. (1) data privacy (2) ease of protocol update (3) data responsiveness (Hamida, Brousmiche, Levard i Thea, 2017). Although the lack of central management has its many advantages, group decision-making requires time that is needed to develop a common position. Therefore, other solutions have been created: private blockchain and consortium blockchain, whose main distinguishing feature is the network management criterion.

\section{Private blockchain}

Network anonymity is not always a desirable feature. In the course of business, the customer would like to know who the supplier is and who the recipient of the goods and services are. Scalability ${ }^{3}$ is also very important. Therefore, to meet the market's challenges, a private blockchain was created, which - as the name suggests - is controlled by the organization. In this model, the administrator (owner of the network) arbitrarily assigns the rights to individual users and assigns responsibility to them so that they can be modified at the same time. This solution increases control over the flow of values in the chain, which means that one can give up the costly consensus protocol based on proof-of-work. On the other hand, it contributes to greater vulnerability to hacking attacks.

\section{Consortium blockchain}

While in a public blockchain every human being can become part of a network, here only a group of nodes can participate in the consensus protocol. This means that although the selected group controls the consensus process, other nodes may be able to participate by obtaining special permissions, i. e. viewing the history of the chain or creating new blocks. Consortium blockchains are faster and provide greater transaction privacy (or information). This type of network is used by the banking sector (Rice, 2017).

Table 2 summarizes the previous considerations of the types of the chains. It is worth analyzing them, because each of them has its advantages and disadvantages as well as limitations.

Defined as participants of the loosely organized network

As of August 2018

Defined as the ability of the network to process a certain number of transactions per second 
Table 2. Comparison of public, private and consortium blockchain network type

\begin{tabular}{llll}
\hline & \multicolumn{1}{c}{ Public blockchain } & Private blockchain & Consortium blockchain \\
\hline Consensus determination & all miners & one organization & selected group of nodes \\
Level of centralization & fully decentralized & fully centralized & quasi-centralized \\
Read permisssion & public & public or restricted & public or restricted \\
Cost of keeping consensus & highest & the lowest & lower \\
Security level & highest & the lowest & lower \\
\hline
\end{tabular}

Table based on: Zheng, et al., 2017

Figure 1 graphically illustrates the differences between the types of given networks. Black color means the level of access to information, source code and functionality, while elliptical figures symbolically represent network users. Their size does not matter. According to the figure, in a public blockchain every network user has full access to information. In a private blockchain there is one node that has full access to information, while other network participants have limited access to it. In the third type, the access to information has several nodes, in this drawing specifically two.

Figure 1. Graphical presentation of blockchain network types. Black points mean nodes, while white points are network users

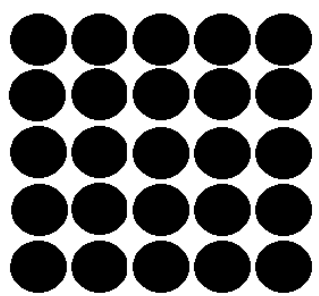

Publik blockchain

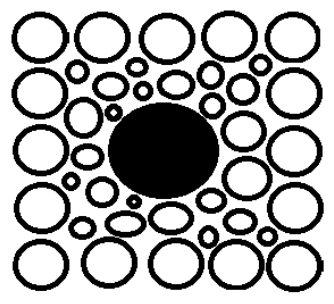

Private blockchain

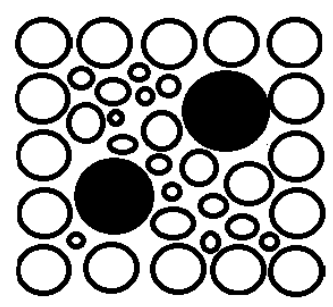

Consortium blockchain

Sources: own elaboration

The selection of the block's network type depends on the purpose for which it is to be used. For example, if we care about full transparency and decentralization of the database, then the solution offered by the public network should be used. Therefore, the choice of the type of network is a key decision determining the later functionalities of the system.

\section{KEY LIMITATIONS OF BLOCKCHAIN}

Blockchain solves the problem of safe and reliable transfer of value (i.e. information, money) between two equal entities without the necessity of participation of a trusted third party, which is why it observes its use in industry. As a new field, it has a number of barriers that may delay or stop its further popularization. It is possible to classify the limitations on the following factors: (1) technical, i.e. those that result directly from the weakness of the technology. This category should include issues related to the complexity, irrevocability, as well as the costs of network 
service; (2) socio-organizational concern of human activity, which is why the main barriers are: lack of infrastructure, demolition of the current order, and a small number of implementations; (3) legal that related to the need for regulation changes.

\section{Technological barriers of the given technology}

Complexity. Blockchain uses advanced cryptography, which makes it a complicated technology, difficult to understand also at the programming level. In addition, BCT, despite its young age, introduced its own terminology to the IT industry. The language used may be difficult to understand for people who are just joining the blockchain community. It requires IT specialists to learn new programming languages, i.e. Solidity. Courses and trainings have recently appeared on the market, which is why today we can talk about the lack of specialists in this field.

Network immutability. This feature is one of the most important benefits of using blockchain, which paradoxically can become a problem in the case of further dissemination of Blockchain technology. It allows you to add further blocks of information without the possibility of their subsequent removal. What if the sensitive information is added to the block, i.e. concerning the employment of employees? An employer, depending on the jurisdiction of a given country, has the obligation to archive data, but it has a temporary character, not an infinite one. Consider whether it is appropriate to use this technology if you edit and delete information from the database frequently.

Service costs. Although in the root assumptions the technology was supposed to eliminate high transaction costs, in practice it may cause for them to increase. In addition to the previously described, economically inefficient, consensus protocol based on the principle of POW (proof-ofwork), it is worth completing the issue of the irrevocability (network immutability) of the network. In addition to the inability to edit content in the chain, the data is stored indefinitely, which entails significant maintenance costs for each decentralized network, where the size of stored data will constantly increase.

\section{Social and organizational barriers}

Lack of infrastructure. The immense potential of blockchain technology lies in its global use, i.e. logistics or supply chain. Third world countries, or developing countries, are not prepared for this technology due to the low level of digitization and technical infrastructure.

Demolishing the current order - the introduction of blockchain technology on a global scale will eliminate the presence of some middlemen. Going further, its implementation will change many relationships and business models, where international relationships built on trust will cease to play a role. It is expected that this will result in opposition of environments that will lose on its implementation. In addition, resistance to change is an immanent feature of the organization and accompanies employees who, in fear of change, strive to maintain their current status quo. As noted by M. Centkowska, employees most strongly oppose the changes that make their existing skills insufficient (Centkowska, 2015). Therefore, this factor will act as a brake on further dissemination of technology.

A small number of implementations - another obstacle that hinders the further development of the industry is a small number of implementations. Business owners will start making decisions on using technologies on a mass scale when they are convinced of its benefits.

\section{The legislative barrier}

Legislative restrictions concern the lack of appropriate legal regulations. Innovations and new technologies usually precede the existing legal order. Therefore, the key element is the flexibility and attitude of the regulations to the dynamically changing market situation. The friendly 
attitude of the authorities to the newly emerging initiatives and technological solutions based on blockchain, such as a smart contract, is fundamental for the further development of the industry. Lack of case law introduces uncertainty, which means that organizations will not be willing to invest and use technologies until the introduction of additional regulations in the discussed area will be completed.

\section{CONCLUSIONS}

Blockchain represents a different approach of the collecting, processing and data analysis, which will contribute to the transformation of existing solutions and will affect the change of business models. The technology is at an early stage of development, which means that more implementations as well as time are needed. This will allow us to assess, understand and learn about other, unknown technological barriers that may slow down the process of further adaptation. The support from the state seems to be necessary, especially in order to encourage research centres and enterprises to conduct further research in this area.

\section{Literature}

Antonopoulos, A. (2014). Bitcoin Security Model: Trust by Computation. O’Reilly-Radar. Retrieved from http:// radar.oreilly.com/2014/02/bitcoin-security-model-trust-by-computation.html (28.08.2018).

Apanowicz, J. (2002). Metodologia ogólna, Wydawnictwo Diecezji Peplińskiej „BERNARDINUM”.

Bashir I. (2017). Mastering Blockchain: Distributed ledgers, decentralization and smart contracts explained, Published by Packt Publishing, Birmingham, UK.

Biedrzycki, N. (2017). Blockchain- the ultimate financial crash. Retrieved from https://norbertbiedrzycki.pl/en/ blockchain-czyli-ostateczny-krach-systemu-finansowego/ (18.08.2018).

Berryhill, J., Bourgery T., Hanson, A. (2018), Blockchains Unchained: Blockchain Technology and its Use in the Public Sector, OECD Working Papers on Public Governance, No. 28, OECD Publishing, Paris.

Buterin, V. (2015). On public and private blockchains. Retrieved from https://blog.ethereum.org/2015/08/07/ on-public-and-private-blockchains/ (19.082018).

Centkowska, M. (2015). Podstawy teoretyczne oporu wobec zmian w organizacji, Zeszyty Naukowe Politechniki Ślaskiej, seria: „Organizacja i Zarządzanie”, 77, 9-18.

De Vries, A. (2018). Bitocin's Growin Energy Problem, Joule, 2. 801-809.

Estonian National Electoral Committee (2017). Retrieved from https://kov2017.valimised.ee/valimistulemus-vald.html (22.08.2018).

Francisco, K., Swanson, D. (2018). The supply chain has no clothes: technology adoption of Blockchain for supply chain transparency, Logistics 2018, 2, 2 https://doi.org/10.3390/logistics2010002.

Hamida, E.B., Brousmiche, K. L., Levard, H., Thea, E. (2017). Blockchain for Enterprise: Overview, Opportunities and Challenges. in The Thirteenth International Conference on Wireless and Mobile Communications (ICWMC 2017), Nice, France, Jul. 2017.

Holotescu, C. (2018). Understanding technology and how to get involved, in the he 14th International Scientific Conference eLearning and Software for Education Bucharest, April 19-20, http://dx.doi.org/10.12753/2066$-026 \mathrm{X}-18-253$.

Khan, M.A., Salah, K.(2017). IoT security: review, blockchain solutions, and open challenges, In: Future Generation Computer Systems. http://dx.doi.org/10.1016/j.future.2017.11.022.

Korycki, K. (2017). Alternatywne techniki głosowania a frekwencja wyborcza. Studia wyborcze, 23, 83-105.

Koteska, B., Karafiloski, E. Mishev, A. (2017). Blockchain Implementation Quality Challenges: A Literature Review. In Proceedings of SQAMIA 2017: 6th Workshop of Software Quality, Analysis, Monitoring, Improvement, and Applications. Belgrade, Serbia, September 11-13. Retrieved from http://ceur-ws.org/Vol-1938/ paper-kot.pdf (31.08.2018).

Nakamoto, S. (2008). Bitcoin: A peer-to-peer electronic cash system. Retrieved from https://bitcoin.org/bitcoin. pdf (20.08.2018).

Piech, K., Zyga, P.(2018). Wykorzystanie blockchain przez rząd estoński. Retrieved from https://www.lazarski. $\mathrm{pl} / \mathrm{pl} /$ wydzialy-i-jednostki/instytuty/wydzial-ekonomii-i-zarzadzania/centrum-technologii-blockchain/wykorzystanie-blockchain-przez-rzad-estonski/ (22.08 2018). 
Rice, A.D. (2017), Blockchain: A Beginner's Guide to Blockchain Technology, CreateSpace Independent Publishing Platform.

Yli-Huumo, J., Ko, D., Choi, S., Park, S., Smolander, K. (2016). Where is current research on blockchain technology? - A systematic review. PLoS One, 11(10), https://doi.org/10.1371/journal.pone.0163477.

Zambrano, R.(2017). Blockchain: Unpacking the disruptive potential of blockchain technology for human development, International Development Research Centre. Retrieved from https:/idl-bnc-idrc.dspacedirect.org/ bitstream/handle/10625/56662/IDL-56662.pdf?sequence=2\&isAllowed=y (31.08. 2018).

Zheng, Z., Xie, S., Dai, H., Chen, X., Wang, H. (2017). An overview of Blockchain Technology: architecture, consensus, and future trends. In: IEEE 6th International Congress on Big Data. http://dx.doi.org/10.1109/ BigDataCongress.2017.85 
